UNIVERSIDADE DE SÃO PAULO

INSTITUTO DE QUÍMICA DE SÃO CARLOS

\title{
BIOCOMPÓSITOS A PARTIR DE BIOPOLIETILENO DE ALTA DENSIDADE REFORÇADO POR FIBRAS DE CURAUÁ
}

Daniele Oliveira de Castro

Dissertação apresentada ao Instituto de Química de São Carlos, na Universidade de São Paulo para a obtenção do título de mestre em Físico Química

Orientadora: Prof ${ }^{\mathrm{a}}$ Dra. Elisabete Frollini

São Carlos 


\section{AGRADECIMENTOS}

A Deus por tudo.

Aos meus pais, as minhas irmãs e a toda minha família pelo incentivo.

À minha orientadora Prof ${ }^{a}$ Dr $\underline{a}$ Elisabete Frollini, pela orientação e dedicação prestada e ao $\operatorname{Prof}^{\circ} \operatorname{Dr}$ Adhemar Ruvolo Filho pela colaboração durante a realização do trabalho.

Ao Fernando, Cristina e Elaine, pela amizade e toda ajuda que me proporcionaram.

Aos amigos do Grupo de Físico-Química Orgânica: Bianca, Jorge, Talita, Érika, Bruno, Daiane, Daniella, Maurício, Franciéli.

Aos queridos amigos da graduação, pela amizade e convivência, neste longo período em São Carlos: Rê, Paty, Qing, Gilmar, Jana, Lari, Fernanda, Camila, Naty, Daiane Piva, Daiany Greice, Manu, Radical, Jiraia, Luiz, Carol, Meire, Gabi, Gi Delboni e Gi Santaella.

Aos técnicos do grupo, Márcia e Luiz.

Aos funcionários do Instituto de Química de São Carlos.

Ao Departamento de Química e Departamento de Engenharia de Materiais (DEMA- UFSCar) pela infraestrutura proporcionada para a realização de grande parte deste trabalho; e ao Juliano, Fábio, Henrique e Vanessa pela grande ajuda prestada.

Ao Instituto de Química de São Carlos, pelo apoio institucional e de infraestrutura; 
A Braskem, a Pematec e a Petroflex, pelo gentil fornecimento dos materiais.

A CAPES, pela bolsa concedida; e à CNPq e FAPESP, pelo suporte financeiro. 


\section{RESUMO}

Neste trabalho, foram utilizadas fibras de curauá visando ação como reforço de matriz termoplástica de biopolietileno de alta densidade. O polietileno utilizado neste trabalho foi obtido pela polimerização de eteno, gerado a partir do etanol de cana de açúcar. Este polímero é também chamado de biopolietileno (BPEAD), por ser preparado a partir de material oriundo de fonte natural. Desta forma, pretendeu-se contribuir para com o desenvolvimento de materiais que, dentre outras propriedades, na sua produção, utilização e substituição, ocorra menor emissão de $\mathrm{CO}_{2}$ para $\mathrm{a}$ atmosfera, comparativamente a outros materiais. A superfície das fibras de curauá foi modificada via tratamento com ar ionizado, visando uma melhor impregnação da fibra pela matriz, o que possivelmente levaria a uma otimização da interface entre a matriz e a fibra. As propriedades dos compósitos reforçados com esta fibra (distribuição aleatória, comprimento de $1 \mathrm{~cm}$, diferentes proporções; materiais obtidos em misturador interno e por termoprensagem), foram comparadas com aquelas do reforçado com fibras não modificadas. Adicionalmente, polibutadieno líquido hidroxilado (PBHL) foi acrescentado à formulação do compósito, visando um aumento na resistência à propagação da trinca durante impacto. Os compósitos e as fibras foram caracterizados por várias técnicas, tais como, microscopia eletrônica de varredura (MEV), Calorimetria Exploratória Diferencial (DSC), Termogravimetria (TG), além, da caracterização dos compósitos quanto à Análise Térmica Dinâmico- Mecânica (DMTA), propriedades mecânicas (impacto e flexão) e absorção de água. A presença das fibras de curauá diminuiu algumas propriedades do BPEAD, como resistência ao impacto. A análise de DMTA mostrou que a presença de fibras leva a um material mais rígido. Pode-se considerar que a introdução de PBHL na formulação do material foi eficiente, levando a uma maior resistência ao impacto do compósito BPEAD/PBHL/fibra, quando comparado ao compósito BPEAD/fibra. A partir de $15 \%$ de PBHL adicionado ao compósito não houve mistura eficiente deste com os outros componentes, conforme evidenciado pelos resultados de resistência à flexão. As propriedades mecânicas dos materiais, no geral, não sofreram grande influência de as fibras terem sido tratadas com ar ionizado. Os resultados apontam no sentido que 
parâmetros de processo podem ser explorados, visando minimizar a degradação do polímero, além de trazerem outros inidicadores importantes, como que provavelmente uma borracha de maior massa molar média que a usada no presente trabalho possa apresentar uma ação mais significativa como modificadora de impacto; que fibras mais longas que aquelas consideradas, na mesma proporção em massa, podem ser testadas, já que fibras curtas implicam em grande número de pontas, as quais podem agir como concentradoras de tensão e prejudicar as propriedades mecânicas do compósito. 


\section{ABSTRACT}

In this work, curaua fibers were used in the reinforcement of a high-density (HDPE) thermoplastic matrix. The polyethylene used in this study was obtained by polymerization of ethene produced from sugarcane ethanol. This polymer, also called high-density biopolyethylene (HDBPE), was prepared from a natural source material. The aim of the present study was to contribute to the development of materials that, among other properties, release less $\mathrm{CO}_{2}$ into the atmosphere as compared to other materials. The curaua fiber surface was modified by treatment with ionized air, seeking improved fiber impregnation by the matrix, which would possibly enhance the fiber/matrix interface adhesion. The properties of the composites reinforced with this fiber (randomly distributed, 1-cm long, different amounts, thermopressed materials) were compared with those reinforced with non-modified fibers. Additionally, liquid hydroxylated polybutadiene (LHPB) was added to the composite formulation, aiming at improving resistance to crack spreading during impact. The fibers and their composites were characterized by several techniques, such as scanning electron microscopy (SEM), differential scanning calorimetry (DSC), and thermal gravimetry (TG). The composites were also characterized by dynamic mechanical thermal analysis (DMTA), mechanical properties (flexural and impact strength), and water absorption. The presence of curaua fibers reduced some of the properties of the HDBPE, such as flexural and impact strength. DMTA showed that the presence of the fibers results in a more rigid material. The addition of LHPB to the formulation was efficient, leading to greater impact strength for the HDBPE/LHPB/fiber composite, as compared to the HDBPE/fiber composite. The addition of over 15\% LHPB to the composite resulted in a poor mixture of the component, as evidenced by the flexural strength. The mechanical properties of the materials were not greatly influenced by their reinforcement with fibers treated with ionized air as a whole, showing that the process parameters can be further investigated to minimize the degradation of the materials. The use of a rubber with a higher average molar mass that the one currently used may have a greater effect on the impact strength. Longer fibers in equal mass proportions to those used in the present study can be tested, since shorter fibers mean a larger number of ends, which 
may act as stress concentrators and worsen some mechanical properties of the composite. 


\section{LISTA DE FIGURAS}

Figura 1: Compósitos de plástico reforçados com fibras usados em 2002, nos diferentes setores industriais.

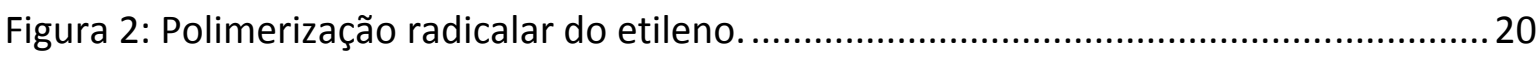

Figura 3: Mecanismo de formação de ramificações no PEAD............................................. 21

Figura 4: Polimerização do etileno utilizando os catalisadores de Ziegler-Natta. ................22

Figura 5: Esquema indicativo do processo de obtenção do BPEAD a partir da cana de

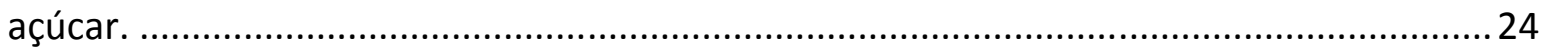

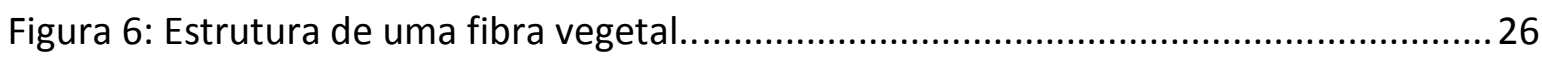

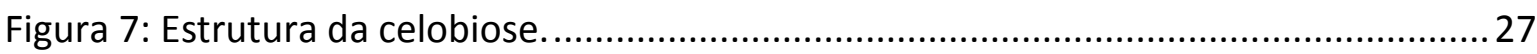

Figura 8: Unidades presentes na lignina: a) p- hidroxi-fenila b) Guaiacila c)Siringila. .......27

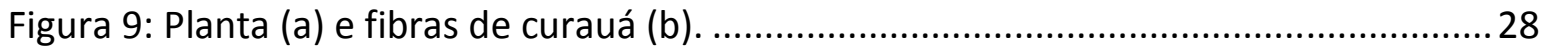

Figura 10: Estrutura química do polibutadieno hidroxilado (PBHL) ................................... 31

Figura 11: Esquema indicativo das interações do PBHL com os grupos hidroxila das fibras e com as cadeias hidrocarbônicas do polietileno. ....................................................... 31

Figura 12: Classificação das matrizes mais utilizadas em compósitos................................. 32

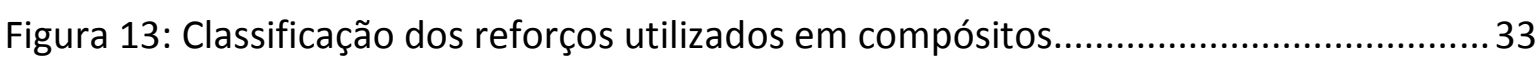

Figura 14: Exemplos de Compósitos: (a) unidirecionais com fibras contínuas; (b)

aleatórias com fibras descontínuas multidirecionais; (c) orientadas de fibras

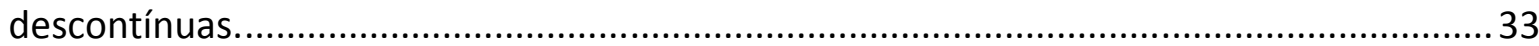

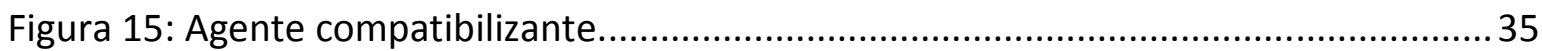

Figura 16: Esquema de descarga corona negativa auto-sustentada. .................................. 38

Figura 17: Misturador interno acoplado ao reômetro de torque Haake............................. 39

Figura 18: Representação esquemática do corte transversal do misturador interno..........44

Figura 19: Representação esquemática de uma termoprensa. ............................................46

Figura 20: (A) Caixa de ionizador de ar fechada, com a fonte elétrica sobre a caixa; (B) Aberta, evidenciando os bicos injetores.

Figura 21: Representação esquemática do sistema utilizado para medidas de resistência ao impacto.

Figura 22: Teor de componentes químicos na fibra de curauá..........................................55

Figura 23: Difratograma de raios $\mathrm{X}$ das fibras de Curauá não tratada e tratada com ar ionizado $5 \mathrm{~h}$.

Figura 24: Curva de DSC da Fibra de Curauá......................................................................56

Figura 25: Curva TG da fibra de curauá sem tratamento e tratada com ar ionizado. .........57 
Figura 26: Curva de primeira derivada da TG da fibra de Curauá tratada e não tratada. ...58 Figura 27: Micrografia dos feixes de fibra de curauá: (a) não tratada, (b) tratada com ar ionizado por $5 \mathrm{~h}$.

Figura 28: Difratograma da análise de raios $X$ do BPEAD não tratado e tratado com ar ionizado $5 \mathrm{~h}$.

Figura 29: Curva TG e de derivada primeira da TG do BPEAD sem tratamento e do BPEAD tratada com ar ionizado (5h).

Figura 30: Curva de DSC do BPEAD

Figura 31: Curvas DMTA do BPEAD não processado e do BPEAD processado (a) E' versus temperatura; (b) E" versus temperatura; (c) tan $\delta$ versus temperatura. 64

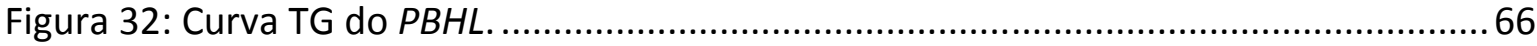

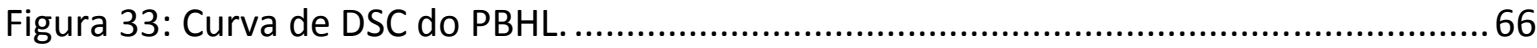

Figura 34: Curvas de Processamento da blenda de BPEAD/PBHL......................................67

Figura 35: Curvas TG e derivada primeira da TG para as blendas de 95\%BPEAD/5\%PBHL

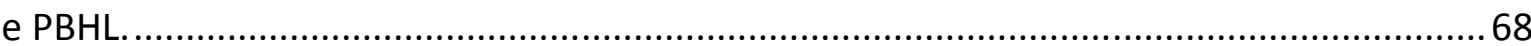

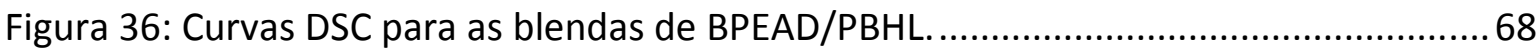

Figura 37: Módulo de armazenamento ( $\left.E^{\prime}\right)$ em função da temperatura para as blendas

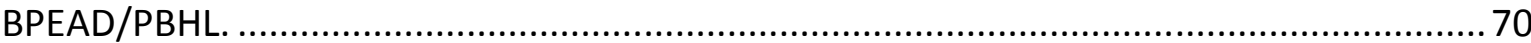

Figura 38: Módulo de perda ( $E^{\prime \prime}$ ) em função da temperatura para as blendas de BPEAD/PBHL e ampliação da região entre -100 e $-50^{\circ} \mathrm{C}$. .................................................... 71

Figura 39: Tan $\delta$ em função da temperatura para as blendas de BPEAD/PBHL.................... 72

Figura 40: Resultados do ensaio de resistência ao impacto Izod das blendas de BPEAD/PBHL para corpos de prova entalhados.

Figura 41: Micrografias obtidas por MEV a partir da superfície de fratura das blendas e do termoplástico: (a) e (b) sem adição de PBHL; (c) com adição de 5\% (em massa) de PBHL; (d) com adição de 15\% (em massa) de PBHL; (e) com adição de $20 \%$ (em massa) de PBHL. 75

Figura 42: Módulo de flexão das blendas de BPEAD/PBHL................................................ 76

Figura 43: Resistência à flexão das blendas de BPEAD/PBHL. ......................................... 76

Figura 44: Curvas de Processamento dos compósitos de BPEAD/fibra...............................77

Figura 45: Curvas TG e de derivada a primeira da TG para os compósitos BPEAD, fibra de curauá, 90\%BPEAD/10\%fibra e 70\%BPEAD/30\%fibra................................................... 78

Figura 46: Curvas DSC para os compósitos BPEAD/fibra................................................... 78

Figura 47: Módulo de armazenamento ( $\left.E^{\prime}\right)$ em função da temperatura para os compósitos BPEAD/fibra.

Figura 48: Módulo de perda (E") em função da temperatura para os compósitos BPEAD/fibra. 
Figura 49: Tan $\delta$ em função da temperatura para os compósitos BPEAD/fibra.

Figura 50: Resistência ao impacto do compósito fibra/matriz para corpos de prova com entalhe.

Figura 51: Resistência ao impacto do compósito fibra/matriz para corpos de prova sem entalhe.

Figura 52: Micrografias obtidas por MEV a partir da superfície de fratura dos compósitos: (a) adição de 5\% de fibra e (b); (c) adição de 10\% de fibra, (d) adição de $15 \%$ de fibra.

Figura 53: Módulo de flexão dos compósitos reforçados com diferentes frações de fibra (em massa).

Figura 54: Resistência à flexão dos compósitos reforçados com diferentes frações de fibra (em massa).

Figura 55: Absorção de água dos compósitos de BPEAD/fibra e para o BPEAD...................86

Figura 56: Curvas de Processamento dos compósitos BPEAD/5\%PBHL/Fibra...................... 88

Figura 57: Curvas de Processamento dos compósitos de BPEAD/PBHL/30\%Fibra...............89

Figura 58: Curvas TG para os compósitos BPEAD/5\%PBHL/fibra e para o BPEAD ................90

Figura 59: Curva derivada primeira da TG para o compósito

85\%BPEAD/5\%PBHL/10\%fibra de curauá e para o BPEAD.

Figura 60: Curvas TG para os compósitos BPEAD/PBHL/ 30\%fibra de curauá e para o BPEAD.

Figura 61: Curvas DSC para os compósitos BPEAD/5\%PBHL/fibra e para o BPEAD.

Figura 62: Módulo de armazenamento ( $\left.E^{\prime}\right)$ em função da temperatura para os compósitos BPEAD/PBHL/fibra.

Figura 63: Módulo de perda ( $\left.E^{\prime \prime}\right)$ em função da temperatura para os compósitos BPEAD/PBHL/fibra.

Figura 64: Tan $\delta$ em função da temperatura para os compósitos BPEAD/PBHL/fibra. .......94

Figura 65: Resistência ao impacto Izod dos compósitos reforçados com diferentes frações de fibra e de PBHL (em massa), corpos de prova não entalhados.

Figura 66: Resistência ao impacto Izod dos compósitos de BPEAD/fibra e BPEAD/PBHL/fibra, corpos de prova entalhados.

Figura 67: Micrografias obtidas por MEV a partir da superfície de fratura dos compósitos: (a) sem adição de PBHL e (b); (c) adição de 5\% (em massa) de PBHL e (d); sem adição de PBHL e (f) $20 \%$ de adição de PBHL.

Figura 68: Curva de Tensão versus Deformação para o compósito de 85\%BPEAD/5\%PBHL/10\%fibra.

Figura 69: Módulo de flexão dos compósitos reforçados com diferentes frações de fibra e PBHL (em massa). 
Figura 70: Resistência à flexão dos compósitos reforçados com diferentes frações de fibra e PBHL (em massa).

Figura 71: Absorção de água dos compósitos de BPEAD/PBHL reforçados com fibra e para o BPEAD 101

Figura 72: Curvas TG para os compósitos BPEAD/PBHL/fibra........................................... 103

Figura 73: Curva derivada primeira da TG para os compósitos BPEAD/PBHL/fibra ...........103

Figura 74: Curvas DSC para os compósitos BPEAD/PBHL/fibra. 104

Figura 75: Módulo de armazenamento ( $E^{\prime}$ ) em função da temperatura para os compósitos 85\%BPEAD/5\%PBHL/10\%Fibra, 85\%BPEAD/5\%PBHL/10\%Fibra tratada, 85\%BPEAD tratado/5\%PBHL/10\%Fibra, 85\%BPEAD tratado/5\%PBHL/10\%Fibra tratada. 105

Figura 76: Módulo de perda ( $\left.E^{\prime \prime}\right)$ em função da temperatura para os compósitos 85\%BPEAD/5\%PBHL/10\%Fibra, 85\%BPEAD/5\%PBHL/10\%Fibra tratada, 85\%BPEAD tratado/5\%PBHL/10\%Fibra, 85\%BPEAD tratado/5\%PBHL/10\%Fibra tratada. 106

Figura 77: Tan $\delta$ em função da temperatura para os compósitos 85\%BPEAD/5\%PBHL/10\%Fibra, 85\%BPEAD/5\%PBHL/10\%Fibra tratada, 85\%BPEAD tratado/5\%PBHL/10\%Fibra, 85\%BPEAD tratado/5\%PBHL/10\%Fibra tratada. 107

Figura 78: Resistência ao impacto para compósitos (1) 85\%BPEAD/5\%PBHL/10\%Fibra, (2) $85 \% \mathrm{BPEAD} / 5 \% \mathrm{PBHL} / 10 \%$ Fibra tratada, (3) 85\%BPEAD tratado/5\%PBHL/10\%Fibra, (4) $85 \%$ BPEAD tratado/5\%PBHL/10\%Fibra tratada. 108

Figura 79: Resistência ao impacto para compósitos (1) 80\%BPEAD/5\%PBHL/15\%Fibra, (2) $80 \%$ BPEAD/5\%PBHL/15\%Fibra tratada, (3) 80\%BPEAD tratado/5\%PBHL/15\%Fibra, (4) $80 \%$ BPEAD tratado/5\%PBHL/15\%Fibra tratada. 108

Figura 80: Micrografias obtidas por MEV a partir da superfície de fratura dos compósitos: (a) 85\%BPEAD/5\%PBHL/10\%Fibra tratada, (b) 80\%BPEAD/5\%PBHL/15\%Fibra tratada; (c) 85\%BPEAD tratado/5\%PBHL/10\%Fibra tratada, (d) 80\%BPEAD tratado/5\%PBHL/15\%Fibra tratada; (e) 85\%BPEAD tratado/5\%PBHL/10\%Fibra tratada, (f) 80\%BPEAD tratado/5\%PBHL/15\%Fibra tratada. . 110

Figura 81: Módulo de flexão para compósitos (1) 85\%BPEAD/5\%PBHL/10\%Fibra, (2) 85\%BPEAD/5\%PBHL/10\%Fibra tratada, (3) 85\%BPEAD tratado/5\%PBHL/10\%Fibra, (4) 85\%BPEAD tratado/5\%PBHL/10\%Fibra tratada.

Figura 82: Resistência à flexão para compósitos (1) 85\%BPEAD/5\%PBHL/10\%Fibra, (2) 85\%BPEAD/5\%PBHL/10\%Fibra tratada, (3) 85\%BPEAD tratado/5\%PBHL/10\%Fibra, (4) 85\%BPEAD tratado/5\%PBHL/10\%Fibra tratada.

Figura 83: Módulo de flexão para compósitos (1) 80\%BPEAD/5\%PBHL/15\%Fibra, (2) 80\%BPEAD/5\%PBHL/15\%Fibra tratada, (3) 80\%BPEAD tratado/5\%PBHL/15\%Fibra, (4) $80 \%$ BPEAD tratado/5\% PBHL/15\%Fibra tratada.

Figura 84: Resistência à flexão para compósitos (1) 80\%BPEAD/5\%PBHL/15\%Fibra, (2) 80\%BPEAD/5\%PBHL/15\%Fibra tratada, (3) 80\%BPEAD tratado/5\%PBHL/15\%Fibra, (4) 80\%BPEAD tratado/5\%PBHL/15\%Fibra tratada. 


\section{LISTA DE TABELAS}

Tabela 1: Caracterização da fibra de curauá. ............................................................. 54

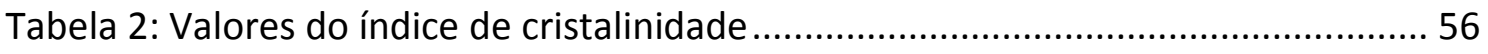

Tabela 3: Resistência a tração e alongamento das fibras de curauá. ….......................... 58

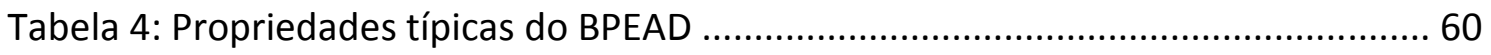

Tabela 5: Índice de cristalinidade para o BPEAD tratado e não tratado com ar ionizado

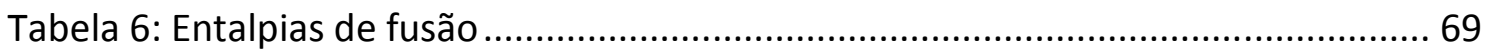

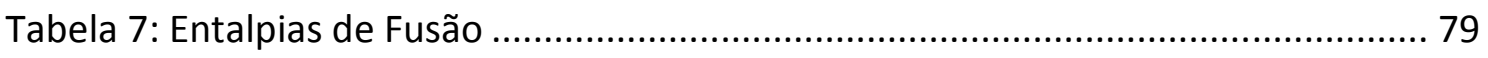

Tabela 8: Coeficiente de difusão, $D$ e constante de afinidade, $k$ para compósitos de

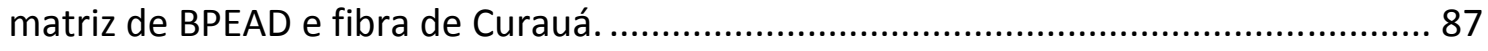

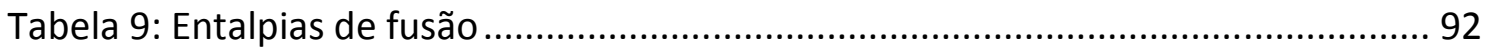

Tabela 10: Relaxações típicas do BPEAD e dos respectivos compósitos........................ 94

Tabela 11: Coeficiente de difusão, $\mathrm{D}$ e constante de afinidade, $\mathrm{k}$ para compósitos de matriz de BPEAD/PBHL e Fibra de Curauá.................................................................... 102

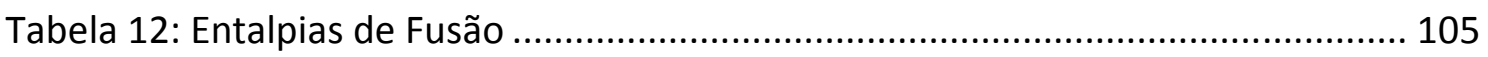




\section{LISTA DE FIGURAS}

\section{LISTA DE TABELAS}

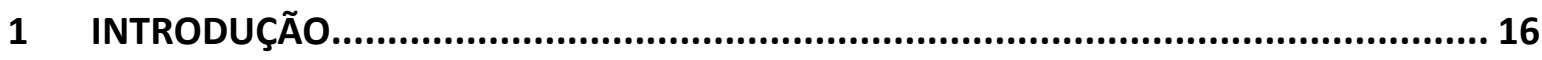

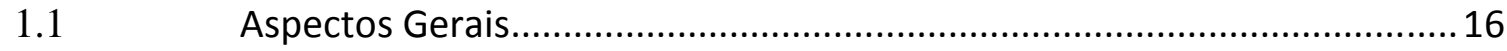

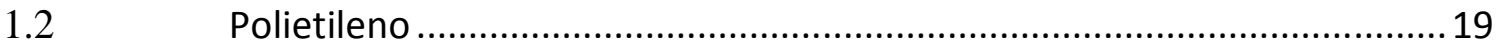

1.2.1 Polietileno de alta densidade (PEAD) …………................................21

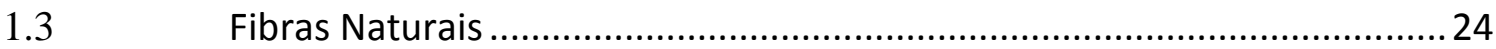

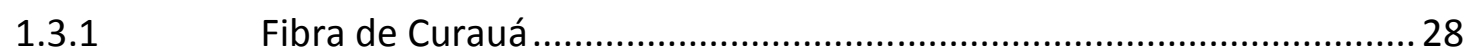

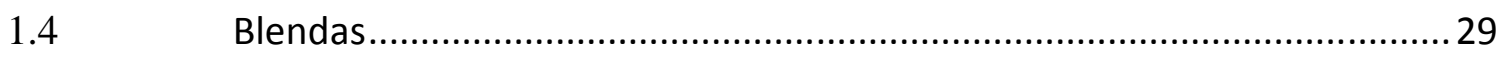

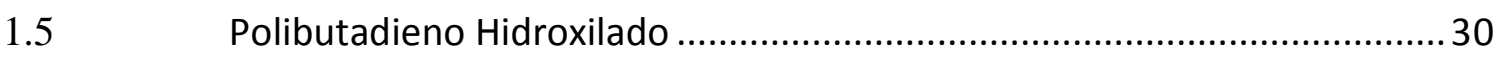

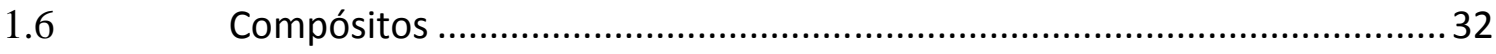

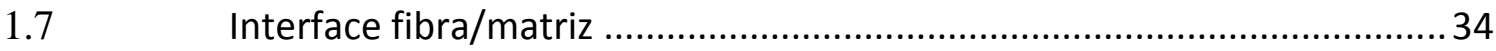

$1.8 \quad$ Modificações das fibras de curauá ..............................................................36

1.8.1 Tratamento das fibras de curauá com ar ionizado .................................37

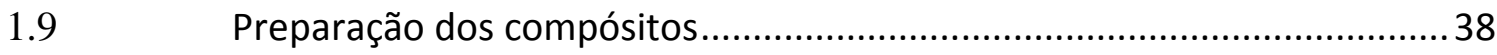

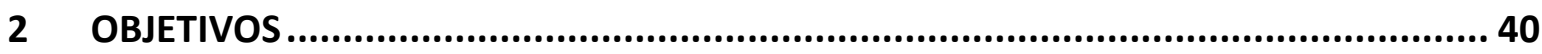

3 MATERIAIS, MÉTODOS E FORMA DE ANÁLISE DOS RESULTADOS ........................... 41

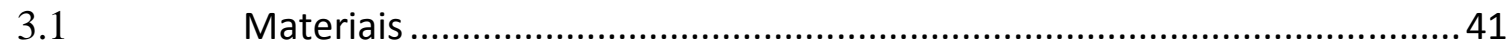

3.2 Purificação e Caracterização das Fibras de Curauá ......................................41

3.3 Ensaio de resistência à tração................................................................... 43

3.4 Determinação do grau de cristalinidade ………………………………....4 43

3.5 Adição de polibutadieno hidroxilado ao biopolietileno ………………........4

3.6 Preparação dos compósitos de matriz biopolietileno/PBHL reforçados

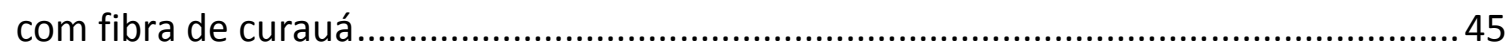

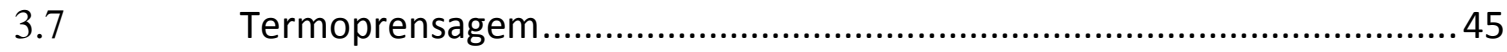

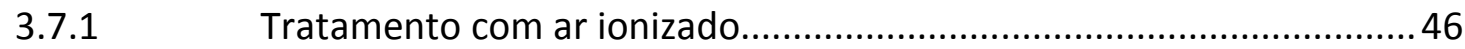

3.8 Caracterização dos materiais .................................................................4

3.8.1 Microscopia eletrônica de varredura (MEV) ........................................47

3.8.2 Calorimetria exploratória deferencial (DSC) .....................................48

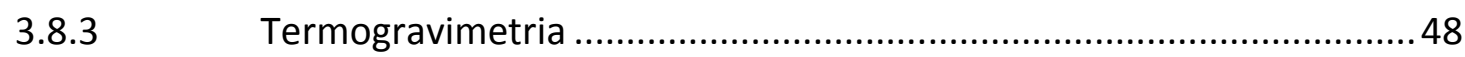

3.9 Resistência mecânica ao impacto ............................................................ 49 


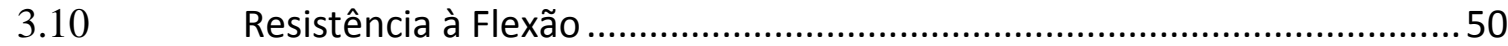

3.11 Análise térmica dinâmico-mecânica ............................................................ 51

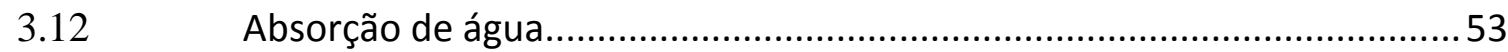

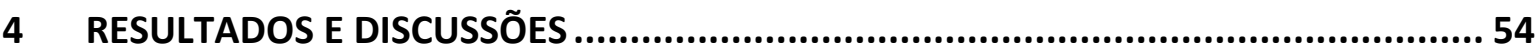

Caracterização das Fibras de Curauá .......................................................... 54

4.1.1 Determinação do Índice de Cristalinidade por Difração de raios X...... 55

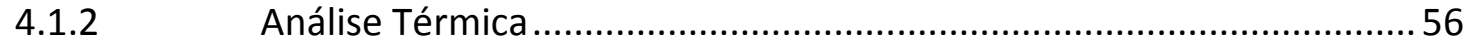

Ensaio de Tração .................................................................................. 58

4.1.4 Microscopia Eletrônica de Varredura .................................................59

4.2 Caracterizações do Biopolietileno de Alta Densidade (BPEAD)...................60

4.2.1 Determinaçao do Índice de Cristalinidade por Difração de raios X......61

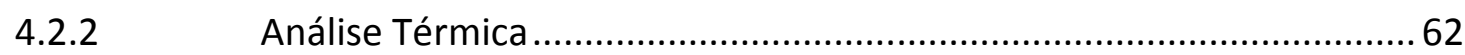

4.2.3 Analise Térmica Dinâmico- Mecânica (DMTA) …................................63

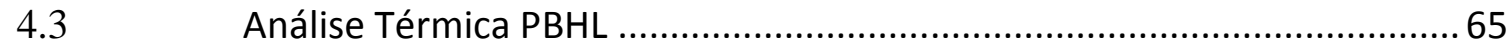

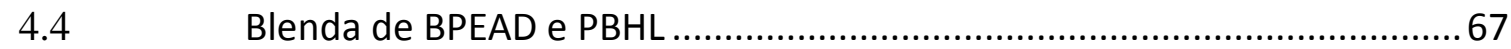

4.4.1 Preparação das amostras em misturador interno .................................67

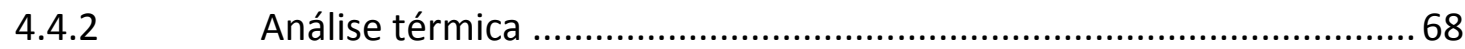

4.4.3 Análise Térmica Dinâmico- Mecânica (DMTA). ..................................... 70

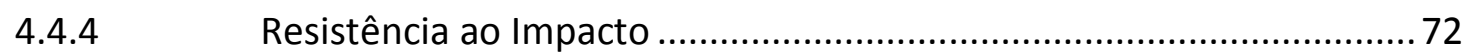

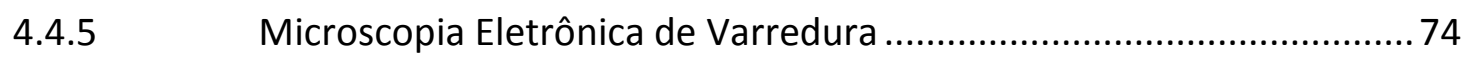

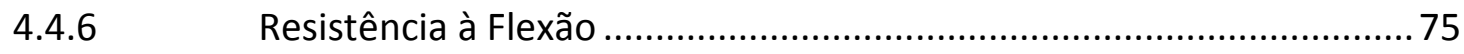

4.4.7 Preparação das amostras em misturador interno ................................77

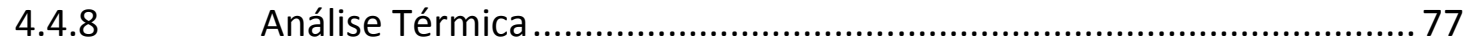

4.4.9 Análise Térmica Dinâmico-Mecânica (DMTA) ….................................. 79

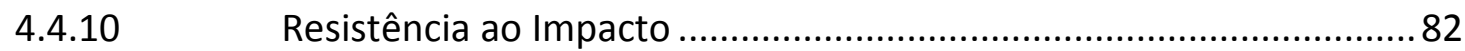

4.4.11 Microscopia Eletrônica de Varredura .................................................... 83

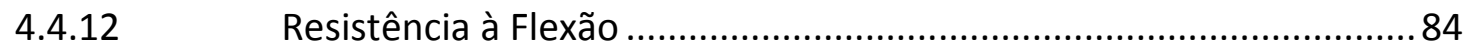

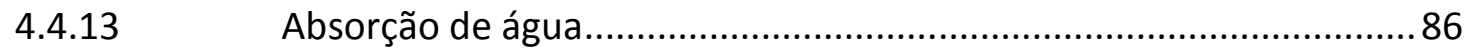

4.5 Adição de Polibutadieno Hidroxilado (PBHL) aos Compósitos reforçados

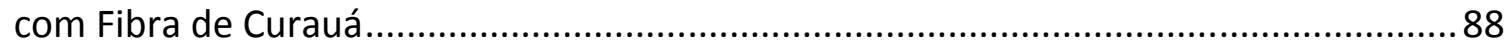

4.5.1 Preparação dos compósitos em misturador interno .............................8 88

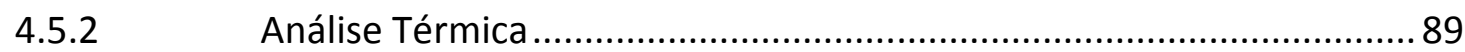

4.5.3 Análise térmica-dinâmico-mecânica...................................................92

4.5.4 Resistência ao Impacto .................................................................. 94 


\begin{tabular}{|c|c|}
\hline 4.5.5 & Microscopia Eletrônica de Varredura .................................................. 97 \\
\hline 4.5.6 & 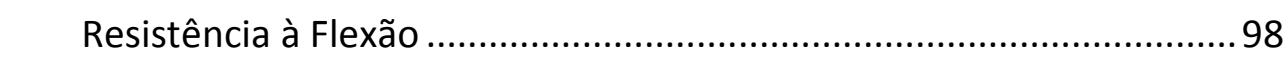 \\
\hline 4.5.7 & 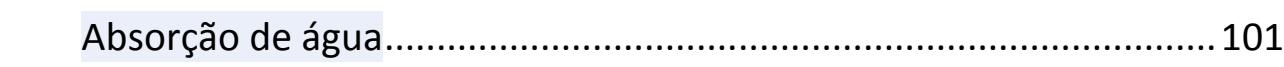 \\
\hline 4.6 & 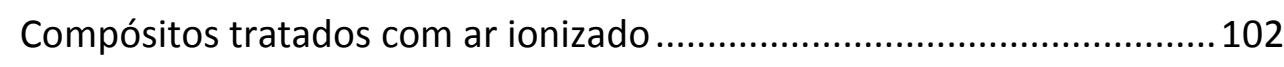 \\
\hline 4.6.1 & Análise térmica \\
\hline 4.6 .2 & Análise térmica dinâmico-mecânica (DMTA)........................................ 105 \\
\hline 4.6 .3 & 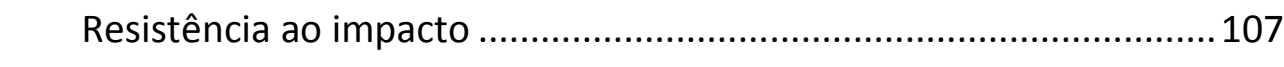 \\
\hline 4.6 .4 & Microscopia eletrônica de varredura.................................................... 109 \\
\hline 4.6 .5 & 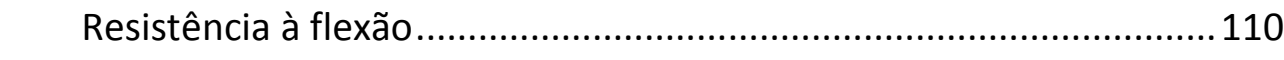 \\
\hline CON & (13 \\
\hline
\end{tabular}




\section{INTRODUÇÃO}

\subsection{Aspectos Gerais}

A necessidade de desenvolver e comercializar materiais compósitos baseados em constituintes de origem natural (biocompósitos) é considerado de extrema importância, o que terá impacto tanto na redução da dependência de materiais provenientes de fontes não renováveis (SOYKEABKAEW et al.,2008), assim como no que diz respeito a aspectos ambientais e econômicos (MOHANTY et al., 2004, MOTHÉ ; ARAÚJO, 2004, SWAMY et al., 2004).

Novas políticas ambientais têm levado indústrias automotivas, de embalagens e construção civil a procurarem novos materiais que possam substituir o tradicional compósito. A utilização de materiais lignocelulósicos na produção de compósitos poliméricos é particularmente atrativa, pelo seu baixo custo e alto volume de aplicações (KHALID et al., 2008).

Fibras de vidro são amplamente utilizadas como reforço em plásticos, entretanto, devido às restrições ambientais, a procura para providenciar à indústria de polímeros novas fibras aumentou. Neste contexto, a melhoria das propriedades mecânicas como módulo de elasticidade como medida de rigidez e resistência do material, tem sido um dos focos de abertura de novos campos de aplicação ou de substituição de materiais. Normalmente, o reforço de um polímero com fibras resulta em um aumento do módulo de elasticidade (SCHOBIG; GRELLMAN; MECKLENBUR, 2010).

A história de plásticos reforçados com fibras começou em 1908 com fibras de celulose reforçando matrizes fenólicas (JONH; THOMAS, 2008). A Figura 1 mostra a distribuição da utilização de fibras reforçando compósitos nos diferentes setores industriais, no início desta década, ou seja, após praticamente um século do início do uso de fibras reforçando plásticos. 


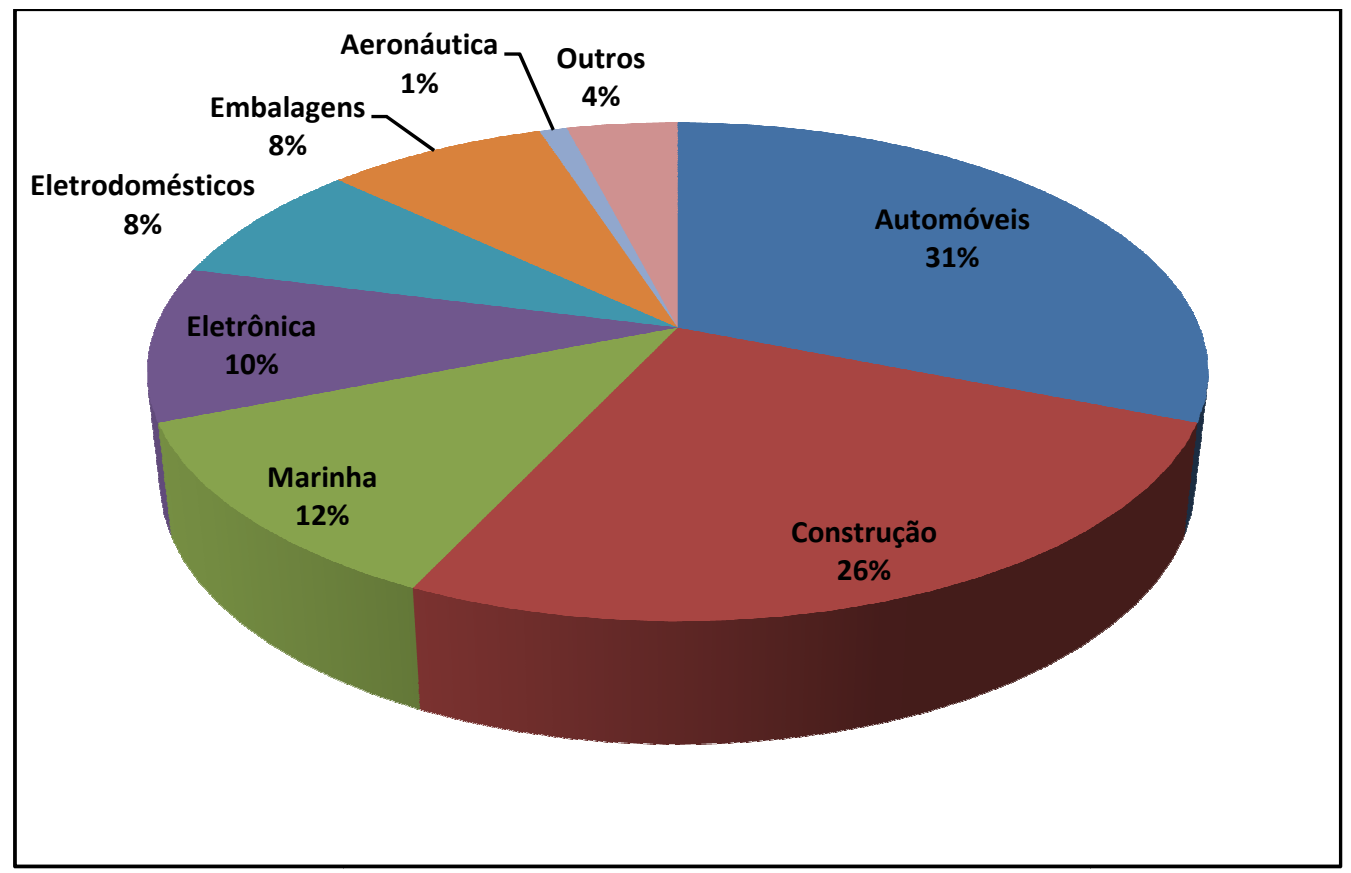

Figura 1: Compósitos de plástico reforçados com fibras usados em 2002, nos diferentes setores industriais (JONH; THOMAS, 2008).

O uso de fibras naturais como aditivos em compósitos apresenta um grande potencial para melhorar o seu desempenho e aplicação tecnológica, devido a seu baixo custo, abundância e biodegradabilidade. Além disso, devido à sua baixa densidade, as fibras naturais devem reduzir a massa do compósito, o que é importante para aplicações em automóveis, construção, dentre outros (CORRADINI et al., 2009).

Atualmente, a maioria dos polímeros sintéticos é produzida a partir de recursos não renováveis (fonte petroquímica) (AVÉROUS; HALLEY, 2009). A preocupação com a preservação ambiental tem tornado atrativa a utilização de polímeros obtidos de fontes renováveis (CAÑIGUERAL et. al, 2009). Biopolímeros ou polímeros sintéticos reforçados com fibras naturais correspondem a uma alternativa viável para compósitos reforçados com fibra de vidro (JONH; THOMAS, 2008).

$\mathrm{Na}$ literatura são encontrados diversos trabalhos em que fibras naturais são usadas em compósitos. As aplicações dos termorrígidos como matriz podem variar desde os segmentos de defesa e aeroespacial, até segmentos tais como: esportivo, médico, eletroeletrônico, automobilístico, construção naval, petroquímico, entre outros (OLIVEIRA; GUIMARÃES; BOTELHO, 2009). Esses materiais apresentam dureza e excelente resistência química. Geralmente, quando estes materiais são destinados a aplicações que solicitam alta 
resistência mecânica, é comum a incorporação de modificadores elastoméricos que originem uma segunda fase dispersa e propiciem uma tenacificação (SOUZA JÚNIOR et al., 2009).

A combinação de baixa massa específica com valores elevados de resistência e rigidez que os compósitos poliméricos avançados proporcionam, permite que essa classe de materiais seja empregada nas indústrias aeronáutica e espacial em substituição aos materiais metálicos tradicionais (MSALLEN et al., 2010). Componentes estruturais de aeronaves para fins civis e militares, que anteriormente eram fabricados em ligas de alumínio, titânio e aços especiais, estão atualmente sendo fabricados em estruturas laminadas de materiais pré-impregnados de compósitos poliméricos avançados (COSTA; REZENDE; BOTELHO, 2005).

Atualmente, há um grande interesse comercial e científico no desenvolvimento e modificação de misturas de poliolefinas, ou seja, termoplásticos, devido ao seu custo relativamente baixo e fácil processabilidade (SARKHEL; CHOUDHURY, 2010).

Devido à limitada estabilidade térmica das fibras vegetais, somente termoplásticos que amolecem a temperaturas abaixo de $200{ }^{\circ} \mathrm{C}$ são comumente usados nestes compósitos. A resina base e as fibras são escolhidas em função de suas propriedades, requisitos da aplicação, disponibilidade e custo (CLEMONS, 2002). Além do comprimento e proporção, a natureza da fibra utilizada tem grande influência nas propriedades dos compósitos (AHMAD; ANUAR, 2007).

Além da fibra e do termoplástico, os compósitos podem também conter estabilizantes, agentes de acoplamento e lubrificantes (FRANCUCCI; RODRÍGUEZ; VÁZQUEZ, 2010). A adição de fibras vegetais aos termoplásticos geralmente provoca um aumento na rigidez do compósito, mas podem torna-los mais frágeis (SANTOS, 2006).

Mano et al. (2010) avaliaram o efeito da adição de fibra de curauá em polipropileno e polietileno de alta densidade, pelo processo de extrusão, na proporção de 20 \% de fibra. Os efeitos do processamento foram avaliados através das propriedades mecânicas e da análise morfológica dos compósitos. Foi observado que a presença do reforço de fibras piorou a resistência à flexão e à tração dos compósitos. As matrizes poliméricas podem sofrer degradação durante o processamento, o que também pode ter contribuido para as mudanças nas propriedades mecânicas observadas. 
Mulinari et al. (2009) avaliaram o efeito da adição de bagaço de cana ao polietileno de alta densidade, PEAD, pelo processo de extrusão, na proporção de $10 \%$ em massa de bagaço de cana. Pode ser observado que o compósito mostrou baixa resistência à tração, em comparação com o PEAD, que foi atribuído ao fato de as fibras terem causado um aumento de defeitos, que foram reduzidos quando as fibras foram modificadas quimicamente com oxicloreto de zircônio.

A natureza polar hidrofílica, portanto, das fibras vegetais pode ser um problema na preparação de compósitos reforçados com as mesmas. A presença de água, depois da sua vaporização pode gerar vazios ("voids") na matriz polimérica, como também levar a uma fraca adesão entre as fibras vegetais e a matriz, quando a matriz é apolar (PAIVA et. al. 2000). O tratamento prévio das fibras, ou utilização de aditivos, na preparação de compósitos pode melhorar as propriedades mecânicas dos materiais (MARCOVICH, 1998).

\subsection{Polietileno}

Os polietilenos são inertes à maioria dos produtos químicos comuns, devido à sua natureza apolar, e sua estrutura parcialmente cristalina.

Em condições normais, os polímeros etilênicos não são tóxicos, podendo inclusive ser usados em contato com produtos alimentícios e farmacêuticos (COUTINHO; MELLO; SANTA MARIA, 2003).

O polietileno pode ser considerado um polialcano, sendo $\mathrm{n}$ o grau da polimerização do etileno. A Figura 2 mostra o mecanismo proposto para a polimerização radicalar do etileno. 
- Iniciação:

$$
\begin{aligned}
& \text { Iniciador: } \mathrm{RH}+\mathrm{O}_{2} \rightarrow \mathrm{ROOH} \\
& \mathrm{R} \bullet+\mathrm{CH}_{2}=\mathrm{CH}_{2} \rightarrow \mathrm{R}-\mathrm{CH}_{2}-\mathrm{CH}_{2}{ }^{\circ}
\end{aligned}
$$

- Propagação:

$$
\sim \sim \sim \sim \mathrm{CH}_{2}-\mathrm{CH}_{2} \bullet+\mathrm{CH}_{2}=\mathrm{CH}_{2} \rightarrow \sim \sim \sim \sim \mathrm{CH}_{2}-\mathrm{CH}_{2}-\mathrm{CH}_{2}-\mathrm{CH}_{2} \bullet
$$

- Término:

(Combinação)

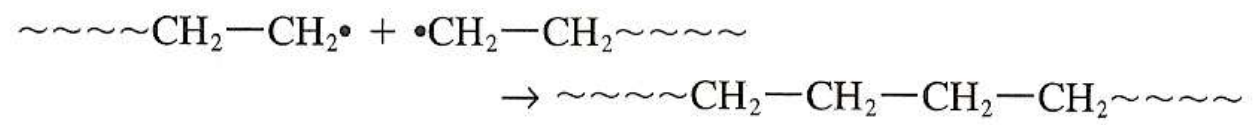

(Desproporcionamento)

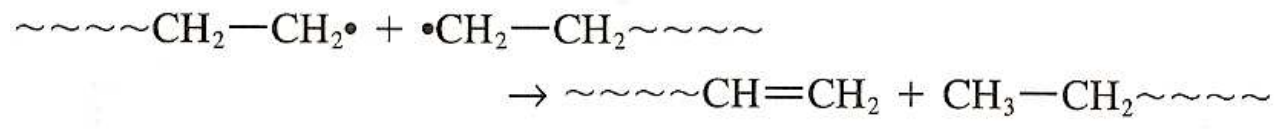

Figura 2: Polimerização radicalar do etileno (PEACOCK, 2000).

O polietileno pode ser obtido por diferentes processos de produção, entre eles está à polimerização radicalar realizada em altos valores de pressão. $\mathrm{O}$ iniciador da polimerização radicalar é uma espécie que possui um elétron desemparelhado formado a partir da decomposição do peróxido. O radical livre ataca a molécula de etileno, e o elétron não emparelhado muda-se para o lado oposto do monômero. O crescimento da cadeia continua na etapa de propagação, até que dois radicais livres se combinem e interrompa a propagação da cadeia, indicando o término da reação.

As ramificações, na polimerização radicalar, podem ser geradas como indicado na Figura 3: 


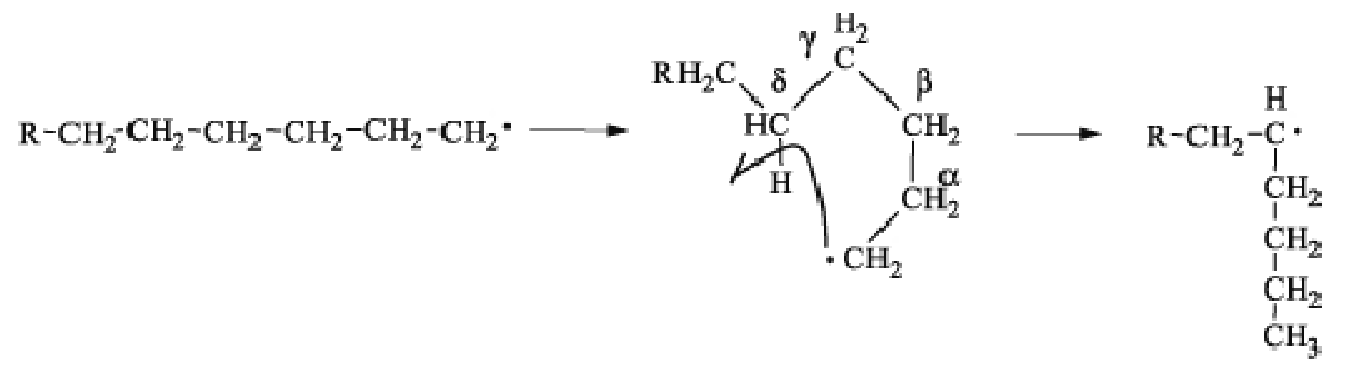

Figura 3: Mecanismo de formação de ramificações no PEBD (COUTINHO; MELLO; SANTA MARIA, 2003).

Dependendo das condições reacionais e do sistema catalítico empregado na polimerização, cinco tipos diferentes de polietileno podem ser produzidos, os quais diferem entre si quanto ao teor de ramificação das cadeias.

- $\quad$ Polietileno de baixa densidade (PEBD);

- $\quad$ Polietileno de alta densidade (PEAD);

- $\quad$ Polietileno linear de baixa densidade (PELBD);

- $\quad$ Polietileno de ultra alto peso molecular (PEUAPM);

- $\quad$ Polietileno de ultra baixa densidade (PEUBD).

\subsubsection{Polietileno de alta densidade (PEAD)}

\subsubsection{Preparação}

Corresponde a um termoplástico que possui número muito pequeno de ramificações ao longo de suas cadeias, motivo pelo qual é considerado um polímero de cadeia linear possuindo alta densidade (entre 0,94 e 0,97 $\mathrm{gcm}^{-3}$ ).

Estes polímeros são obtidos via reações em que catalisadores específicos são usados. A polimerização do etileno utilizando os catalisadores de Ziegler e Natta (combinação de trietil-alumínio e tetracloreto de titânio) é um dos métodos mais utilizados comercialmente para a produção do polietileno de alta densidade (PEACOK, 2000). Esses sistemas catalíticos são ativos o suficiente para permitir que a reação ocorra, inclusive, à pressão atmosférica e temperaturas inferiores a $100^{\circ} \mathrm{C}$ (COUTINHO; MELLO; SANTA MARIA, 2003). A Figura 4 
ilustra de forma simplificada um mecanismo proposto para a obtenção do polietileno de alta densidade.
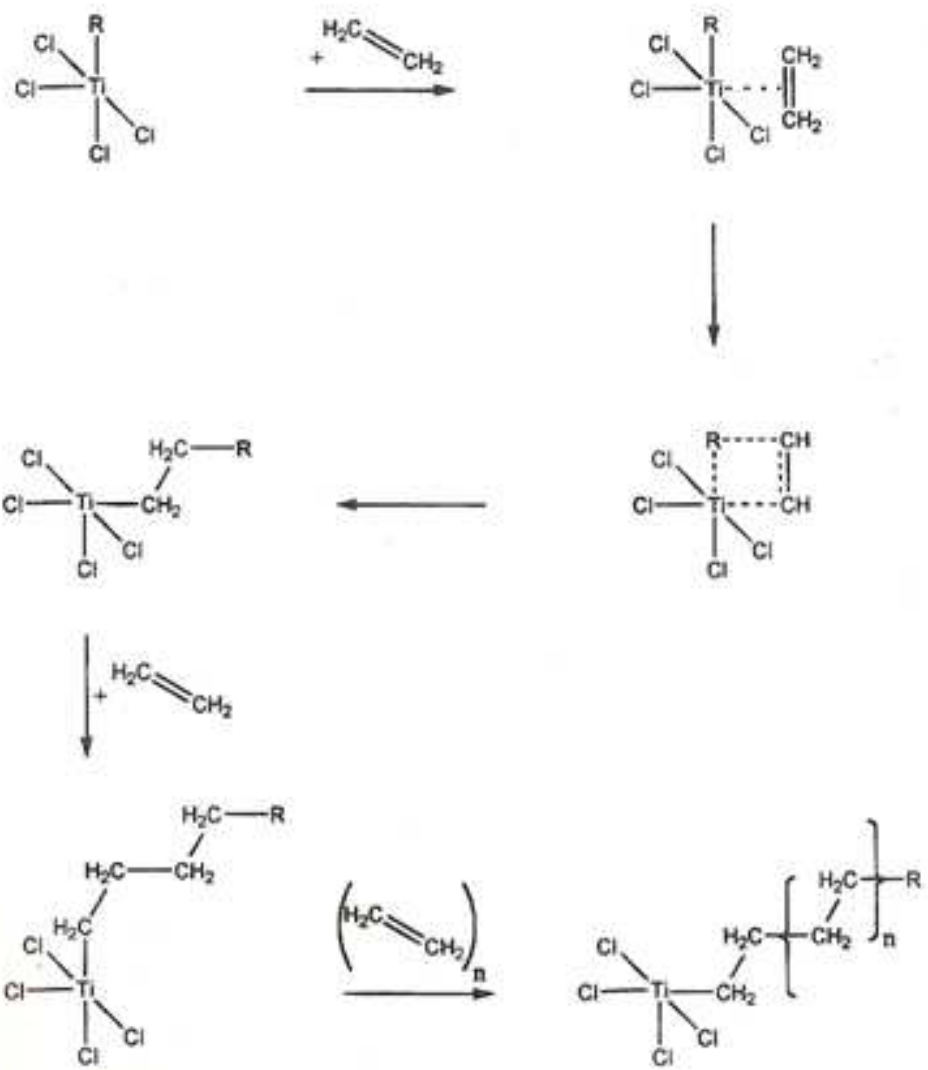

Figura 4: Polimerização do etileno utilizando os catalisadores de Ziegler-Natta (PEACOK, 2000).

De forma simplificada, o centro ativo do catalisador de Ziegler e Natta contem um átomo de titânio coordenado com 4 átomos de cloro e um grupo alquila em uma configuração octaédrica, possuindo uma região que corresponde a um "orbital vazio", ou seja, região apta a receber densidade eletrônica. Pode-se considerar que a molécula de etileno se coordena com esta região do catalisador, usando seus elétrons $\pi$. $O$ grupo R se rearranja, ligando-se a um dos átomos de $C$ do etileno, que usa seus elétrons $\pi$ para definitivamente se ligar ao $\mathrm{Ti}$, através do outro átomo de $\mathrm{C}$, sendo que o complexo formado reagirá com novas moléculas de etileno, obtendo-se assim, o polietileno de alta densidade (Figura 4) (PEACOK, 2000).

No presente trabalho, polietileno de alta densidade foi utilizado. 


\subsubsection{Propriedades}

A temperatura de transição vítrea ( $\mathrm{Tg}$ ) é um importante parâmetro que pode ser utilizado para a caracterização de plásticos e outros materiais não cristalinos ou semicristalinos. Nesta transição, ocorre a passagem do material do estado vítreo para um estado borrachoso, sem que ocorra uma mudança estrutural. A Tg para o polietileno de alta densidade varia de -90 a $-120 \circ \mathrm{C}$, pois depende de fatores como massa molar média sendo consequência de rotações em torno de ligações, envolvendo segmentos das cadeias presentes na fase não cristalina do polietileno (CALLISTER, 2002).

A linearidade das cadeias, e consequentemente a maior densidade do PEAD fazem com que a orientação, o alinhamento e o empacotamento das cadeias sejam mais eficientes; as forças intermoleculares (van der Waals) sejam mais intensas, e, como conseqüência, a cristalinidade seja maior que no caso do PEBD. A temperatura de fusão $\left(T_{m}\right)$, relacionada à região cristalina, ocorre normalmente entre 128 e $135^{\circ} \mathrm{C}$ (BRIDSON, 1982).

O polietileno de alta densidade (PEAD) é altamente cristalino (acima de 90\%), pois apresenta um baixo teor de ramificações (BRIDSON, 1982).

As propriedades elétricas são pouco afetadas pela densidade e pela massa molecular média do polímero, mas as propriedades mecânicas sofrem uma forte influência deste parâmetro, assim como do teor de ramificações (COUTINHO; MELLO; SANTA MARIA, 2003).

À temperatura ambiente, PEAD não é solúvel em nenhum solvente conhecido, sob altas temperaturas, se dissolve em alguns hidrocarbonetos alifáticos e aromáticos (BRIDSON, 1982).

O PEAD é utilizado em diferentes segmentos da indústria de transformação de plásticos, abrangendo os processamentos de moldagem por sopro, extrusão e moldagem por injeção (COUTINHO; MELLO; SANTA MARIA, 2003).

Neste trabalho foi utilizado o "polietileno verde", ou biopolietileno (BPEAD) que é obtido a partir de eteno, por sua vez gerado pela fermentação e destilação do caldo da cana, que produz inicialmente o etanol. Na fase seguinte, o etanol é desidratado e transformado em eteno (Figura 5). 


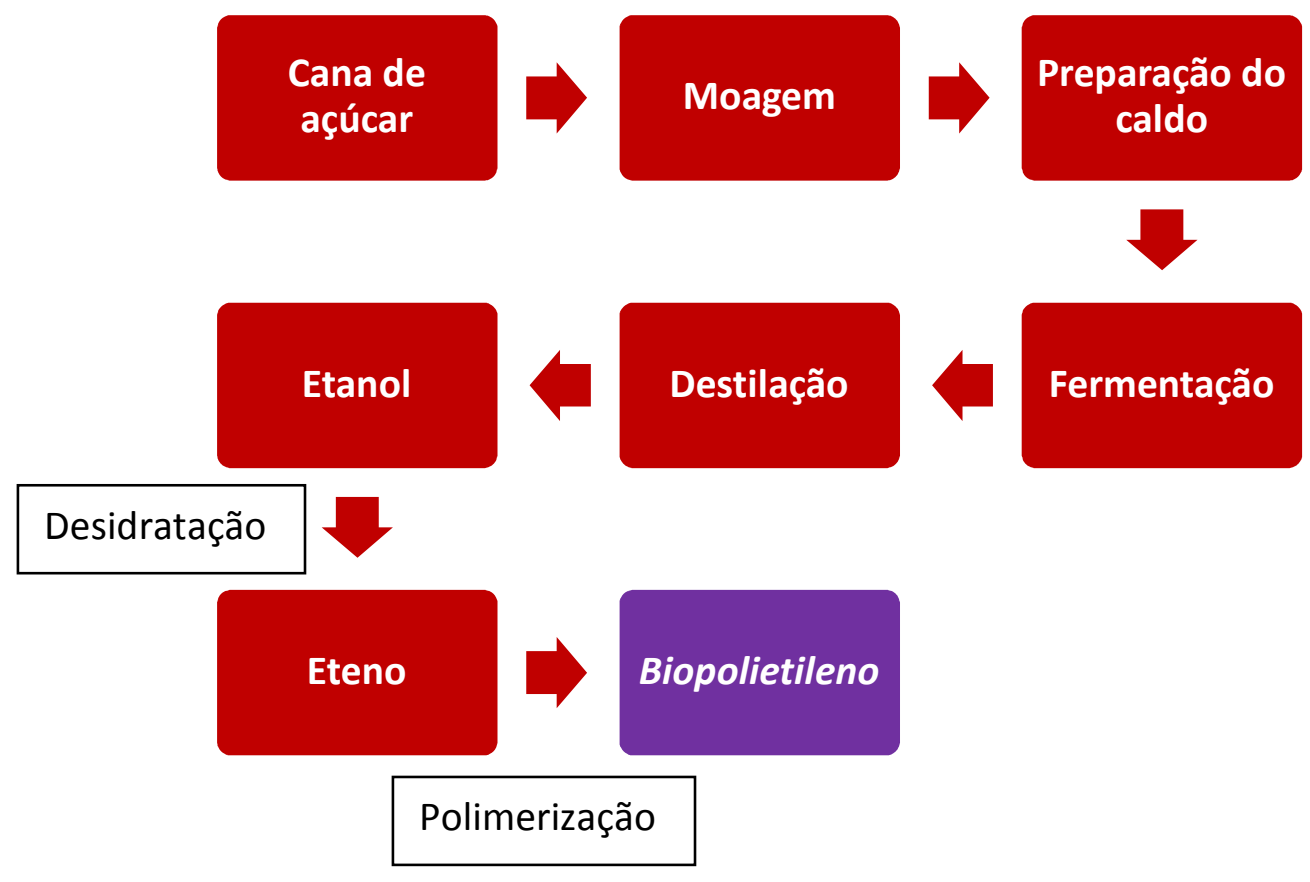

Figura 5: Esquema indicativo do processo de obtenção do BPEAD a partir da cana de açúcar.

O "polietileno verde" logicamente tem estrutura semelhante ao polímero originado a partir do eteno oriundo de rota petroquímica, e corresponde a uma inovação tecnológica, pois além de ocorrer absorção de $\mathrm{CO}_{2}$ da atmosfera no ciclo de produção, ainda reduz a dependência de matérias-primas de origem fóssil para fabricação de produtos plásticos (disponível em <http://www.braskem.com.br/>).

\subsection{Fibras Naturais}

A procura por materias que causem menor impacto ambiental tem se tornado crescente. Assim, fibras naturais vêm sendo amplamente utilizadas na indústria (NUNES et al., 2000). As fibras vegetais correspondem a um excelente agente de reforço para plásticos, por serem resistentes, leves e não abrasivas. Um dos aspectos mais interessantes sobre as fibras naturais é o seu impacto ambiental positivo, por ser um recurso renovável com produção que exige pouca energia (JONH; THOMAS, 2008). Por possuírem um baixo custo, sua aplicação é também economicamente interessante (ZAH; LEÃO; BRAUN, 2007).

Um grande destaque deve ser dado à utilização de fibras naturais de origem vegetal, em razão da variedade de espécies. Algumas fibras ocorrem espontaneamente na natureza, 
outras são cultivadas e há aquelas que são resíduo gerado principalmente pela agroindústria (SILVA et al., 2009).

Nas últimas duas décadas, a produção de fibra no mundo aumentou 0,8 milhões ton. No entanto, atualmente se têm sinais de uma possível estabilização na produção. A China tem sido apontada como o maior produtor do mundo e, contrastando com o comportamento da produção mundial, a sua produção tem aumentado nestes últimos anos. O Brasil mantém sua posição como quinto maior produtor de fibra do mundo, com 1,3 milhões toneladas em 2007 (Organização das Nações Unidas para agricultura e alimentaçãoFAO, 2008). Tradicionalmente, estas fibras são usadas por artesãos ou setores industriais (na indústria têxtil ou como fonte de energia). Uma tendência crescente no mundo é a máxima utilização dos recursos naturais através de novos processos, gerando novas aplicações para as fibras lignocelulósicas na indústria automotiva, na produção de adesivos, etanol, ácido láctico, carvão ativado, furfural ou no desenvolvimento de materiais compostos (BRÍGIDA et al., 2010).

O Brasil tem um elevado potencial para a produção de fibras naturais e produz um número elevado de fibras lignocelulósicas diferentes (TOMCZACK; SATYNARAYANA 2007). Sucessivos governos no Brasil têm dado atenção especial para as políticas agrícolas. Estas políticas incluem o aumento de terras cultiváveis, o desenvolvimento de novas técnicas e a melhoria das formas existentes de cultivo (SATYANARAYANA; GUIMARÃES; SWYPYCH, 2007).

A organização mais comum de uma fibra vegetal está representada na Figura 6. Cada fibra lignocelulósica tem uma estrutura de camadas complexas; constituída por uma parede primária fina, que circunda uma parede secundária. A parede secundária é constituída por três camadas (S1, S2 e S3), a camada (S2) determina as propriedades mecânicas da fibra e consiste em uma série de microfibrilas, helicoidalmente formadas por longas cadeias de celulose e organizadas no sentido da fibra (SILVA et al., 2009). 


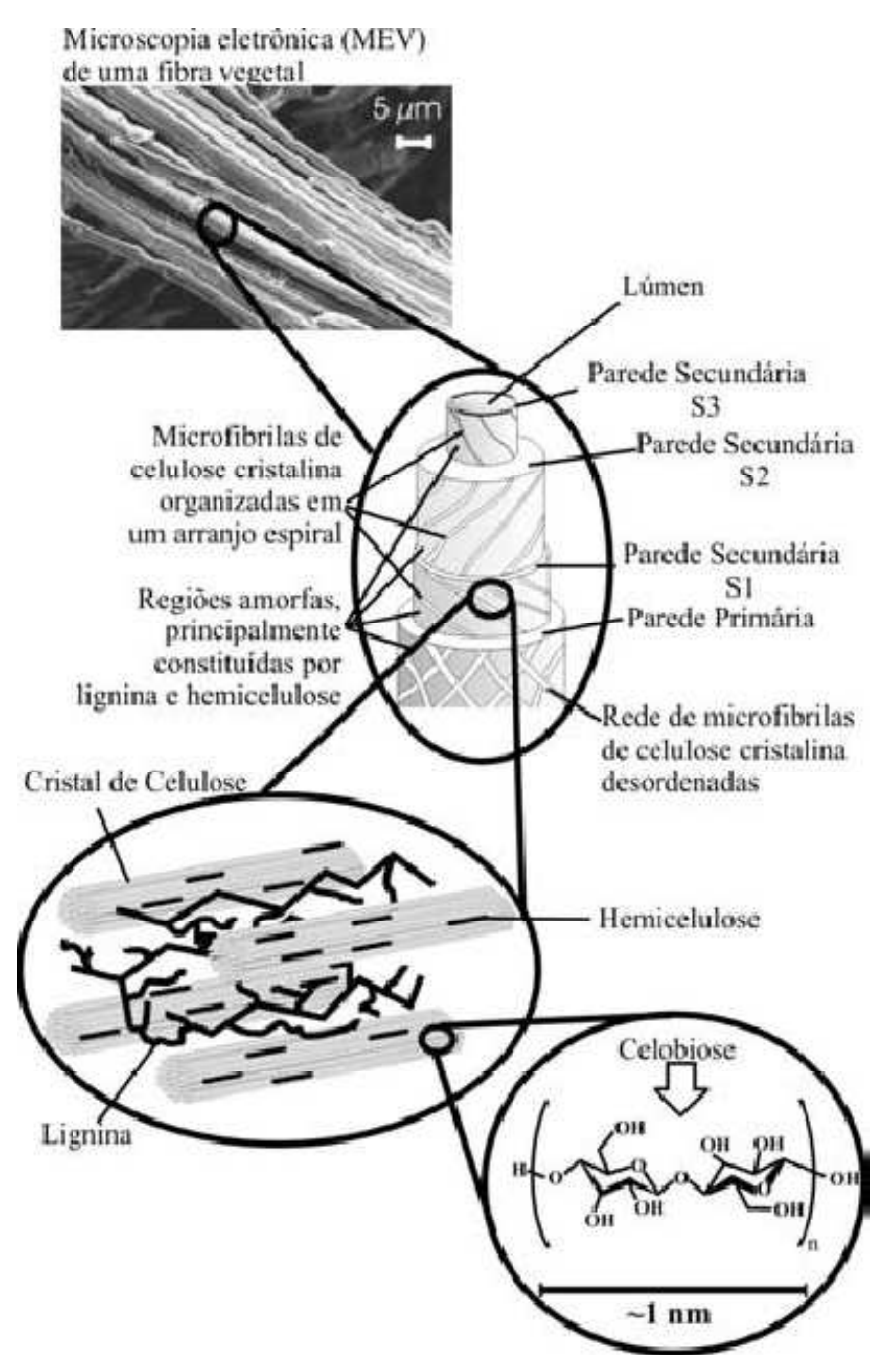

Figura 6: Estrutura de uma fibra vegetal. A imagem de MEV se refere à fibra de Eucalipto (SILVA et al., 2009).

As fibras de curauá, usadas no presente trabalho, assim como as demais fibras lignocelulósicas, são constituídas de celulose, hemicelulose (ou polioses), lignina, pectina, cera e substâncias solúveis em água, sendo os três primeiros componentes majoritários e os responsáveis pelas propriedades físicas das fibras (GEORGOPOULOS et al., 2005).

A celulose é o material de origem vegetal mais abundante da Terra, sendo o componente orgânico principal das fibras naturais, consistindo de uma cadeia linear de unidades de celobiose interligadas (Figura 7). É um polissacarídeo com fórmula geral $\left(\mathrm{C}_{6} \mathrm{H}_{10} \mathrm{O}_{5}\right)_{n}$ (ROWELL, et al., 2000). 


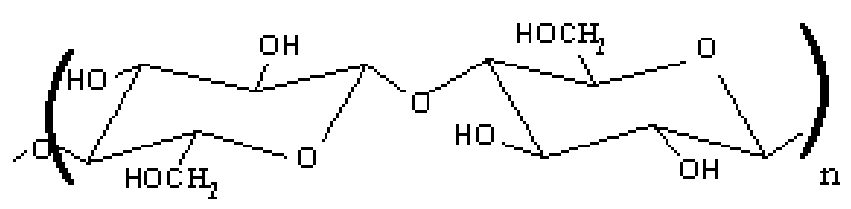

Figura 7: Estrutura da celobiose (FENGEL, 1989).

As hemiceluloses, também chamadas de polioses, correspondem a polissacarídeos com grau de polimerização menor (da ordem de 10 a 100 vezes) com relação ao da celulose (FENGEL, 1989).

Costuma-se dividir a lignina em duas classes: guaiacila e guaiacila-siringila. Nas guaiacilas, existem principalmente unidades guaiacila e nas guaiacila-siringila existem unidades guaiacila e siringila em proporções aproximadas (Figura 8), sendo que ambas as classes possuem proporções menores de unidades para-hidroxifenila (FENGEL, 1989).<smiles>Cc1ccc(O)cc1</smiles>

a)<smiles>COc1cc(C)ccc1O</smiles>

b)<smiles>COc1cc(C)cc(OC)c1O</smiles>

c)

Figura 8: Unidades presentes na lignina: a) p- hidroxi-fenila b) Guaiacila c)Siringila (Fengel, 1989).

Os compósitos reforçados com fibras naturais apresentam boas propriedades mecânicas, baixo custo e baixa densidade. São termicamente estáveis até aproximadamente $200^{\circ} \mathrm{C}$ (PAIVA; FROLLINI, 2006). No entanto, como as fibras de vidro comerciais sem tratamento, as fibras naturais apresentam baixa compatibilidade com os polímeros não polares e uma alta absorção de água, o que pode afetar as propriedades mecânicas dos compósitos (SPINANCÉ et al., 2009).

A fim de melhorar a adesão polímero/fibra e reduzir a absorção de água, a superfície das fibras pode ser modificada por métodos físicos ou químicos (MEGIATTO et al., 2007). As propriedades destes materiais podem ser aprimoradas, se ocorrer intensificação nas interações entre a fibra e a matriz (HASSAN; et al., 2000). Estas interações dependem da 
extensão da área de contato e da afinidade entre os componentes, podendo ser intensificadas através de tratamentos físicos e químicos aplicados à superfície das fibras (TRINDADE, 2005).

\subsubsection{Fibra de Curauá}

A Ananas erictifolius, conhecida popularmente por fibra de curauá, é uma espécie encontrada principalmente na região amazônica, é semelhante ao abacaxi, no entanto, o interesse dos agricultores está em suas fibras (MOTHÉ; ARAÚJO; WANG, 2009). A Figura 9 ilustra, respectivamente, o aspecto da planta de curauá (a) e fibras extraídas das folhas (b).

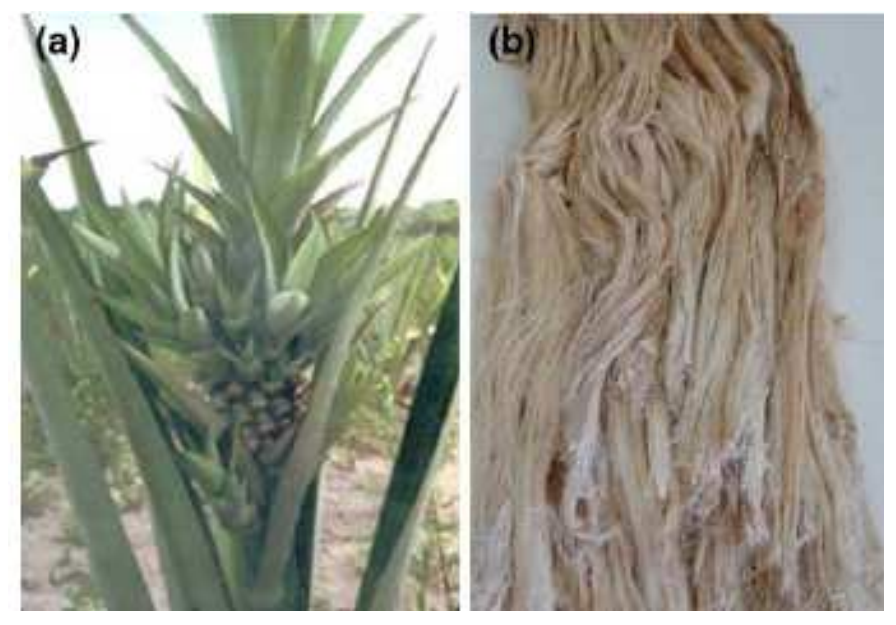

Figura 9: Planta (a) e fibras de curauá (b) (MONTEIRO; AQUINO, 2007).

Tendo em média um metro de comprimento e quatro centímetros de largura, suas folhas são duras, eretas e possuem uma superfície plana com espinhos em toda a sua extensão (SILVA; AQUINO ,2008). Cada hectare tem cerca de dez mil plantas e cada planta produz cerca de cinquenta - sessenta folhas por ano (SATYANARAYAMA; GUIMARÃES; WYPYCH, 2007).

O curauá pode ser encontrado próximo aos rios Xingu, Tocantins, Tapajós, Marcuru, Trombetas, Paru, Acara e Guama, em áreas onde o índice pluviométrico é de 2000 mm/ano aproximadamente, que é o índice mínimo necessário para o cultivo da planta (TRINDADE, et al., 2005). Existem quatro tipos conhecidos de curauá: o branco, cujo broto possui uma coloração luminosa e várias fibras resistentes; o púrpura, o vermelho e o branco brilhante. 
As fibras são especialmente indicadas para a fabricação de barbantes e cordas finas (TRINDADE, 2005).

A substituição de fibras de vidro por fibras naturais, por exemplo na indústria automobilística, pode gerar benefícios econômicos, ambientais e sociais. Há vantagens econômicas e sociais da aplicação de compósitos reforçados com fibras em peças de automóveis. Além de custar $50 \%$ menos do que fibra de vidro, a utilização de fibras de curauá pode promover o desenvolvimento regional da Amazônia (ZAH et al., 2007). É importante mencionar que novas políticas devem ser desenvolvidas para garantir o atendimento da demanda.

Fibras de curauá são utilizadas no setor doméstico para redes e linhas de pesca, também como cordas e como redes de dormir (SATYANARAYAMA; GUIMARÃES; WYPYCH, 2007). As características desta fibra vêm despertando os interesses da indústria automobilística. As fibras de curauá e outras fibras naturais misturadas com plástico podem ser usadas, por exemplo, em painéis de cabines de carro (ZAH et al.,2007).

No presente trabalho, o curauá foi utilizado como agente de reforço de matriz termoplástica (BPEAD).

\subsection{Blendas}

Blendas poliméricas são sistemas poliméricos originários da mistura física de dois ou mais polímeros, com características constitucionais ou configuracionais diferentes, sem que haja, necessariamente reações químicas entre eles. Para ser considerada uma blenda, os compostos devem ter concentração em massa do segundo componente acima de $2 \%$ (DE PAOLI, 2009).

A preparação de blendas tornou-se uma prática freqüente na década de 80 . Entre os seus objetivos, estão: reduzir custos, melhorar a processabilidade, obter materiais com propriedades físicas superiores e desenvolver novas técnicas de processamento na área de misturas, dando origem a materiais com aplicações em vários segmentos industriais, como o alimentício, de papel,de adesivos, de embalagens e de petróleo (CALLISTER, 2002).

Blendas poliméricas podem ser miscíveis, imiscíveis ou parcialmente miscíveis. A miscibilidade relaciona-se com a capacidade de dois ou mais componentes se misturarem 
em nível molecular, resultando numa mistura homogênea. Nas blendas miscíveis, os polímeros formam uma única fase e estão intimamente misturados em nível molecular, apresentando somente um valor de $\mathrm{Tg}$, entre os valores das $\mathrm{Tg}$ dos polímeros individuais. Já os componentes das blendas imiscíveis são essencialmente independentes. Este tipo de blenda apresenta um número de fases relacionado ao número de seus componentes. Consequentemente, espera-se que as blendas apresentem valores de $\mathrm{Tg}$ praticamente iguais às dos polímeros individuais. As blendas parcialmente miscíveis devem apresentar, valores de $\mathrm{Tg}$ relativos aos seus componentes, mas situados entre os valores dos polímeros individuais (CALLISTER, 2002).

As blendas comerciais podem formar materiais monofásicos (homogêneos) ou bifásicos (com separação de microfases). Essa morfologia dependerá de vários fatores, tais como temperatura de processamento, cinética do processo de mistura, viscosidade e presença de aditivos.

No presente trabalho, blendas foram preparadas a partir de BPEAD e polibutadieno líquido hidroxilado (PBHL). A adição do elastômero pode promover um aumento na resistência à propagação da trinca durante o impacto, conforme será discutido posteriormente. Destaca-se que estas blendas foram preparadas para avaliação de propriedades como amostra controle, já que o objetivo final consistiu na preparação de compósitos.

Sarkel et al. (2010) prepararam blendas de polietileno e borracha natural, sendo observado que a adição de uma pequena quantidade de borracha à matriz levou a melhoras significativas na resistência ao impacto e no alongamento de ruptura da blenda.

\subsection{Polibutadieno Líquido Hidroxilado}

Os elastômeros são materiais que podem ser utilizados como agente de tenacificação, pois quando se aplica uma tensão, as partículas elastoméricas dispersas podem concentrar ou absorver essa tensão, provocando uma alteração do estado de tensão da fase matricial e uma deformação plástica, melhorando assim a resistência ao impacto do material. A introdução de uma pequena quantidade de borracha líquida, como polibutadieno 
hidroxilado (Figura 10) como segunda fase à matriz, portanto, pode aumentar a resistência à fratura destes materiais.<smiles>OCCC=CCCO</smiles>

Figura 10: Estrutura química do polibutadieno hidroxilado (PBHL).

A técnica mais comumente empregada no processo de tenacificação de polímeros corresponde à mistura física entre a matriz e o elastômero. Utilizando-se uma borracha líquida de baixa massa molar média, como PBHL (Figura 10), a viscosidade da matriz não aumenta excessivamente e uma mistura com boa processabilidade pode ser obtida. Desta forma, a matriz apresentará em sua composição partículas de borracha, as quais podem promover um aumento na resistência à propagação da trinca e na resistência ao impacto (AHMAD; WONG, 2006). Quando a trinca atinge a região do elastômero, este se deforma com facilidade, dissipando a tensão localizada na ponta da trinca por toda a superfície da partícula elastomérica, impedindo a propagação da falha (MEGIATTO; RAMIRES; FROLLINI, 2010).

No caso de compósitos, a adesão entre borracha/matriz e a superfície da fibra é muito importante para as propriedades mecânicas do material (KONDO et al., 2009).

A Figura 11 mostra de forma esquemática que o PBHL, no presente trabalho, além de poder atuar como agente modificador de impacto, pode atuar como agente de acoplamento, pois tem cadeias hidrocarbônicas, com afinidade por polietileno, e grupos hidroxilas com afinidade por grupos presentes nas fibras.

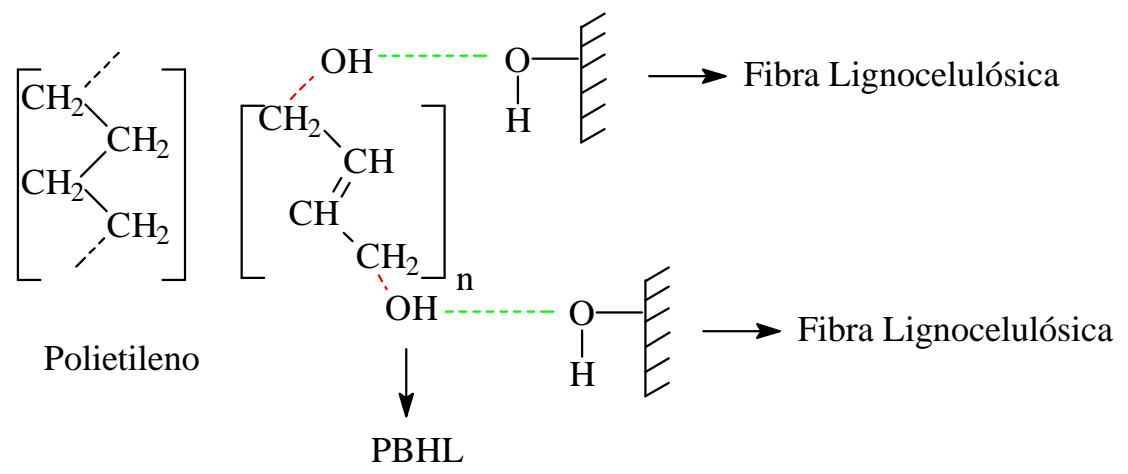

Figura 11: Esquema indicativo das interações do PBHL com os grupos hidroxila das fibras e com as cadeias hidrocarbônicas do polietileno. 
No presente trabalho, buscando melhorar o desempenho dos compósitos poliméricos reforçados com fibras de curauá, PBHL foi usado na formulação do compósito como agente modificador de impacto, com a possibilidade de atuar também como agente de acoplamento.

\subsection{Compósitos}

De forma simplificada, um compósito pode ser definido como um material que apresenta duas ou mais fases distintas, sendo, portanto, um material heterogêneo (HERAKOVICH, 1998).

Pode ser ou não polimérico, em que um dos componentes é descontínuo, sendo o principal responsável pela resistência ao esforço (componente estrutural ou reforço) e o constituinte que é contínuo e está freqüentemente, mas nem sempre, presente em maior quantidade no compósito é denominado de matriz (MANO, 1991). A matriz pode ser polimérica, metálica ou cerâmica (Figura 12).

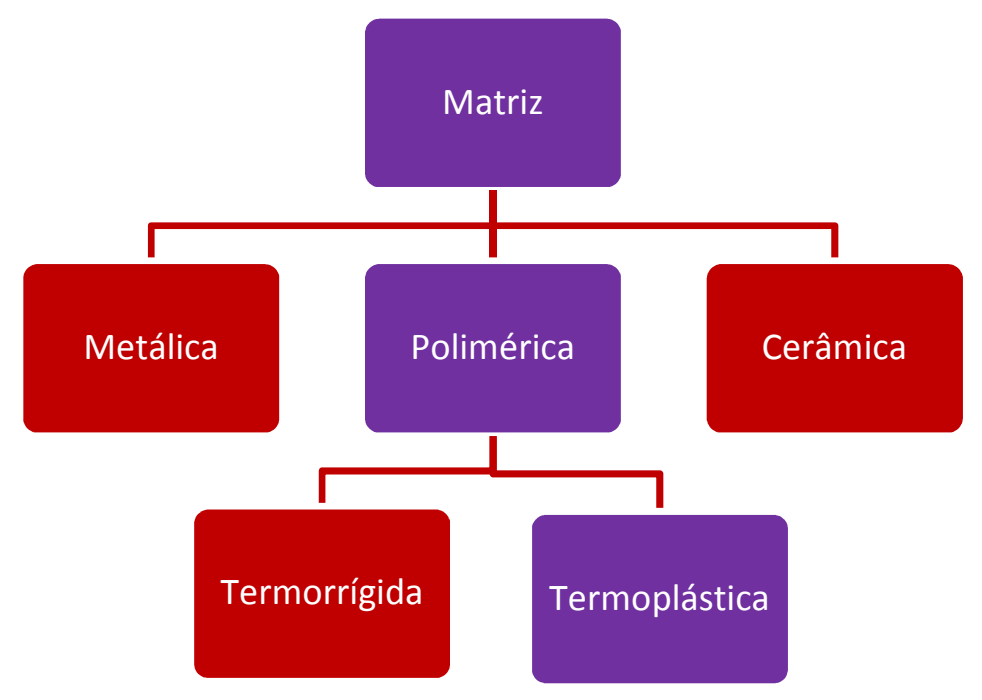

Figura 12: Classificação das matrizes mais utilizadas em compósitos (MATHEWS;

RAWLINGS, 1994).

O componente descontínuo (reforço) pode ser classificado de acordo com o esquema mostrado na Figura 13: 


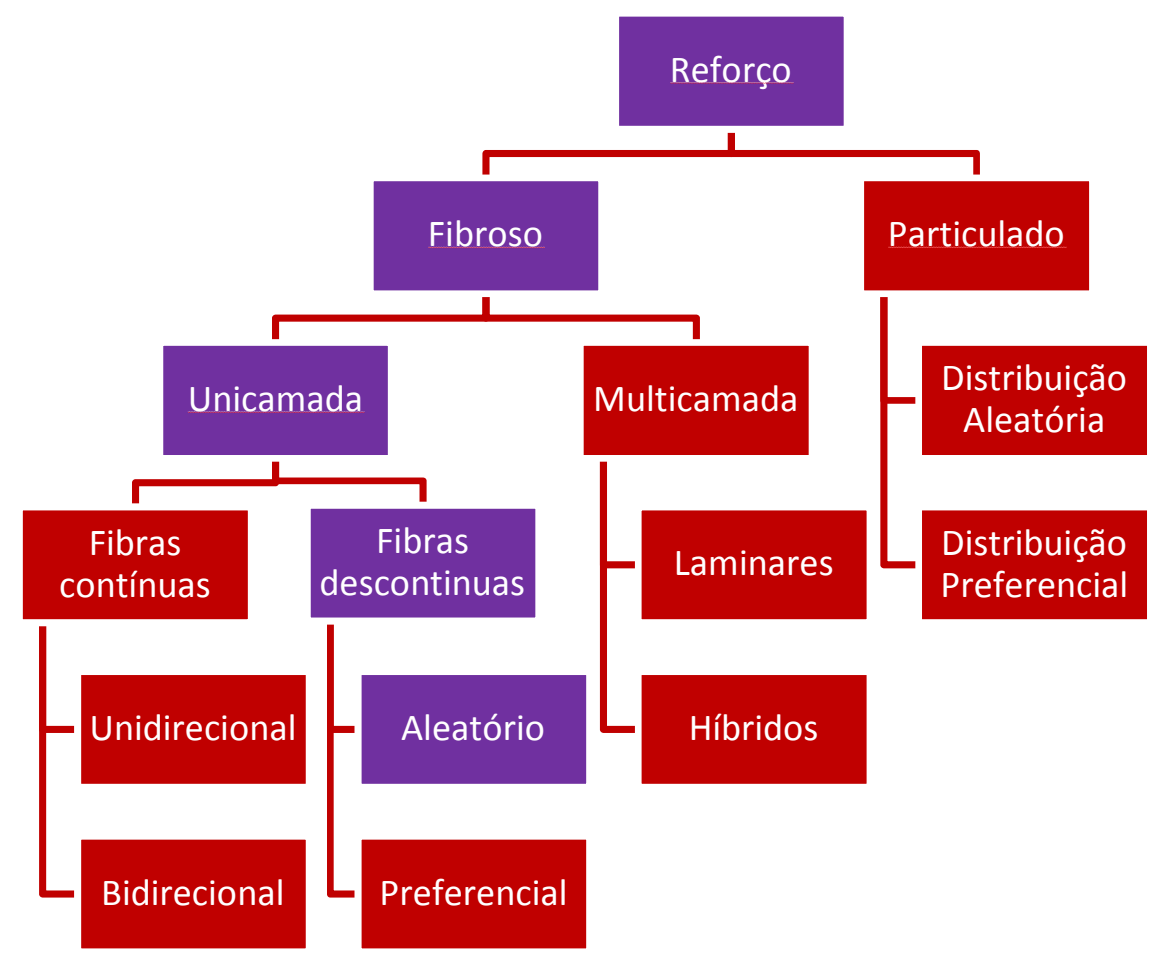

Figura 13: Classificação dos reforços utilizados em compósitos (MATHEWS; RAWLINGS, 1994).

Quanto à orientação das fibras, pode ser de três tipos: unidirecionadas com fibras contínuas (Figura 14 a); aleatórias com fibras descontínuas multidirecionais (Figura 14 b) e orientadas de fibras descontínuas (Figura 14 c).

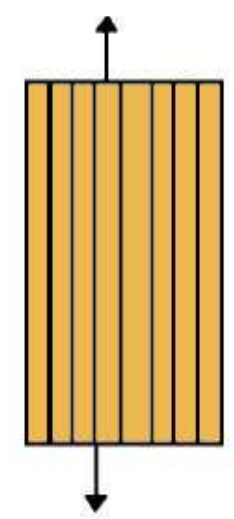

(a)

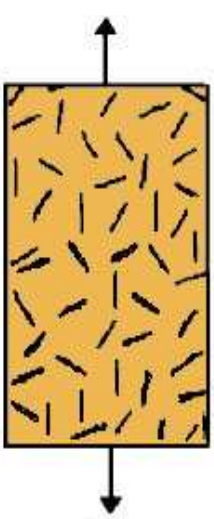

(b)

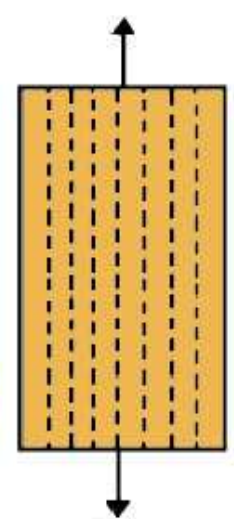

(c)

Figura 14: Exemplos de Compósitos: (a) unidirecionais com fibras contínuas; (b) aleatórias com fibras descontínuas multidirecionais; (c) orientadas de fibras descontínuas

(MATHEWS; RAWLINGS, 1994). 
Para que ocorra uma interação na mistura de dois componentes de natureza química diversa, é essencial a existência de áreas de contato entre eles (MANO, 1991). Agentes de acoplamento fibra-matriz ou tratamentos químicos são sugeridos para intensificar a adesão fibra-matriz e reduzir a absorção de água de compósitos reforçados por fibras naturais (MEGIATTO; RAMIRES; FROLLINI, 2010).

Em geral as ligações na interface são descritas em termos de força intermolecular e energia livre na superfície, mas na prática os fatores que influem na interação interfacial são: (1) umidade, (2) reação química, (3) adsorção e difusão, (4) camada de tensão residual, (5) morfologia da superfície, e (6) efeito de rugosidade (YOSOMIYA et al. 1989).

As vantagens do uso de fibras naturais sobre as sintéticas tradicionais (fibras de vidro) como reforço em compósitos são: fibras vegetais são produzidas a partir de fontes renováveis, apresentam baixa densidade, não são abrasivas aos equipamentos de processamento e são biodegradáveis (MANO et al. 2010).

No presente trabalho, os compósitos foram preparados a partir matrizes polimérica (BPEAD, BPEAD/PBHL), reforçada com fibras descontínuas e multidirecionadas, já que os compósitos assim preparados apresentam facilidade de preparação e requisitam, no geral, uma menor quantidade de equipamentos para a sua manufatura.

\subsection{Interface fibra/matriz}

Devido à presença de hidroxila e outros grupos polares em seus constituintes, as fibras naturais apresentam alta absorção de umidade (MUKHOPADHYAY; FANGUEIRO, 2009). As fibras naturais são bastante higroscópicas e sua superfície é incompatível com a maioria das resinas poliméricas, o que pode levar a presença de "voids", devido às fracas interações, o que pode prejudicar as baixas propriedades mecânicas. Portanto, muitos estudos foram e tem sido feitos para minimizar essas deficiências e melhorar as propriedades mecânicas dos compósitos (LEÃO; CARVALHO; FROLLINI, 1997).

Pode-se afirmar que para as modificações na superfície das fibras serem bem sucedidas devem ser eficazes e de baixo custo, a fim de gerar produtos também de baixo custo e com boas propriedades. Caso contrário, a partir de um ponto de vista econômico, a substituição dos sintéticos por fibras naturais não serão de interesse, pois as fibras vegetais 
em geral, têm baixa resistência se comparada às fibras sintéticas (LEÃO; CARVALHO; FROLLINI, 1997).

O desenvolvimento de uma ligação química ou interação física, na região interfacial, promove a adesão necessária entre a fibra e a matriz, produzindo compósitos com melhores propriedades. Muitas vezes é preciso melhorar a adesão entre as duas superfícies com a utilização de agentes de acoplamento ou modificadores de superfície (BRÍGIDA et al., 2010).

A obtenção de uma interface distinta depende da adesão fibra-matriz, e esta adesão pode depender de vários fatores ou mecanismos, tais como interdifusão, atração eletrostática, ligação química, adesão mecânica entre outros (MEGIATTO, 2006).

A qualidade da interface fibra-matriz é importante para a aplicação de fibra natural como material de reforço em compósitos. Para aperfeiçoar esta interface podem ser utilizados vários procedimentos, por exemplo copolimerização por graftização.

PANTHAPULAKKAL et al. estudou o potencial de compósitos de polietileno de alta densidade reforçados com resíduos agro-industriais. As propriedades mecânicas e a absorção de água dos compósitos foram estudadas para avaliar a viabilidade do uso destas fibras como reforço em PEAD. Foi utilizado como compatibilizante polietileno graftizado com éster acrílico-anidrido maléico (Figura 15), o que levou a diminuição na absorção de água na presença do produto final.

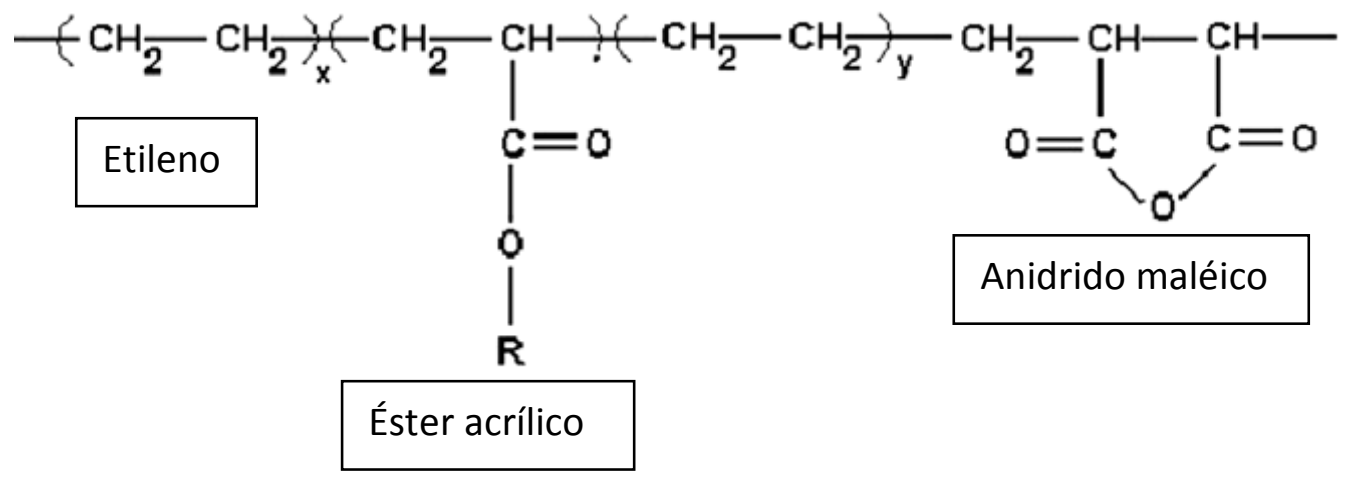

Figura 15: Agente compatibilizante.

Ao invés de a matriz ser modificada, isto pode ser feito com a fibra, ou com ambos. 


\subsection{Modificações das fibras de curauá}

O objetivo do tratamento consiste em modificar ou introduzir grupos na superfície das fibras que possam atuar como agentes de acoplamento, ou seja, possam aumentar a compatibilidade (adesão) entre as fibras naturais e as matrizes poliméricas, o que pode levar a otimização da interface entre a matriz e a fibra, resultando em compósitos com melhores propriedades (MOHANTY; NAYAK, 2007). As características da superfície das fibras são determinantes à transferência de tensão da matriz para a fibra. Em muitos casos, o pré tratamento resulta em uma melhor dispersão e as propriedades mecânicas são melhoradas (KALIA; KAITH; KAUR, 2009).

A modificação consiste em uma etapa adicional na preparação dos compósitos, aumentando o custo de produção. Tendo isso em vista, um importante aspecto a ser considerado é que idealmente os reagentes utilizados nas modificações não devem ter alto custo e as modificações devem envolver compostos provenientes de fontes renováveis. Quando se trata de modificação química a utilização de reagentes obtidos de fontes não renováveis pode anular o benefício oriundo da utilização de fibras vegetais (MEGIATTO, 2006).

No presente trabalho foi utilizado o tratamento com ar ionizado, que possui a vantagem de ser um tratamento realizado em via seca, evitando os problemas provocados pela presença de água ou outro solvente nas fibras. Deve-se ressaltar também o baixo custo do processo, que não requer a compra e utilização de reagentes químicos, somente o investimento inicial para a montagem do sistema de ar ionizado.

Adicionalmente, o polímero termoplástico também pode ser modificado por este tratamento, pois o ar ionizado pode provocar cisões em ligações da cadeia de polietileno, gerando sítios que podem ser oxidados pelas espécies presentes no ar ionizado. Estes grupos, se introduzidos na matriz, podem interagir com grupos polares presentes nos constituintes das fibras. 


\subsubsection{Tratamento das fibras de curauá com ar ionizado}

A agregação de feixes pode estar relacionada a interações eletrostática, envolvendo a superfície de feixes de fibras, os quais quando mais desagregados permitem uma maior impregnação da fibra pelo termoplástico, o que por sua vez leva a um compósito com interações fibra/matriz mais intensas (MUKHOPADHYAY; FANGUEIRO, 2009).

A fibra lignocelulósica é um material isolante, e o fluxo de elétrons em seu interior é limitado, o que faz com que possa reter um grande número de cargas por toda a extensão de sua superfície. A fricção entre as suas superfícies pode viabilizar a migração de elétrons entre as mesmas, causando o surgimento de cargas, levando as interações atrativas entre cargas opostas (TRINDADE et al., 2008).

A submissão de materiais a ambientes em que ocorra a ionização de moléculas presentes no ar, corresponde a um tratamento para a eliminação de cargas eletrostáticas em materiais não condutores. Tal princípio permite que ocorram cisões nas moléculas componentes do ar, gerando fragmentos que podem ter carga positiva e negativa. Estes fragmentos podem potencialmente interagir com a superfície do material, diminuindo a possibilidade de interações eletrostáticas atrativas. No caso das fibras lignocelulósicas, presume-se que neste ponto a agregação seja minimizada. Outra possibilidade consiste na saturação da superfície das fibras com cargas de mesmo sinal, o que leva a repulsão eletrostática, que também desfavorece a agregação de feixes das fibras. Um dos métodos utilizados para a ionização em ar é o chamado de Descarga Corona (DONG; SAPIEHA; SCHREIBER, 1992; ZHANG; SUN; WADSWORTH, 1998; SUN; DONG; WARDSWORTH,1999; GASSAN; GUTOWSKI; BLEDZKI, 2000). A atmosfera de Descarga Corona tem sido usada em precipitadores eletrostáticos industriais, em foto copiadoras, impressoras, limpadores de ar em ambiente fechado, e em processos industriais como no tratamento de filmes poliméricos e tecidos, destruição de contaminantes gasosos e produção de ozônio.

A Figura 16 mostra um esquema de uma descarga corona negativa em que os elétrons livres produzidos no início do processo de ionização são acelerados por um campo elétrico aplicado. As colisões inelásticas dos elétrons e de moléculas neutras do gás produzem partículas carregadas positivamente e mais elétrons, os quais podem reiniciar o 
ciclo. Este processo auto-sustentado é conhecido como avalanche eletrônica (CHEN; DAVIDSON, 2003).

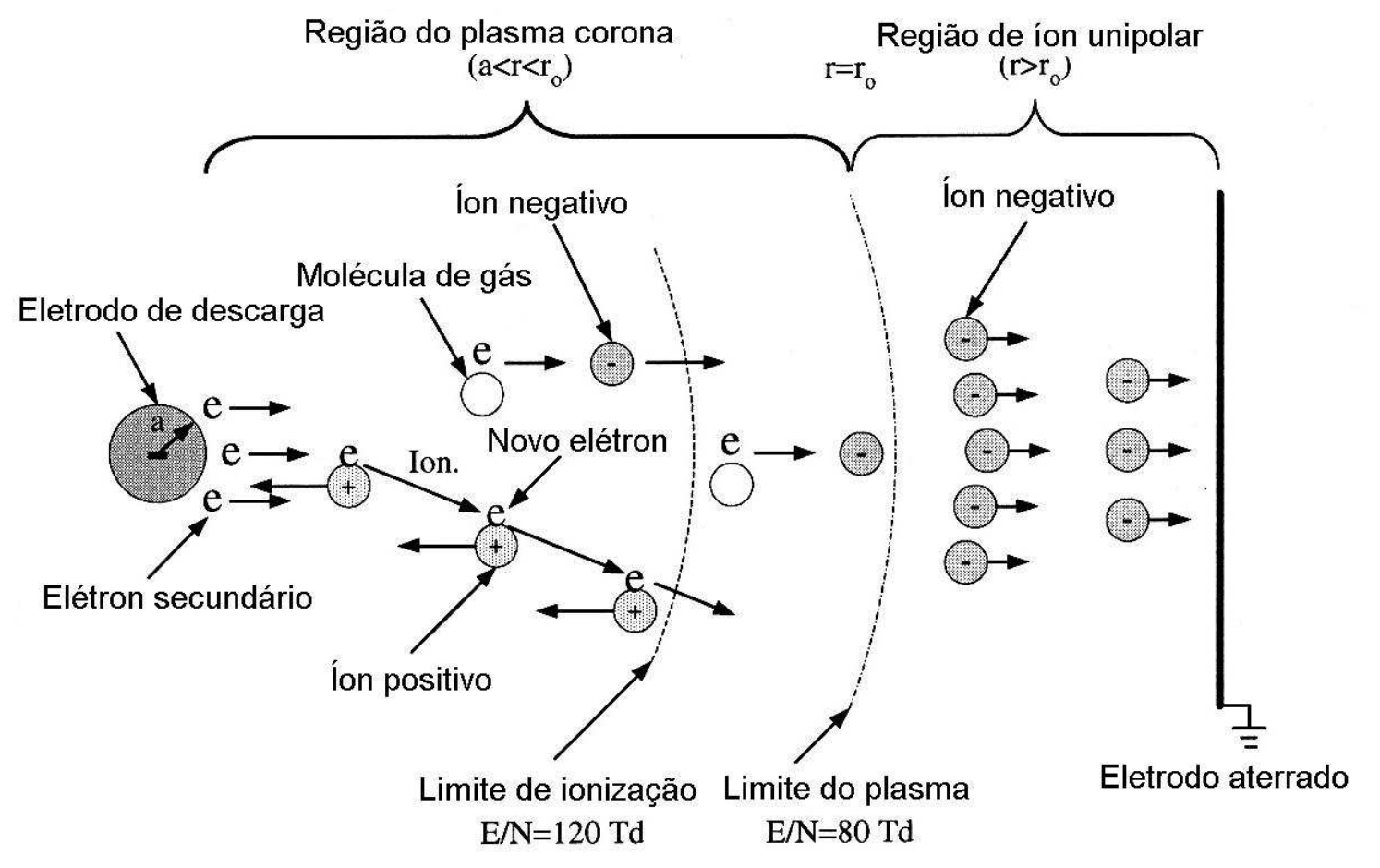

Figura 16: Esquema de descarga corona negativa auto-sustentada (TRINDADE ,2005).

No presente trabalho, as fibras de curauá foram submetidas a tratamento com ar ionizado, assim como o BPEAD.

\subsection{Preparação dos compósitos}

Os polímeros passam por uma ou mais fases de processamento para chegar ao seu formato final. Durante o processamento, estão sujeitos à variações de temperatura, ao esforço de cisalhamento e a exposição ao oxigênio. O tempo e o grau de aplicação de cada um destes efeitos dependem do método de processamento ao qual o material é submetido (DE PAOLI, 2009).

De um modo geral, classifica-se o processamento de termoplásticos como: termoformagem, moldagem por compressão, calandragem, extrusão, extrusão e sopro, injeção, injeção seguida de sopro e rotomoldagem (DE PAOLI, 2009). 
Há uma ampla variedade de equipamentos de mistura que podem ser utilizados para preparação de compósitos celulósicos termoplásticos, tais como misturadores internos e as extrusoras de rosca simples ou dupla (SANTOS, 2006).

Para o processamento, a umidade da fibra deve ser removida, o que pode ser feito num processo de secagem em estufa (SANTOS, 2006).

A temperatura de processamento é um fator extremamente importante para o estabelecimento das condições ótimas. Em temperaturas acima de $160{ }^{\circ} \mathrm{C}$ e na presença de oxigênio, as fibras podem sofrer termo-oxidação levando ao escurecimento e, em temperaturas acima de $230{ }^{\circ} \mathrm{C}$ ocorre decomposição da mesma, com consequente perda de propriedades (IANNACE; ALI; NICOLAIS, 2000).

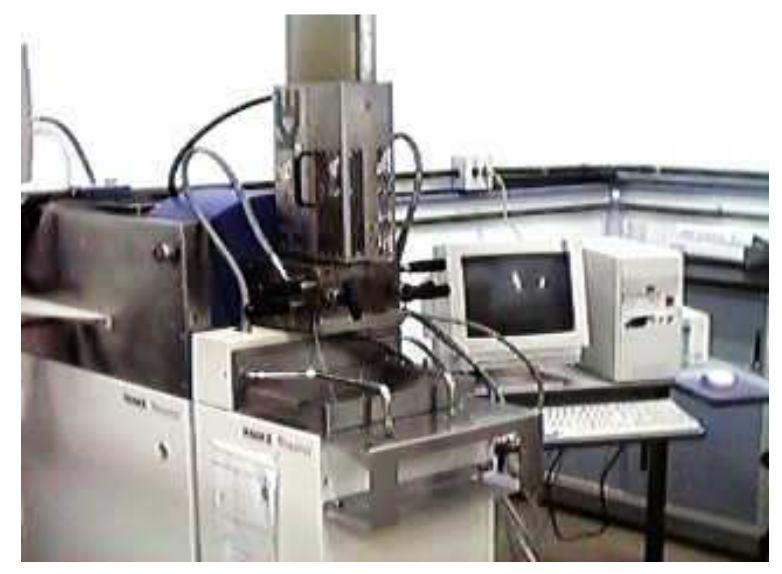

Figura 17: Misturador interno acoplado ao reômetro de torque Haake (disponível em <http://www.dema.ufscar.br/>).

Compósitos reforçados com fibras naturais podem ser processados utilizando tecnologias de processamento empregadas para termoplásticos. Para conseguir uma boa dispersão da fibra na matriz, é necessário recorrer à utilização de extrusoras dupla rosca ou a utilização de dispositivos acoplados a extrusoras mono rosca. Em ambos os casos, as altas tensões de cisalhamento que ocorrem durante mistura pode resultar na quebra das fibras (IANNACE; ALI; NICOLAIS, 2000).

Neste trabalho, foi utilizado um misturador interno acoplado a um reômetro de torque Haake para a obtenção dos compósitos (fibra/BPEAD e fibras/BPEAD/PBHL) e das blendas (BPEAD,PBHL) poliméricas (Figura 17). 


\section{OBJETIVOS}

O objetivo deste trabalho consistiu no desenvolvimento e caracterização de biocompósitos gerados a partir de polietileno obtido pela polimerização de eteno, por sua vez gerado a partir do etanol de cana de açúcar (biopolietileno) como matriz, e fibras de curauá tratada ou não com ar ionizado, a fim de avaliar a ação destas fibras como reforço do biopolietileno. Adicionalmente, uma borracha, polibutadieno hidroxilado, foi acrescentada à formulação do material, visando avaliar sua ação como modificador de impacto e agente de acoplamento na interface fibra/matriz.

Desta forma, foram preparados materiais baseados principalmente em matéria prima proveniente de fontes renovavéis, ou seja, materiais do tipo biocompósitos. 


\section{MATERIAIS, MÉTODOS E FORMA DE ANÁLISE DOS RESULTADOS}

Este trabalho foi desenvolvido em cooperação com Professor Adhemar Colla Ruvolo Filho do Departamento de Química da Universidade Federal de São Carlos (UFSCar, São Carlos, SP).

\subsection{Materiais}

O "polietileno verde", também chamado de biopolietileno, pelo fato de ser preparado a partir de eteno oriundo de processamento de fonte renovável (cana de açúcar) ${ }^{1}$ é um material comercial de procedência BRASKEM, tem sido gentilmente cedido por esta empresa.

As fibras de curauá utilizadas foram gentilmente cedidas pela Pematec Triangel do Brasil Ltda (São Paulo, SP).

O polibutadieno líquido hidroxilado ( $P B H L)$, nome comercial Liquiflex $H$, foi gentilmente cedido por Petroflex Ind. Com. (Rio de Janeiro, RJ). O PBHL é classificado como sendo um polímero do tipo poliol, derivado do butadieno com hidroxilas terminais reativas, apresentando baixo teor de umidade, funcionalidade 2,2 e baixa massa molar média (no caso, massa molar média $=2900$ gmol $^{-1}$, conforme informação da Petroflex), sendo obtido a partir de um processo de polimerização em solução, com alta pressão e temperatura. 0 PBHL foi usado sem nenhum tipo de tratamento prévio.

\subsection{Purificação e Caracterização das Fibras de Curauá}

Primeiramente, as fibras de curauá foram colocadas em extrator soxhlet com uma mistura de cicloexano/etanol $(1: 1, v / v)$, durante $48 \mathrm{~h}$, com o objetivo de extrair ceras e outras substâncias solúveis em solventes orgânicos. Em seguida, as fibras foram extraídas

\footnotetext{
${ }^{1}$ Termos similares são usados atualmente também para outros polímeros, tendo o significado de "biobased plastic" ou "renewable based plastics" (disponível em <http: //www.ecoproducts.com).
} 
com $\mathrm{H}_{2} \mathrm{O}$ no mesmo extrator soxhlet por 24 h, para extração de impurezas solúveis em água, como sais, e depois secas em estufa com circulação de ar a $100^{\circ} \mathrm{C}$, até massa constante.

As análises mencionadas a seguir foram feitas em triplicata.

Para a determinação do teor de umidade da fibra a norma ABNT (NBR9656) foi seguida.

O teor de lignina foi determinado pelo método Klason (Fengel, 1984), fundamentado na hidrólise ácida dos polissacarídeos e, conseqüente separação e determinação gravimétrica da lignina insolúvel em ácido sulfúrico (72\%).

Para determinar o teor de cinzas da fibra de curauá, esta foi previamente extraída em cicloexano/etanol e em seguida com $\mathrm{H}_{2} \mathrm{O}$, sendo então a norma TAPPI T211 om-85 [ASH, 1991] seguida.

A determinação do teor de holocelulose (celulose + hemicelulose) foi realizada de acordo com o método descrito na norma TAPPI T19 om-54, baseado na eliminação de lignina via reação com clorito de sódio. As fibras de curauá utilizadas foram previamente submetidas à extração com cicloexano/etanol.

A determinação do teor de celulose foi realizada com as amostras resultantes da determinação do teor de holocelulose. Colocou-se $1,0 \mathrm{~g}$ de amostra obtida para determinação de holocelulose em um béquer com $10 \mathrm{~mL}$ de solução de $\mathrm{NaOH}$ 17,5\%, deixou-se em repouso por 2 min, em seguida, com um bastão de vidro, mascerou-se a amostra. Após, adicionou-se mais $10 \mathrm{~mL}$ de solução de $\mathrm{NaOH} 17,5 \%$ e deixou-se a mistura em repouso por $20 \mathrm{~min}$. Em seguida, adicionou-se $40 \mathrm{~mL}$ de água destilada, filtrou-se a mistura em funil de vidro sintezado previamente tarado, lavando o precipitado com solução de ácido acético diluído $50 \%$ filtrou-se novamente e, em seguida lavou-se com água destilada até neutralizar o excesso de ácido. A fração de amostra insolúvel em solução de $\mathrm{NaOH} 17,5 \%$ corresponde a $\alpha$-celulose. Secou-se a celulose obtida em estufa de circulação de $\operatorname{ar}\left(105^{\circ} \mathrm{C}\right)$ até massa constante. $\mathrm{O}$ teor de $\alpha$-celulose foi calculado pela diferença de massa, antes e após o tratamento da amostra com solução de $\mathrm{NaOH} 17,5 \%$. 


\subsection{Ensaio de resistência à tração}

Foram realizados ensaios de tração nas fibras de curauá, utilizando-se o equipamento de DMA da marca TA Instruments, modelo 2980 , no modo de tração para as amostras de fibra de curauá não tratadas e tratadas.

As análises foram realizadas para 40 corpos de prova (fibras) nas seguintes condições:

- Rampa de força: 1 Newton $\min ^{-1}$ até 15 Newton

- Pré-carga: 1 Newton

- Módulo: Força controlada

- Comprimento médio da amostra: $15 \mathrm{~mm}$

- Garra: Tensão para filme

\subsection{Determinação do grau de cristalinidade}

O índice de cristalinidade (Ic) das fibras, decorrente da presença de celulose e do termoplástico foi avaliado por difração de raios $\mathrm{X}$.

Pelo difratograma de raios-X da fibra é possível observar a presença de picos

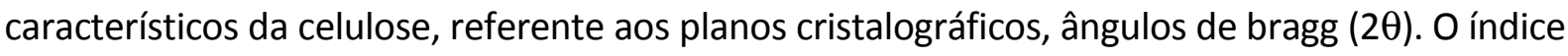
de cristalinidade informa sobre a proporção de regiões cristalinas com relação às não cristalinas presentes na amostra. Este é um dado importante, pois em materiais lignocelulósicos, a acessibilidade dos grupos hidroxila da celulose se relaciona de maneira direta com a cristalinidade da mesma, isto é, nas regiões cristalinas o acesso de reagentes e solventes aos grupos hidroxilas é dificultado, em relação às regiões não cristalinas (TITA, 2002). 0 índice de cristalinidade é calculado utilizando-se a equação 1 descrita por Buschle-Diller e Zeronian (BUSCHLE, 1992):

$I_{c}=1-\frac{I_{1}}{I_{2}}$

I c= índice de cristalinidade;

$I_{1}=$ intensidade do mínimo de difração;

$I_{2}=$ intensidade do máximo de difração. 
Para o BPEAD, o cálculo do grau de cristalinidade foi realizado pelo método estabelecido por Ruland (1974). Esse método permite calcular a cristalinidade de um polímero pela Equação 2:

$\% C=\frac{I c}{(I c+K I a)} \times 100$

Sendo \%C a cristalinidade em porcentagem, la é a área sob o halo amorfo, Ic é o resultado da integração dos picos de difração ou as áreas dos picos cristalinos e K é uma constante de proporcionalidade para cada polímero.

As análises de raios $X$ para as fibras de curauá e para o BPEAD tratados e não tratados, foram feitas em um difratômetro RIGAKU com tubo de cobre selado, radiação (ka) e comprimento de onda $1542(\mathrm{k} \alpha) \AA ̊$. . As medidas foram realizadas à velocidade de $2^{\circ} \mathrm{min}^{-1}$, no intervalo angular de $5-50^{\circ}$ (ângulo de Bragg 20), potência de $40 \mathrm{~mA}$ e $40 \mathrm{kV}$.

\subsection{Adição de polibutadieno hidroxilado ao biopolietileno}

O PBHL em diferentes proporções $(5,10,20$ e 30\% em relação à massa de polímero) foi inicialmente misturado ao BPEAD, em seguida, levado ao reômetro de torque Haake com câmara de mistura Rheomix $3000 \mathrm{p}$ com capacidade de $45 \mathrm{~g}$ à $180^{\circ} \mathrm{C}$ e $60 \mathrm{rpm}$ por um período de 6min, disponível no Departamento de Engenharia de Materiais da Universidade Federal de São Carlos (São Carlos, SP).

O misturador usado consiste de dois rotores que giram em contra-rotação na câmara de mistura. Ele requer uma pequena quantidade de material que é inserida no interior da câmara através de um alimentador superior (CORRANDINI et al. 2007). Na Figura 18 pode-se observar o arranjo dos rotores.

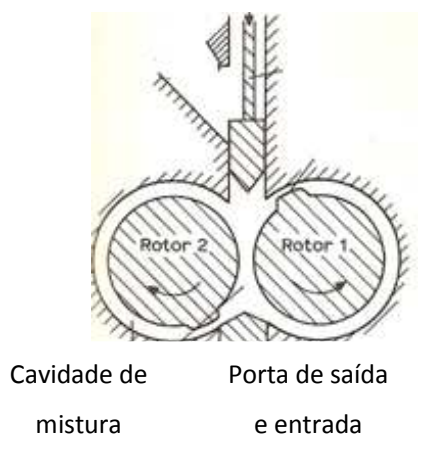

Figura 18: Representação esquemática do corte transversal do misturador interno (PEARSON, 1985). 
O misturador é conectado a um reômetro de torque, permitindo analisar o comportamento reológico do material (o qual está relacionado à viscosidade do material fundido) (PEARSON, 1985).

A seguir, o material obtido foi cortado em pedaços pequenos.

\subsection{Preparação dos compósitos de matriz biopolietileno/PBHL reforçados com fibra de curauá}

Nesta etapa, foram introduzidas diferentes frações de PBHL $(5,10,20$ e $30 \%$ em relação à massa total do compósito a ser formado) a fibra de curauá, com comprimento médio de $1 \mathrm{~cm}$ e com porcentagens diversificadas $(5,10,20$ e 30\%), com a finalidade de aumentar a tenacidade da matriz termoplástica e por conseqüência, dos compósitos finais obtidos. O BPEAD e a mistura PBHL/fibra de curauá obtida foram processados em um reômetro de torque Haake com câmara de mistura Rheomix 3000p com capacidade de 45g à $180^{\circ} \mathrm{C}$ e $60 \mathrm{rpm}$, com a vantagem de poder ser processada no mesmo equipamento que é utilizado para os termoplásticos (ANUAR; AHMAD, 2007).

A seguir, o material obtido foi cortado em pedaços pequenos para facilitar a termoprensagem.

\subsection{Termoprensagem}

Aproximadamente $45 \mathrm{~g}$ do compósito de BPEAD/PBHL/fibras de curauá, obtido através do procedimento 3.6 foi colocada entre duas placas de aço inox, na forma de "sanduíche" entre películas de teflon, sobre as quais foi colocada uma moldura de alumínio, para garantir a regularidade da espessura final desejada. Este conjunto foi levado a uma termoprensa (Figura 19), previamente aquecida à temperatura de $180^{\circ} \mathrm{C}$, por um intervalo curto de tempo (em torno de $3 \mathrm{~min}$ ), sendo então submetidos à pressão por mais $1 \mathrm{~min}$. Nesta etapa, ocorreu a fusão do polietileno (em torno de $130^{\circ} \mathrm{C}$ ), sendo a fibra impregnada pelo termoplástico/PBHL. Placas com espessura em torno de $2 \mathrm{~mm}$ foram obtidas. Em seguida, o conjunto foi resfriado a temperatura ambiente pela circulação de água através do sistema. 


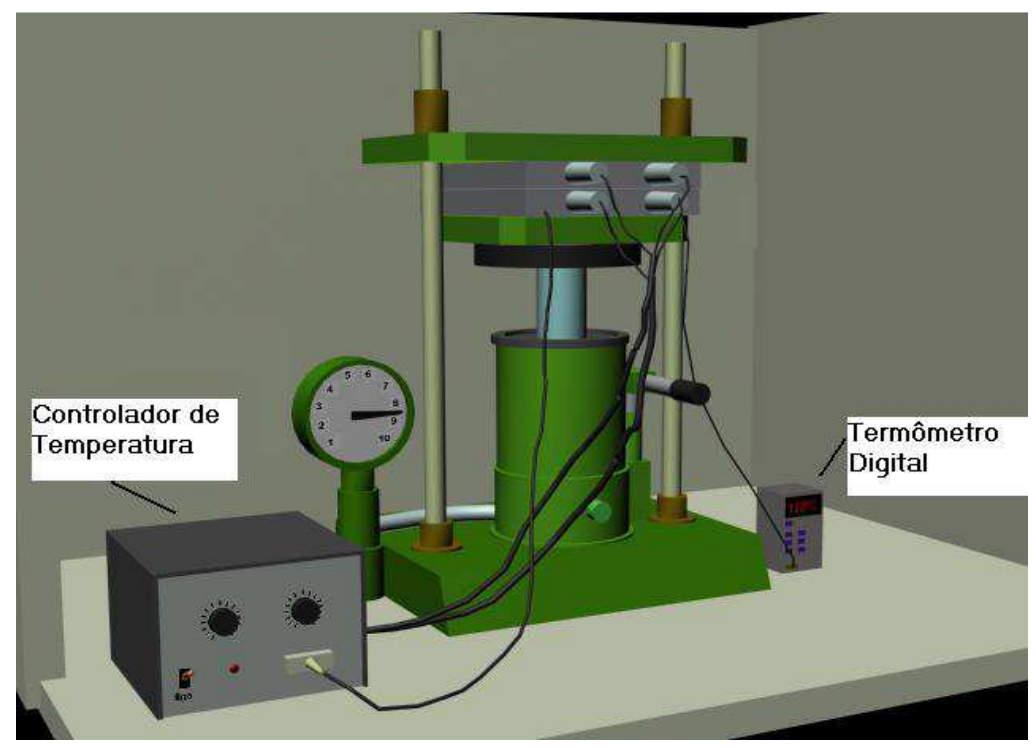

Figura 19: Representação esquemática de uma termoprensa.

Para controle, também foram preparadas placas a partir de BPEAD, BPEAD/fibra e BPEAD/PBHL.

\subsubsection{Tratamento com ar ionizado}

As fibras de curauá foram colocadas (previamente secas por $4 \mathrm{~h}$ em estufa com circulação de $\left.\operatorname{ar}, 105^{\circ} \mathrm{C}\right)$ em um sistema constituído de uma caixa $(50 \times 30 \mathrm{~cm})$ de aço inox, com seis bicos injetores de ar, ligados em série, presos à tampa da caixa e ligados a uma fonte de alta tensão. Submete-se as fibras à descarga elétrica com corrente de $5 \mathrm{~mA}$ e voltagem de 7,5 kV. Simultaneamente, o ar filtrado é injetado no sistema por $5 \mathrm{~h}$.

A cada 30 min, o sistema foi desligado para a movimentação manual das fibras, a fim de que todas as faces das fibras entrem em contato com o ar ionizado.

A Figura 20 mostra imagens da caixa utilizada para tratamento com ar ionizado. 


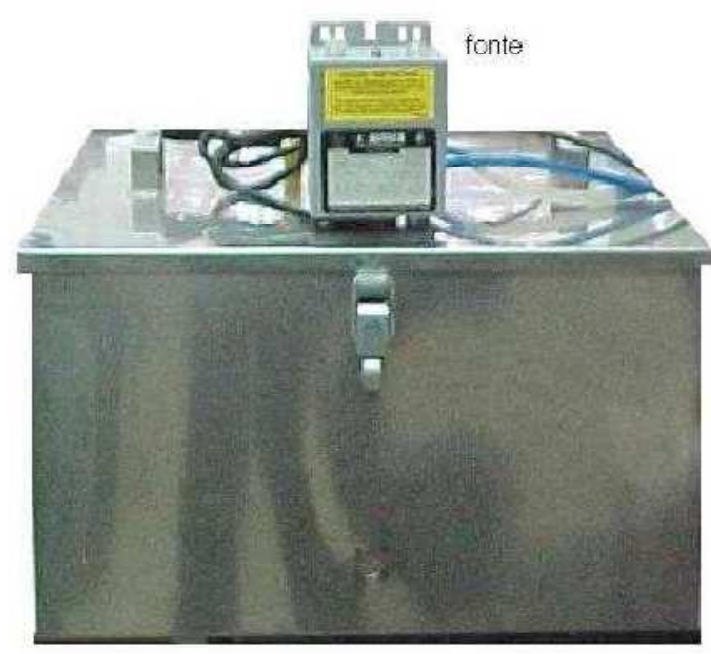

(A)

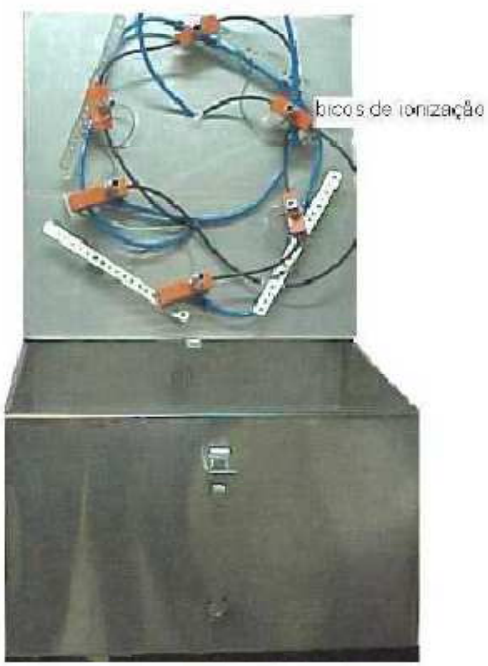

(B)

Figura 20: (A) Caixa de ionizador de ar fechada, com a fonte elétrica sobre a caixa; (B)

Aberta, evidenciando os bicos injetores.

O termoplástico, na forma de grânulos, também foi submetido ao mesmo tratamento, com a finalidade de que o ar ionizado provocasse cisões em ligações da cadeia de polietileno, gerando sítios que podem ser oxidados pelas espécies presentes no ar ionizado, estes grupos, se introduzidos na matriz, podem interagir com grupos polares presentes nos constituintes das fibras. Compósitos foram preparados a partir de fibras (tratadas ou não) e do termoplástico (tratado ou não) na presença de PBHL.

\subsection{Caracterização dos materiais}

\subsubsection{Microscopia eletrônica de varredura (MEV)}

A microscopia eletrônica de varredura foi realizada com o auxílio de um MEV DSM 940 Zeiss modelo 440; voltagem de aceleração de $20 \mathrm{keV}$. As amostras foram coladas em um porta-amostra com base de alumínio, sendo previamente secas em estufa de circulação de $\operatorname{ar}\left(105^{\circ} \mathrm{C}\right)$, em seguida, submetidas a um fino recobrimento com ouro usando um sistema denominado "Spitter Coat", sendo analisadas as fibras de curauá tratadas com ar ionizado e não tratadas, compósitos reforçados com estas fibras e compósitos reforçados com fibras 
não modificadas, tendo como matriz o BPEAD, tratado ou não, ou na presença ou não de PBHL.

\subsubsection{Calorimetria exploratória deferencial (DSC)}

Quando uma substância sofre uma mudança física ou química, pode ser observada uma variação na entalpia. Se o processo for promovido por uma variação controlada de temperatura, isto constitui a base da técnica conhecida como calorimetria exploratória diferencial (DSC), na qual é medida a variação de entalpia entre o material em estudo e uma amostra inerte (referência ou padrão) (LUCAS; SOARES; MONTEIRO, 2001).

Numa curva DSC típica, três tipos básicos de transformações podem ser detectadas: transformações endotérmicas, transformações exotérmicas e transições de segunda ordem, como a temperatura de transição vítrea $(\mathrm{Tg})$, na qual a entalpia não sofre variação, mas o calor específico sofre uma mudança repentina, que é detectada por uma simples descontinuidade no fluxo de calor, observada como uma alteração na linha base da curva de DSC. Como exemplo de transição exotérmica pode-se citar reações de decomposição, cristalização, volatilização de água ou outras moléculas de baixa massa molar presentes (LUCAS; SOARES; MONTEIRO, 2001).

As análises de DSC foram realizadas com auxílio de um equipamento ShimadzuTA50WSI, utilizando as fibras de curauá, O BPEAD submetidos a tratamentos e os não submetidos e para os polímeros termoplásticos reforçados com a fibra de curauá.

\subsubsection{Termogravimetria}

Em termogravimetria, a análise da massa da amostra em uma atmosfera controlada é medida como uma função da temperatura ou do tempo a uma dada temperatura.

A termogravimetria é uma ferramenta importante para determinar a estabilidade térmica dos materiais poliméricos, como a perda de água associada com a umidade das fibras, o início da decomposição térmica do termoplástico e da fibra (TOMECZAC; SATYANARAYNA, 2007). 
As análises TG foram realizadas com auxílio de um equipamento Shimadzu TG modelo 50, segundo a norma NBR 14692. As mesmas amostras caracterizadas por DSC também serão submetidas à análise por TG.

\subsection{Resistência mecânica ao impacto}

Existem dois ensaios padronizados nos ensaios de fratura por impacto, as técnicas Charpy e Izod. Tanto na técnica Izod como na técnica Charpy, o corpo de prova possui o formato de uma barra com seção reta quadrada, em que pode ser ou não em entalhe formato em "v" (CALLISTER, 2002).

A carga é aplicada como um impacto instantâneo de um martelo de pêndulo balanceado, que é liberado de uma posição elevada que se encontra, a uma altura fixa h. A amostra fica posicionada na base, com a liberação, uma aresta em forma de faca montada sobre o pêndulo atinge e fratura o corpo de prova exatamente no entalhe, quando este está presente atua como ponte de concentração das tensões para este impacto de alta velocidade. O pêndulo continua o seu balanço, elevando-se a uma altura máxima $h^{\prime}$, que é inferior a h. A absorção de energia, computada a partir da diferença entre $h$ e $h^{\prime}$, representa uma medida da energia de impacto. Variáveis que incluem o tamanho e o formato do corpo de prova, bem como a configuração e a profundidade do entalhe, influenciam os resultados dos testes (CALLISTER, 2002).

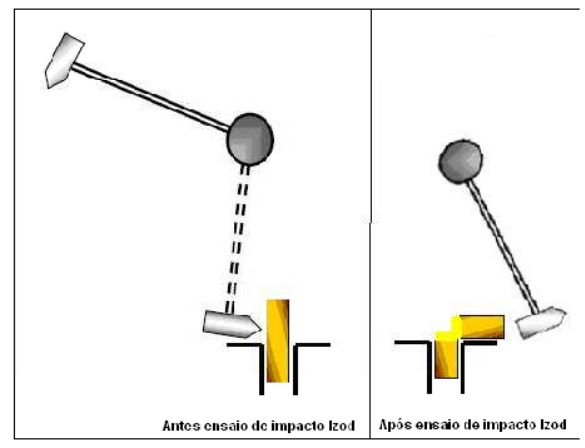

Figura 21: Representação esquemática do sistema utilizado para medidas de resistência ao impacto izod (MEGIATTO, 2006).

Os ensaios de resistência mecânica ao impacto foram realizados no Departamento de Engenharia de Materiais (DEMA) da Universidade Federal de São Carlos (São Carlos, SP, 
laboratório sob responsabilidade de Prof. Elias Hage), segundo a norma ASTM D256 para o polímero termoplástico e para os polímeros termoplásticos reforçados com a fibra de curauá, para corpos de prova do tipo Izod, sem e com entalhe.

\subsection{Resistência à Flexão}

O ensaio de flexão pode utilizar carregamento em um sistema com três ou quatro pontos. Nos ensaios com três pontos, o corpo de prova, uma barra de seção cruzada retangular é ajustada em dois pontos de apoios fixados a um suporte (travessa fixa), e o carregamento é realizado por meio de um terceiro apoio (travessa móvel), posicionado a uma distância média entre os apoios fixados ao suportes. Os apoios devem possuir superfícies cilíndricas, de modo a evitar falhas devido à concentração de tensões nos corpos de provas (CALLISTER, 2002).

Estes ensaios são aplicados a materiais poliméricos rígidos e semi-rígidos. O corpo de prova é defletido até que sua ruptura ocorra na superfície oposta ao carregamento, ou até que uma deformação máxima de 5,0\% seja alcançada. Entretanto, a resistência à flexão não pode ser determinada para aqueles materiais que não rompem ou não falham na superfície oposta ao carregamento dentro de um limite máximo de 5,0\% de deformação. Em um ensaio de flexão em três pontos, a deflexão na qual a máxima deformação permitida $(5,0 \%)$ irá ocorrer pode ser calculada através da seguinte equação, adotando-se $r$ igual a $0,05 \mathrm{~mm} / \mathrm{mm}$ :

$D=\frac{r L^{2}}{6 d}$

Sendo: $D$ a deflexão no ponto médio entre os apoios, $r$ a deformação, $L$ a distância entre os apoios e $d$ a profundidade do corpo de provas.

Materiais que não falham até a máxima deformação permitida para estes ensaios devem utilizar o método de quatro pontos. A diferença básica entre os dois métodos está na localização do momento da carga máxima e na tensão de tração axial na superfície aposta ao carregamento (CANEVAROLO, 2004).

Existem dois procedimentos básicos para ensaios de flexão em três pontos: 
- $A$ é aplicado principalmente nos materiais que rompem em deflexões comparativamente pequenas.

- $B$ é aplicado particularmente naqueles materiais que suportam grandes deflexões durante o teste.

Os ensaios de resistência à flexão foram realizados para o termoplástico, para a blenda PBEAD/PBHL, para os compósitos fibra/BPEAD e fibra/BPEAD/PBHL seguindo a norma ASTM 790-96a, utilizando o ensaio de flexão de três pontos. Os corpos de prova foram cortados nas seguintes dimensões: $127 \mathrm{~mm}$ de comprimento, $12,7 \mathrm{~mm}$ de largura e $3,2 \mathrm{~mm}$ de espessura e submetidos ao ensaio de flexão.

\subsection{Análise térmica dinâmico-mecânica}

A análise térmica dinâmico-mecânica, DMTA, tem sido amplamente utilizada para a caracterização dos polímeros através da detecção dos processos de relaxação, tanto macroscópico quanto molecular, por apresentar uma grande sensibilidade, quando comparada às técnicas convencionais de análise térmica (CANEVAROLO,2004).

Essa técnica fornece informações a respeito do módulo elástico ( $\left.E^{\prime}\right)$, do módulo de dissipação viscosa ( $\left.E^{\prime \prime}\right)$ e do amortecimento mecânico ou atrito interno (tan $\left.\delta=E^{\prime \prime} / E^{\prime}\right)$ de um material, quando sujeito a uma solicitação dinâmica. A partir dessas variáveis, pode-se correlacionar várias propriedades, como tenacidade, resistência ao impacto, entre outras (CANEVAROLO, 2004).

Uma das mais importantes aplicações da técnica de DMTA consiste na determinação da temperatura de transição vítrea (Tg) (CANEVAROLO, 2004).

A análise de DMTA fornece informações a respeito do comportamento viscoelástico do sistema, que é desmembrado em duas componentes: a contribuição elástica e a viscosa (CANEVAROLO, 2004).

O módulo oriundo da componente tensão resposta em fase com a deformação, E', é denominado módulo de armazenamento. E o módulo oriundo da componente de tensão resposta 90 으 fora de fase com a deformação, E”, é denominado módulo de perda. 
A razão entre os valores de módulo de perda, E", e módulo de armazenamento, E', define uma grandeza denominada tangente de perda, $\tan \delta$.

A tangente de perda, também denominada fricção interna ou amortecimento, é a razão entre a energia dissipada por ciclo e a energia potencial máxima armazenada durante o ciclo. Assim materiais mais rígidos irão apresentar valores de $\tan \delta$ menores e, materiais mais flexíveis irão apresentar valores de $\tan \delta$ maiores. As grandezas $\mathrm{E}^{\prime}, \mathrm{E}^{\prime \prime}$ e $\tan \delta$ são dadas em função da temperatura ou da freqüência em um ensaio de DMTA (LUCAS; SOARES; MONTEIRO, 2001).

Os métodos dinâmicos- mecânicos são muito sensíveis às transformações que ocorrem em nível molecular, sendo capazes de detectar movimentos discretos como relaxações secundárias (LUCAS; SOARES; MONTEIRO, 2001). Nos compósitos, as interações envolvendo matriz e/ou PBHL com as fibras, pode influir nas relaxações das cadeias presentes na interface fibra-matriz, o que pode ser detectado por deslocamento nas curvas de $E^{\prime \prime}$ e tan $\delta$, quando comparadas às amostras sem fibras.

As transições que ocorrem nas moléculas podem ser divididas em transições que ocorrem na fase cristalina e transições que ocorrem na fase não cristalina. As relaxações primárias são descrita pela letra $\alpha$, assim, a transição relacionada à temperatura de transição vítrea, que é a relaxação acentuada da fase não cristalina, é representada por $\alpha_{\mathrm{a}}$. E a transição relacionada à temperatura de fusão cristalina, que é a relaxação acentuada na fase cristalina, é representada por $\alpha_{c}$. Relaxações secundárias que ocorre abaixo de $\alpha_{c}$ e acima de $\alpha_{a}$ estão relacionadas com a parte cristalina e são representadas por $\alpha_{c}^{\prime}$. Transições que ocorrem abaixo de $\alpha_{a}$ estão relacionadas com a parte não cristalina do material e são representadas pelas letras $\beta_{\alpha}, \gamma_{\alpha}, \delta_{\alpha}$, entre outros, da mais alta para a mais baixa temperatura. Estas transições são melhores observadas pelos picos formados nas curvas de E" ou tan $\delta$ (LUCAS; SOARES; MONTEIRO, 2001).

Os ensaios dinâmico térmico mecânico dos compósitos obtidos foram realizados no equipamento DMA, modelo 2980 da TA instruments, modo de flexão, amplitude de oscilação de $20 \mu \mathrm{m}$, frequência de $1 \mathrm{~Hz}$, taxa de aquecimento de $2^{\circ} \mathrm{Cmin}^{-1}$, de -130 a $105^{\circ} \mathrm{C}$, para o polímero termoplástico tratado ou não, e para o polímero termoplástico reforçado com fibras tratadas ou não. 
Este ensaio, além de caracterizar a fibra, indica se o tratamento aplicado altera esta propriedade mecânica, o que por sua vez pode influir na ação da fibra como reforço no compósito.

Os ensaios de DMTA foram realizados para o termoplástico, para a blenda PBEAD/PBHL, para os compósitos fibra/BPEAD e fibra/BPEAD/PBHL. Os corpos de prova foram cortados nas seguintes dimensões: $127 \mathrm{~mm}$ de comprimento, $12,7 \mathrm{~mm}$ de largura e $3,2 \mathrm{~mm}$ de espessura e submetidos ao ensaio de flexão.

\subsection{Absorção de água}

Para avaliar o comportamento do material sob análise no que diz respeito a absorção de água, pode-se considerar a curva de sorção versus o tempo representado por (COMYN, 1985):

$M_{T} / M_{\infty}=K t^{n}$

Sendo $M_{T}$ relativo ao ganho de massa com relação ao tempo $t, M_{o o}$ relativo ao ganho de massa no equilíbrio e k e $n$ são constante.

Para uma espécie de espessura 'b', exposta a água por todos os lados, o coeficiente de difusão de água, D é igual a:

$M_{T} / M_{\infty}=4 / b(D / \pi)^{0,5} t^{0,5}$

O estudo de absorção de água foi realizado para todos os compósitos que serão obtidos no presente trabalho, além do biopolietileno e da blenda deste com PHBL.

A absorção de água pelos compósitos foi determinada por imersão por $24 \mathrm{~h}$ e imersão longa até saturação. Para estes ensaios foram preparados corpos de prova com as seguintes dimensões: $63,50 \times 12,70 \times 2,80 \mathrm{~mm}$. 


\section{RESULTADOS E DISCUSSÕES}

\subsection{Caracterização das Fibras de Curauá}

As fibras de curauá, assim como as demais fibras lignocelulósicas, são constituídas de celulose, hemicelulose (ou polioses), lignina, pectina, cera e substâncias solúveis em água, sendo os três primeiros componentes majoritários e responsáveis pelas propriedades físicas das fibras (FENGEL, 1984). A Tabela 1 relaciona os valores médios dos componentes encontrados para a fibra de curauá utilizada no presente trabalho, após extração no soxhlet. A Figura 22 ilustra o teor de cada componente da fibra, sendo os dados referentes à fibra livre de umidade.

Tabela 1: Caracterização da fibra de curauá.

\begin{tabular}{|c|c|}
\hline Propriedades & Teor (\%) \\
\hline Umidade & $8,0 \pm 0,2$ \\
\hline Cinzas & $0,50 \pm 0,1$ \\
\hline Holocelulose & $93,0 \pm 1,2$ \\
\hline$\alpha$ celulose & $63,4 \pm 0,9$ \\
\hline Hemicelulose & $29,6 \pm 0,2$ \\
\hline Lignina Klason insolúvel & $4,7 \pm 0,1$ \\
\hline Lignina Klason solúvel & $0,50 \pm 0,02$ \\
\hline Lignina Klason total & $5,2 \pm 0,1$ \\
\hline
\end{tabular}

Os resultados obtidos estão próximos aos de trabalhos prévios, em que outros lotes de curauá foram utilizados, destacando-se que o teor de hemicelulose e $\alpha$ celulose encontrado no presente trabalho são superiores ao da fibra utilizada em trabalhos prévios. Trindade et al. (2008) caracterizaram as fibras de curauá obtendo proporções de $83,5 \%$ de holocelulose, $73,6 \%$ de $\alpha$ celulose e $9,9 \%$ de hemicelulose. 


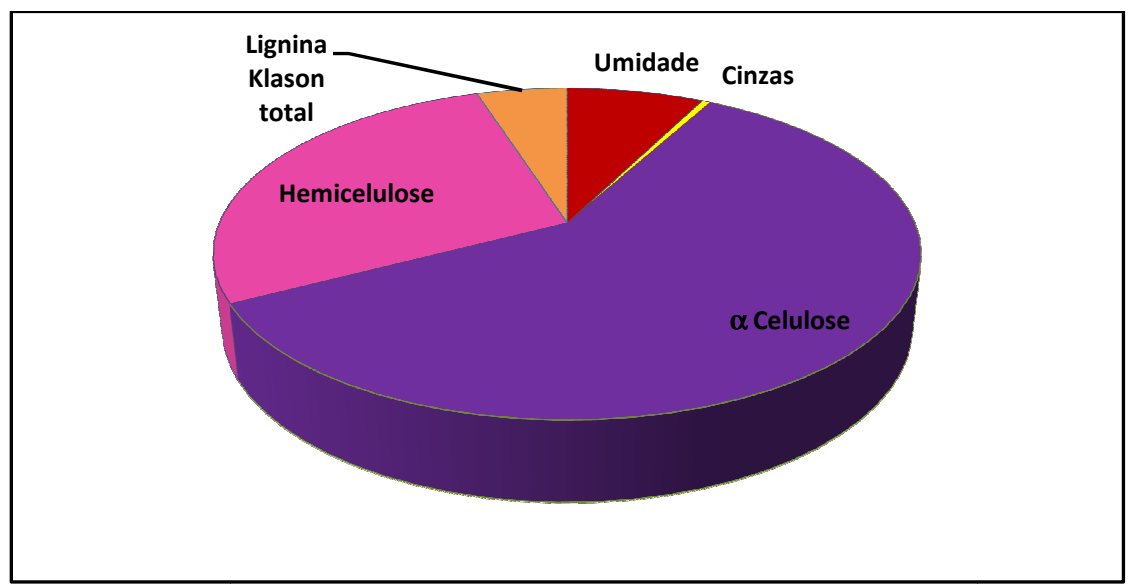

Figura 22: Teor de componentes químicos na fibra de curauá.

A composição química das fibras, mesmo as de mesma natureza, pode apresentar proporções diferentes devido às diferentes condições de cultivo a que as plantas são submetidas (GOMES et al., 2007).

\subsubsection{Determinação do Índice de Cristalinidade por Difração de raios X}

Foram obtidos os difratogramas de raios $\mathrm{X}$ das fibras de curauá tratada com ar ionizado por 5 h e não tratada (Figura 23).

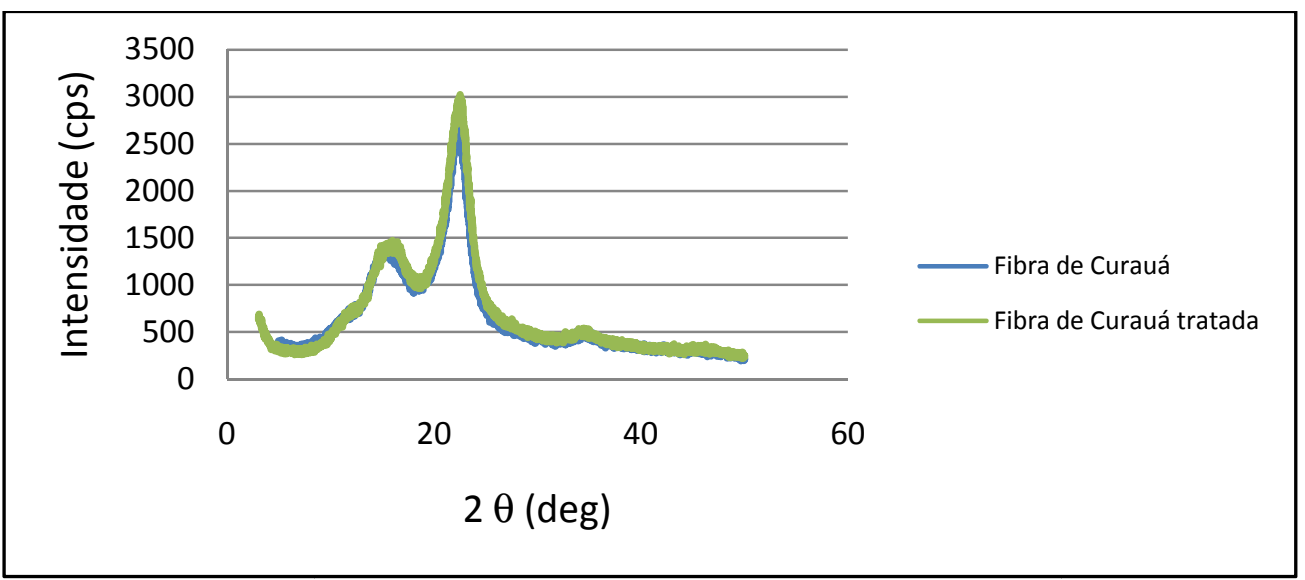

Figura 23: Difratograma de raios $\mathrm{X}$ das fibras de Curauá não tratada e tratada com ar ionizado $5 \mathrm{~h}$.

O índice de cristalinidade foi determinado pela relação entre as intensidades máxima (Imáx) e mínima (Imín), de acordo com equação 1 (mostrada na parte de Materiais e Métodos). Os resultados obtidos estão mostrados na Tabela 2. 
Tabela 2: Valores do índice de cristalinidade

\begin{tabular}{|c|c|}
\hline Amostra & Cristalinidade (\%) \\
\hline Fibra de Curauá & 64 \\
\hline Fibra de Curauá tratada 5h & 59 \\
\hline
\end{tabular}

Os resultados mostram que há alteração na porcentagem de cristalinidade da fibra de curauá tratada, se comparada à fibra não tratada (Tabela 2). A diminuição, observada após o tratamento da fibra com ar ionizado, indica que o tratamento atingiu os domínios cristalinos, levando a modificações na região correspondente à celulose que alteraram a organização das cadeias deste polissacarídeo.

\subsubsection{Análise Térmica}

As fibras foram caracterizadas via DSC e TG, Figuras 24 e 25.

O pico exotérmico em torno de $340^{\circ} \mathrm{C}$ é decorrente da decomposição térmica da hemicelulose e da celulose presentes na fibra de curauá. O pico observado acima de $400^{\circ} \mathrm{C}$ é atribuído a decomposição térmica da lignina (LEÃO; CARASCHI, 2000).

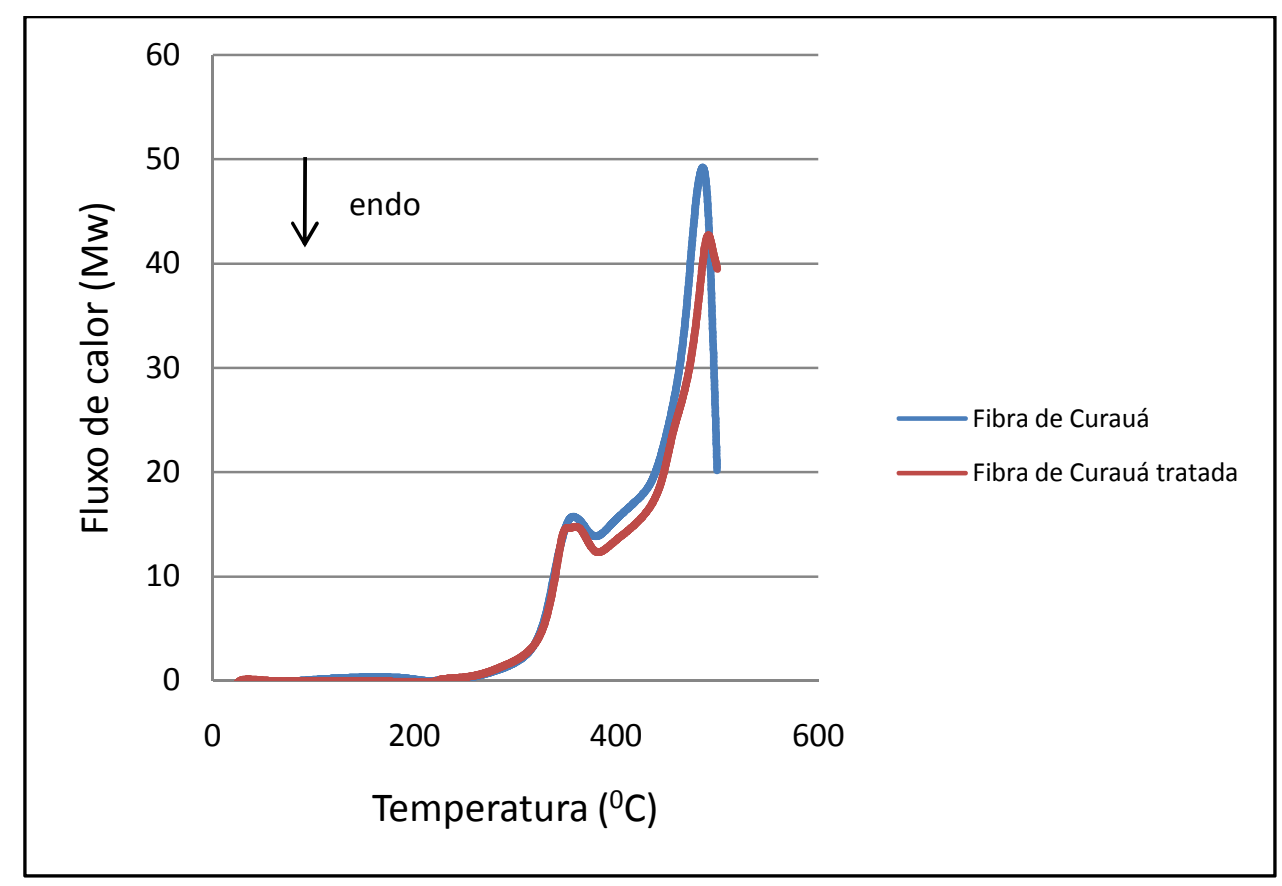

Figura 24: Curva de DSC da Fibra de Curauá tratada e não tratada, atmosfera de $\mathrm{N}_{2}$, fluxo de $20 \mathrm{mLmin}^{-1}$ e razão de aquecimento de $10^{\circ} \mathrm{Cmin}^{-1}$. 
Estes eventos observados nas curvas DSC podem ser detectados nas curvas TG, pelas perdas de massa identificadas.

As curvas TG mostram perda de massa de $5 \%$ em torno de $100^{\circ} \mathrm{C}$, atribuída à perda de água aderida as fibras de curauá, devido ao caráter hidrofílico desta. Até em torno de $260^{\circ} \mathrm{C}$ às fibras de curauá possuem estabilidade térmica, quando então ocorre o início da decomposição da hemicelulose, seguida da celulose. Em torno de $400^{\circ} \mathrm{C}$ observa-se uma mudança de inclinação na curva devido ao processo de decomposição envolvendo quebra das ligações $\mathrm{C}-\mathrm{C}$ da lignina, liberação de água, $\mathrm{CO}$ e $\mathrm{CO}_{2}$ (TOMECZAK; SATYANARAYANA, 2007).

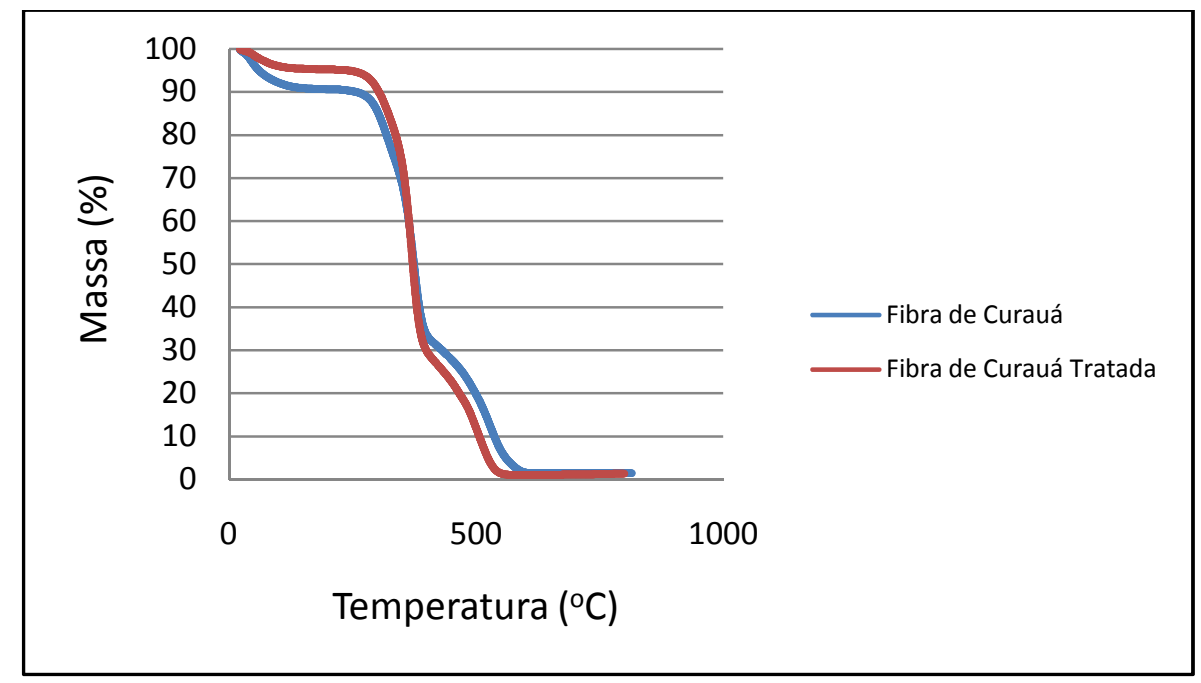

Figura 25: Curva TG da fibra de curauá sem tratamento e tratada com ar ionizado por $5 \mathrm{~h}$, atmosfera de $\mathrm{N}_{2}$, fluxo de $20 \mathrm{mLmin}^{-1}$ e razão de aquecimento de $10^{\circ} \mathrm{Cmin}^{-1}$.

A Figura 26 mostra a derivada primeira da curva TG, onde dois processos principais de perda de massa são observados, correspondentes a decomposição da celulose e a da liginina. 


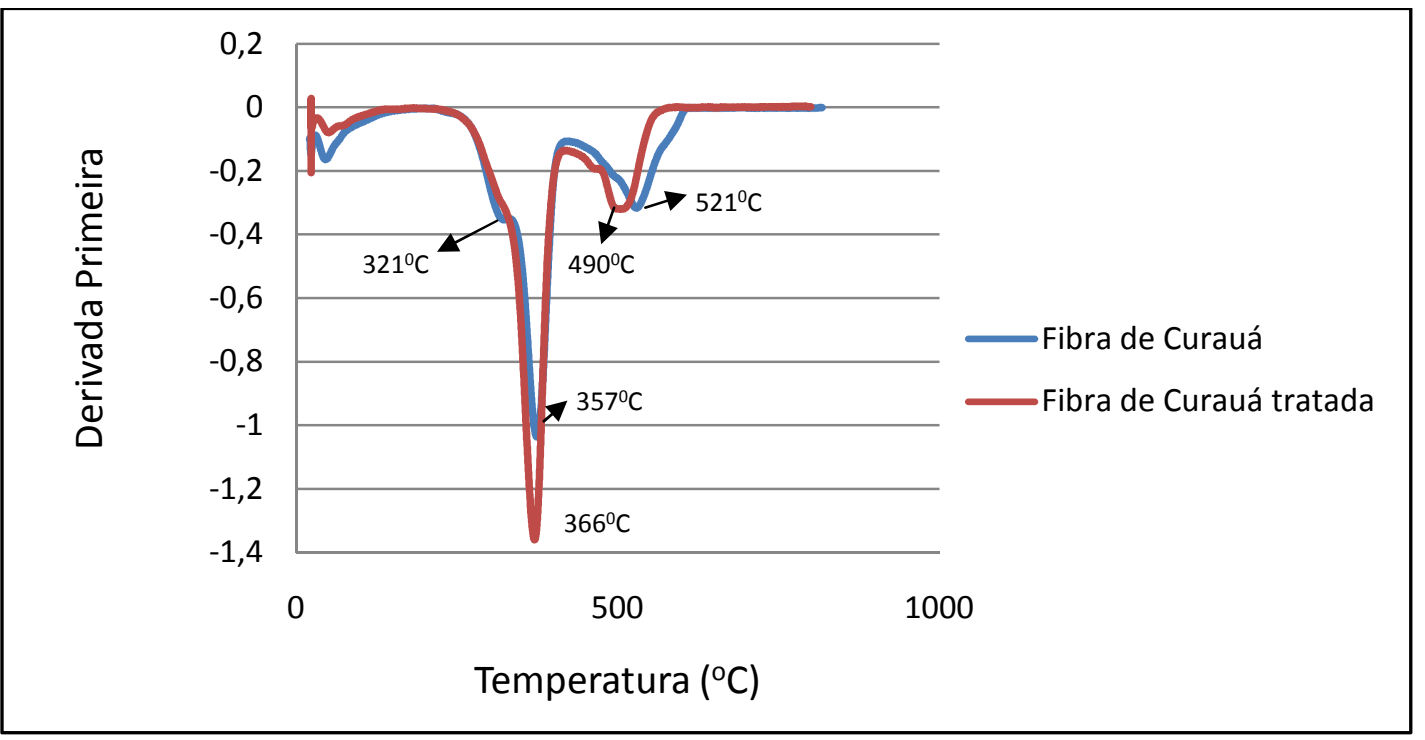

Figura 26: Curva de primeira derivada da TG da fibra de Curauá tratada e não tratada.

O pico correspondente à decomposição da celulose, em torno de $350^{\circ} \mathrm{C}$ é mais intenso quando a fibra é tratada com ar ionizado ( 5 h), e o "ombro" observado para a fibra não tratada a $321^{\circ} \mathrm{C}$, correspondente a hemicelulose, desaparece indicando que houve um rearranjo na região correspondente à celulose. 0 pico correspondente à decomposição da lignina é deslocado para temperatura menor quando a fibra é tratada com ar ionizado (5 h), indicando que o tratamento interfere nos domínios correspondentes à lignina.

\subsubsection{Ensaio de Tração}

As fibras foram caracterizadas quanto à resistência a tração e porcentagem de alongamento (Tabela 3).

Tabela 3: Resistência a tração e alongamento das fibras de curauá tratadas e não tratada.

\begin{tabular}{|c|c|c|}
\hline Amostra & Resistência à tração (MPa) & Alongamento \\
\hline Fibra de Curauá & $399 \pm 36$ & $0,84 \pm 0,08$ \\
\hline Fibra de Curauá tratada & $652 \pm 75$ & $0,74 \pm 0,14$ \\
\hline
\end{tabular}

Os resultados obtidos estão mais baixos se comparados aos de trabalhos prévios, em que outros lotes de curauá foram utilizados. Trindade et al. (2005) obtiveram resistência à tração de $636 \mathrm{MPa}$ e alongamento de 0,8\%, enquanto Gomes et al. (2007) determinaram um valor de resistência à tração de $913 \mathrm{MPa}$. 
O tratamento com ar ionizado por intervalo de tempo de $5 \mathrm{~h}$ levou a fibras com resistência à tração significativamente superior (Tabela 3), indicando possivelmente modificações nos arranjos das fibras principalmente nas regiões cristalinas. De acordo com a Tabela 3, as fibras de curauá tratadas com ar ionizado (5 h) apresentaram valores de porcentagem de alongamento semelhantes aos das fibras não modificadas (Tabela 3).

\subsubsection{Microscopia Eletrônica de Varredura}

Foram realizadas análises de microscopia eletrônica de varredura (MEV) para as fibras de curauá (Figura 27 (a) e (b)). Observa-se a presença de alguns fragmentos na superfície da fibra, provavelmente provenientes de resíduos de células parênquimas, nas quais a fibra estava ligada (MEGIATTO, 2006).

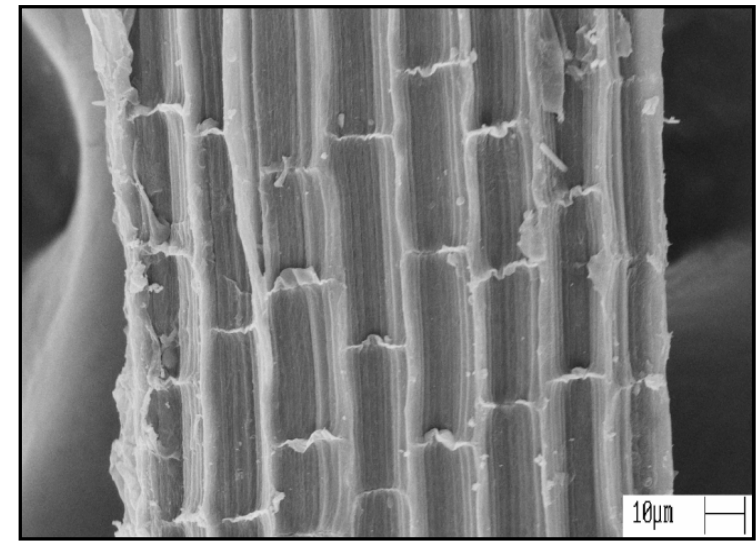

(a)

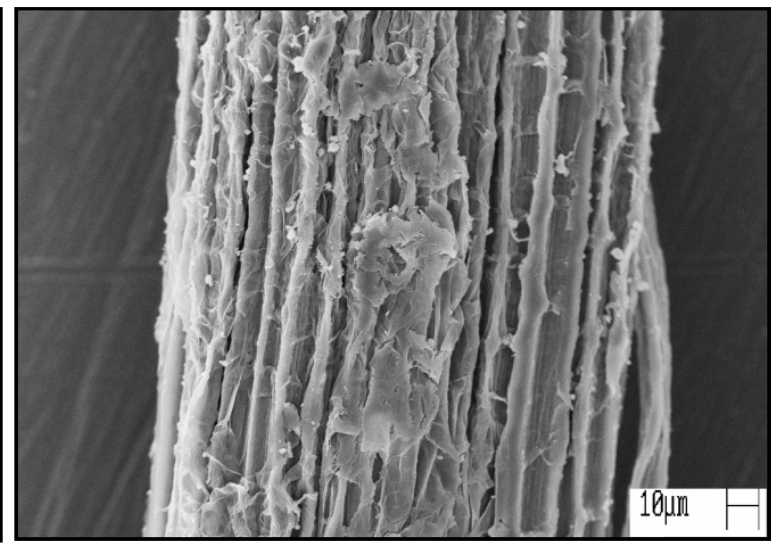

(b)

Figura 27: Micrografia dos feixes de fibra de curauá: (a) não tratada, (b) tratada com ar ionizado por $5 \mathrm{~h}$.

Comparando as fibras de curauá não tratadas (Figura 27 a) com as submetidas a tratamento com ar ionizado por $5 \mathrm{~h}$ (Figura $27 \mathrm{~b}$ ), observa-se que as fibras submetidas ao tratamento com ar ionizado apresentaram modificações na sua superfície. O tratamento aumentou a rugosidade e a separação dos feixes de fibras, o que é positivo, já que feixes mais desagregados podem favorecer uma maior interação da fibra com a matriz polimérica e, consequentemente, uma melhor adesão na interface matriz/fibra (TRINDADE et al., 2008).

A utilização de ar ionizado tem como objetivo modificação do padrão de cargas estáticas presentes na superfície das fibras, com o intuito de diminuir a atração entre as 
mesmas, afastando os feixes de fibra, tornando-as mais expostas à impregnação pela matriz polimérica.

\subsection{Caracterizações do Biopolietileno de Alta Densidade (BPEAD)}

O BPEAD foi utilizado como matriz polimérica para a produção dos compósitos. $\mathrm{Na}$ Tabela 4 encontram-se os valores de alguns parâmetros avaliados para o BPEAD.

Para verificar possíveis efeitos do processamento sobre a massa molar média do polímero o índice de fluidez, que pode ser tomado como indicativo indireto da massa molar foi avaliado antes e após processamento.

Tabela 4: Propriedades típicas do BPEAD

\begin{tabular}{|c|c|c|c|}
\hline Propriedade & Método ASTM & Unidade & Valor \\
\hline $\begin{array}{c}\text { Índice de Fluidez } \\
\text { (BPEAD) }\end{array}$ & $\mathrm{D}-1238$ & $\mathrm{~g}(10 \mathrm{~min})^{-1}$ & $0,10 \pm 0,01$ \\
\hline $\begin{array}{c}\text { Índice de Fluidez } \\
\text { (BPEAD processado) }\end{array}$ & $\mathrm{D}-1238$ & $\mathrm{~g}\left(10 \mathrm{~min}^{-1}\right.$ & $0,17 \pm 0,01$ \\
\hline $\begin{array}{c}\text { Resistência ao impacto } \\
\text { IZOD com entalhe } \\
\text { (processado) }\end{array}$ & $\mathrm{D}-256$ & $\mathrm{Jm}^{-1}$ & $224 \pm 31$ \\
\hline $\begin{array}{c}\text { Módulo de Flexão } \\
\text { (BPEAD) }\end{array}$ & ASTM D790-02 & $\mathrm{GPa}$ & $0,52 \pm 0,03$ \\
\hline $\begin{array}{c}\text { Módulo de Flexão } \\
\text { (BPEAD processado) }\end{array}$ & ASTM D790-02 & $\mathrm{GPa}$ & $0,54 \pm 0,03$ \\
\hline
\end{tabular}

$\mathrm{Na}$ indústria de processamento de termoplásticos o índice de fluidez é um importante parâmetro, amplamente usado para caracterizar a propriedade de escoamento, devido a sua fácil medição. Pode-se notar certo aumento do BPEAD para o BPEAD processado, o que, deve ter como provável causa degradação parcial das cadeias, e ou quebra de ligações envolvendo ramificações, dentre as poucas presente nas cadeias, diminuindo assim os valores de viscosidade e consequentemente aumentando o índice de fluidez (LIANG; LI; TJONG, 1999). 


\subsubsection{Determinaçao do Índice de Cristalinidade por Difração de raios X}

Foram obtidos os difratogramas de raios $\mathrm{X}$ do BPEAD tratado com ar ionizado por $5 \mathrm{~h}$ e não tratado (Figura 28).

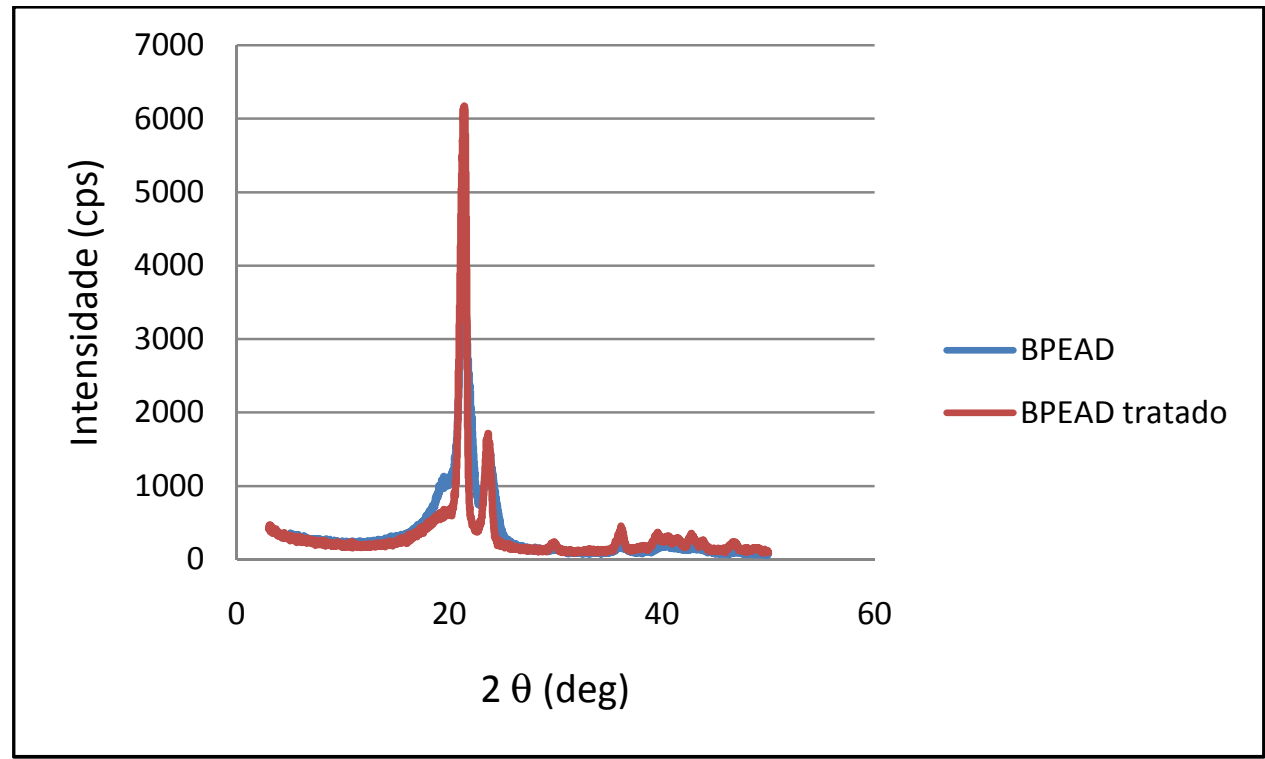

Figura 28: Difratograma da análise de raios $X$ do BPEAD não tratado e tratado com ar ionizado $5 \mathrm{~h}$.

O índice de cristalinidade (Tabela 5) foi determinado pelo cálculo da área sob o halo amorfo $I_{a}$, pela integração dos picos de difração $I_{C}$, usando a constante de proporcionalidade para o polietileno de alta densidade $\mathrm{K}$, de acordo com a equação 2 (mostrada na parte Materiais e Métodos).

Tabela 5: Índice de cristalinidade para o BPEAD tratado e não tratado com ar ionizado

\begin{tabular}{|c|c|}
\hline Amostra & Cristalinidade (\%) \\
\hline BPEAD não processado & 76 \\
\hline BPEAD tratado & 71 \\
\hline
\end{tabular}

Os resultados obtidos mostram que o tratamento leva a uma pequena diminuição na cristalinidade do BPEAD (Tabela 5). 


\subsubsection{Análise Térmica}

A Figura 29 mostra as curvas termogravimétricas para as amostras de BPEAD tratada com ar ionizado (5h) e não tratada.

Devido ao caráter hidrofóbico do BPEAD não há praticamente interação com as moléculas de água, não sendo observado praticamente perda de massa até aproximadamente $350^{\circ} \mathrm{C}$.

Pela análise das curvas da Figura 29, pode-se observar que ambas as amostras apresentam temperatura de início de perda de massa em torno de $350^{\circ} \mathrm{C}$, com deslocamento do pico de perda máxima da amostra tratada com ar ionizado no sentido de menor temperatura. A diminuição na cristalinidade da amostra tratada pode ter deslocado o máximo de decomposição para menor temperatura.
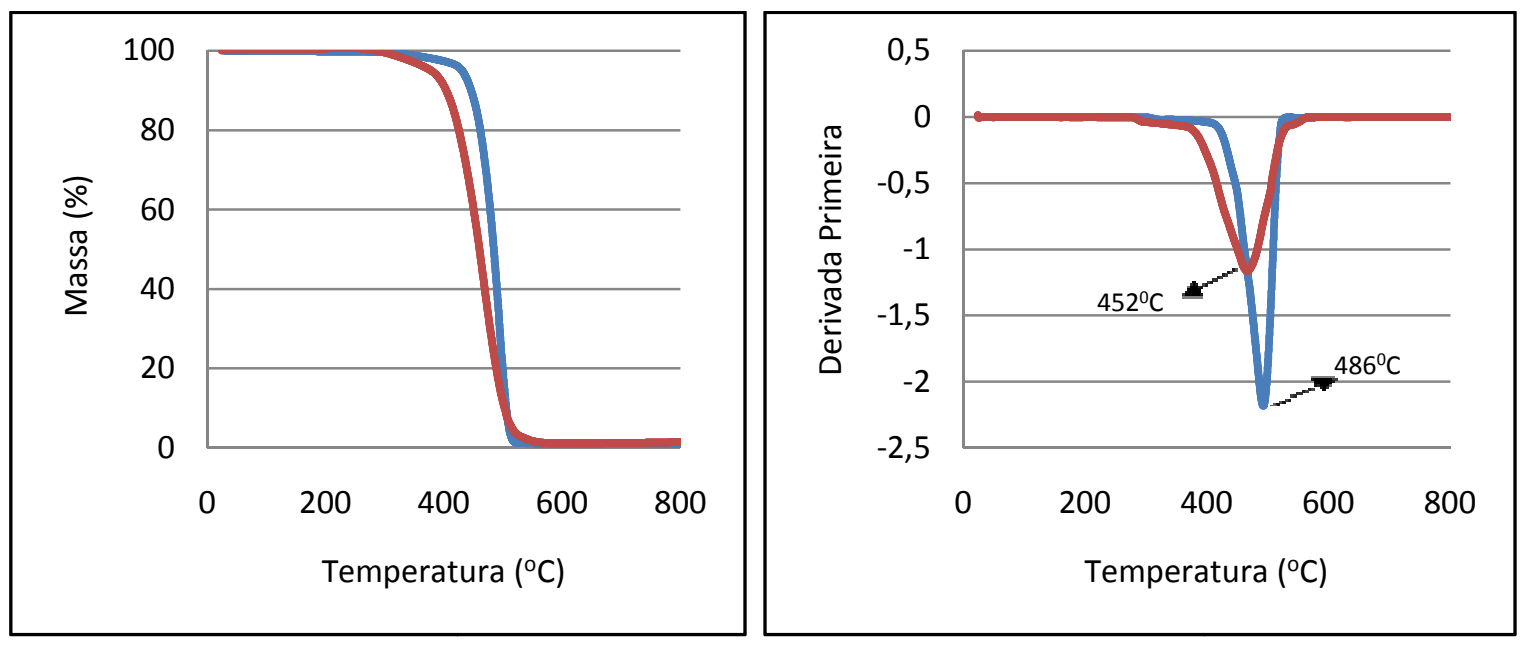

Figura 29: Curva TG e de derivada primeira da TG do BPEAD sem tratamento e do BPEAD tratado com ar ionizado ( $5 \mathrm{~h}$ ), atmosfera de $\mathrm{N}_{2}$, fluxo de $20 \mathrm{mLmin}^{-1}$ e razão de aquecimento de $10^{\circ} \mathrm{Cmin}^{-1}$.

Na Figura 30 são apresentadas as curvas de DSC para o BPEAD tratado e não tratado.

Em ambas as curvas foi possível observar picos endotérmicos em torno de $130^{\circ} \mathrm{C}$ relacionados com a temperatura de fusão do BPEAD. Pelo cálculo da área do pico da temperatura de fusão da curva de DSC, foram obtidas entalpias de fusão de $-196 \mathrm{Jg}^{-1}$ para o BPEAD e -173 $\mathrm{Jg}^{-1}$ para o BPEAD tratado com ar ionizado indicando diferenças de cristalinidade entre as amostras, o que confirma o observado via difração de raio X (Tabela 5). 


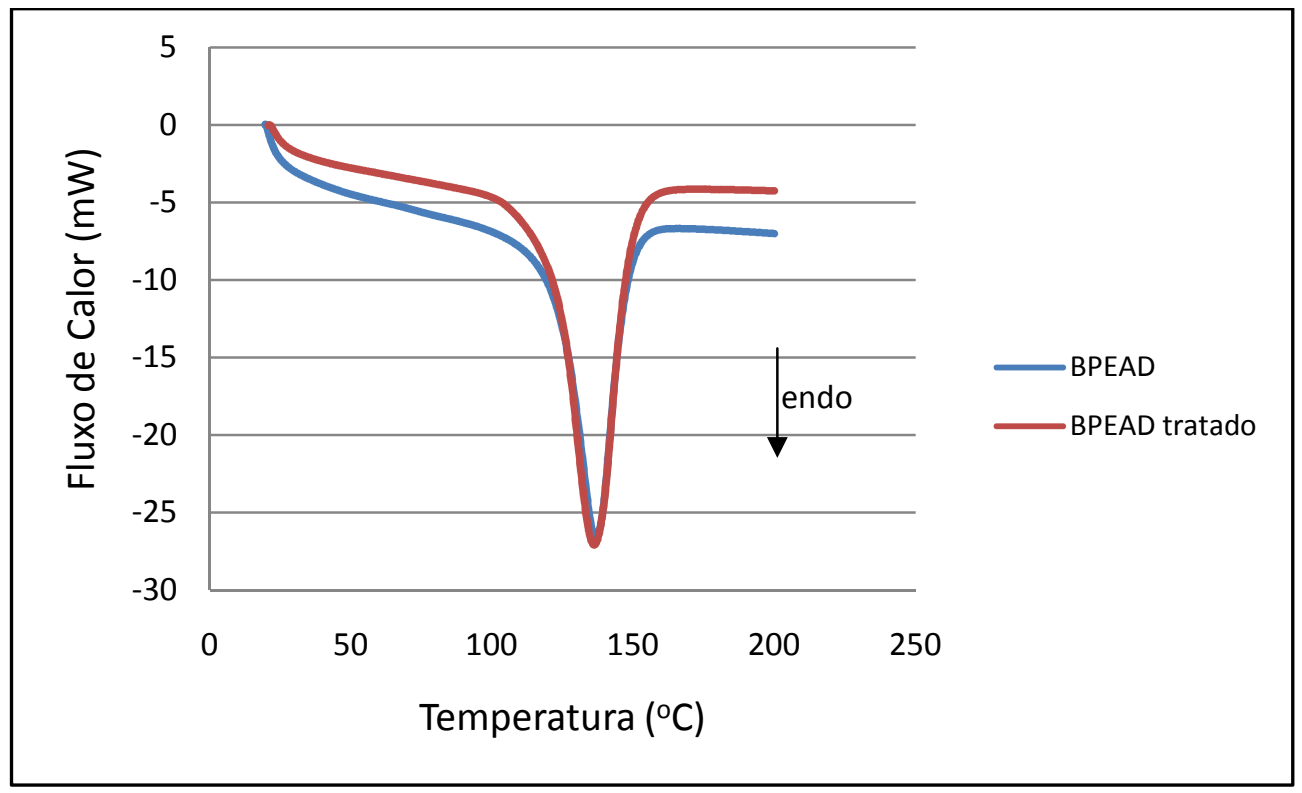

Figura 30: Curva de DSC do BPEAD, atmosfera de $\mathrm{N}_{2}$, fluxo de $20 \mathrm{mLmin}^{-1}$ e razão de aquecimento de $10^{\circ} \mathrm{Cmin}^{-1}$.

A varredura não foi feita até a temperatura de decomposição do material, observada na curva TG (Figura 29).

\subsubsection{Analise Térmica Dinâmico- Mecânica (DMTA)}

A analise térmica dinâmico- mecânica (DMTA) fornece informações a respeito do módulo de elasticidade ou armazenamento $\left(E^{\prime}\right)$, do modulo de dissipação viscosa ou perda ( $\left.E^{\prime \prime}\right)$ e do amortecimento mecânico ou atrito interno ( $\left.\tan \delta=E^{\prime \prime} / E^{\prime}\right)$ de um material, quando sujeito a uma solicitação dinâmica.

Na Figura 31 (a), (b) e (c) estão mostrados curvas, para o módulo de armazenamento $\left(E^{\prime}\right)$, para o módulo de perda ( $\left.E^{\prime \prime}\right)$ e para $\tan \delta$ em função da temperatura, obtido no ensaio dinâmico térmico-mecânico.

O módulo de armazenamento é uma medida da energia mecânica que o material é capaz de armazenar, na forma de energia potencial ou elástica. Pode-se observar uma queda no módulo de armazenamento do BPEAD processado quando comparado ao não processado. Este efeito pode estar relacionado com a degradação ocorrendo com o polímero no misturador interno, onde macrorradicais livres podem ser gerados, os quais 
podem reagir com $\mathrm{O} \mathrm{O}_{2}$, produzindo radicais peroxi, iniciando o processo de auto-oxidação do material (MAHENDRAN et al., 2008).

Normalmente, no polietileno de alta densidade, duas relaxações são observadas, uma em torno de $-120^{\circ} \mathrm{C}$, chamada de $\gamma$ por muitos autores, relacionada à região não cristalina e associada à transição vítrea por pesquisadores (PEGORETTI et al. 2000, SILVA et al. 2001), embora alguns considerem a necessidade de investigação mais aprofundada para esta atribuição entre 50 e $120{ }^{\circ} \mathrm{C}$ (PEREÑA, 2006).

A relaxação que aparece entre 50 e $120{ }^{\circ} \mathrm{C}$ (chamada de $\alpha$ ) é associada com um processo de cisalhamento interlamelar, em alguns casos podendo ocorrer desdobramento em dois picos, devido a não homogeneidade das regiões cristalinas (PEGORETTI et al., 2000).

Polietilenos também podem apresentar uma relaxação $(\beta)$ abaixo de $0{ }^{0} \mathrm{C}$, atribuída ao movimento de cadeias com conformações menos estendidas, sendo, mais acentuada para polietilenos de baixa densidade (PEGORETTI et al., 2000).

Analisando a curva do módulo de perda e tan $\delta$ do BPEAD não processado pode-se observar três picos.

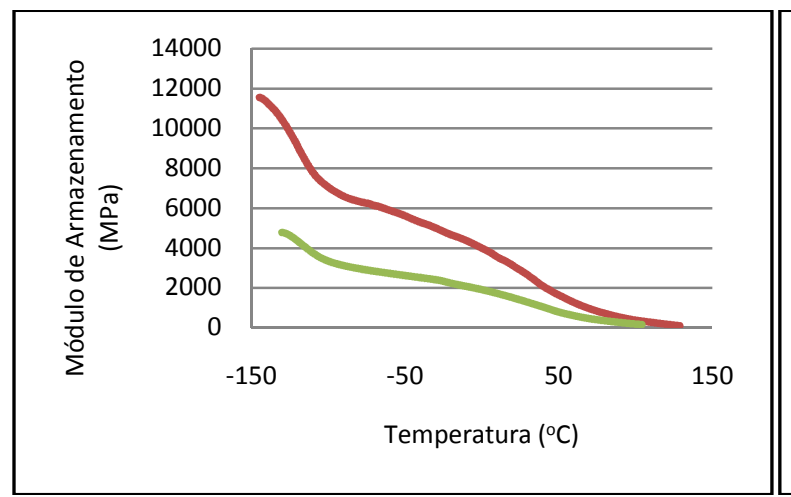

(a)

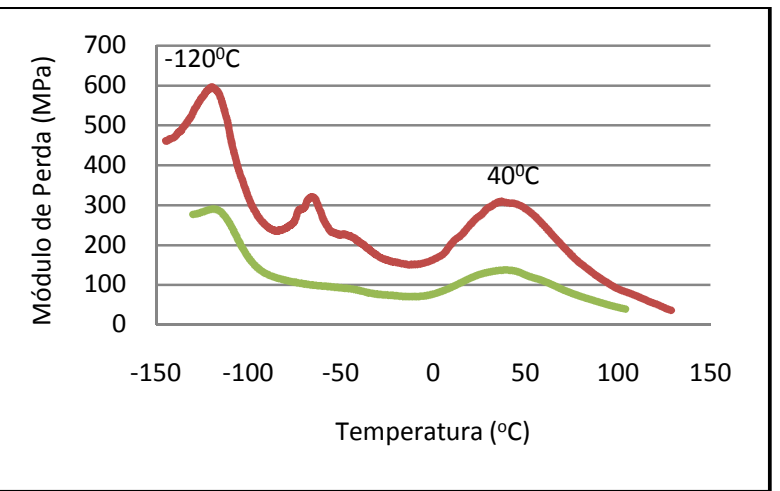

(b)

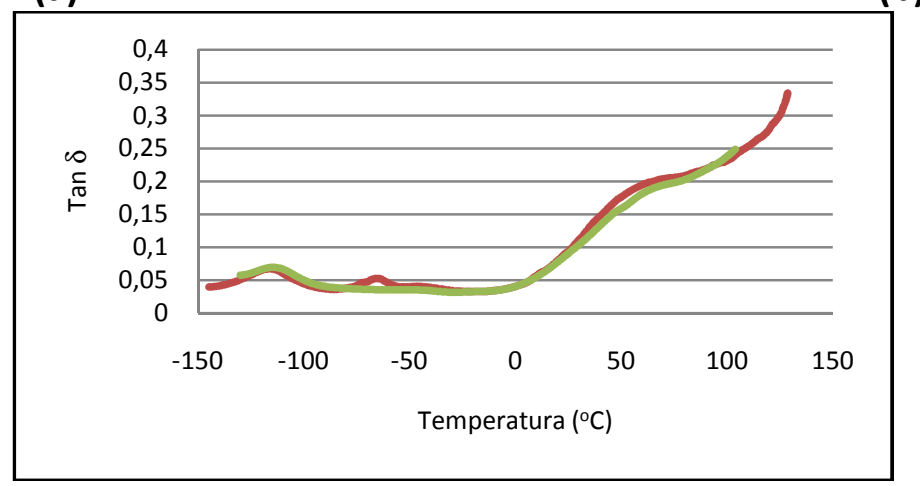

(c)

Figura 31: Curvas DMTA do BPEAD não processado e do BPEAD processado (a) E' versus temperatura; (b) E" versus temperatura; (c) $\tan \delta$ versus temperatura. 
O pico em torno de $-120^{\circ} \mathrm{C}$ se refere à relaxação de segmentos de cadeia da fase não cristalina, tendo em vista o pequeno número de ramificações deste material, provavelmente relaxações referentes a estas ramificações não são detectadas por esta técnica, a região $\alpha_{a}$ em torno de $-60^{\circ} \mathrm{C}$, pode ser atribuída à relaxação envolvendo cadeias pouco estendidas, mais facilmente detectadas para polietileno de baixa densidade, o pico em torno de $40^{\circ} \mathrm{C}$ é atribuído a fase não cristalina interlamelar (CANEVAROLO, 2004).

Após o processamento, o pico máximo $\gamma$ é deslocado para aproximadamente $-110^{\circ} \mathrm{C}$ e o pico a $-60^{\circ} \mathrm{C}$ não é visualizado (somente uma pequena alteração na linha de base é observada), o mesmo ocorrendo nas curvas de $\tan \delta$, indicando que o processamento interferiu nas regiões em que as cadeias menos estendidas se encontravam. O pico em torno de $40^{\circ} \mathrm{C}$, relacionando ao cisalhamento interlamelar, praticamente não é alterado.

\subsection{Análise Térmica PBHL}

O polibutadieno líquido hidroxilado foi acrescentado à formulação do compósito, o qual passa a ter então em sua composição partículas de borracha, as quais podem promover um aumento na resistência à propagação da trinca durante impacto (MEGIATTO; RAMIRES FROLLINI, 2010). Além do PBHL atuar como agente modificador de impacto, acredita-se que a hidroxila terminal presente na estrutura do PBHL interage através de ligações hidrogênio com os grupos polares da fibra lignocelulósica, e a cadeia hidrocarbônica presente no PBHL interage com o BPEAD (Figura 11), o que viabiliza a ação da borracha também como agente de compatibilização.

A Figura 32 apresenta as curvas TG, dTG (derivada primeira da TG) para o polibutadieno líquido hidroxilado.

A curva TG mostra estabilidade térmica até $340^{\circ} \mathrm{C}$, quando então ocorre o início da decomposição da borracha. Este evento é representado na curva dTG por um pico com máximo em torno de $500^{\circ} \mathrm{C}$. Pode-se observar que tanto o PBHL como o BPEAD (Figura 29) apresentam curvas de TG similares, já que apresentam estabilidade térmica até em torno de $350^{\circ} \mathrm{C}$. 

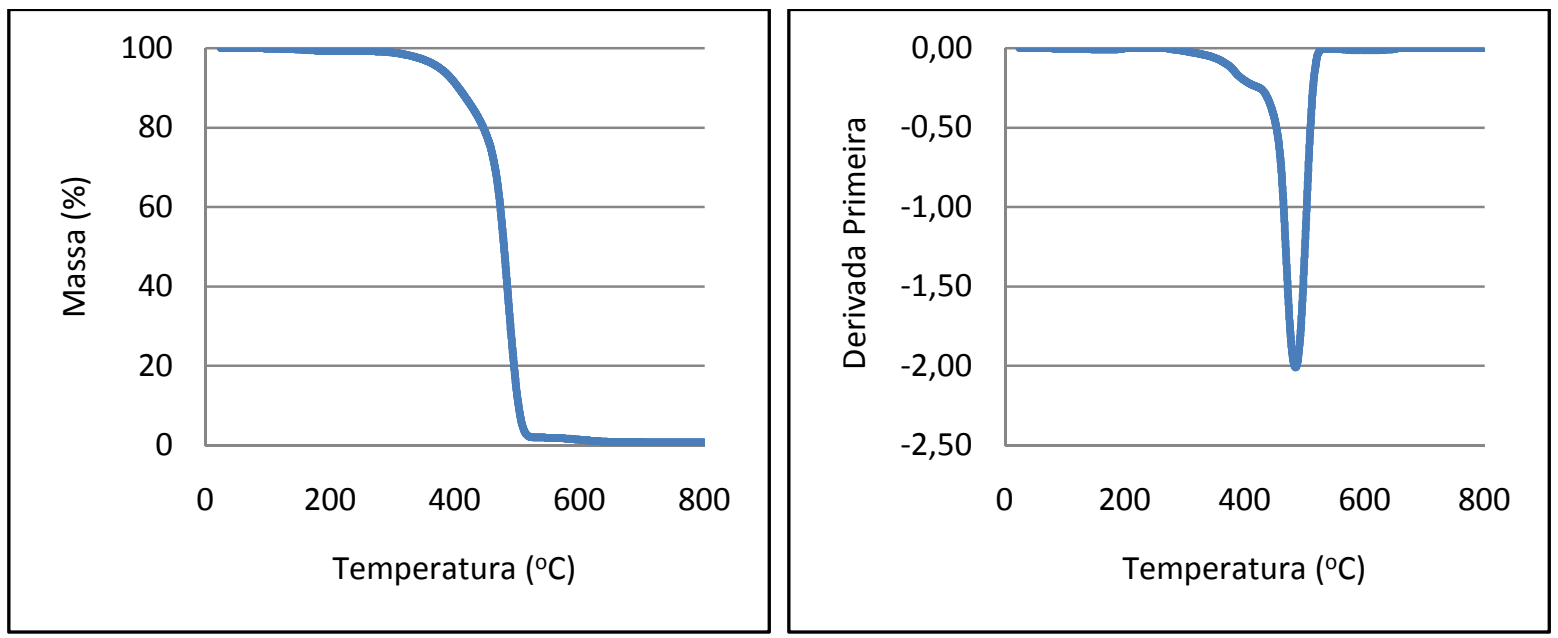

Figura 32: Curva TG do $P B H L$, atmosfera de $\mathrm{N}_{2}$, fluxo de $20 \mathrm{mLmin}^{-1}$ e razão de aquecimento de $10^{\circ} \mathrm{Cmin}^{-1}$.

A Figura 33 mostra a curva DSC para o PBHL.

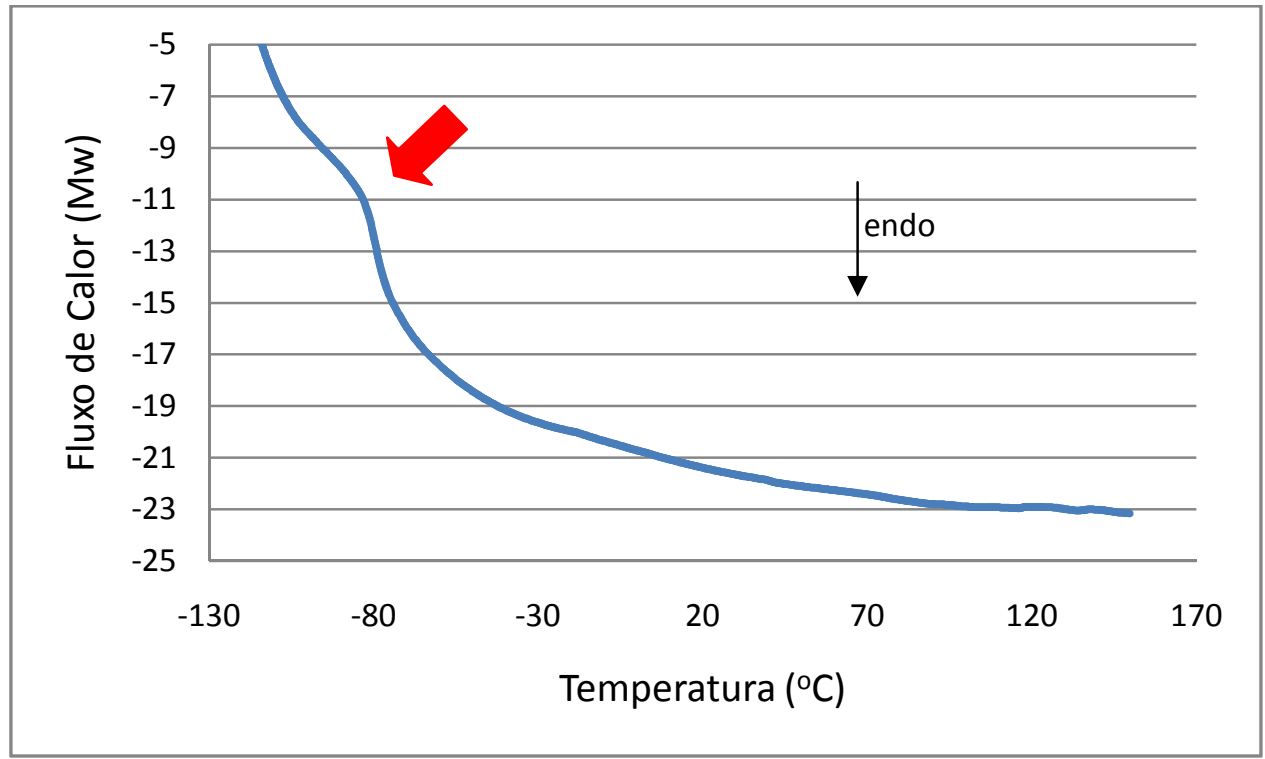

Figura 33: Curva de DSC do PBHL, atmosfera de $\mathrm{N}_{2}$, fluxo de $100 \mathrm{mLmin}^{-1}$ e razão de aquecimento de $20^{\circ} \mathrm{Cmin}^{-1}$.

Na curva (Figura 33) observa-se uma mudança torno de $-80^{\circ} \mathrm{C}$, que pode caracterizar transiçao vítrea $(\mathrm{Tg})$ do $\mathrm{PBHL}$, pois este valor é próximo ao encontrado por Jaindann et al. (2008) que caracteriza a transição vítrea do PBHL através da análise da curva de DSC em $80,95^{\circ} \mathrm{C}$ e de Lee et al. (2006) em $-80^{\circ} \mathrm{C}$. A varredura não foi feita até a decomposição térmica do material, mostrada na Figura 32. 


\subsection{Blenda de BPEAD e PBHL}

\subsubsection{Preparação das amostras em misturador interno}

$\mathrm{Na}$ Figura 34 estão representadas as curvas de variação de torque em função do tempo obtidas durante o processamento da mistura de BPEAD/PBHL.

Primeiramente o PBHL em diferentes proporções foi adicionado ao BPEAD, em seguida, esta mistura alimentou a câmara.

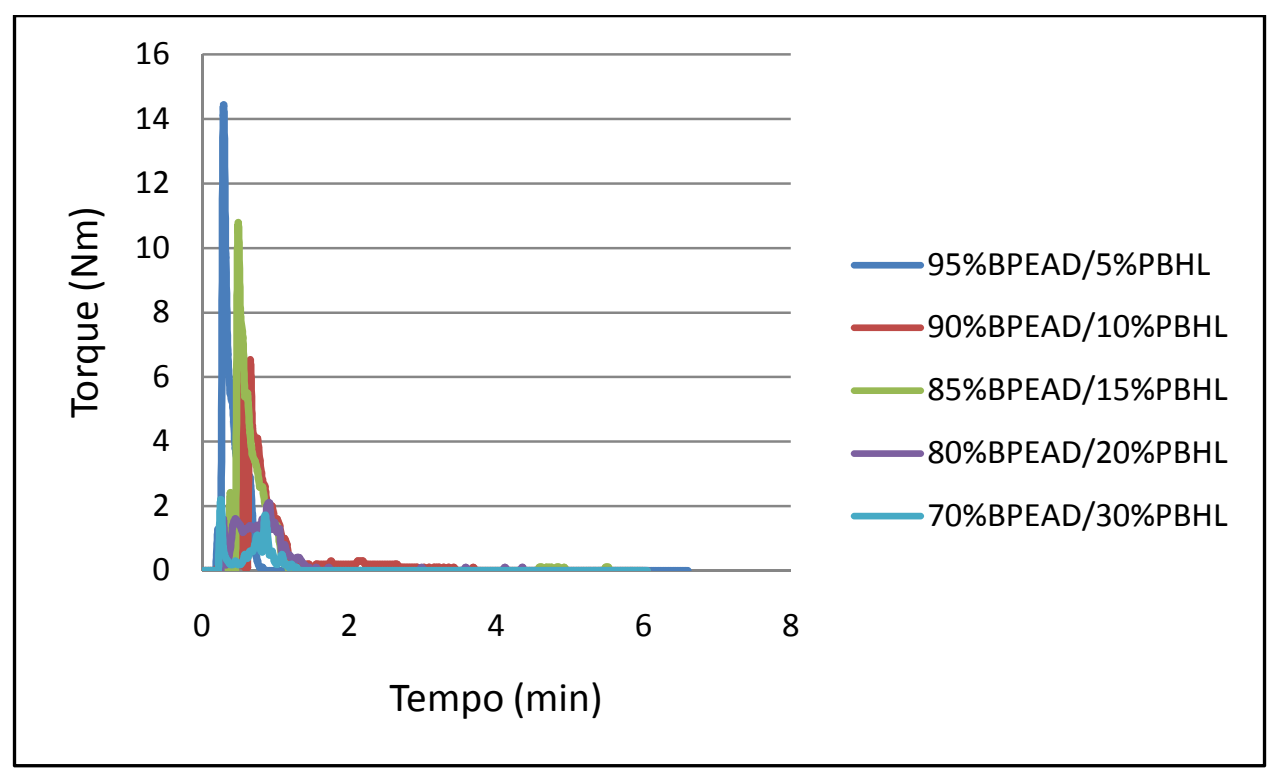

Figura 34: Curvas de Processamento da blenda de BPEAD/PBHL.

Pode-se observar um aumento do torque devido à alimentação da blenda na câmara de mistura, seguido da fusão do BPEAD e, consequentemente, queda do torque para as diferentes composições de BPEAD/PBHL. As blendas apresentam uma baixa viscosidade sendo que há degradação do PBHL e do BPEAD durante o processamento (ARAÚJO; HAGE JR.; CARVALHO, 2003).

Observou-se visualmente que adicionando 20 e $30 \%$ de borracha à blenda, certa quantidade de PBHL adicionada ficou retida, no misturador interno, o que leva a uma porcentagem real de PBHL, menor que 20 e $30 \%$ na blenda. 


\subsubsection{Análise térmica}

A Figura 35 apresenta as curvas TG e de dTG (derivada primeira) da blenda de 95\%BPEAD/5\%PBHL e do PBHL puro.

A curva TG mostra estabilidade térmica até $350^{\circ} \mathrm{C}$, quando então ocorre o início da decomposição dos componentes da blenda. O material em estudo suporta temperaturas de até $350^{\circ} \mathrm{C}$ sem sofrer qualquer perda de massa. Este evento é representado na curva dTG por um pico com máximo em torno de $470^{\circ} \mathrm{C}$. Pode-se observar que tanto o $\mathrm{PBHL}$ como o BPEAD (Figuras 29 e 32) apresentam curvas TG e dTG similares.
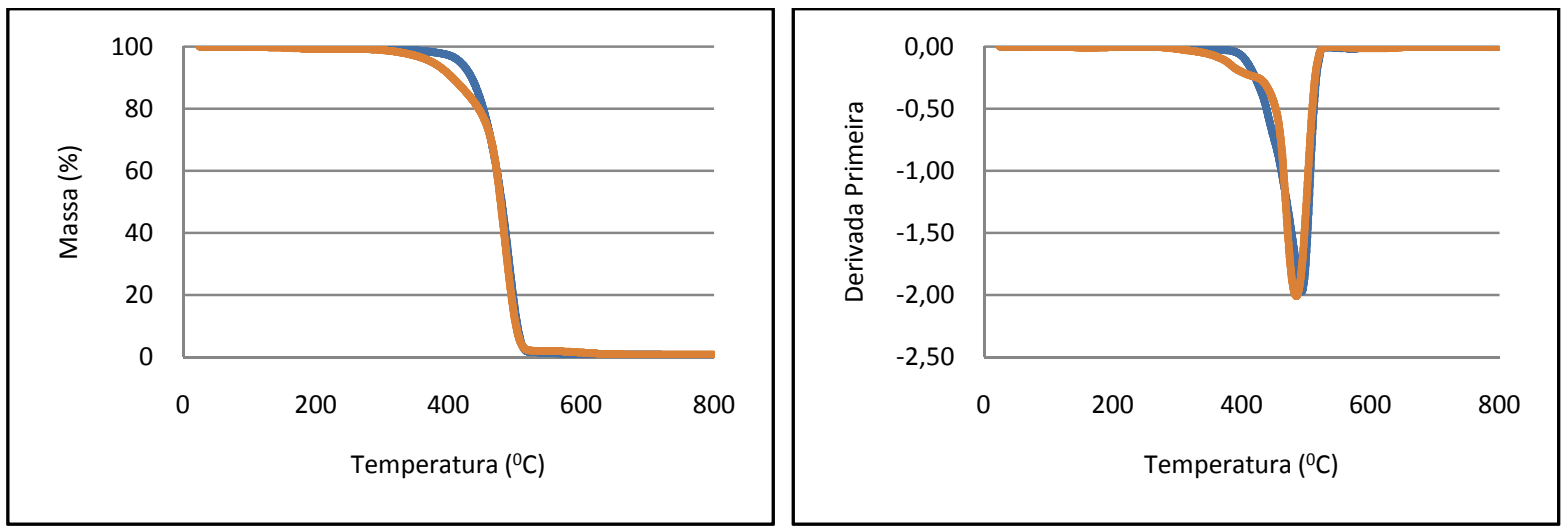

Figura 35: Curvas TG e derivada primeira da TG para as blendas de 95\%BPEAD/5\%PBHL e PBHL atmosfera de $\mathrm{N}_{2}$, fluxo de $20 \mathrm{mLmin}^{-1}$ e razão de aquecimento de $10^{\circ} \mathrm{Cmin}^{-1}$.

As curvas DSC para as blendas de BPEAD/PBHL estão representadas na Figura 36. Pode-se observar que todas as amostras apresentam um pico endotérmico relativo à fusão, próximo de $130^{\circ} \mathrm{C}$, típico do polietileno.

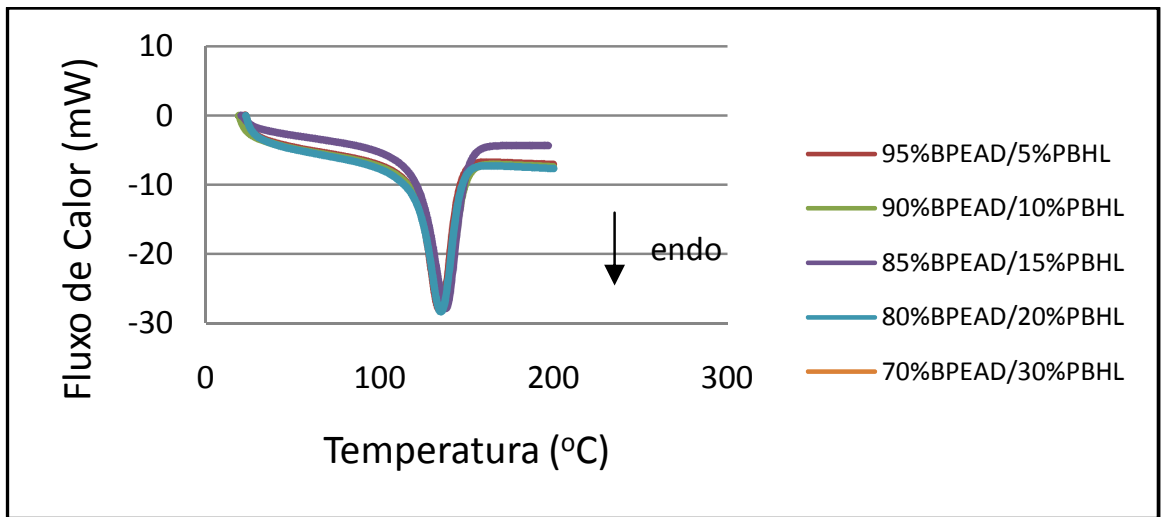

Figura 36: Curvas DSC para as blendas de BPEAD/PBHL, atmosfera de $\mathrm{N}_{2}$, fluxo de $20 \mathrm{mLmin}^{-1}$ e razão de aquecimento de $10^{\circ} \mathrm{Cmin}^{-1}$. 
As análises via DSC podem fornecer a temperatura de fusão $\left(T_{m}\right)$, a entalpia de fusão $\left(\Delta H_{m}\right)$ e o grau de cristalinidade $\left(X_{c}\right)$, para polímeros que apresentam essas transições (CANEVAROLO, 2004).

O índice de cristalinidade para os compósitos, para as blendas e para o BPEAD puro, pode ser calculado através da seguinte relação:

$X c=\frac{\Delta H_{f}}{\Delta H^{0} \varphi_{m}} \times 100$

Sendo, $\mathrm{X}_{\mathrm{c}} \mathrm{o}$ índice de cristalinidade, $\Delta \mathrm{H}_{\mathrm{f}}$ a entalpia de fusão da amostra, $\Delta \mathrm{H}_{\mathrm{f}}^{0} \mathrm{a}$ entalpia de fusão do PEAD hipoteticamente $100 \%$ cristalino e $\varphi_{m}$ a fração mássica do PEAD no compósito ou na blenda, no entanto, o índice de cristalinidade não pode ser calculado para as diferentes amostras já que se utilizou neste trabalho o BPEAD, e a entalpia de fusão para o BPEAD 100\% cristalino é desconhecida. Assim, a discussão é feita considerando a relação entre $\Delta \mathrm{H}_{\mathrm{f}} / \varphi_{\mathrm{m}}$

A entalpia de fusão pode ser determinada através do cálculo da área do pico endotérmico representado na Figura 36. Na Tabela 6 são apresentadas as entalpias de fusão.

Tabela 6: Entalpias de fusão

\begin{tabular}{|c|c|c|}
\hline Blenda & $\Delta \mathbf{H}_{\mathbf{f}}\left(\mathrm{Jg}^{-1}\right)$ & $\Delta \mathbf{H}_{\mathrm{f}} / \boldsymbol{\varphi}_{\mathbf{m}}$ \\
\hline BPEAD processado & 196,0 & 196,0 \\
\hline 95\%BPEAD/5\%PBHL & 151,2 & 159,0 \\
\hline 90\%BPEAD/10\%PBHL & 149,0 & 166,0 \\
\hline 85\%BPEAD/15\%PBHL & 148,6 & 175,0 \\
\hline 80\%BPEAD/20\%PBHL & 143,1 & 179,0 \\
\hline 70\%BPEAD/30\%PBHL & 136,6 & 195,0 \\
\hline
\end{tabular}

Pode-se observar que com a adição de PBHL, há uma diminuição da razão $\Delta \mathrm{H}_{\mathrm{f}} / \varphi_{\mathrm{m}} \mathrm{e}$ consequentemente do grau de cristalinidade do BPEAD. O processamento na presença das cadeias menores de PBHL pode fazer com que estas cadeias perturbem o arranjo das cadeias de BPEAD, diminuindo a cristalinidade (MOLY et al., 2005). Com a adição de $30 \%$ de PBHL a cristalinidade é aumentada, possivelmente porque para $30 \%$ de PBHL há a separação de fases. Deve-se considerar também que quantidade de PBHL adicionada ficou retida, no misturador interno, o que leva a uma porcentagem real de $\mathrm{PBHL}$, menor que $30 \%$ na blenda. 


\subsubsection{Análise Térmica Dinâmico- Mecânica (DMTA).}

Analisando as curvas referentes ao módulo de armazenamento E' (Figura 37), verifica-se que a blenda com 90\%BPEAD/10\% PBHL apresentou o maior valor de $\mathrm{E}^{\prime}$, indicando maior rigidez se comparada às demais blendas, sendo que todas apresentam maior módulo que o BPEAD. A rigidez das blendas, com exceção de $10 \%$ decresceu com o aumento da concentração do componente elastomérico (GUIMARÃES; ROCHA; COUTINHO, 2002).

Durante todo o aquecimento, o módulo de armazenamento reduz de uma maneira acentuada, seguindo de uma queda mais brusca próxima a temperatura de fusão do BPEAD em torno de $130^{\circ} \mathrm{C}$ (CASSU; FELISBERTI, 2005).

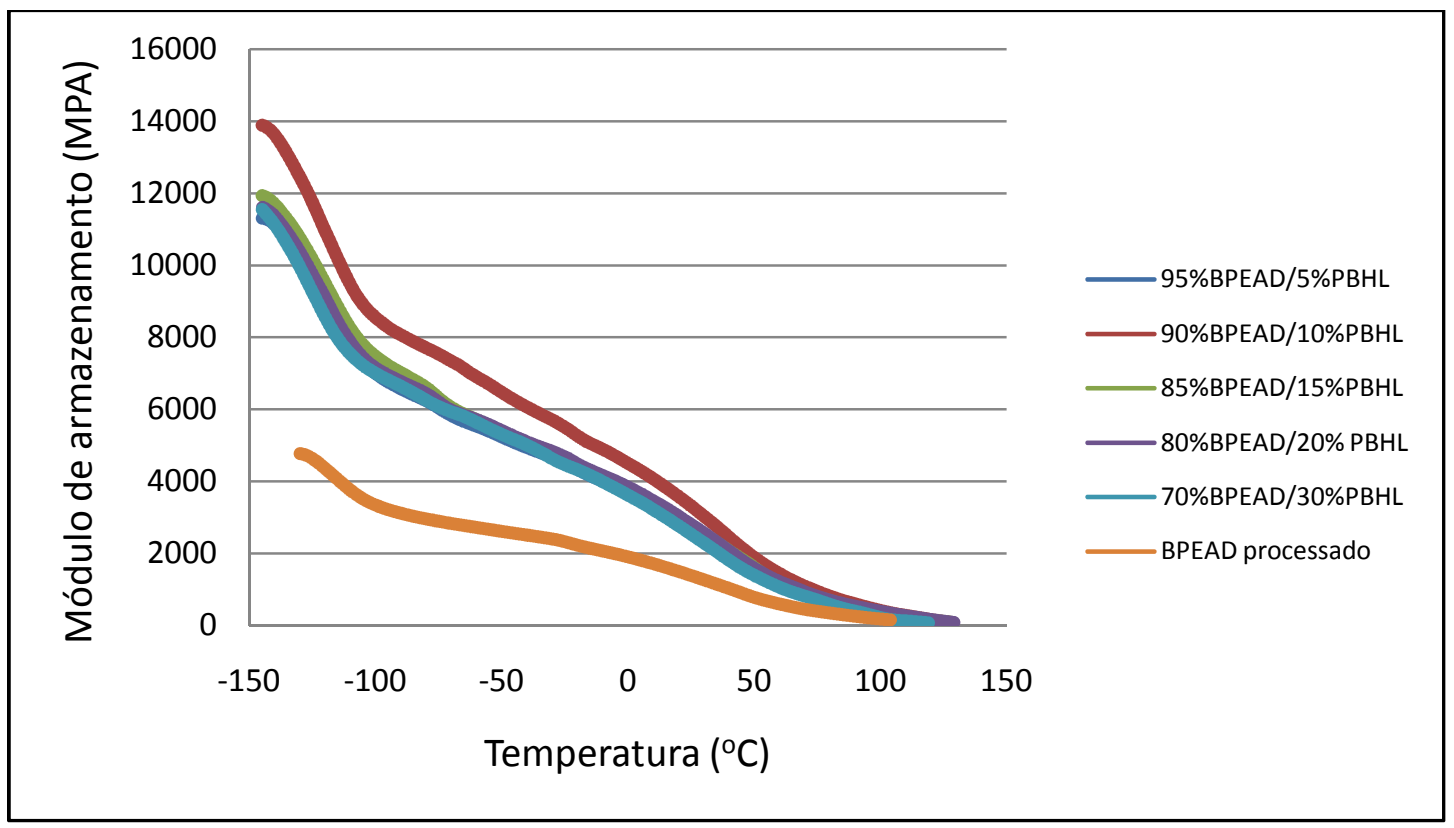

Figura 37: Módulo de armazenamento ( $\left.E^{\prime}\right)$ em função da temperatura para as blendas BPEAD/PBHL.

A Figura 38 apresenta a curva, para o módulo de perda ( $\left.E^{\prime \prime}\right)$ e para tan $\delta$ em função da temperatura, obtido no ensaio dinâmico térmico-mecânico. O pico que aparece em torno de $-110^{\circ} \mathrm{C}$ para o BPEAD é deslocado para aproximadamente $-125^{\circ} \mathrm{C}$ nas blendas, indicando que na presença da borracha, a relaxação dos segmentos de polietileno (região não cristalina) ocorre a temperatura mais baixa. Em torno de -75 a $-60^{\circ} \mathrm{C}$ é o observado um pico para as blendas. Este pico parece próximo a $\mathrm{Tg}$ do $\mathrm{PBHL}\left(-80^{\circ} \mathrm{C}\right)$ e também do pico observado para o $B P E A D$ não processado $\left(-60^{\circ} \mathrm{C}\right)$, não sendo trivial se o pico a $-60^{\circ} \mathrm{C}$ teria novamente 
sido detectado para as blendas, embora para algumas blendas seja possível dois picos nesta região. Um dos critérios para a avaliação da miscibilidade em blendas é a análise da transição vítrea. Sob este critério, uma blenda é considerada miscível quando apresenta uma única transição vítrea. A condição para a aplicação deste critério é que haja uma diferença de pelo menos $20^{\circ} \mathrm{C}$ entre as temperaturas de transição vítrea dos componentes da blenda. Tendo em vista a discussão prévia, não é simples usar este critério para avaliar a miscibilidade das blendas.

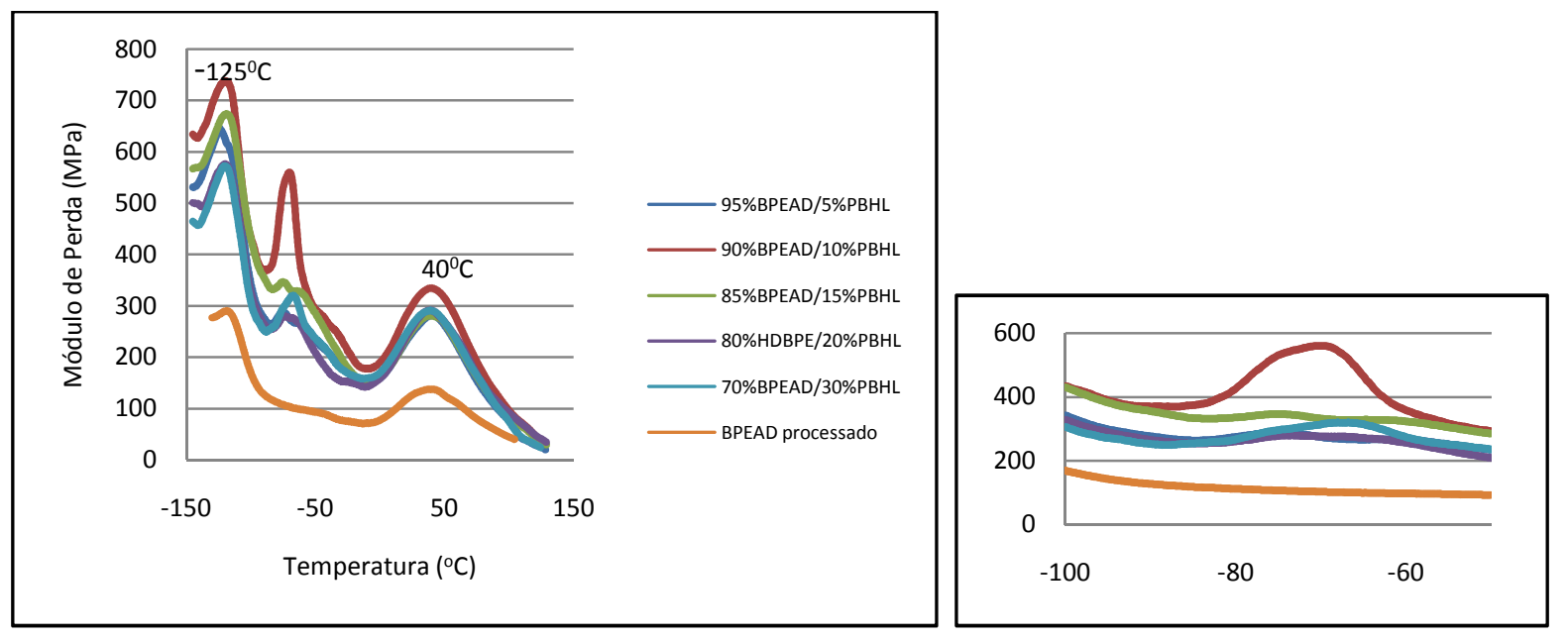

Figura 38: Módulo de perda (E”) em função da temperatura para as blendas de BPEAD/PBHL e ampliação da região entre -100 e $-50^{\circ} \mathrm{C}$.

O valor da $\tan \delta$ é uma medida do grau de amortecimento mecânico do material, e, quanto mais dúctil ou tenaz o material, maior o seu grau de amortecimento. Materiais com alto amortecimento dissipam grande parte da energia que foi utilizada no seu processo de deformação, na forma de calor (GATTI; SILVA; TAPANI, 2006). 


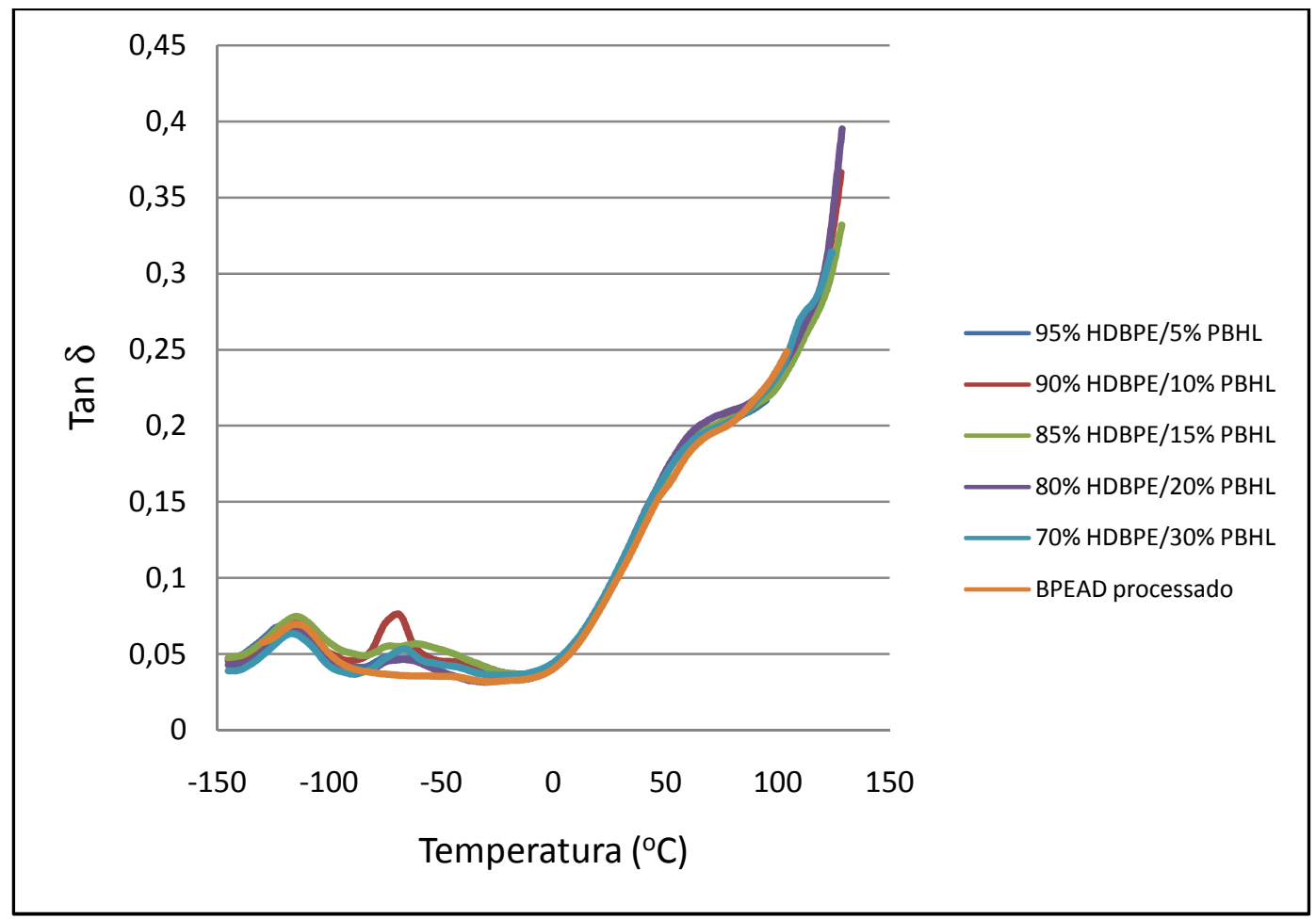

Figura 39: Tan $\delta$ em função da temperatura para as blendas de BPEAD/PBHL.

A Figura 39 apresenta as curvas tan $\delta$. A mesma discussão feita para E" pode ser aplicada para $\tan \delta$. Pode-se observar um expressivo aumento do amortecimento a partir de $-10^{\circ} \mathrm{C}$.

\subsubsection{Resistência ao Impacto}

A avaliação de resistência ao impacto de materiais poliméricos é um fator decisivo na seleção de materiais para determinada aplicação (ASHORI, 2008). O corpo de prova ensaiado sob impacto recebe a solicitação mecânica através de um martelo, em queda livre, ou presa na extremidade de um pêndulo. Os corpos de prova assim ensaiados têm sua resistência ao impacto medida através da energia absorvida por eles durante o processo de ruptura (CANEVAROLO, 2004).

Quando um material polimérico é submetido a certo esforço de impacto, a energia aplicada é dissipada no ponto de impacto fazendo com que o material apresente uma determinada resistência. Em um nível molecular, as cadeias podem ser rompidas, 
transferindo a solicitação mecânica para as cadeias vizinhas, podendo ocorrer à propagação do efeito, que pode levar a trinca (PAIVA; FROLLINI, 2002).

A Figura 40 apresenta os resultados do ensaio de resistência ao impacto Izod para o BPEAD processado e para o termoplástico com adição de 5, 10, 15, 20 e 30\% (em massa) de PBHL.

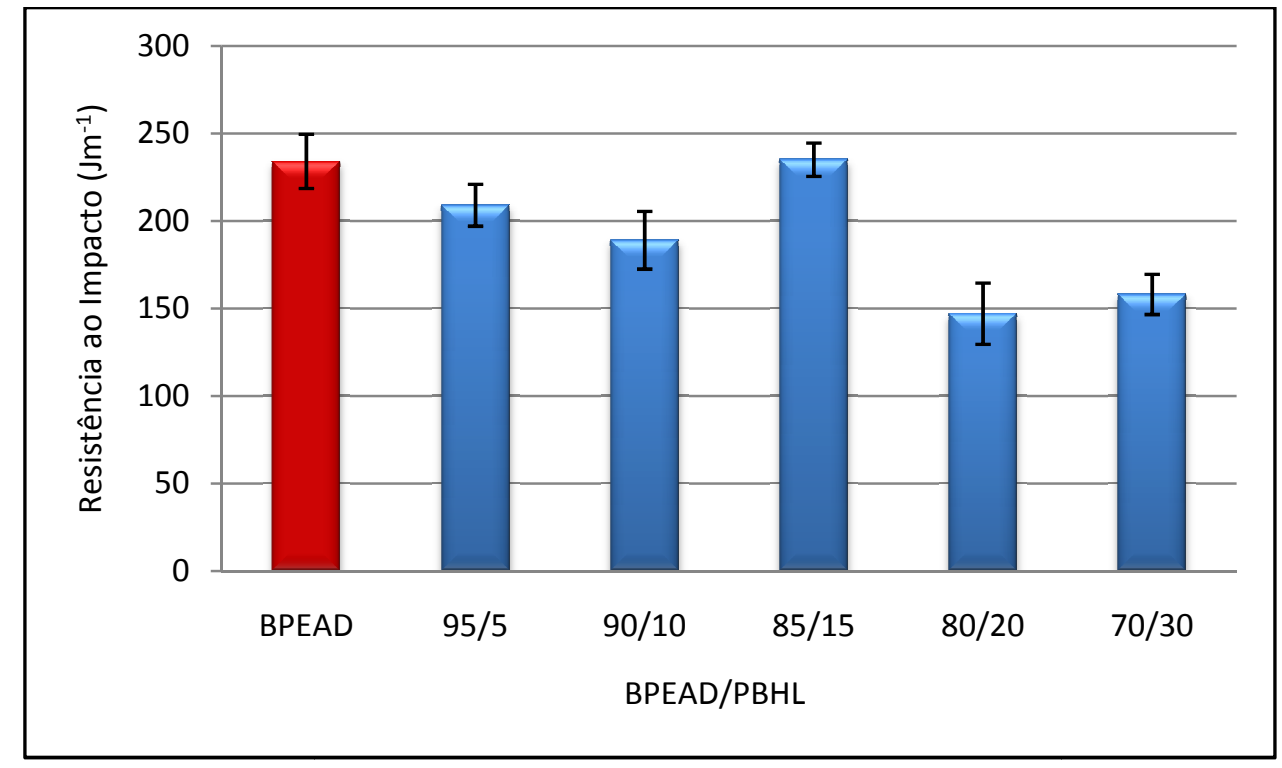

Figura 40: Resultados do ensaio de resistência ao impacto Izod das blendas de BPEAD/PBHL para corpos de prova entalhados.

Analisando os resultados apresentadas na Figura 40, pode-se observar que a adição de PBHL ao BPEAD não aumentou a resistência ao impacto da blenda formada como era, em princípio, esperado.

A introdução de frações maiores que $15 \%$ (em massa) de PBHL diminui consideravelmente a resistência ao impacto. Esta diminuição se deve, provavelmente, a maior dificuldade em se misturar o PBHL no BPEAD. Na ausência de fibras, com as quais podem interagir os grupos- $\mathrm{OH}$ do $\mathrm{PBHL}$, estes podem representar um fator de dificuldade, tendo em vista a característica apolar do BPEAD. Destaca-se que, conforme já mencionado, para 20 e 30\% de PBHL parte da borracha ficou retida no misturador, o que indica que, nas condições de processamento, estas porcentagens já estavam acima do limite que permitiria obter mistura dos dois componentes. Lembra-se ainda que a 20 e $30 \%$ correspondem, portanto, as porcentagens nominais, e não reais.

Deve-se lembrar que o PBHL corresponde a uma borracha de baixa massa molar média, o que pode também afetar o comportamento como modificador de impacto. A 
escolha desta borracha foi feita, como mencionado, pelo fato de possuir grupos -OH em sua estrutura.

O BPEAD e a blenda BPEAD/PBHL sem entalhe apresentaram comportamento de supertenacificação e não fraturaram sob as condições de teste usadas (GUIMARÃES; ROCHA; COUTINHO, 2002).

\subsubsection{Microscopia Eletrônica de Varredura}

Visando correlacionar os resultados do ensaio de impacto com a morfologia das blendas BPEAD/PBHL, a superfície de fratura dos corpos-de-prova, após ensaio de impacto, foram analisadas por microscopia eletrônica de varredura (MEV).

A Figura 41 (a) e (b) mostra a superfície de fratura típica para o BPEAD. São observadas linhas de deformação, que indicam deformação plástica.

A micrografia referente ao BPEAD contendo 5\% de PBHL (Figura 41 (c) e (d)), mostra uma razoável dispersão do PBHL ao longo da matriz e uma camada de polibutadieno hidroxilado recobrindo a superfície da matriz. Também há formação de uma região mais escura, que pode indicar a formação de algum tipo de interação entre a matriz e o PBHL (MEGIATTO; RAMIRES; FROLLINI, 2010).

As micrografias referentes ao termoplástico contendo 20\% de PBHL (Figura 41 (e)), revelam o início da formação de alguns aglomerados de borracha. A formação de aglomerados não é desejada, levando-se em consideração que estes podem agir como concentradores de tensão facilitando a propagação de trincas e diminuindo a resistência do material (MEGIATTO, 2006).

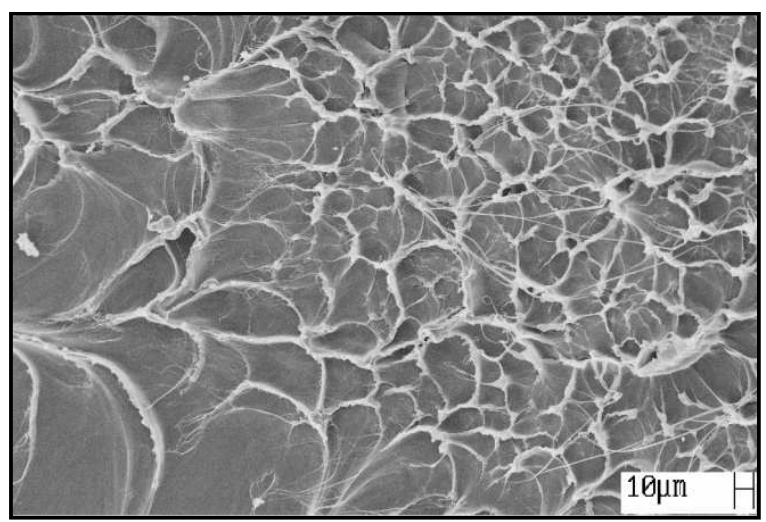

(a)

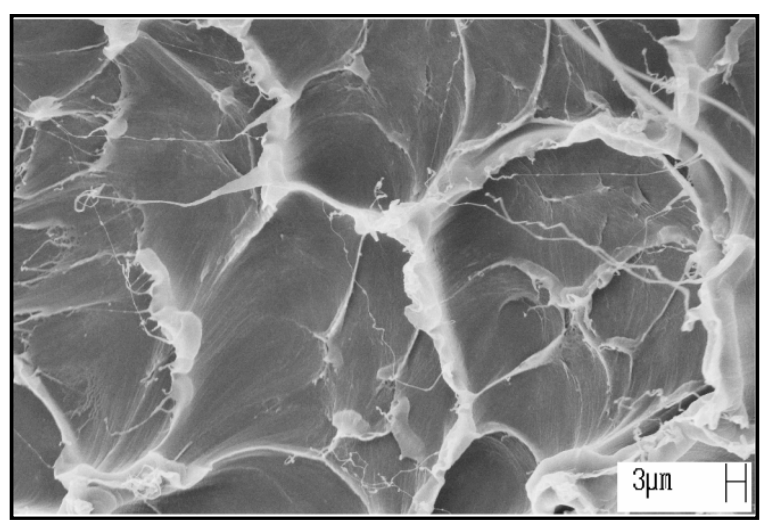

(b) 


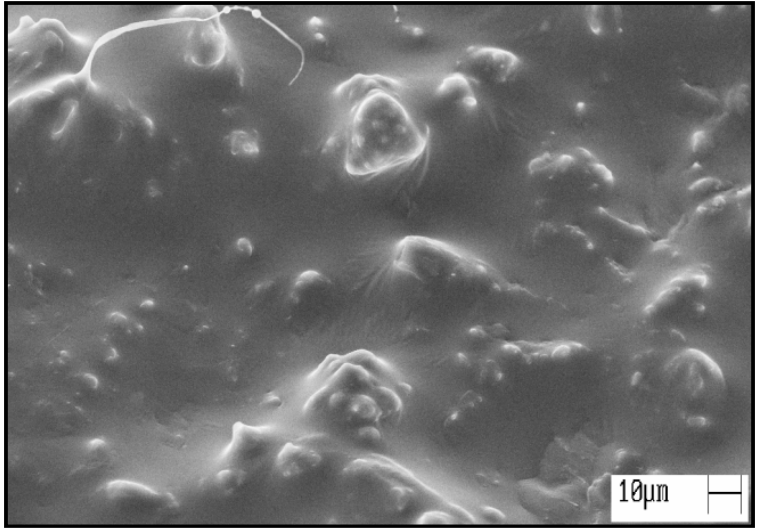

(c)

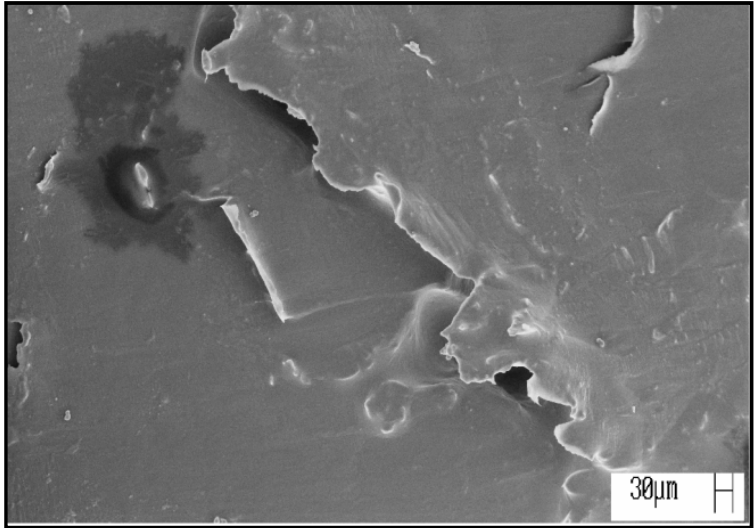

(d)

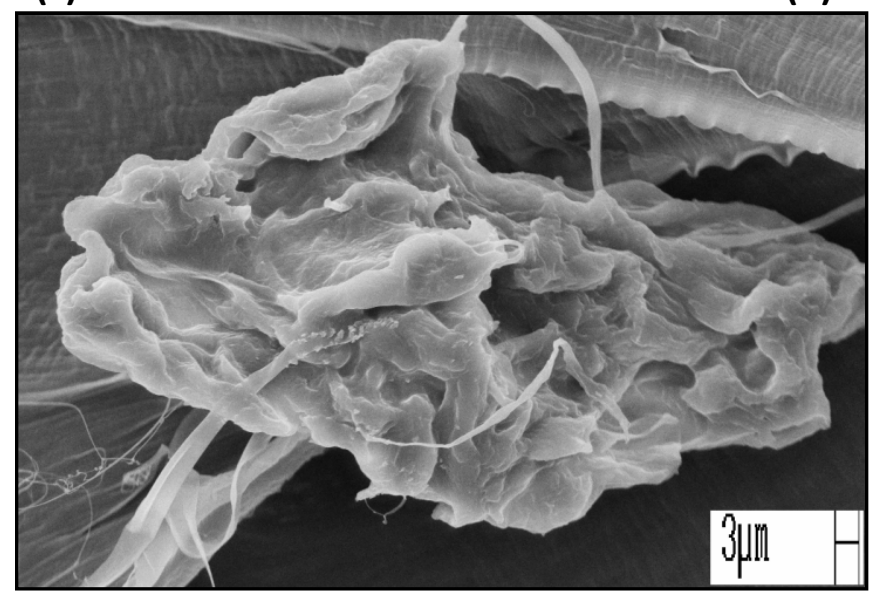

(e)

Figura 41: Micrografias obtidas por MEV a partir da superfície de fratura das blendas e do termoplástico: (a) e (b) sem adição de PBHL; (c) com adição de 5\% (em massa) de PBHL; (d) com adição de 15\% (em massa) de PBHL; (e) com adição de $20 \%$ (em massa) de PBHL.

As imagens mostram que há difusão do PBHL na matriz, o que deve favorecer as interações entre fibra/matriz, quando a fibra de curauá for adicionada. Na blenda a adição PBHL não levou a maior resistência ao impacto provavelmente devido à ausência de interações envolvendo toda a estrutura da cadeia de borracha e do BPEAD.

\subsubsection{Resistência à Flexão}

Nas Figuras 42 e 43 estão representados os módulos e a resistência à flexão para as blendas de BPEAD/PBHL. 


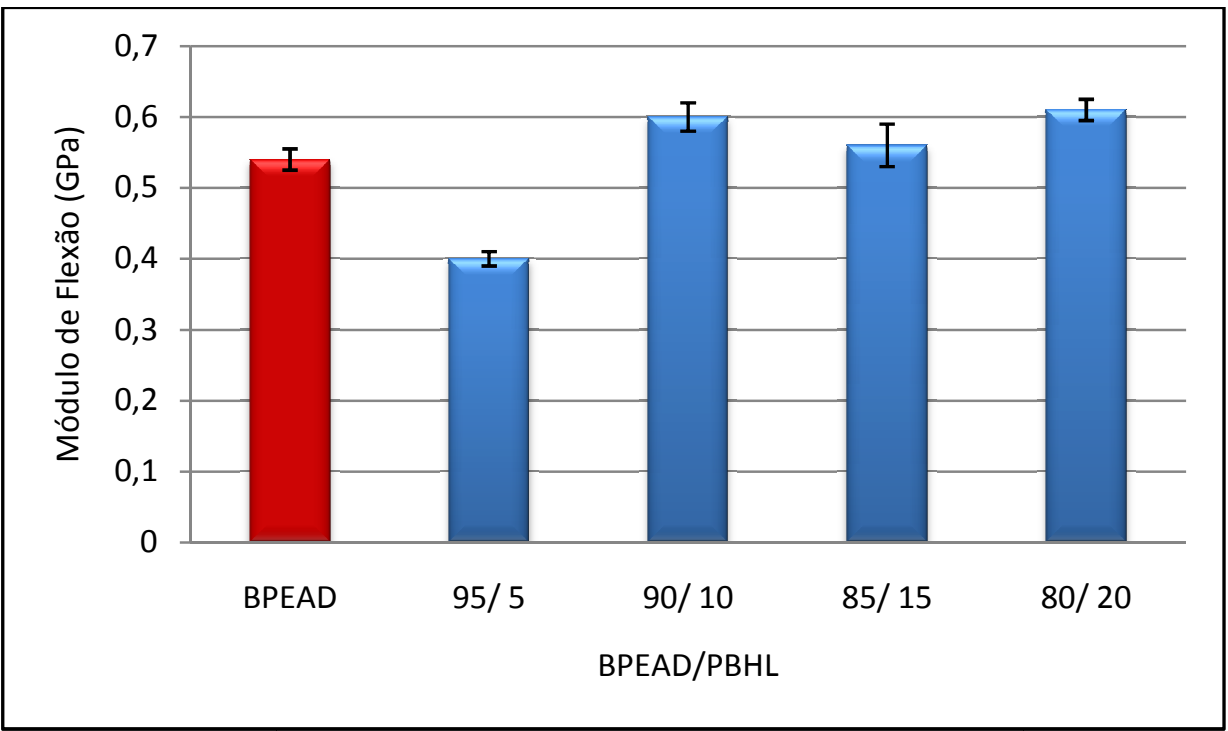

Figura 42: Módulo de flexão das blendas de BPEAD/PBHL.

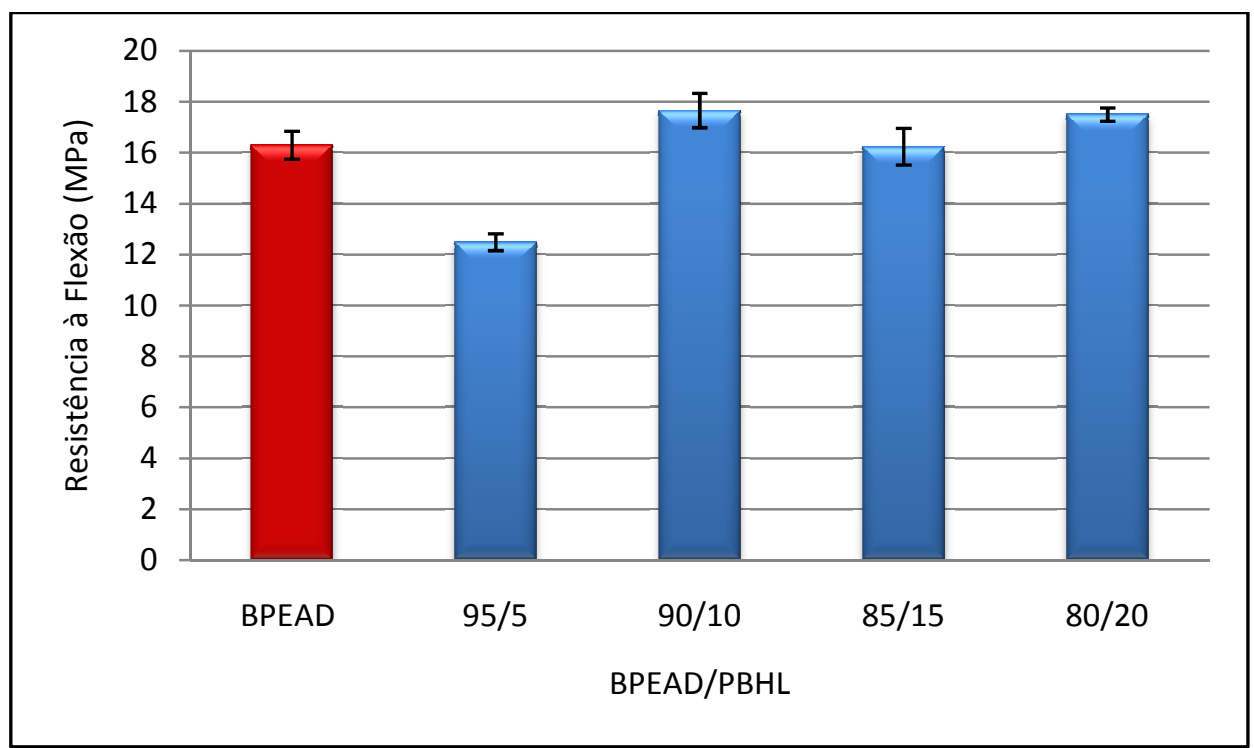

Figura 43: Resistência à flexão das blendas de BPEAD/PBHL.

O módulo e a resistência a resistência a flexão do BPEAD diminui para a blenda de 95\%BPEAD/5\%PBHL, mas para as outras blendas (10 e 20\% PBHL) se observa uma tendência de aumento. Devido às dificuldades experimentais, a blenda com $30 \%$ de PBHL não foi ainda caracterizada. 


\subsection{Compósitos de BPEAD e Fibra}

\subsubsection{Preparação das amostras em misturador interno}

As curvas de torque obtidas durante o processamento em misturador interno, representadas na Figura 44, apresentam um aumento do torque devido à adição de fibras, em seguida, ocorre à diminuição devido à fusão dos componentes na câmara de mistura.

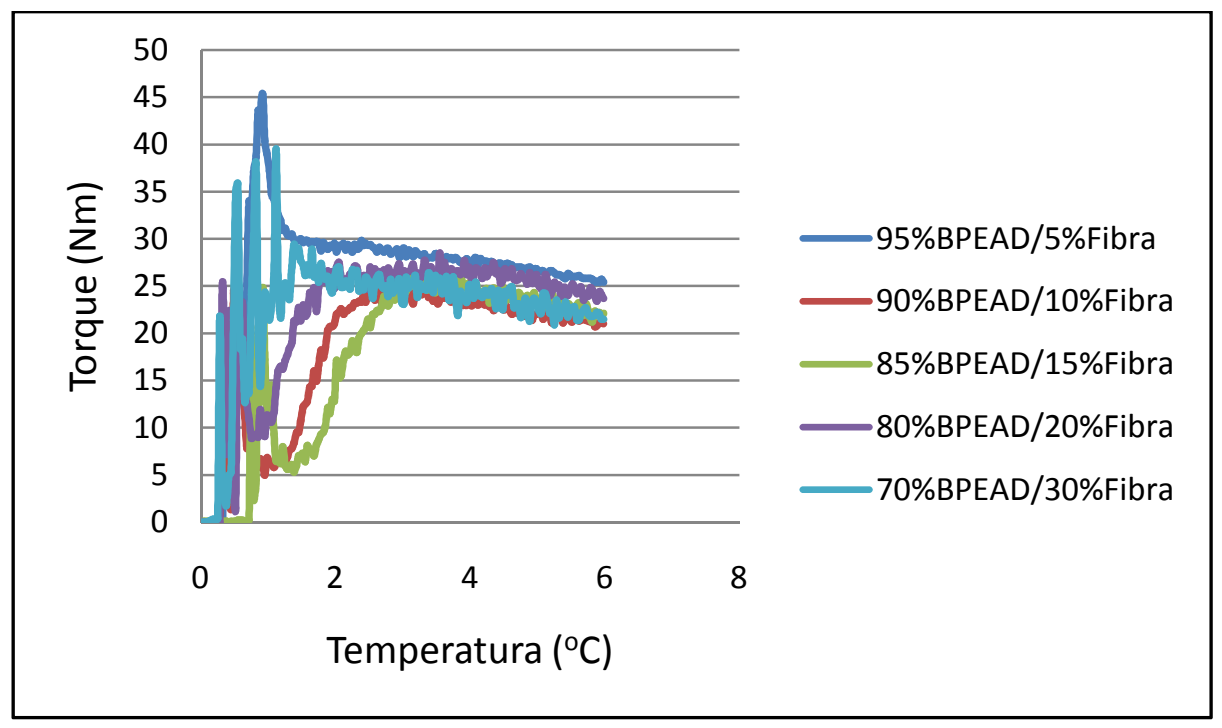

Figura 44: Curvas de Processamento dos compósitos de BPEAD/fibra.

O torque máximo em aproximadamente 2 min é inversamente proporcional ao teor de fibras no compósito. Durante o processamento das amostras no misturador interno, pode ocorrer a degradação das amostras ou, um desfibrilamento dos aglomerados de fibra.

\subsubsection{Análise Térmica}

A Figura 45 mostra as curvas TG obtidas para os compósitos de BPEAD/Fibra, para o BPEAD e para a fibra de curauá.

Quanto maior a quantidade de fibra adicionada ao compósito, maior é a similaridade da curva de TG do compósito com a curva de TG da fibra, o que fica mais evidente com as curvas de derivada primeira da TG.

O compósito contendo $30 \%$ de fibra apresenta temperatura de início de degradação em torno de $270^{\circ} \mathrm{C}$, enquanto os demais compósitos iniciam a perda de massa em uma 
temperatura mais elevada. A decomposição em torno de $270^{\circ} \mathrm{C}$ está relacionada com o rompimento das ligações químicas que constituem a hemicelulose (ligações $\mathrm{C}-\mathrm{C}, \mathrm{C}-\mathrm{H}, \mathrm{C}-\mathrm{O}$ ). A lignina é o componente que apresenta degradação térmica em temperaturas mais altas, sua decomposição é próxima de $420^{\circ} \mathrm{C}$ para o compósito com $30 \%$ de fibra.
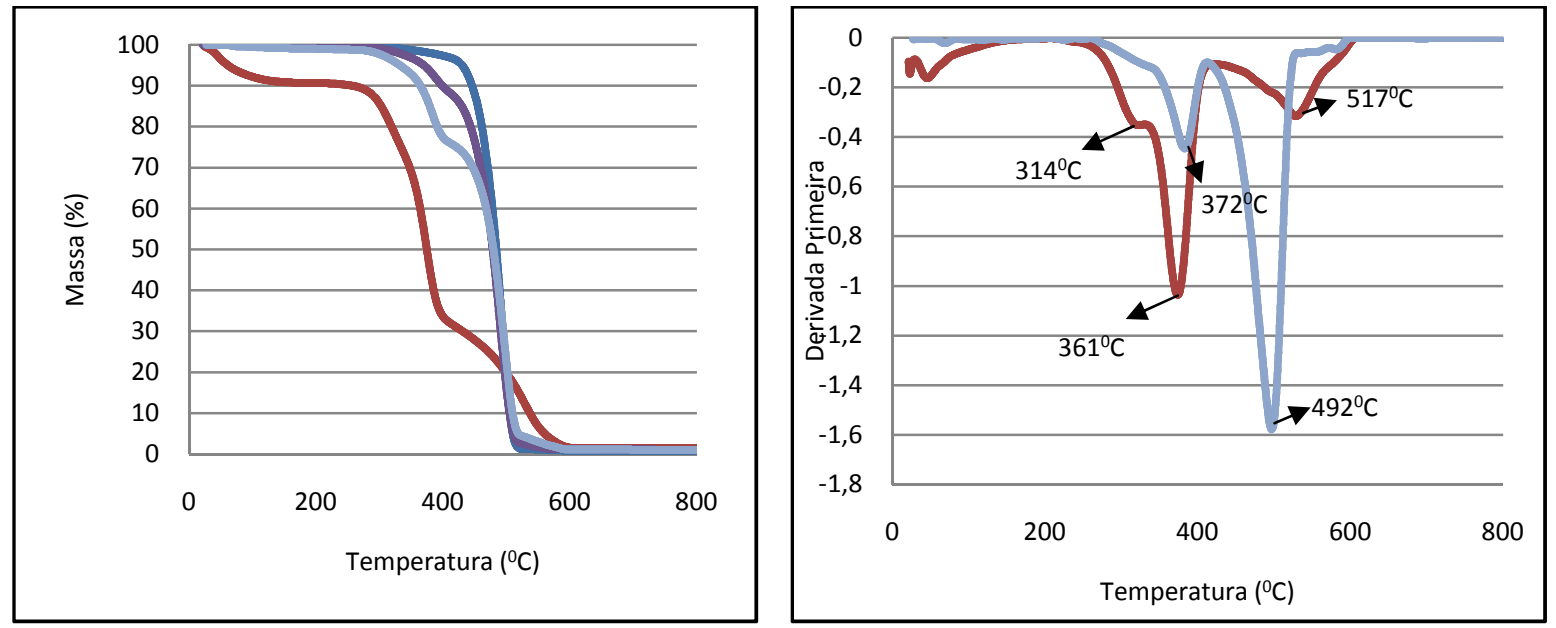

Figura 45: Curvas TG e de derivada a primeira da TG para os compósitos BPEAD, fibra de curauá, 90\%BPEAD/10\%fibra e 70\%BPEAD/30\%fibra, atmosfera de $\mathbf{N}_{\mathbf{2}}$, fluxo de $20 \mathrm{mLmin}^{-1}$ e razão de aquecimento de $10^{\circ} \mathrm{Cmin}^{-1}$.

No intervalo de temperatura considerado, as curvas DSC dos compósitos (Figura 46) mostram um único pico correspondente à temperatura de fusão do BPEAD $\left(130^{\circ} \mathrm{C}\right)$, a partir do qual as entalpias de fusão do BPEAD foram calculadas (Tabela 7).

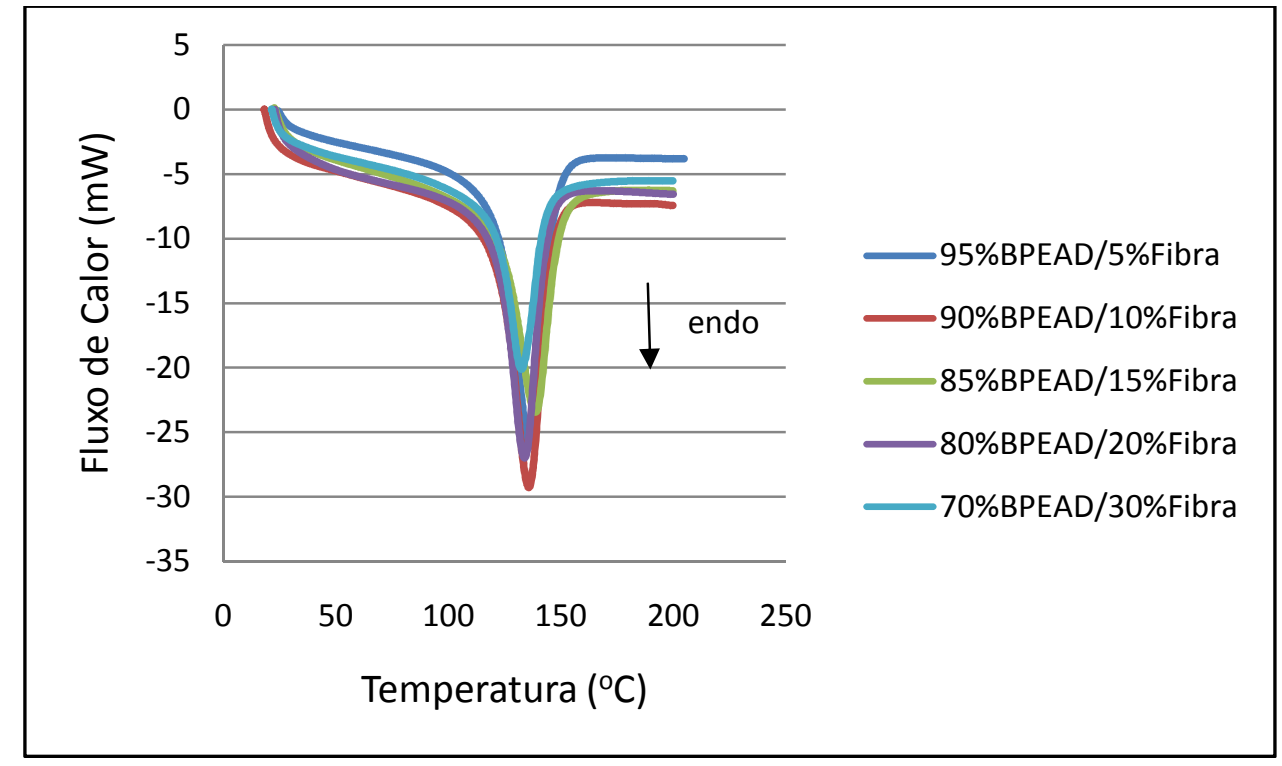

Figura 46: Curvas DSC para os compósitos BPEAD/Fibra de Curauá, atmosfera de $\mathrm{N}_{2}$, fluxo de $20 \mathrm{mLmin}^{-1}$ e razão de aquecimento de $10^{\circ} \mathrm{Cmin}^{-1}$. 
Na Tabela 7 se encontra a razão entre a entalpia de fusão e respectiva fração mássica do BPEAD no material. Esta razão foi considerada por não ser conhecida a constante para o BPEAD 100\% cristalino necessário para cálculo de cristalinidade.

Tabela 7: Entalpias de Fusão

\begin{tabular}{|c|c|c|}
\hline Compósito & $\mathbf{\Delta H}_{\mathbf{f}}\left(\mathbf{J g}^{-1}\right)$ & $\Delta \mathbf{H}_{\mathbf{f}} / \boldsymbol{\varphi}_{\mathbf{m}}$ \\
\hline BPEAD processado & 196,0 & 196 \\
\hline 95\%BPEAD/5\%Fibra & 169,1 & 178 \\
\hline 90\%BPEAD/10\%Fibra & 141,2 & 156,8 \\
\hline 85\%BPEAD/15\%Fibra & 127,9 & 150,4 \\
\hline 80\%BPEAD/20\%Fibra & 126,7 & 158,3 \\
\hline 70\%BPEAD/30\%Fibra & 125,0 & 178,6 \\
\hline
\end{tabular}

Observa-se a variação da relação entre a entalpia de fusão $\left(\Delta \mathrm{H}_{\mathrm{f}}\right)$ e da fração mássica $\left(\varphi_{m}\right)$ para as amostras com $5 \%$ de fibra de curauá $\left(-178 \mathrm{Jg}^{-1}\right)$ em relação ao BPEAD e aquela com $10 \%$ de fibra de curauá $\left(-156,8 \mathrm{Jg}^{-1}\right)$ diminui de modo proporcional à quantidade de fibra contida na amostra. No entanto, para as amostras contendo 15 e $20 \%$ de fibra a relação manteve-se praticamente constante, o que pode ser tomado como indicação que para os compósitos com 15 e 20\% fibra a cristalinidade da matriz não é alterada e que com a adição de $30 \%$ de fibra a cristalinidade é aumentada, possivelmente porque para $30 \%$ de fibra há a separação de fases. Deve-se considerar também que a pequena quantidade de amostra usada nesta análise, não necessariamente representa exatamente a proporção de fibras usada na preparação da placa.

\subsubsection{Análise Térmica Dinâmico-Mecânica (DMTA)}

As propriedades dinâmico-mecânicas dos compósitos são determinadas pelas propriedades de seus componentes, pela morfologia do sistema e pela natureza da interação entre os componentes (ABDELMOULEH et al., 2006). A camada da matriz que recobre as fibras, imediatamente posterior a interface, pode ter propriedades diferentes do restante do material, pois as interações com as fibras podem alterar a mobilidade das cadeias poliméricas da matriz (TRINDADE, 2005; PAIVA, FROLLINI, 2002). 
As Figuras 47, 48 e 49 apresentam as curvas de módulo de armazenamento ( $\left.E^{\prime}\right)$, módulo de perda ( $\left.E^{\prime \prime}\right)$ e tan $\delta$ versus a temperatura, respectivamente, para os compósitos de BPEAD/fibra.

A incorporação de fibras ou cargas na matriz polimérica pode alterar as propriedades mecânicas dos compósitos. No entanto, as propriedades dependem das características da fibra (ANUAR; AHMAD, 2007). A adição de fibra aumenta o módulo de armazenamento em todo intervalo de temperatura, devido ao aumento da rigidez que a adição de fibra provoca no compósito. Dentre os compósitos, não é observado correlação entre o modulo e a porcentagem de fibra presente.

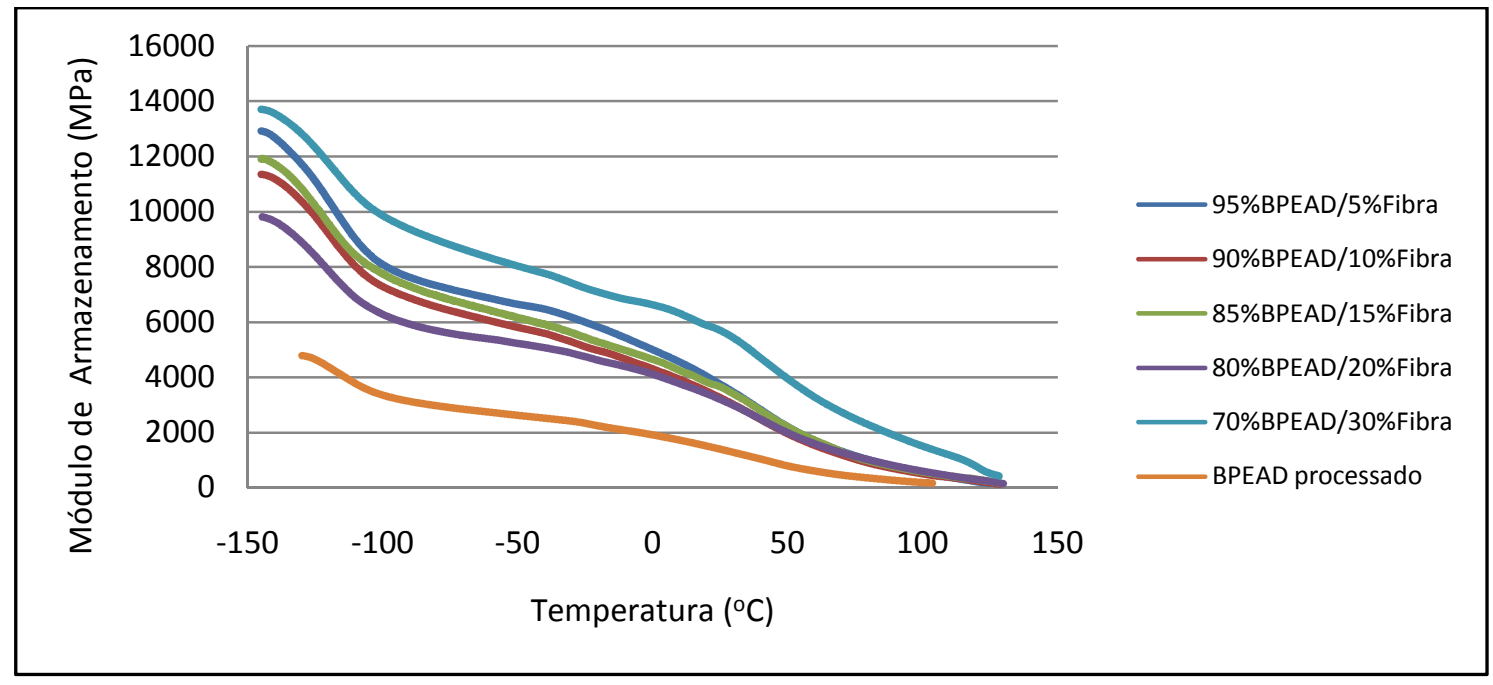

Figura 47: Módulo de armazenamento (E') em função da temperatura para os compósitos BPEAD/fibra de curauá.

O pico observado em torno de $-110^{\circ} \mathrm{C}$ para o BPEAD é deslocado para aproximadamente $-125^{\circ} \mathrm{C}$, à semelhança do observado para as blendas BPEAD/PBHL. O pico em torno de $-60^{\circ} \mathrm{C}$ não é observado nos compósitos e aquele próximo a $35^{\circ} \mathrm{C}$ praticamente não é deslocado do BPEAD para seus compósitos. 


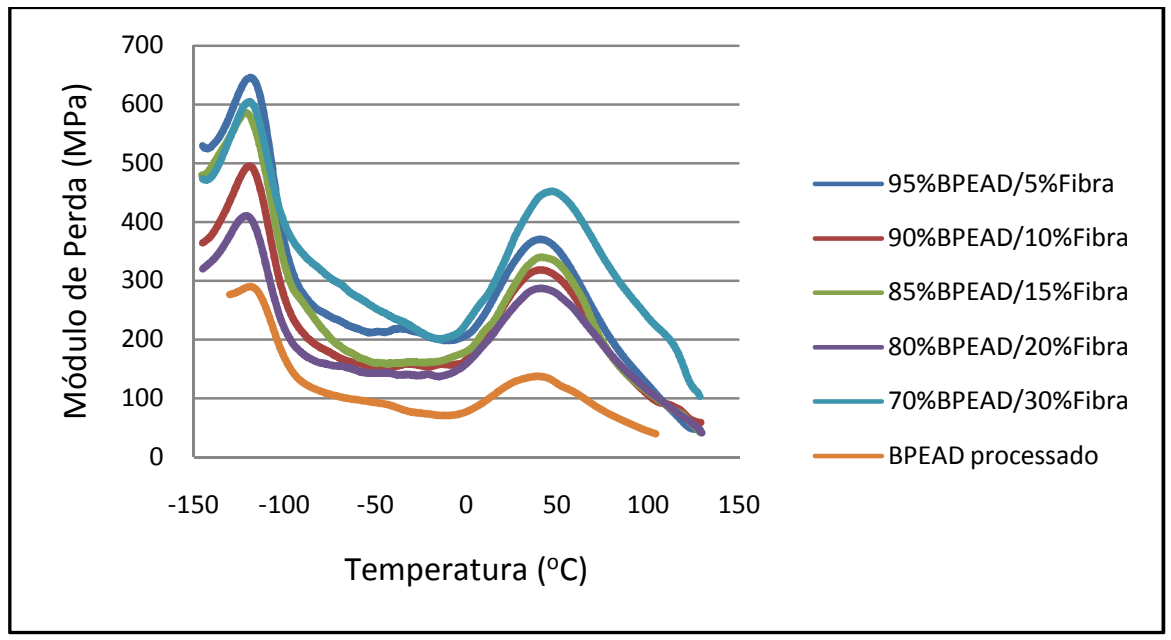

\begin{tabular}{c|c|c|}
\hline BPEAD/Fibra & Transições $\left({ }^{\circ} \mathrm{C}\right)$ \\
\hline BPEAD & -110 & 32,4 \\
\hline $95 / 5$ & -124 & 34,8 \\
\hline $90 / 10$ & $-123,6$ & 36,4 \\
\hline $85 / 15$ & $-125,2$ & 37,2 \\
\hline $80 / 20$ & -126 & 35,6 \\
\hline $70 / 30$ & $-124,2$ & 39 \\
\hline
\end{tabular}

Figura 48: Módulo de perda (E") em função da temperatura para os compósitos BPEAD/fibra de curauá.

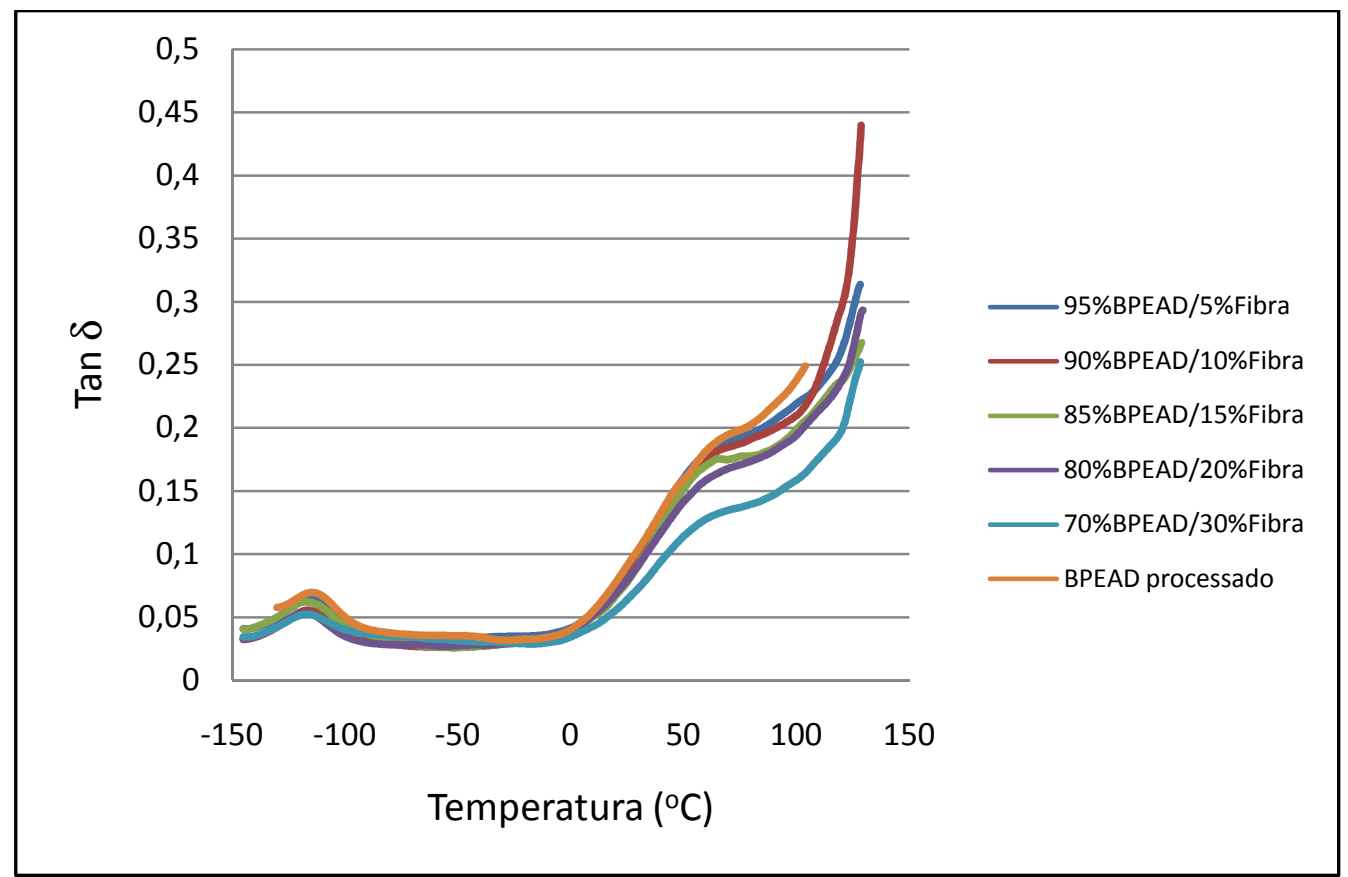

Figura 49: Tan $\delta$ em função da temperatura para os compósitos BPEAD/fibra de curauá.

Pelo mesmo motivo discutido para $\mathrm{E}^{\prime \prime}$, também na curva tan $\delta$ um pico é observado em torno de $-110^{\circ} \mathrm{C}$ e outro em $50^{\circ} \mathrm{C}$. 


\subsubsection{Resistência ao Impacto}

O ensaio de resistência mecânica ao impacto foi realizado de acordo com a norma ASTM D 256. Considerou-se para efeito de cálculo no mínimo os resultados dos cinco corpos de prova, conforme estabelecido pela norma.

Em geral, os compósitos de matriz termoplástica reforçados com fibras vegetais apresentam uma queda na resistência ao impacto com a adição de fibras (JARUKUMJORN; SUPPAKARN, 2009).

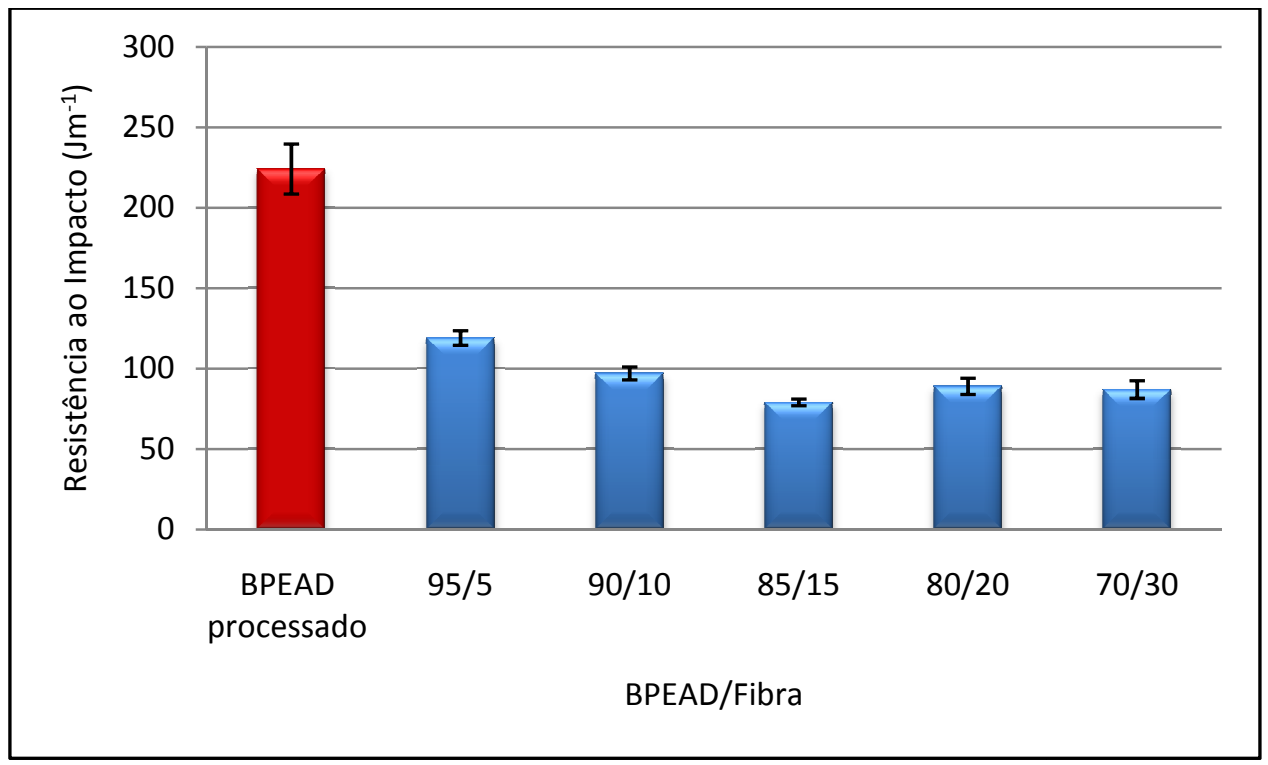

Figura 50: Resistência ao impacto Izod do compósito fibra/matriz para corpos de prova com entalhe.

Com a adição de fibra ao compósito há um aumento da rigidez do material, assim, observa-se uma diminuição da resistência ao impacto do material, já que este se torna menos dúctil se comparado ao BPEAD, corroborando com o aumento de E' apresentado anteriormente.

A resistência ao impacto de $119 \mathrm{Jm}^{-1}$ para $79 \mathrm{Jm}^{-1}$ para o compósito com $5 \%$ de fibra relativamente com $15 \%$ de fibra, pode estar relacionado com o comportamento frágil apresentado pelo compósito com o aumento do teor de fibra. Além disso, a probabilidade de aglomeração de fibra também aumenta, criando regiões de concentração de tensões que 
requerem menos energia para dar início ou propagar uma trinca (LEÃO; CARVALHO; FROLLINI, 1997).

O entalhe inserido num corpo de prova reduz drasticamente a resistência ao impacto do material ensaiado, criando uma concentração de tensão localizada (CANEVAROLO, 2004), assim, o material também foi analisado utilizando corpos de prova não entalhados (Figura 51). Pode-se observar uma queda da resistência ao impacto dos compósitos com 15, 20 e $30 \%$ de fibra, comparativamente a 5 e 10\%. Todos os materiais apresentam maior resistência, com relação aos corpos de prova entalhados.

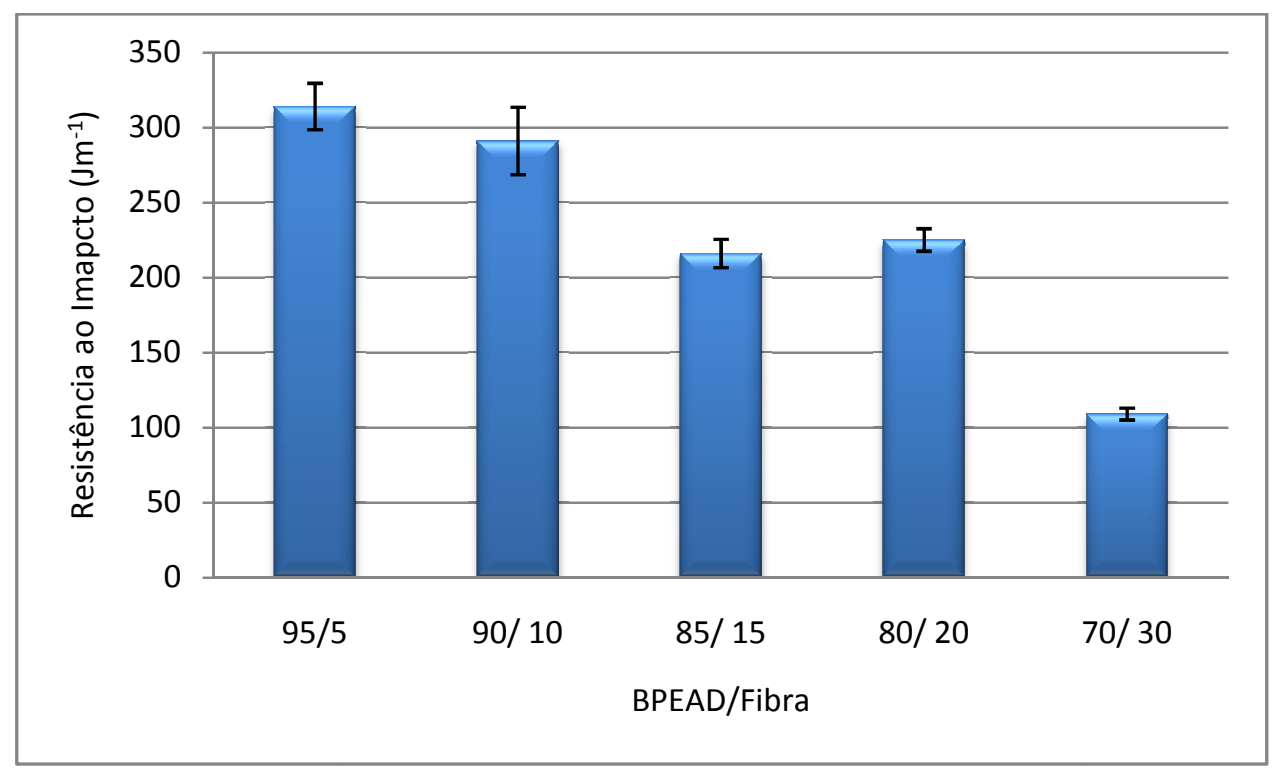

Figura 51: Resistência ao impacto Izod do compósito fibra/matriz para corpos de prova sem entalhe.

Santos e cols. (2009) avaliaram o uso de fibras de curauá no compósito de poliamida6, observando uma diminuição na resistência ao impacto dos compósitos, independente do teor e do tamanho da fibra adicionada.

\subsubsection{Microscopia Eletrônica de Varredura}

As figuras a seguir mostram imagens das fraturas, após o ensaio de impacto, das amostras dos compósitos reforçados com fibras de curauá.

A observação da superfície de fratura dos corpos de prova indica que várias fibras sofreram "pull out" (arrancamento da fibra) resultando em "vazios" e fibras que sofreram 
"descolamento" na superfície de fratura devido à fraca interação entre a fibra e a matriz (Figura 52 (a) e (b)).

Observa-se também que houve uma boa dispersão das fibras no polímero (Figura 52 (c) e (d)).

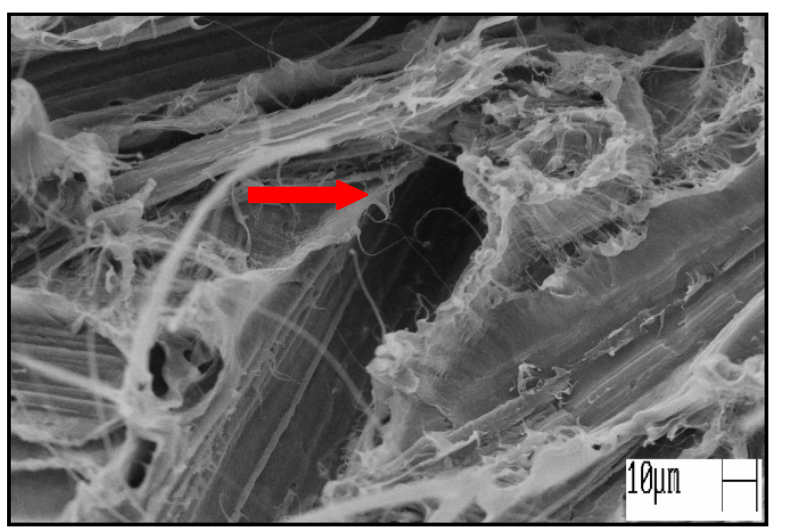

(a)

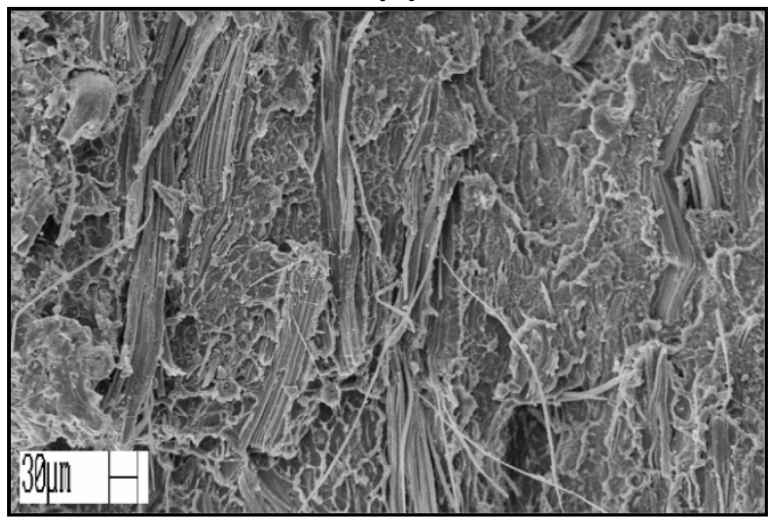

(c)

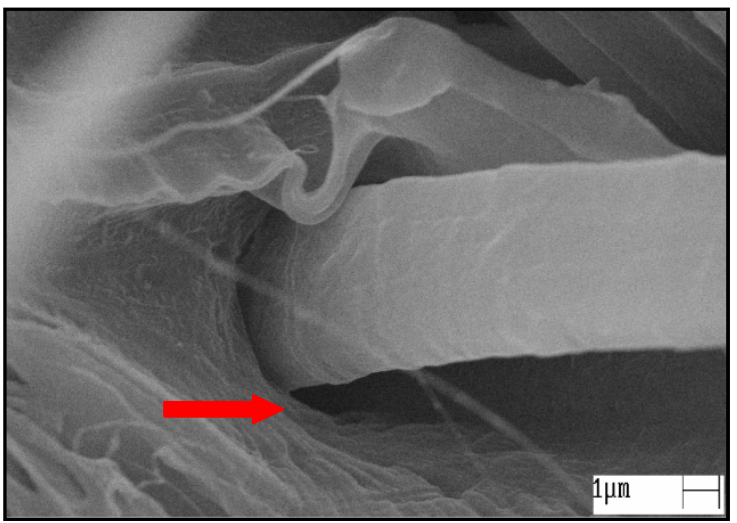

(b)

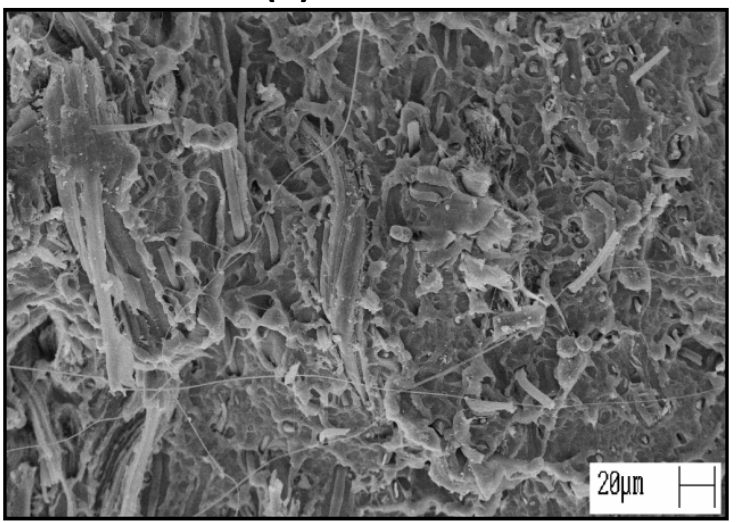

(d)

Figura 52: Micrografias obtidas por MEV a partir da superfície de fratura dos compósitos:

(a) adição de $5 \%$ de fibra e (b); (c) adição de $10 \%$ de fibra, (d) adição de $15 \%$ de fibra.

\subsubsection{Resistência à Flexão}

Nas Figuras 53 e 54 estão representados os resultados de módulo e resistência à flexão para os compósitos de BPEAD/fibra e para o BPEAD.

Pode-se observar um aumento do módulo de flexão quando é adicionada fibra à matriz, como consequência a aumento da fragilização do compósito quando a fibra de curauá é adicionada (KAYNAC; ORGUN; TINCER, 2005). 


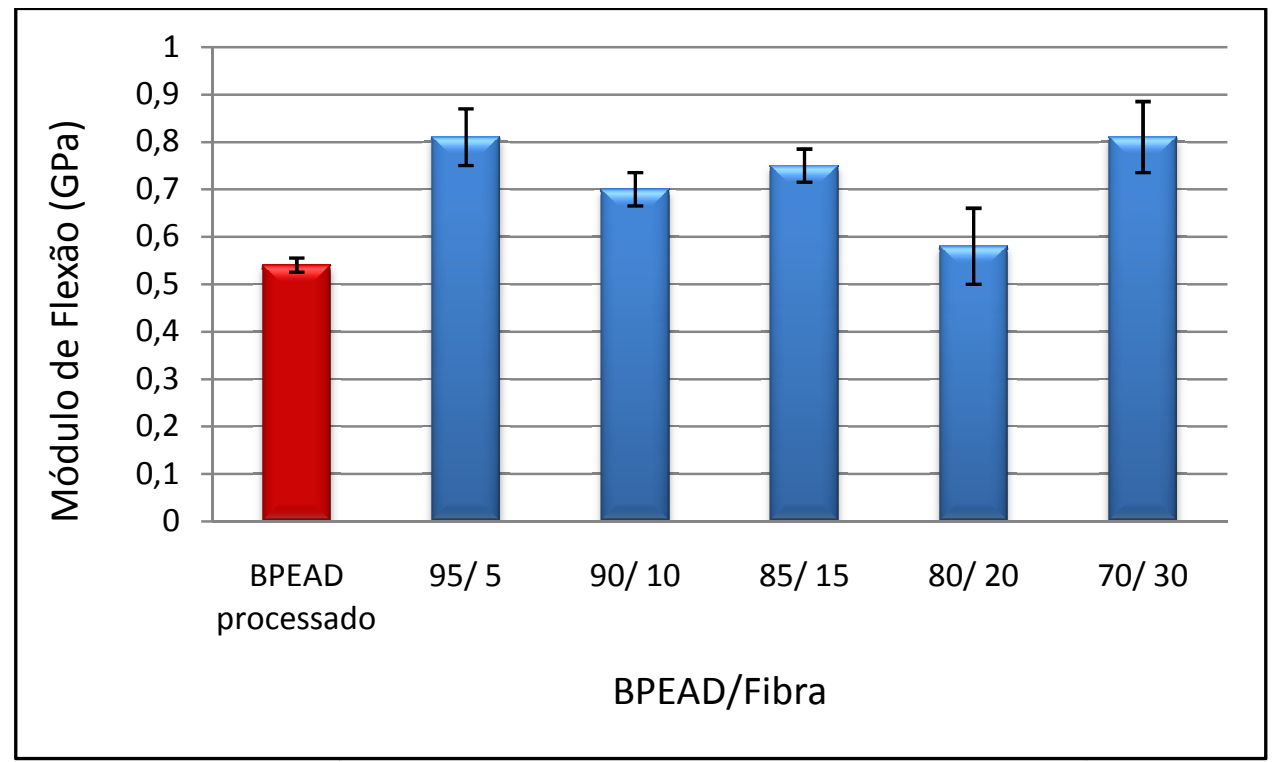

Figura 53: Módulo de flexão dos compósitos reforçados com diferentes frações de fibra de curauá (em massa).

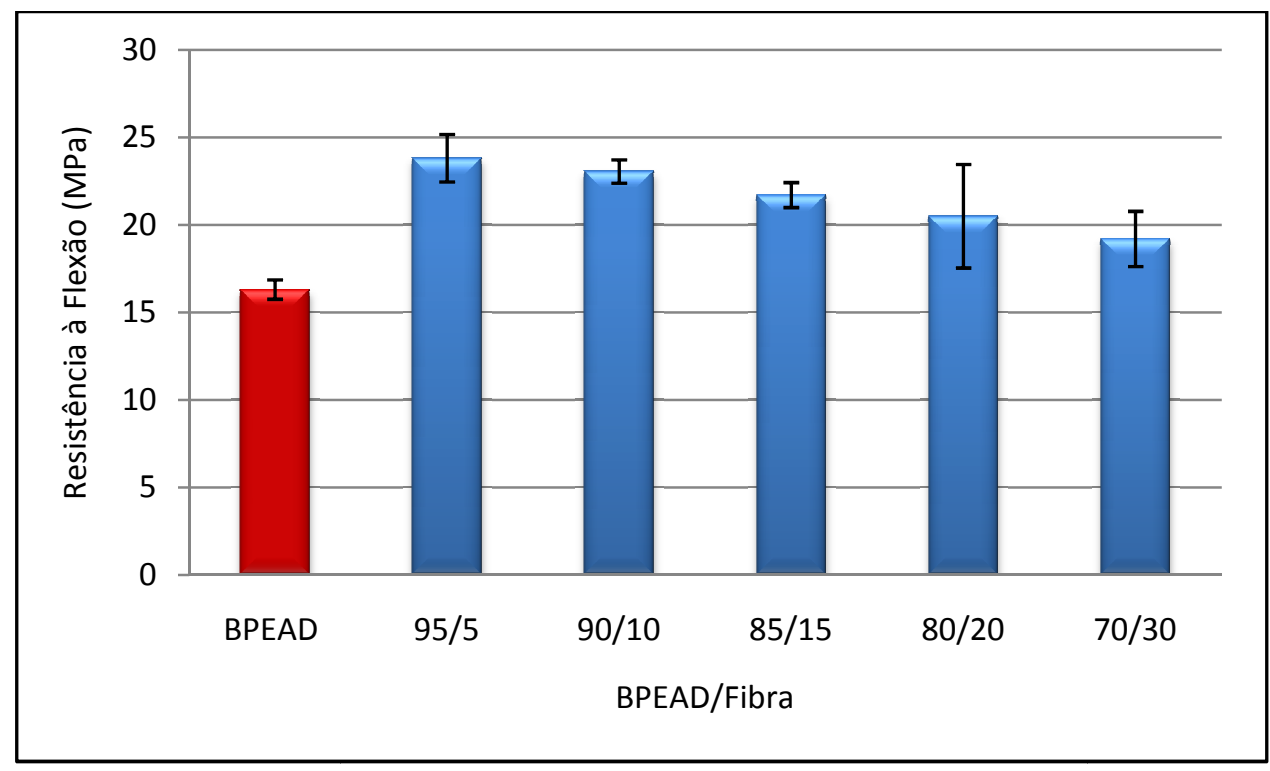

Figura 54: Resistência à flexão dos compósitos reforçados com diferentes frações de fibra de curauá (em massa).

Não há uma correlação entre a porcentagem de fibras e o módulo de flexão do compósito. Assim, pode-se substituir até $30 \%$ do polímero pela fibra observando-se o mesmo efeito praticamente de $5 \%$ de fibra (Figuras 53 e 54).

Observa-se uma tendência de diminuição de resistência à flexão, conforme aumenta a proporção de fibras, embora os desvios aproximem os valores. A adição de $5 \%$ de fibras à 
matriz aumenta razoavelmente o módulo, o que pode ser atrativo para aplicações em que a resistência à flexão seja importante.

\subsubsection{Absorção de água}

Os ensaios de absorção de água permitem avaliar propriedades como a estabilidade dimensional dos materiais e a interface fibra/matriz. E importante ressaltar que as condições nas quais as amostras foram submetidas neste ensaio foram mais agressivas do que aquelas em que normalmente estes materiais são utilizados.

A Figura 55 mostra o perfil de absorção de água do compósito de BPEAD reforçados com fibra de curauá e do BPEAD.

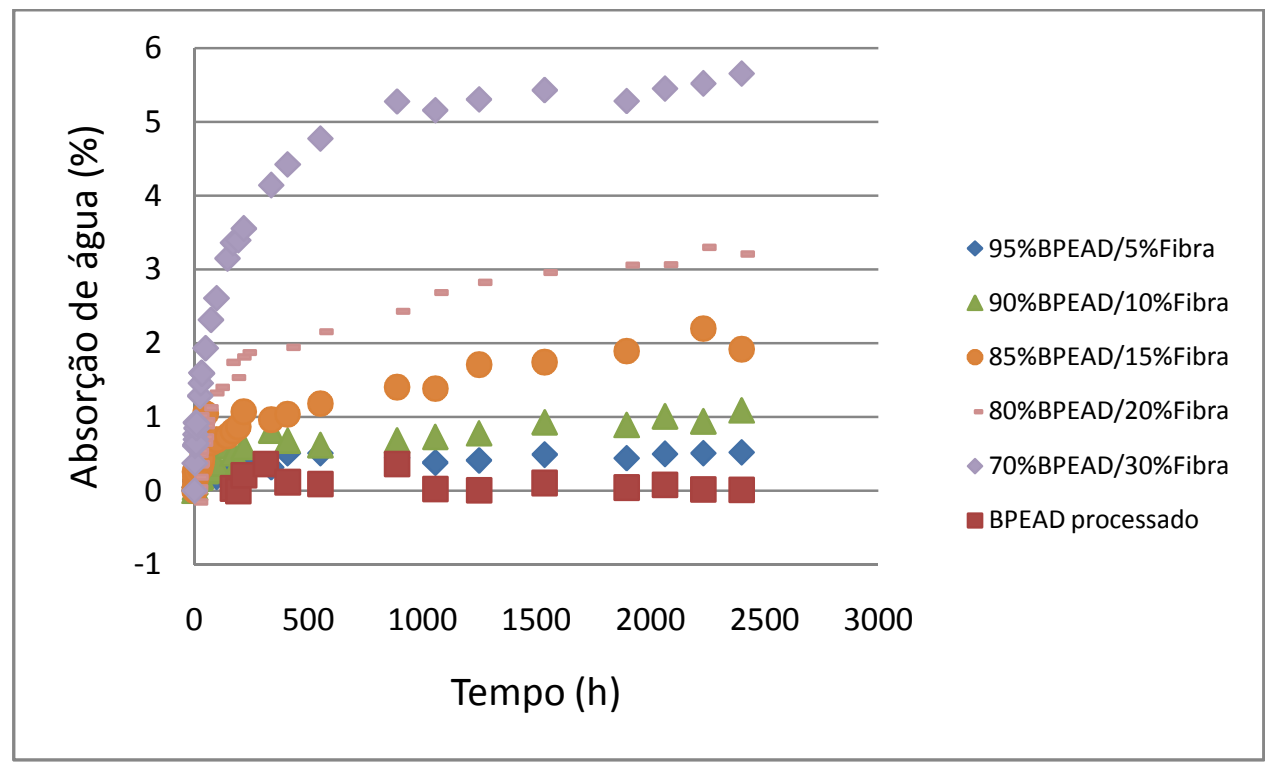

Figura 55: Absorção de água dos compósitos de BPEAD/fibra de curauá e para o BPEAD.

Os compósitos contendo fibras de curauá apresentaram aumento na porcentagem de absorção de água conforme aumenta a porcentagem de fibra na matriz, devido ao caráter hodrofílico da fibra de curauá. No entanto, até $15 \%$ de fibra, a porcentagem de água absorvida pode ser considerada como muito pequena, tendo em vista que o corpo de prova estava imerso em água, sem nenhuma proteção nas laterais. Pode-se observar que a saturação ocorre em aproximadamente 1000 horas para o compósito com diferentes composições de curauá adicionado. 


\subsubsection{Coeficiente de Difusão (D)}

Os valores apresentados na Tabela 8 foram obtidos aplicando-se as equações relacionadas à teoria de Fick, descritas na parte experimental. Para todos os materiais, podese considerar que o comportamento se aproxima do fickiano devido a linearidade dos gráficos de massa de água absorvida pelo material (Mt/Moo) em função de $t^{1 / 2} L^{-1}$.

Devido ao caráter hidrofílico do BPEAD, na ausência de fibras praticamente não foi observado absorção de água e portanto, esta amostra não foi avaliada segundo o modelo de Fick.

Tabela 8: Coeficiente de difusão, $\mathrm{D}$ e constante de afinidade, $\mathrm{k}$ para compósitos de matriz de BPEAD e fibra de Curauá.

\begin{tabular}{|c|c|c|}
\hline Compósito & $\mathbf{D}\left(\mathbf{m m}^{\mathbf{2}} \mathbf{h}^{-\mathbf{1}}\right) \mathbf{1 0}^{-\mathbf{3}}$ & $\mathbf{k}$ \\
\hline 95\%BPEAD/5\%Fibra & 2,5 & 0,05 \\
\hline 90\%BPEAD/10\%Fibra & 2,3 & 0,03 \\
\hline 85\%BPEAD /15\% Fibra & 2,8 & 0,03 \\
\hline 80\%BPEAD/20\% Fibra & 2,9 & 0,05 \\
\hline 70\%BPEAD/30\% Fibra & 2,7 & 0,06 \\
\hline
\end{tabular}

A difusão de água no interior de um compósito é influenciada pelo estabelecimento de ligações hidrogênio entre água e matriz polimérica e/ou fibras. Neste trabalho, devido à presença de muitos grupos polares nas fibras, muitas e intensa ligações de hidrogênio são estabelecidas entre a água e a fibra, desacelerando as moléculas de água, que então levarão mais tempo para se difundir no interior do material, diminuindo o seu coeficiente de difusão (D). No caso da matriz, neste caso não são estabelecidas interações com a água.

Os valores de $\mathrm{k}$ (Tabela 8) mostram que a utilização de BPEAD como matriz levou a baixa afinidade por água pelos compósitos, devido ao caráter hidrofóbico do BPEAD. A variação no coeficiente de difusão foi pequena, considerando todos os compósitos mesmo com a variação de 5 a 30\% de fibras. 


\subsection{Adição de Polibutadieno Hidroxilado (PBHL) aos Compósitos reforçados com Fibra de}

Curauá

\subsubsection{Preparação dos compósitos em misturador interno}

O processo de mistura de BPEAD, PBHL e fibra de curauá foi analisado através da reometria de torque. As Figuras 56 e 57 mostram as curvas de torque para os compósitos de BPEAD/PBHL/Fibra em diferentes composições.

$\mathrm{Na}$ Figura 56, pode-se observar dois picos durante a mistura dos componentes do compósito. O primeiro está relacionado com o carregamento da fibra na câmara de mistura, seguido de sua fusão do polietileno, e consequentemente, queda do torque; o segundo aumento no torque está relacionado com o aumento de viscosidade, o qual é significativo a partir de aproximadamente 1 min de mistura (ARAÚJO; HAGE JR., CARVALHO, 2003).

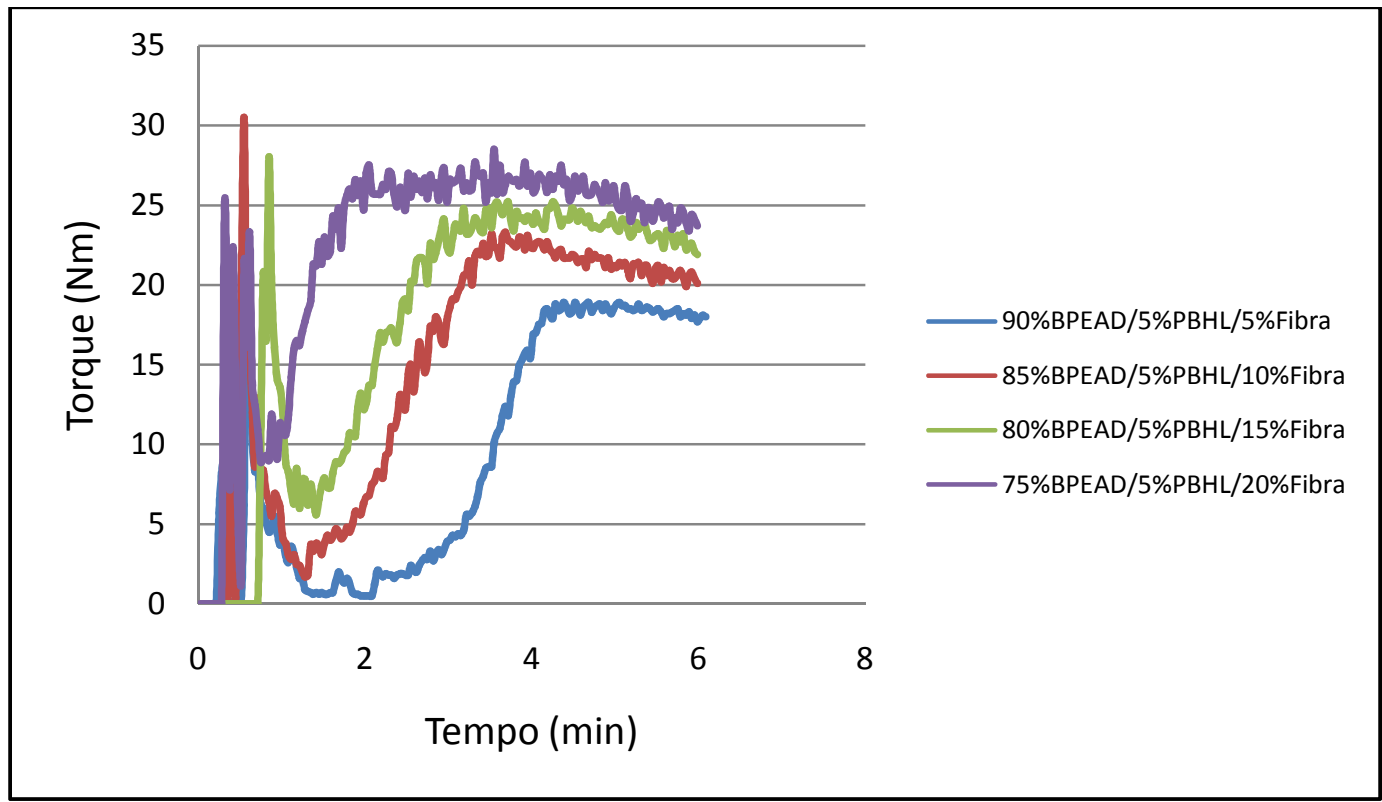

Figura 56: Curvas de Processamento dos compósitos BPEAD/5\%PBHL/Fibra.

O aumento significativo no torque está relacionado com o aumento da viscosidade da mistura quando a fibra de curauá é adicionada. Durante o processamento, os materiais poliméricos estão sujeitos a diferentes esforços que poderão causar a degradação ou gerar grupos químicos que irão iniciar ou acelerar o processo de degradação (DE PAOLI, 2009). 
A Figura 57 mostra a curva de processamento para os compósitos com $30 \%$ de fibra de curauá.

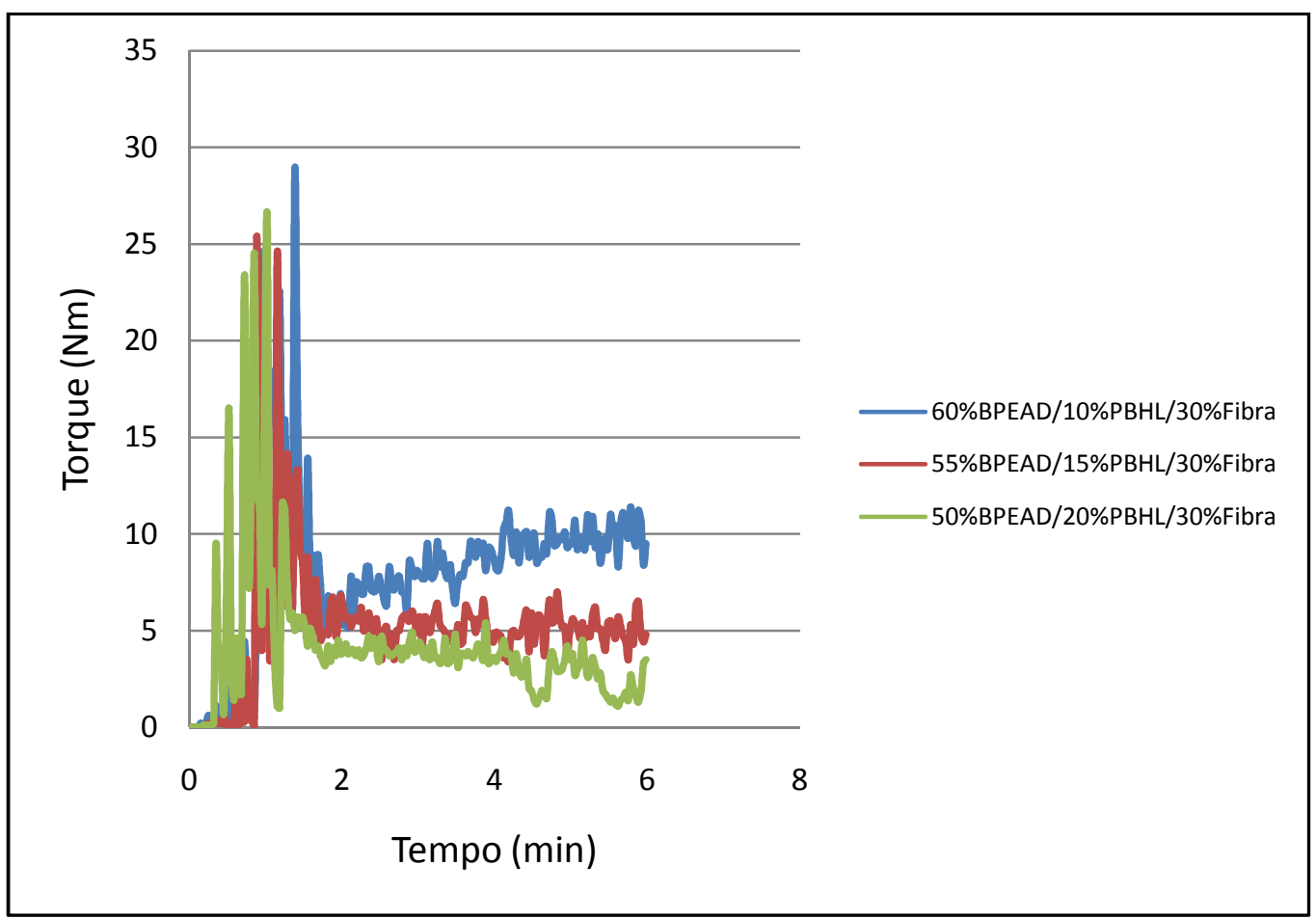

Figura 57: Curvas de Processamento dos compósitos de BPEAD/PBHL/30\%Fibra.

Quando o sistema apresenta 30\% de Fibra de Curauá (Figura 57), o torque se mantém abaixo daqueles das misturas anteriormente mencionadas, indicando que, provavelmente, os grupos polares presentes no PBHL não interagem tão eficientemente se comparado aos compósitos BPEAD/5\%PBHL/Fibra com os grupos polares presentes na superfície da fibra, já que o volume de fibra é relativamente alto para interagir com a matriz BPEAD/PBHL.

\subsubsection{Análise Térmica}

As Figuras 58 e 59 apresentam as curvas TG, dTG (derivada primeira da TG).

As curvas TG mostram perda de massa de $5 \%$ em torno de $100^{\circ} \mathrm{C}$, que pode ser atribuída à perda de água aderida as fibras de curauá. Até $260^{\circ} \mathrm{C}$ as fibras de curauá possuem estabilidade térmica, quando então ocorre o início da decomposição, correspondente ao início da decomposição da hemicelulose, seguida da celulose. Em torno de $400^{\circ} \mathrm{C}$ observa-se uma mudança de inclinação na curva devido ao início de outro processo de decomposição, envolvendo quebra das ligações da lignina, prosseguindo rapidamente 
com o aumento de temperatura até ocorrer à perda de massa quase total em torno de $600^{\circ} \mathrm{C}$ (SATYANARAYANA; GUIMARÃES; WYPYCH, 2007).

É possível observar que a degradação se apresenta de forma mais intensa nos compósitos do que na matriz termoplástica devido ao fato que a presença de fibra lignocelulósica diminui a estabilidade térmica do material.

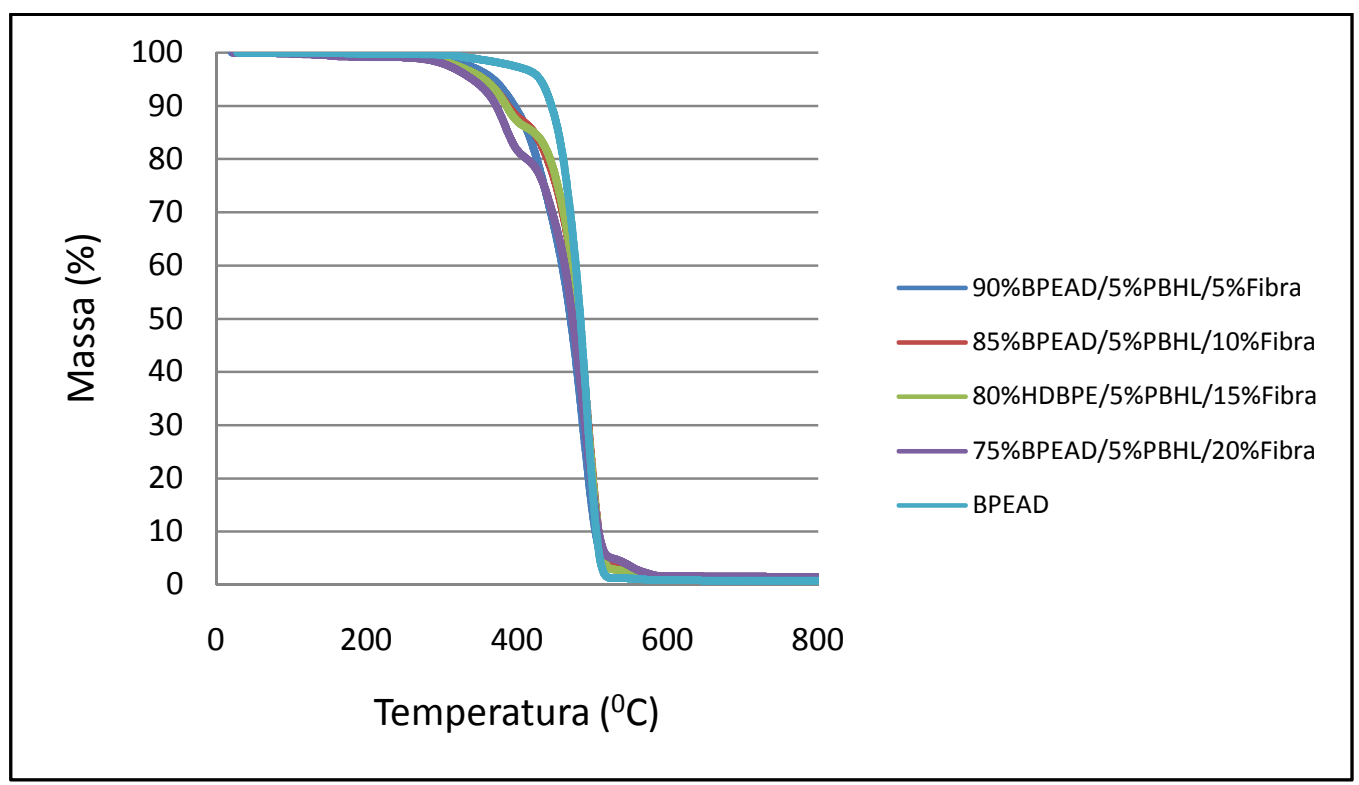

Figura 58: Curvas TG para os compósitos BPEAD/5\%PBHL/fibra de curauá e para o BPEAD, atmosfera de $\mathrm{N}_{2}$, fluxo de $20 \mathrm{mLmin}^{-1}$ e razão de aquecimento de $10^{\circ} \mathrm{Cmin}^{-1}$.

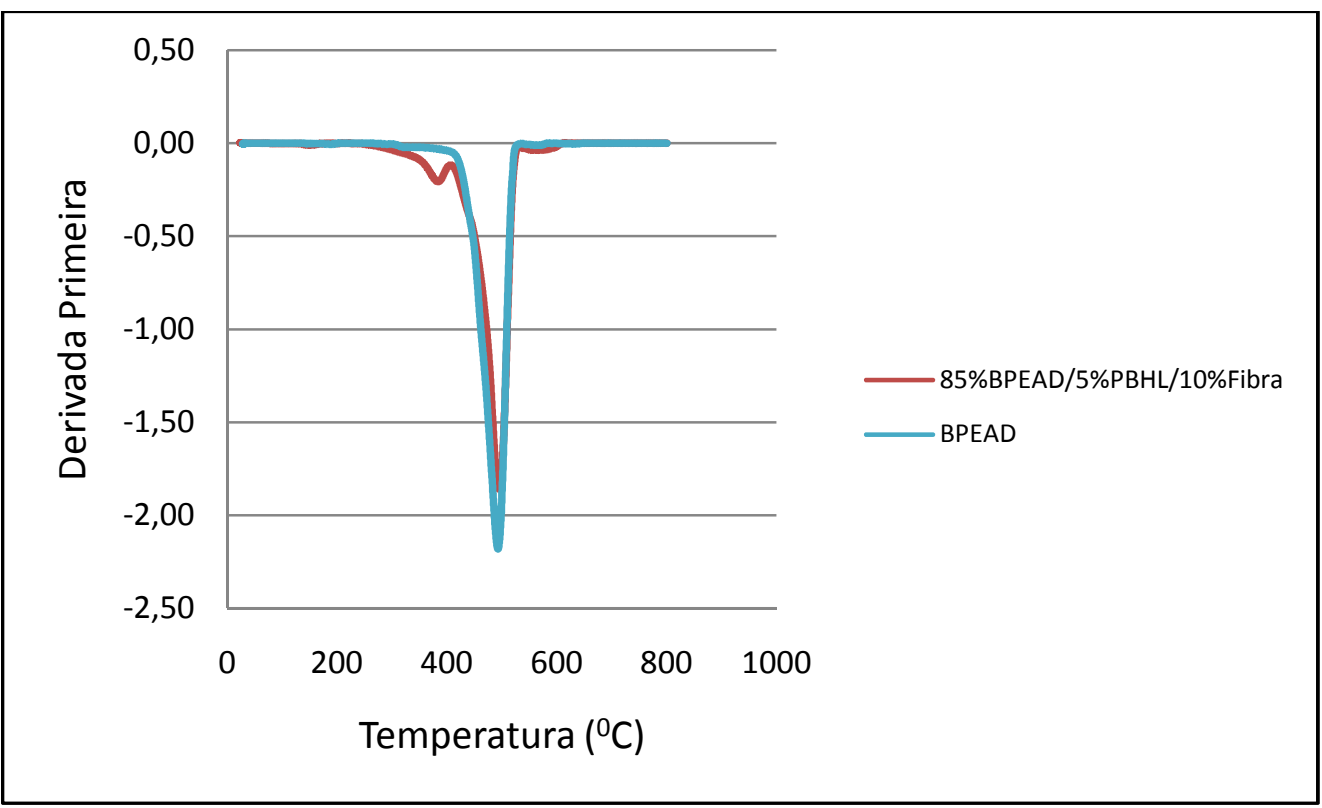

Figura 59: Curva derivada primeira da TG para o compósito 85\%BPEAD/5\%PBHL/10\%fibra de curauá e para o BPEAD. 
É possível observar que a degradação se apresenta de forma mais intensa nos compósitos, proporcionalmente a adição de um maior teor de fibras (Figura 60).

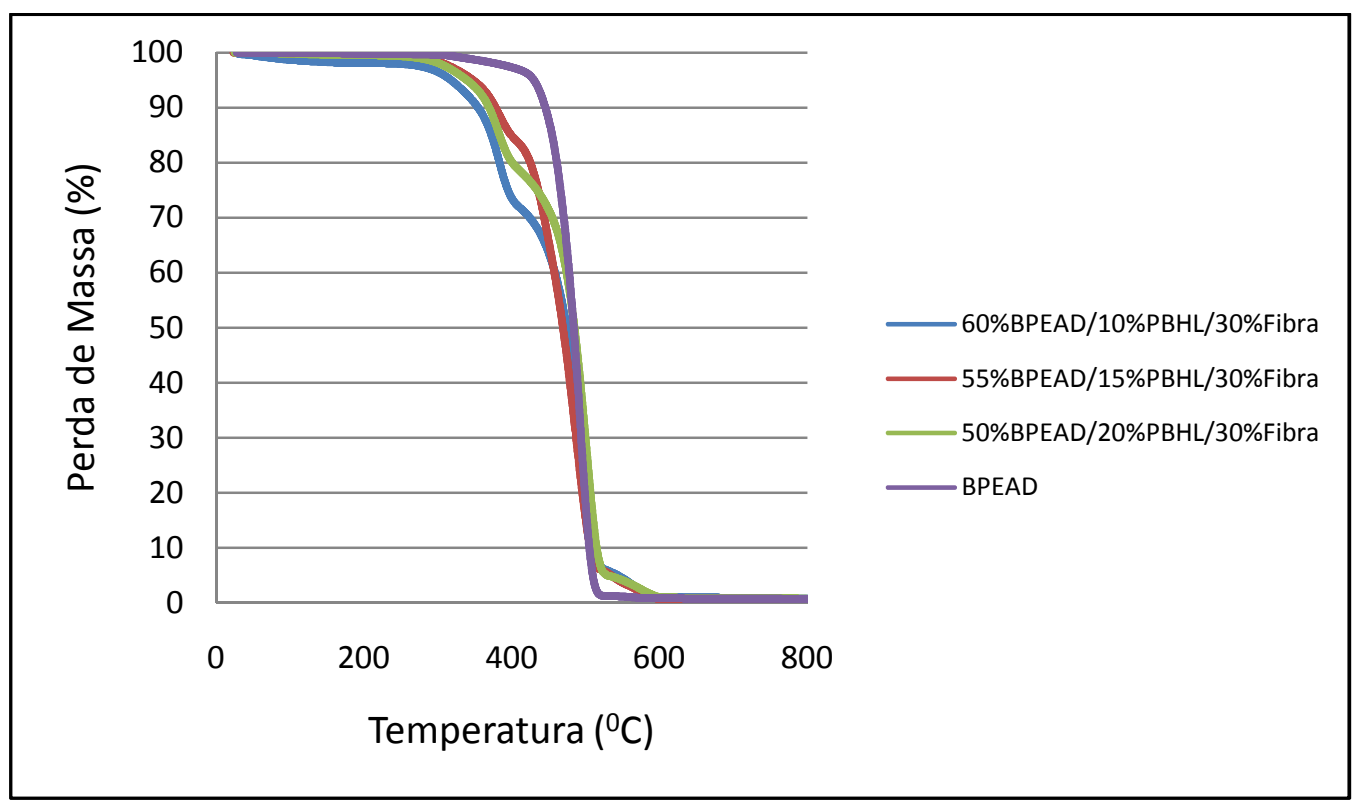

Figura 60: Curvas TG para os compósitos BPEAD/PBHL/ 30\%fibra de curauá e para o BPEAD, atmosfera de $\mathrm{N}_{2}$, fluxo de $20 \mathrm{mLmin}^{-1}$ e razão de aquecimento de $10^{\circ} \mathrm{Cmin}^{-1}$.

O evento observado nas curvas DSC dos compósitos (Figura 61) corresponde a um pico endotérmico, relacionado à temperatura de fusão do BPEAD, a presença de um pico estreito é característica de materiais semicristalinos como o BPEAD (MAZUR et al., 2008). Este pico aparece em torno de $130^{\circ} \mathrm{C}$ para os diferentes compósitos mostrados na Figura 61.

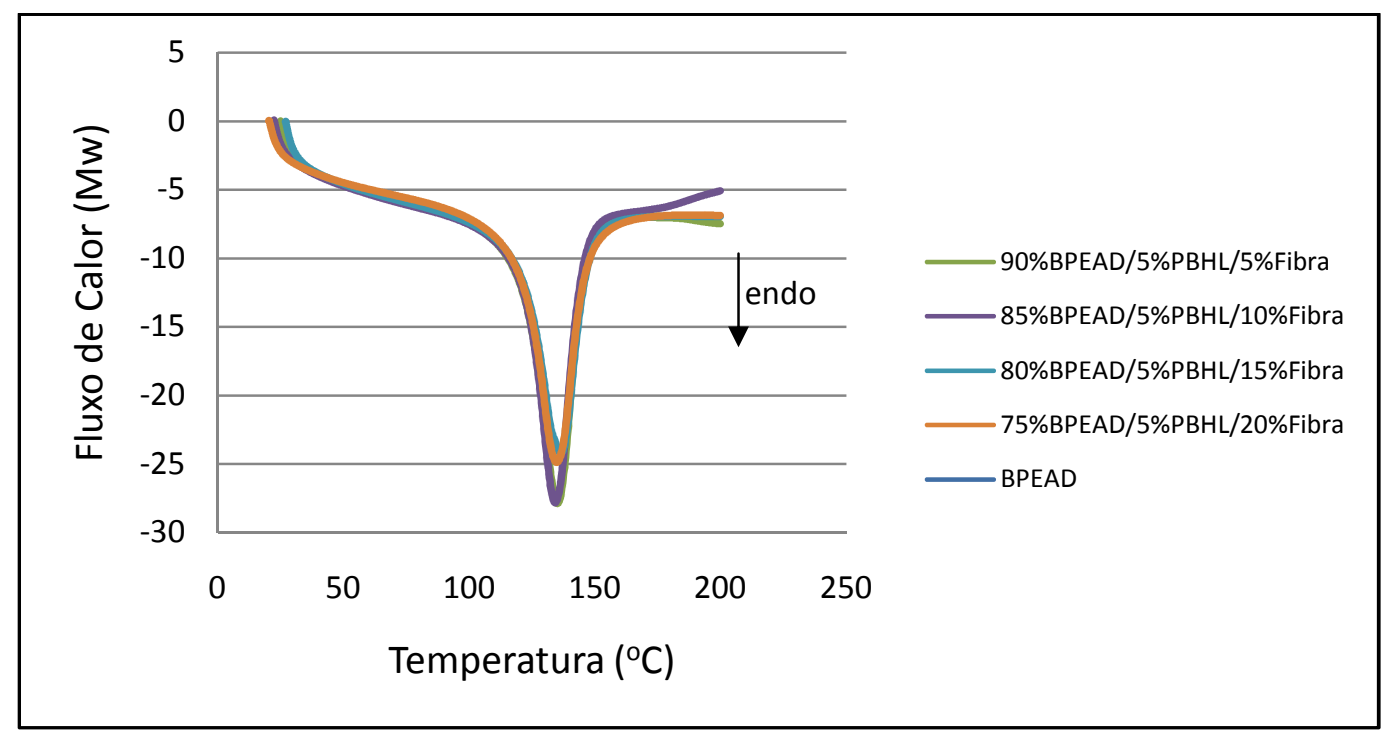

Figura 61: Curvas DSC para os compósitos BPEAD/5\%PBHL/fibra de curauá e para o BPEAD, atmosfera de $\mathrm{N}_{2}$, fluxo de $20 \mathrm{mLmin}^{-1}$ e razão de aquecimento de $10^{\circ} \mathrm{Cmin}^{-1}$. 
A partir das curvas DSC obtidas para os compósitos e BPEAD, podem ser obtidos os valores das $\Delta \mathrm{H}_{\mathrm{f}}$ para os compósitos com diferentes porcentagens de PBHL e fibra. Na Tabela 9 são apresentadas as entalpias de fusão $\left(\Delta \mathrm{H}_{f}\right)$ para os compósitos e para o BPEAD, assim como a razão entre $\Delta \mathrm{H}_{\mathrm{f}}$ e a fração mássica $/ \varphi_{\mathrm{m}}$

Tabela 9: Entalpias de fusão

\begin{tabular}{|c|c|c|}
\hline Compósito & $\Delta \mathbf{H}_{\mathbf{f}}\left(\mathrm{Jg}^{-1}\right)$ & $\Delta \mathbf{H}_{\mathrm{f}} / \varphi_{\mathrm{m}}$ \\
\hline BPEAD processado & 196,0 & 196,0 \\
\hline 90\%BPEAD/5\%PBHL/5\%Fibra & 145,0 & 161,1 \\
\hline 85\%BPEAD/5\%PBHL/10\%Fibra & 142,0 & 167,0 \\
\hline 80\%BPEAD/5\%PBHL/15\%Fibra & 144,8 & 181,0 \\
\hline 75\%BPEAD/5\%PBHL/20\%Fibra & 143,9 & 191,8 \\
\hline 60\%BPEAD/10\%PBHL/30\%Fibra & 103,9 & 173,2 \\
\hline 55\%BPEAD/15\%PBHL/30\%Fibra & 92,9 & 168,9 \\
\hline 50\%BPEAD/20\%PBHL/30\%Fibra & 88,0 & 176,0 \\
\hline
\end{tabular}

As razões entre as entalpias de fusão e as frações mássica do BPEAD do compósito com 5 e 10\% de fibra adicionada, são menores que a do BPEAD, e proporcional ao teor de fibra, indicando diminuição da cristalinidade da matriz, indo ao encontro dos resultados das blendas de BPEAD/PBHL (Tabela 6).

Para as amostras contendo 15 e $20 \%$ de fibra, na presença de $5 \%$ de PBHL são observadas diferenças significativas, sugerindo um aumento na cristalinidade da matriz, com relação aos outros compósitos. No entanto, para 30 \% de fibras e 10, 15 e 20\% de PBHL não são praticamente observadas diferenças na relação $\Delta \mathrm{Hm} / \varphi_{\mathrm{m}}$.

\subsubsection{Análise térmica-dinâmico-mecânica}

Conforme aumenta a fração da fibra de curauá no compósito, a partir de 5\%, observa-se o aumento da rigidez do material, evidenciado pelos maiores valores de módulo de armazenamento apresentados pelos compósitos contendo maior teor de fibras (10 $20 \%)$ em todo o intervalo de temperatura considerado, como indicado na Figura 62. 


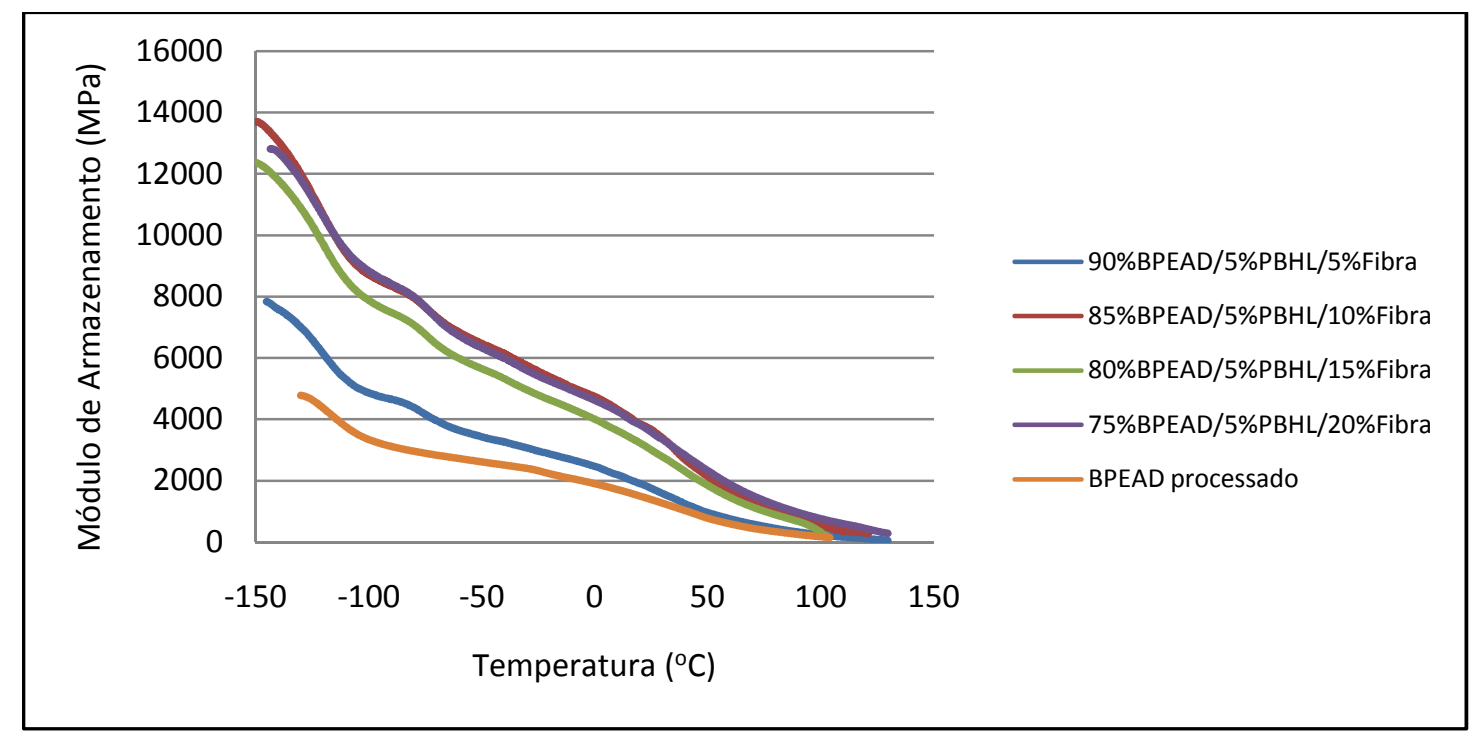

Figura 62: Módulo de armazenamento ( $\left.E^{\prime}\right)$ em função da temperatura para os compósitos BPEAD/PBHL/fibra de curauá.

Nas Figuras 63 e 64 estão mostradas curvas, para o módulo de perda ( $E^{\prime \prime}$ ) e $\tan \delta$ em função da temperatura, obtido no ensaio dinâmico térmico-mecânico.

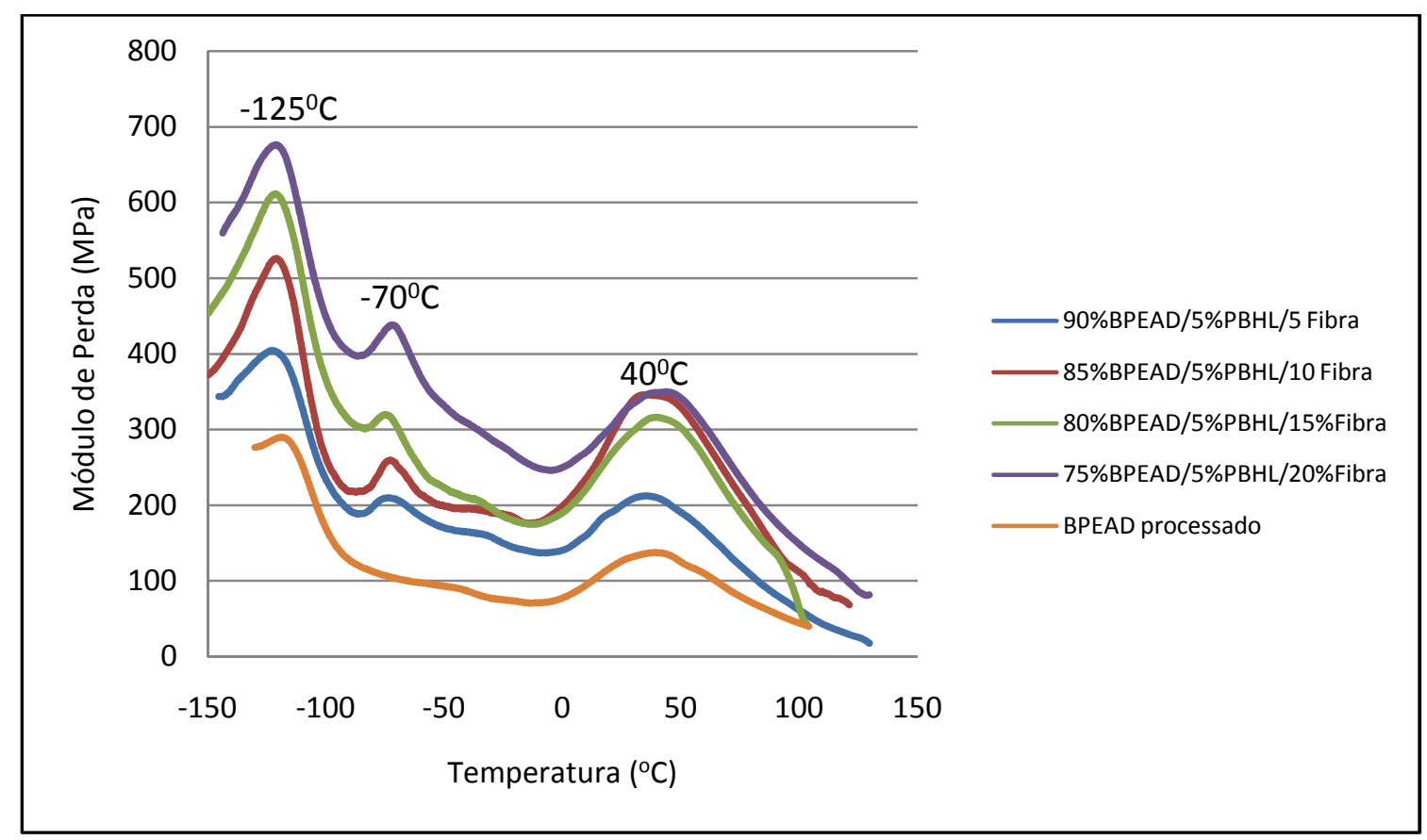

Figura 63: Módulo de perda (E") em função da temperatura para os compósitos BPEAD/PBHL/fibra de curauá.

Para os compósitos BPEAD/PBHL/fibras o pico a mais baixa temperatura aparece em torno de $-125^{\circ} \mathrm{C}$, como observado para BPEAD/fibras (Figura 48), o pico entre -75 e $-50{ }^{\circ} \mathrm{C}$, 
observado para BPEAD/PBHL, é também aqui observado e o pico em torno de $35^{\circ} \mathrm{C}$ é observado, como ocorreu com todos os materiais avaliados via DMTA, sendo característica de relaxações envolvendo cisalhamento da região interlamelar (PEGORETTI et al., 2000). Um deslocamento no sentido de maior temperatura é observado para os compósitos (Tabela 10).

Tabela 10: Relaxações típicas do BPEAD e dos respectivos compósitos.

\begin{tabular}{|c|c|c|c|}
\cline { 2 - 4 } \multicolumn{1}{c|}{} & \multicolumn{3}{c|}{ Relaxações (C) } \\
\hline BPEAD não processado & $-120,0$ & $-60,2$ & 36,0 \\
\hline 90\%HDPE/ 5\% PBHL/ 5\% Fibra & $-122,02$ & $-73,21$ & 36,52 \\
\hline 85\%HDPE/ 5\% PBHL/ 10\% Fibra & $-121,1$ & $-73,4$ & 39,78 \\
\hline 80\%HDPE/ 5\% PBHL/ 15\% Fibra & $-121,1$ & $-73,6$ & 40,86 \\
\hline 75\%HDPE/5\% PBHL/ 20\% Fibra & $-121,27$ & $-72,04$ & 40,92 \\
\hline
\end{tabular}

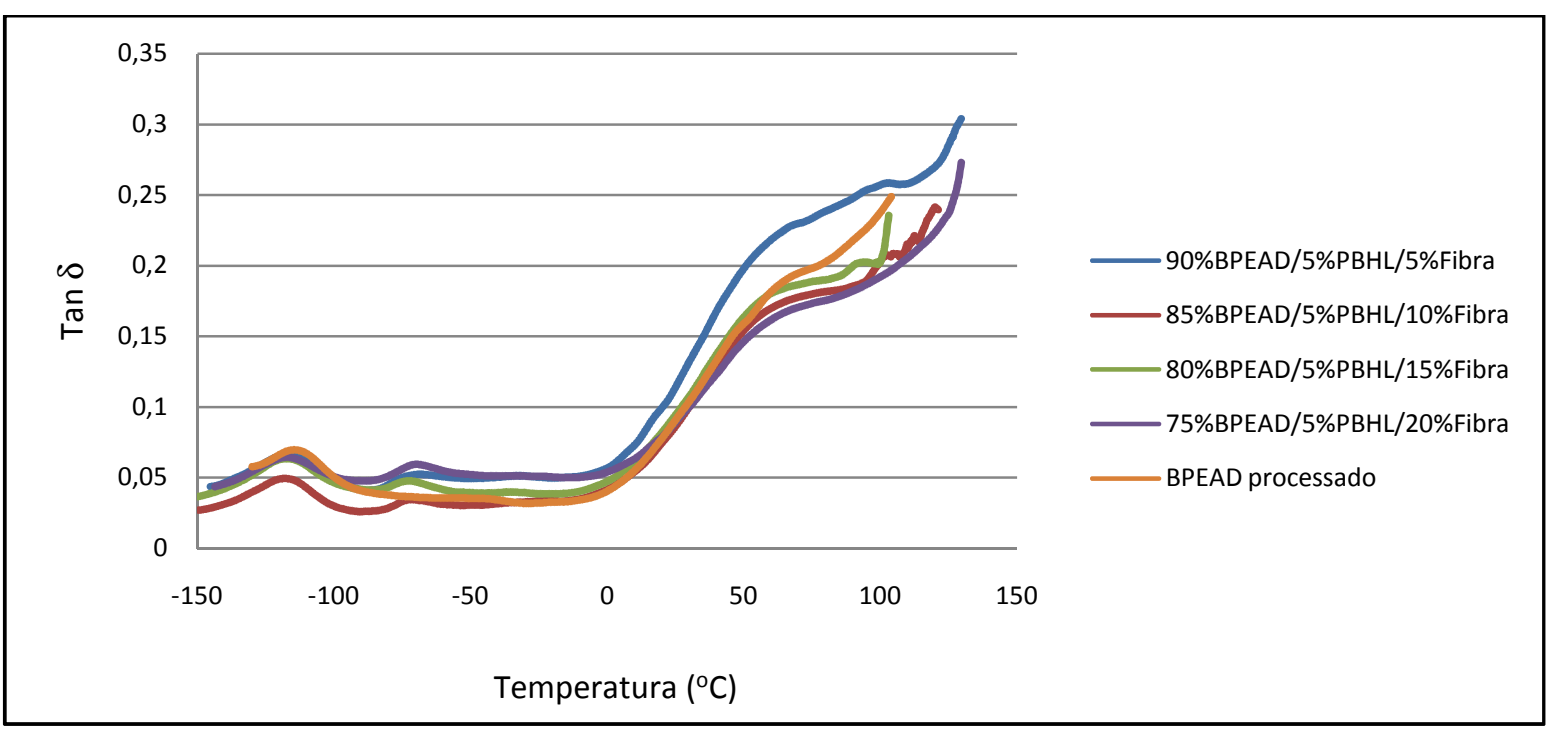

Figura 64: Tan $\delta$ em função da temperatura para os compósitos BPEAD/PBHL/fibra de curauá.

Os relaxamentos mencionados na discussão de E"também apareceram com picos em $\tan \delta$.

\subsubsection{Resistência ao Impacto}

A Figura 65 mostra os resultados obtidos para a resistência ao impacto dos compósitos obtidos variando a porcentagem de fibras e PBHL presentes. 
De acordo com os resultados deste ensaio (Figura 65), observa-se que o compósito contendo $10 \%$ em massa de fibras apresenta o maior valor de resistência ao impacto. Os compósitos contendo reforço acima de 10\% apresentaram menor resistência ao impacto. Este resultado pode indicar que uma fração maior de fibras produz um número maior de defeitos ou vazios, distribuição não homogênea das fibras na matriz. O maior volume de fibras gera regiões com aglomerados de fibras intensificando as interações fibra/fibra. Essa concentração de fibras em determinadas regiões torna o material menos homogêneo resultando em um menor valor de resistência ao impacto (THREEPOPNATKUL; KAERKITCHA; ATHIPONGARPORN 2009).

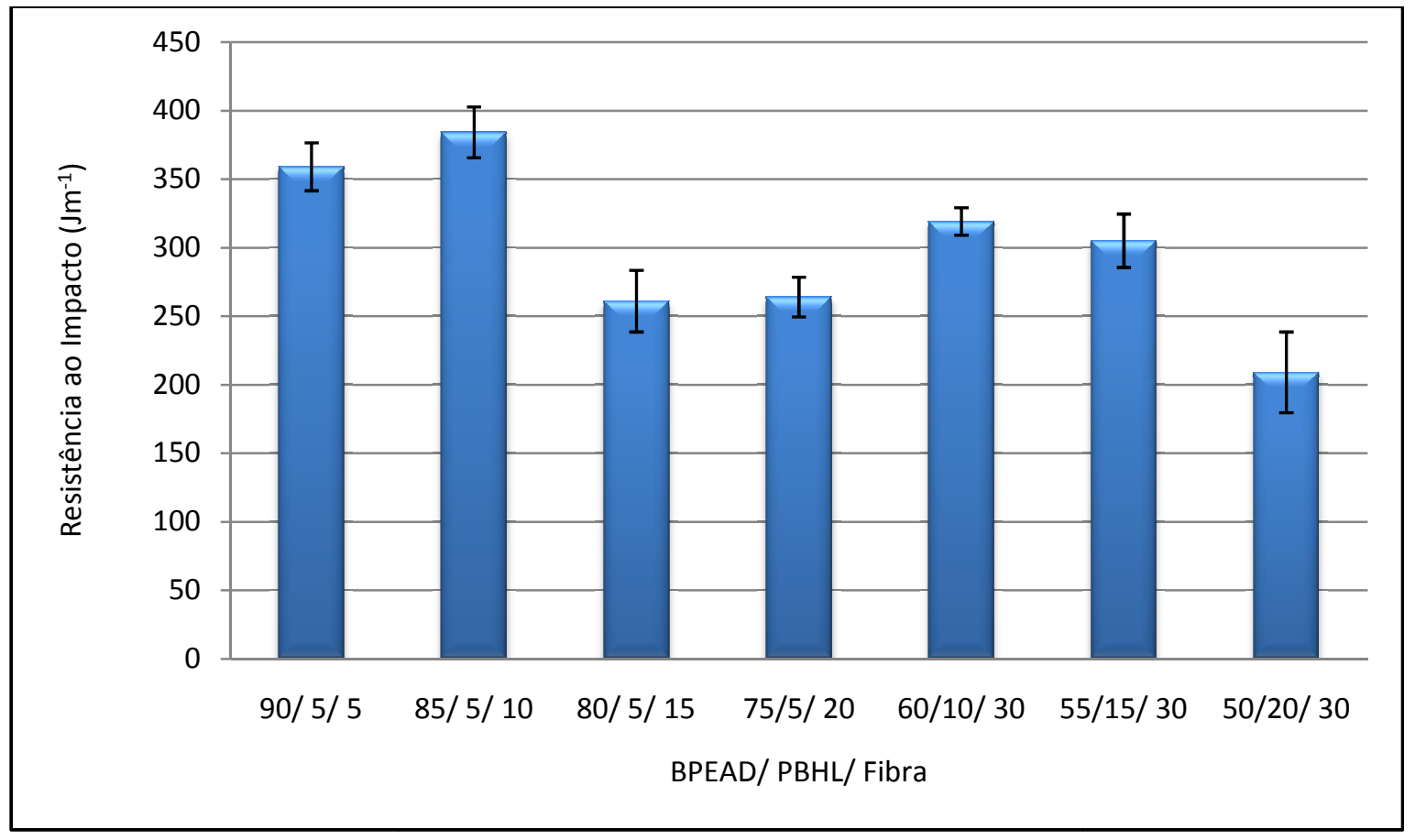

Figura 65: Resistência ao impacto Izod dos compósitos reforçados com diferentes frações de fibra de curauá e de PBHL (em massa), corpos de prova não entalhados.

Analisando os resultados apresentados na Figura 66, pode-se observar o efeito da adição de $\mathrm{PBHL}$ aos compósitos. A introdução de PBHL aumenta a resistência ao impacto do compósito, devido ao efeito de tenacificação provocado pela adição da borracha. No caso, a resistência ao impacto dos compósitos aumentou consideravelmente se comparada à mistura de BPEAD/fibra. Estes valores confirmam que o PBHL atua como agente amortecedor de impacto aumentando a tenacidade do compósito. A presença das fibras viabilizou interações entre os grupos $\mathrm{OH}$ destas e da borracha, permitindo que o PBHL 
atuasse no sentido de melhorar o impacto, o que não foi observado na blenda BPEAD/PBHL (Figura 40) na ausência de fibras.

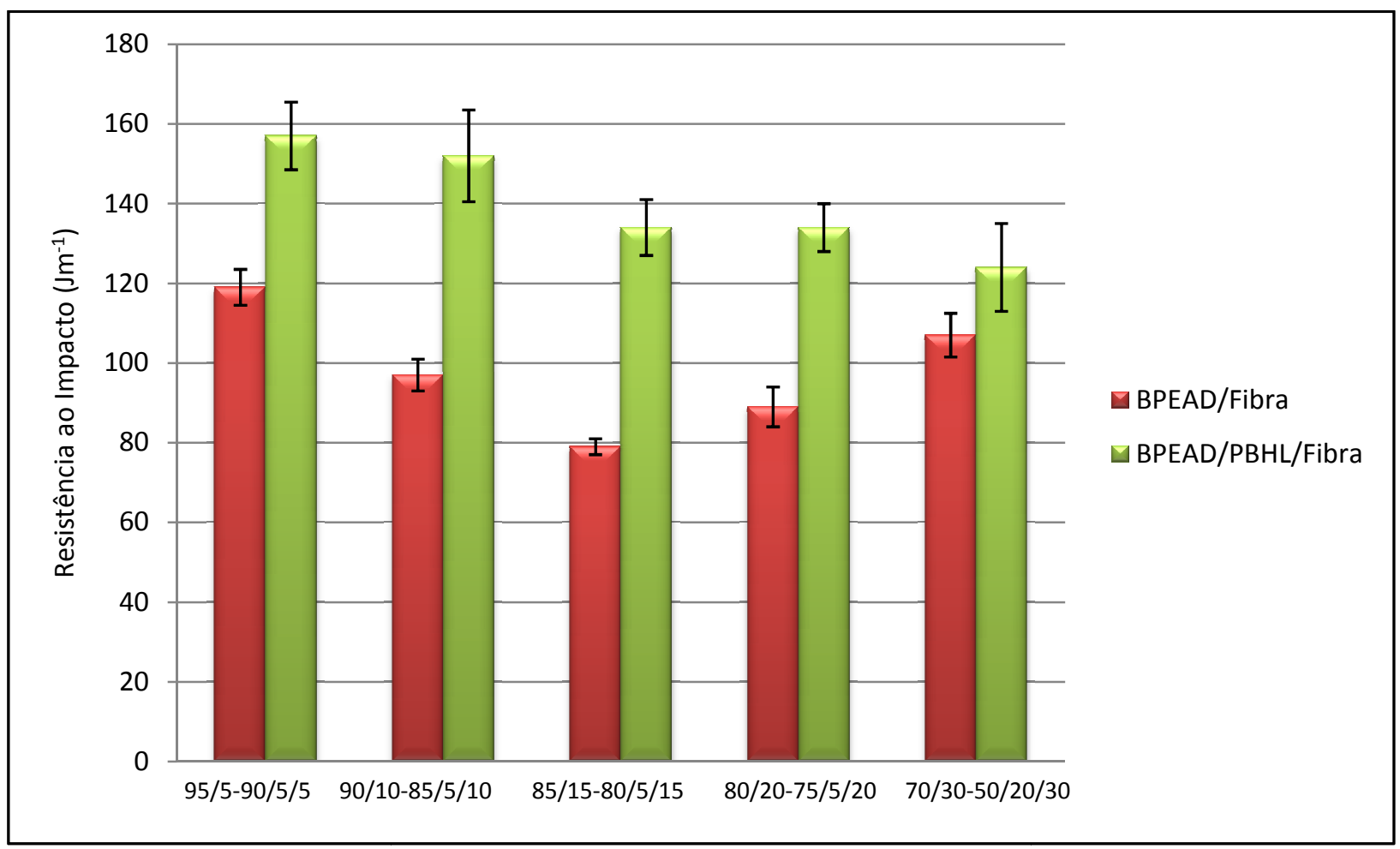

Figura 66: Resistência ao impacto Izod dos compósitos de BPEAD/fibra e BPEAD/PBHL/fibra, corpos de prova entalhados.

Analisando o efeito da introdução de agente modificador de impacto $(\mathrm{PBHL})$ à matriz de polietileno, nas propriedades dos compósitos finais obtidos, verifica-se que o compósito preparado a partir de matriz termoplástica modificada com 5\% de PBHL apresenta, relativamente, o melhor desempenho no teste de resistência ao impacto.

Para os compósitos com 30\% fibra, pode-se observar uma diminuição da resistência ao impacto, indicando possivelmente, que $20 \%$ de PBHL é a fração máxima a ser introduzida no compósito, já que a resistência ao impacto do compósito cai quando a adição de borracha passa de $5 \%$ para $20 \%$, provavelmente porque o efeito passa a ser de fragilização do material. 


\subsubsection{Microscopia Eletrônica de Varredura}

Visando correlacionar os resultados do teste de impacto com a morfologia dos compósitos modificados com PBHL e reforçados com fibra de curauá, a superfície de fratura dos corpos-de-prova, após ensaio de impacto, foram analisadas por microscopia eletrônica de varredura (MEV). A Figura 67 mostra as micrografias obtidas.

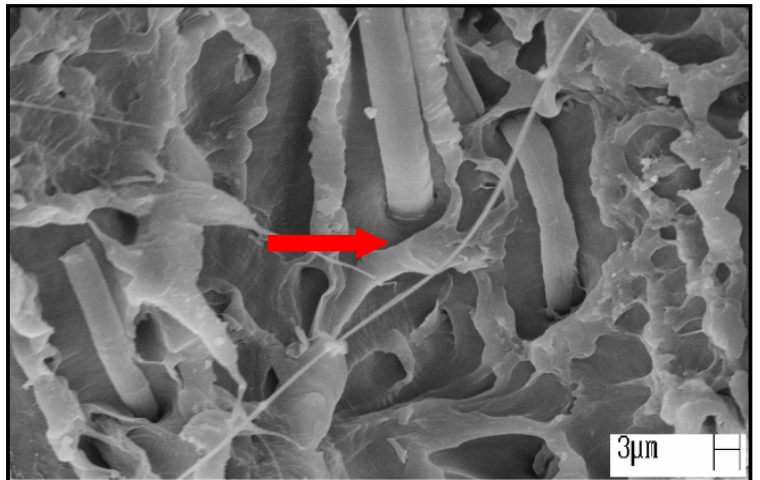

(a)

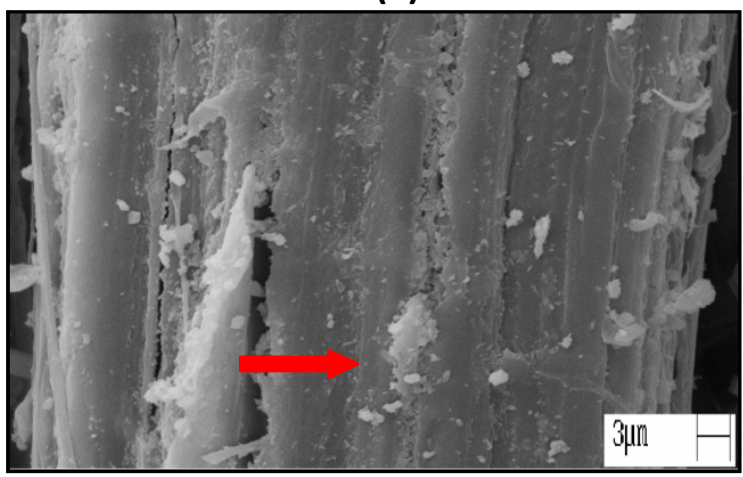

(c)

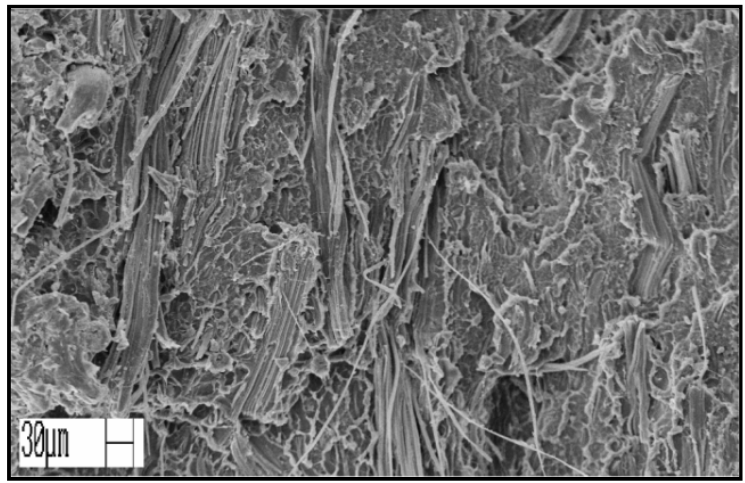

(e)

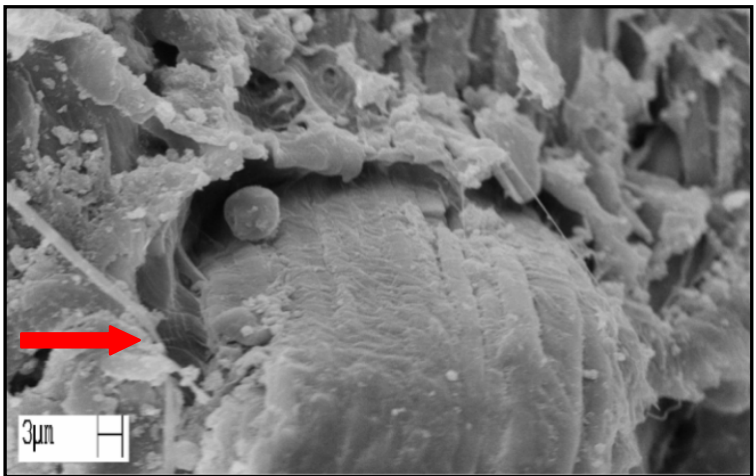

(b)

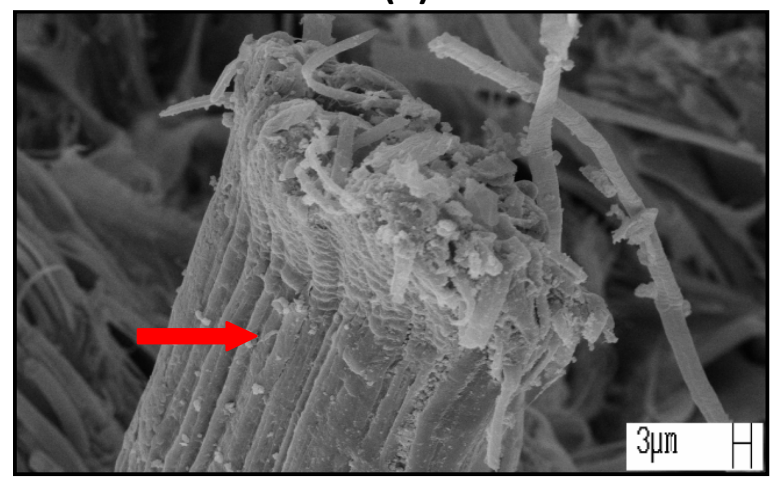

(d)

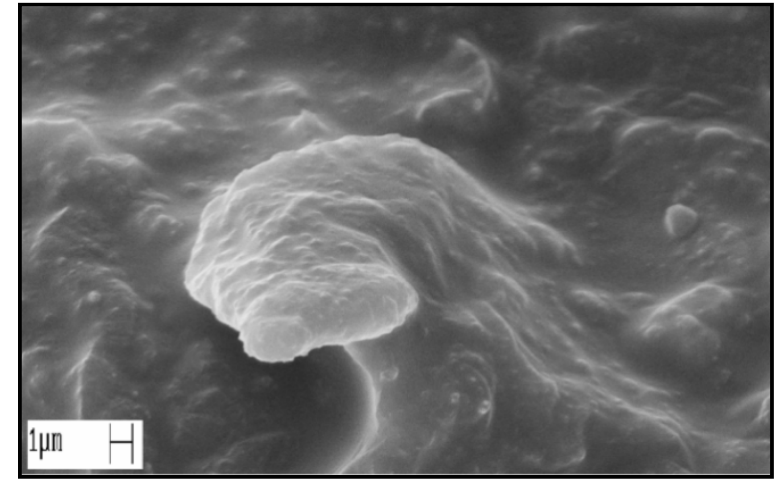

(f)

Figura 67: Micrografias obtidas por MEV a partir da superfície de fratura dos compósitos:

(a) sem adição de PBHL e (b); (c) adição de 5\% (em massa) de PBHL e (d); sem adição de PBHL e (f) $20 \%$ de adição de PBHL. 
A micrografia referente ao compósito de BPEAD/Fibra apresenta regiões que exibem certa adesão fibra-matriz (Figura 67 (a)). Porém, há micrografias que revelam um descolamento da fibra da matriz, ao encontrar a fibra, o deslocamento se propaga ao redor desta, contornado-a e indicando uma fraca interação da fibra/matriz (Figura 67 (b)).

Na Figura 67 (c) observa-se que o PBHL não se encontra uniformemente distribuído pela matriz. Observa-se a presença do elastômero, na região de interface fibra/matriz indicando que o PBHL também apresenta afinidade pelas fibras de curauá. Este resultado demonstra que o PBHL pode atuar como agente de compatibilização entre as fibras e a matriz. A intensificação das interações aumenta a adesão fibra-matriz na interface a qual produz compósitos com melhores propriedades. Ainda, a presença de PBHL nesta região pode dar origem a uma interface fibra-matriz mais flexível, a qual e capaz de dissipar maior quantidade de energia. Desta forma, a presença de PBHL na interface fibra-matriz deve, entre outros fatores, contribuir para o maior valor de resistência ao impacto apresentado pelos compósitos contendo 5\% de PBHL.

Comparando as imagens obtidas por MEV das fibras de curauá do compósito de BPEAD/20\%PBHL/30\% fibra na Figura 67 (d) é possível observar uma camada de polibutadieno hidroxilado recobrindo a superfície da fibra e da matriz se comparado ao compósito BPEAD/10\%fibra na Figura 67 (e), indicando uma maior adesão da fibra à matriz.

\subsubsection{Resistência à Flexão}

A resistência à flexão corresponde à capacidade do material de resistir à força de dobragem aplicada perpendicularmente ao seu eixo longitudinal. Neste trabalho, os compósitos com diferentes porcentagens de fibra de curauá e de PBHL, assim como o BPEAD foram analisados por essa técnica. O perfil da curva de tensão versus deformação para o compósito de 85\%BPEAD/5\%PBHL/10\%Fibra de Curauá é mostrado na Figura 68.

O mesmo comportamento é observado para a blenda de BPEAD, para o compósito de

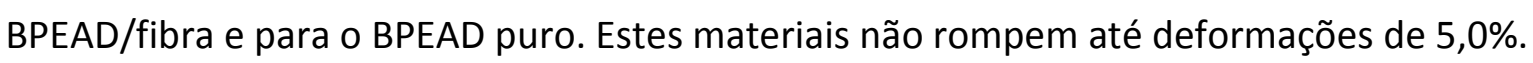




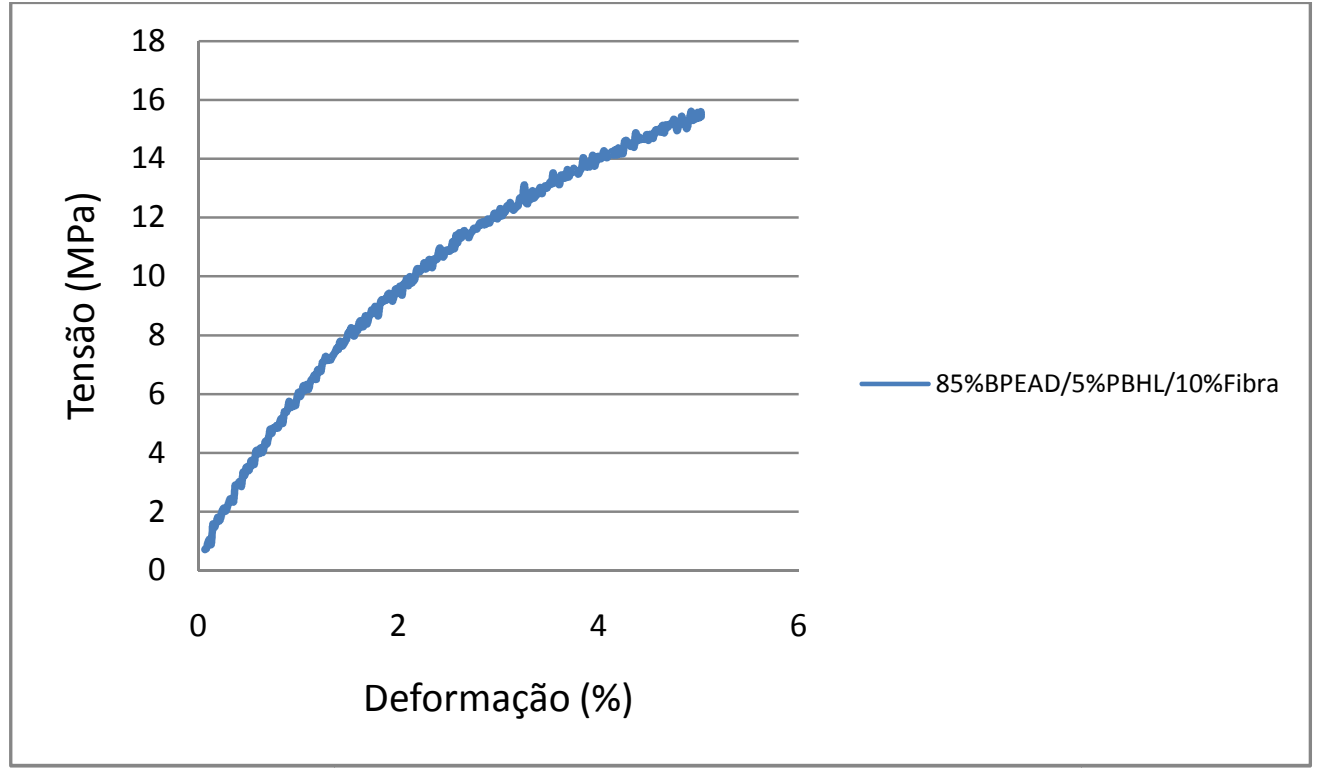

Figura 68: Curva de Tensão versus Deformação para o compósito de 85\%BPEAD/5\%PBHL/10\%fibra de curauá.

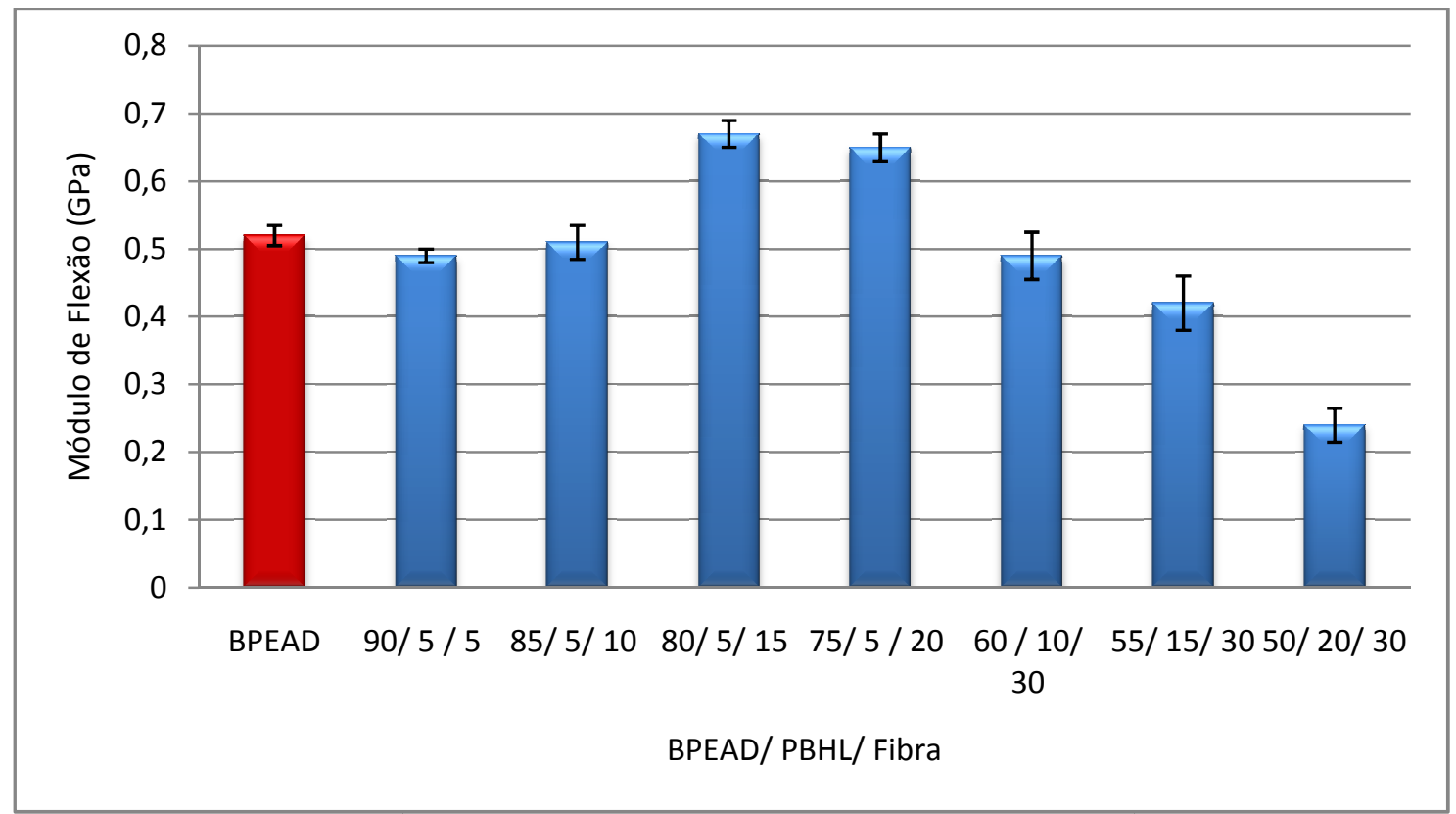

Figura 69: Módulo de flexão dos compósitos reforçados com diferentes frações de fibra de curauá e PBHL (em massa). 


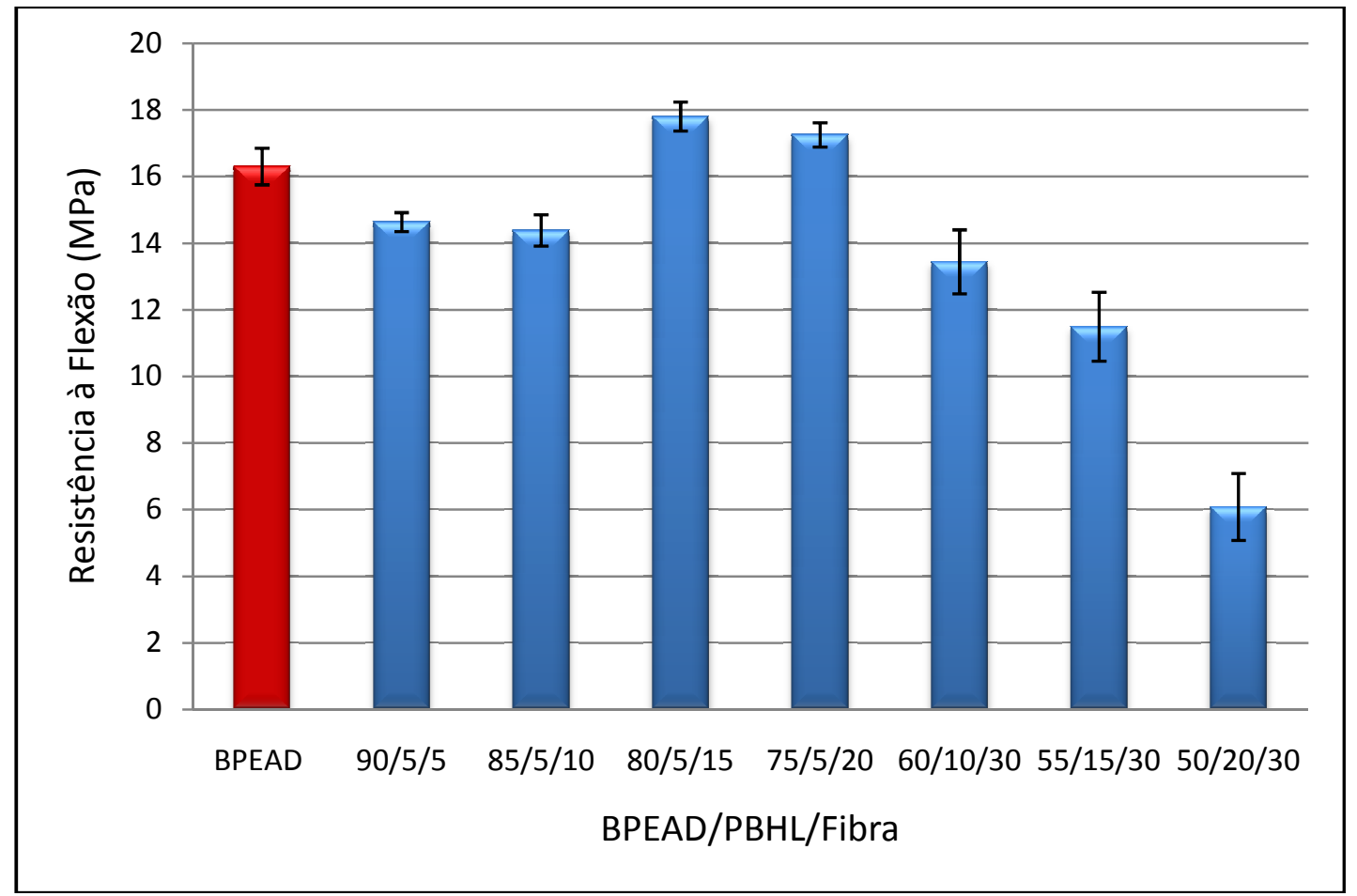

Figura 70: Resistência à flexão dos compósitos reforçados com diferentes frações de fibra de curauá e PBHL (em massa).

Na Figura 69 pode-se observar que o aumento do teor de fibra de 5 a 15\% leva há um aumento no módulo de flexão dos compósitos (5\%PBHL). O compósito com $20 \%$ de fibras tem aproximadamente o mesmo módulo que aquele com 15\%, sendo observado um decréscimo após essa porcentagem, provavelmente, influenciado pelas interações fibra/fibra, que se tornam mais intensas a com $30 \%$ de fibra de curauá adicionada ao compósito (SIGATELLI; YOSHIDA; GONÇALVES, 2010).

Com o aumento da porcentagem de PBHL adicionado ao compósito, pode-se perceber uma diminuição no módulo de flexão, já que há um aumento na deformação elástica de flexão e consequentemente, uma diminuição na resistência à flexão (KAYNAC; ARIKAN; TINCER, 2003). 


\subsubsection{Absorção de água}

A Figura 71 mostra o perfil de absorção de água dos compósitos de BPEAD/PBHL reforçados com fibra de curauá.

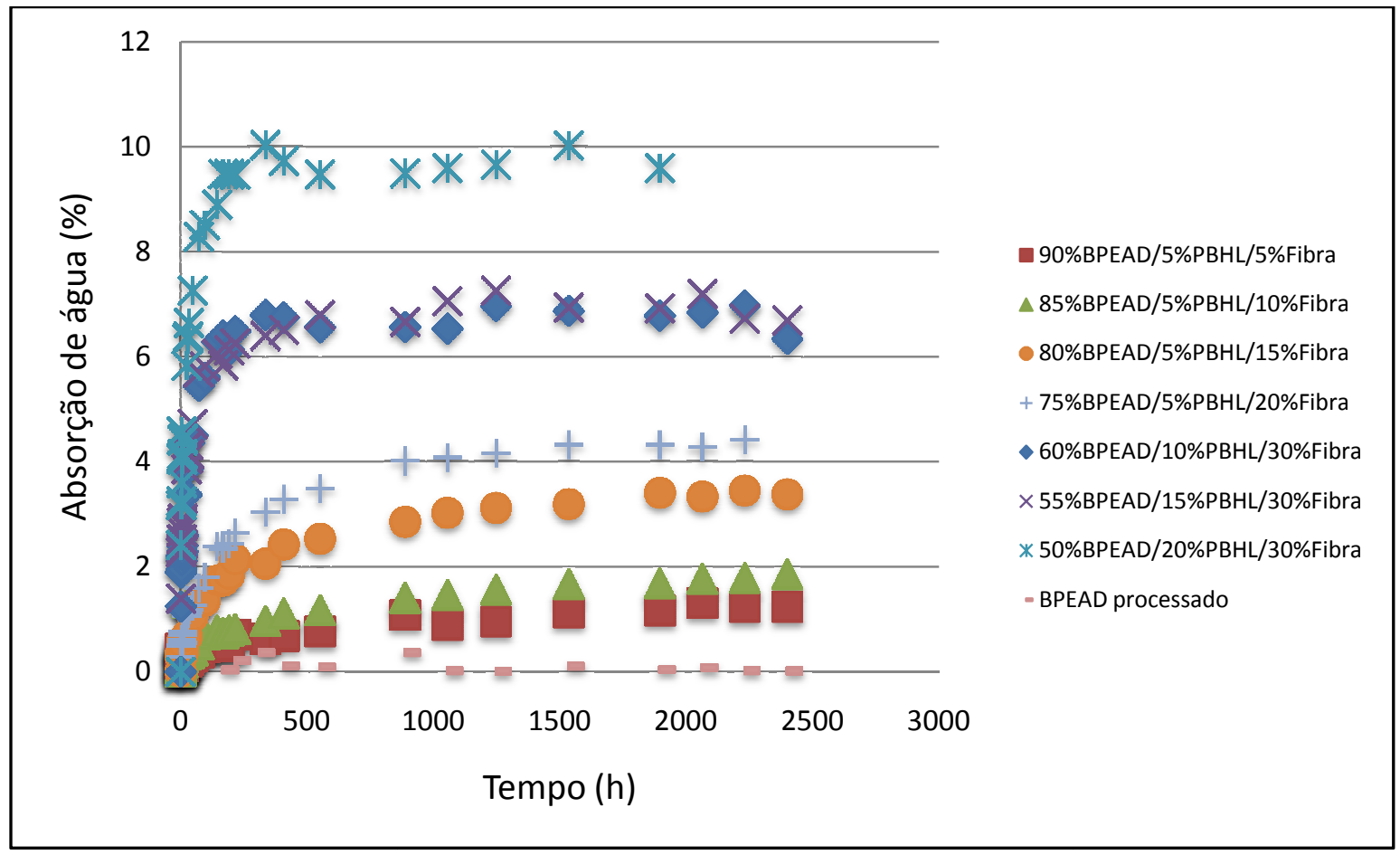

Figura 71: Absorção de água dos compósitos de BPEAD/PBHL reforçados com fibra de curauá e para o BPEAD.

Observa-se durante todo o ensaio comportamento semelhante aos compósitos de BPEAD/Fibra, um aumento progressivo da quantidade de água absorvida pelo material conforme aumenta a quantidade de fibra e de PBHL adicionada ao material, devido à higroscópicidade da fibra vegetal e dos grupos hidroxilas disponíveis presentes na borracha líquida (FARIAS et al., 2009).

\subsubsection{Coeficiente de Difusão}

A Tabela 11 mostra os valores de coeficiente de difusão, $\boldsymbol{D}$ e constante de afinidade, $\boldsymbol{k}$ para os compósitos preparados. 
Tabela 11: Coeficiente de difusão, $\mathrm{D}$ e constante de afinidade, $\mathrm{k}$ para compósitos de matriz de BPEAD/PBHL e Fibra de Curauá.

\begin{tabular}{|c|c|c|}
\hline Compósito & $\mathbf{D}\left(\mathbf{m m}^{\mathbf{2}} \mathbf{h}^{-1} \mathbf{1}\right) \mathbf{1 0}^{-\mathbf{3}}$ & $\mathbf{k}$ \\
\hline 90\%BPEAD/5\%PBHL/5\% Fibra & 2,5 & 0,007 \\
\hline 85\%BPEAD /5\%PBHL/10\%Fibra & 2,2 & 0,002 \\
\hline 80\%BPEAD/5\%PBHL/15\%Fibra & 2,1 & 0,002 \\
\hline 75\%BPEAD/5\%PBHL/20\%Fibra & 2,0 & 0,2 \\
\hline 60\%BPEAD/10\% PBHL/30\%Fibra & 2,9 & 0,2 \\
\hline 55\%BPEAD/15\% PBHL/30\%Fibra & 2,6 & 0,3 \\
\hline 50\%BPEAD/20\%PBHL/30\%Fibra & 2,7 & 0,3 \\
\hline
\end{tabular}

Apesar dos compósitos reforçados com $30 \%$ de fibra terem absorvido mais água, o coeficiente de difusão praticamente não foi alterado. No entanto, a constante de afinidade do compósito contendo 20 e 30\% de fibra aumentou consideravelmente, devido ao caráter hidrofílico da fibra e do PBHL, presentes em maior proporção, assim como à baixa adesão fibra-matriz observada para estes compósitos, corroborando com os resultados obtidos anteriormente.

\subsection{Compósitos tratados com ar ionizado}

Os compósitos foram preparados levando em conta os melhores resultados obtidos até este ponto (85\%BPEAD/5\%PBHL/10\%Fibra e $80 \% \mathrm{BPEAD} / 5 \% \mathrm{PBHL} / 15 \%$ Fibra), no que se refere a parâmetros da matriz/PBHL/Fibra de Curauá.

\subsubsection{Análise térmica}

Quando se compara as curvas de TG referentes às fibras de curauá sem tratamento e tratadas com ar ionizado (Figura 72), não se observa diferenças significativas no perfil das curvas, se comparadas àquela dos compósitos reforçados com fibras de curauá sem tratamento. 


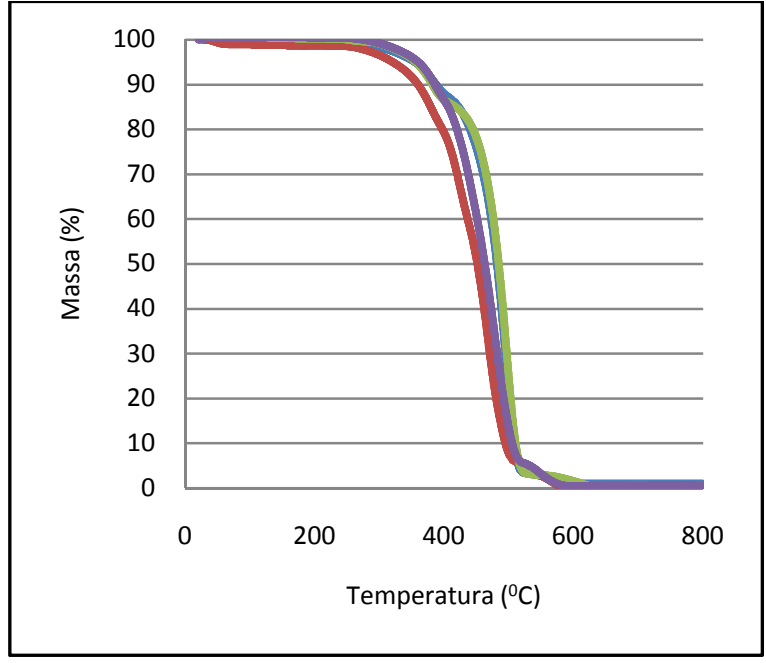

(a)

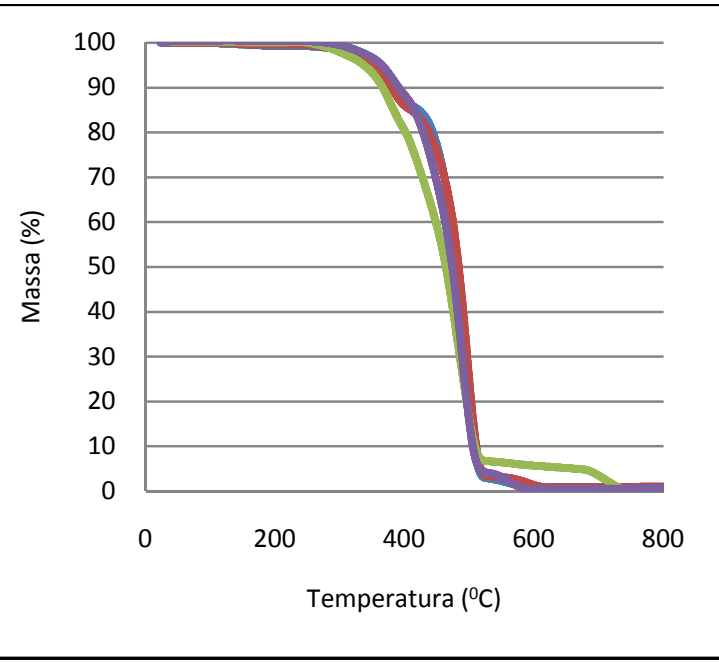

(b)

Figura 72: Curvas TG para os compósitos:

(a) 85\%BPEAD/5\%PBHL/10\%Fibra, 85\%BPEAD/5\%PBHL/10\%Fibra tratada, 85\%BPEAD tratado/5\% PBHL/10\%Fibra, 85\%BPEAD tratado/5\%PBHL/10\%Fibra tratada;

(b) $80 \% \mathrm{BPEAD} / 5 \% \mathrm{PBHL} / 15 \%$ Fibra, $80 \% \mathrm{BPEAD} / 5 \% \mathrm{PBHL} / 15 \%$ Fibra tratada, 80\%BPEAD tratado/5\%PBHL/15\%Fibra, 80\%BPEAD tratado/5\%PBHL/15\%Fibra tratada, atmosfera de $\mathrm{N}_{2}$, fluxo de $20 \mathrm{mLmin}^{-1}$ e razão de aquecimento de $10^{\circ} \mathrm{Cmin}^{-1}$.

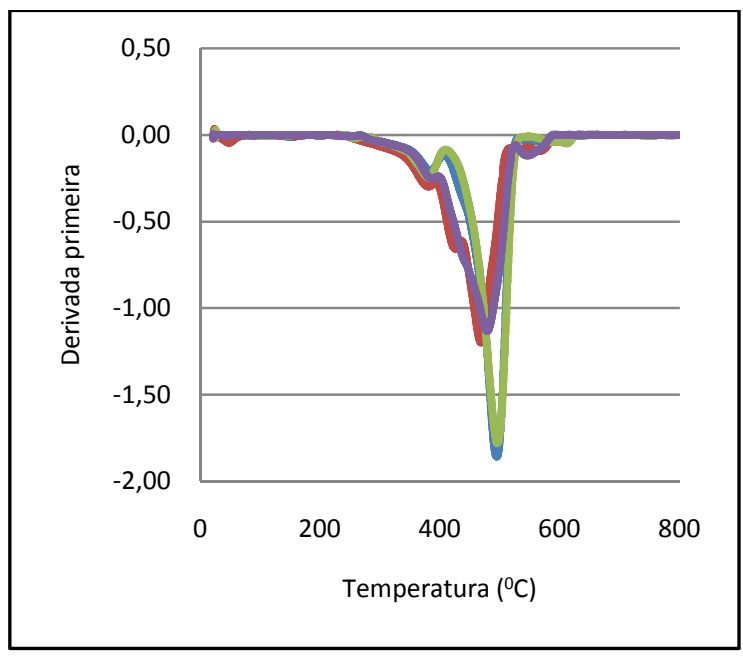

(a)

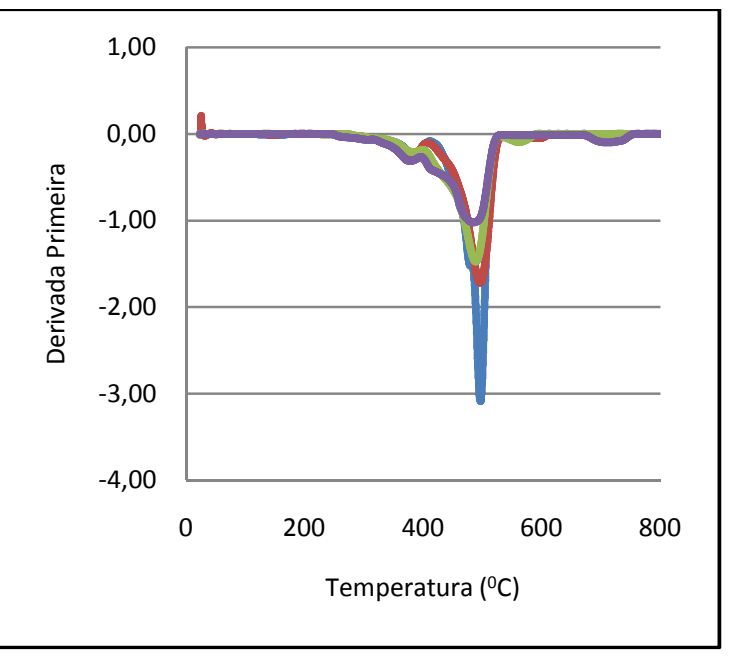

(b)

Figura 73: Curva derivada primeira da TG para os compósitos:

(a) 85\%BPEAD/5\%PBHL/10\%Fibra, 85\%BPEAD/5\%PBHL/10\%Fibra tratada, 85\%BPEAD tratado/5\%PBHL/10\%Fibra, 85\%BPEAD tratado/5\%PBHL/10\%Fibra tratada;

(b) $80 \%$ BPEAD/5\%PBHL/15\%Fibra, 80\%BPEAD/5\%PBHL/15\%Fibra tratada, 80\%BPEAD tratado/5\% PBHL/15\%Fibra, 80\%BPEAD tratado/5\%PBHL/15\%Fibra tratada. 
Observa-se na Figura 73 (a) e (b) que, no geral, as amostras que possuem fibra de curauá tratada com ar ionizado (5h) apresentam um pico em torno de $490^{\circ} \mathrm{C}$ com uma menor intensidade se comparada aos compósitos em que as fibras não foram submetidas ao tratamento, este pico é atribuído a decomposição da lignina.

A curva de DSC dos compósitos (Figura 74) mostra um único pico correspondente à temperatura de fusão do $\operatorname{BPEAD}\left(130^{\circ} \mathrm{C}\right)$. Não se observa diferenças significativas entre as amostras tratadas e não tratadas com ar ionizado.

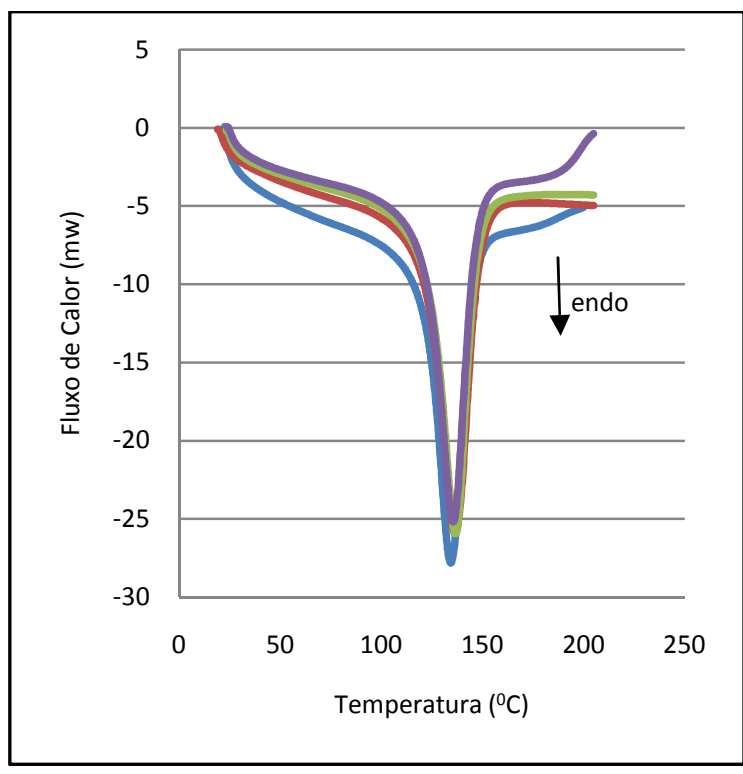

(a)

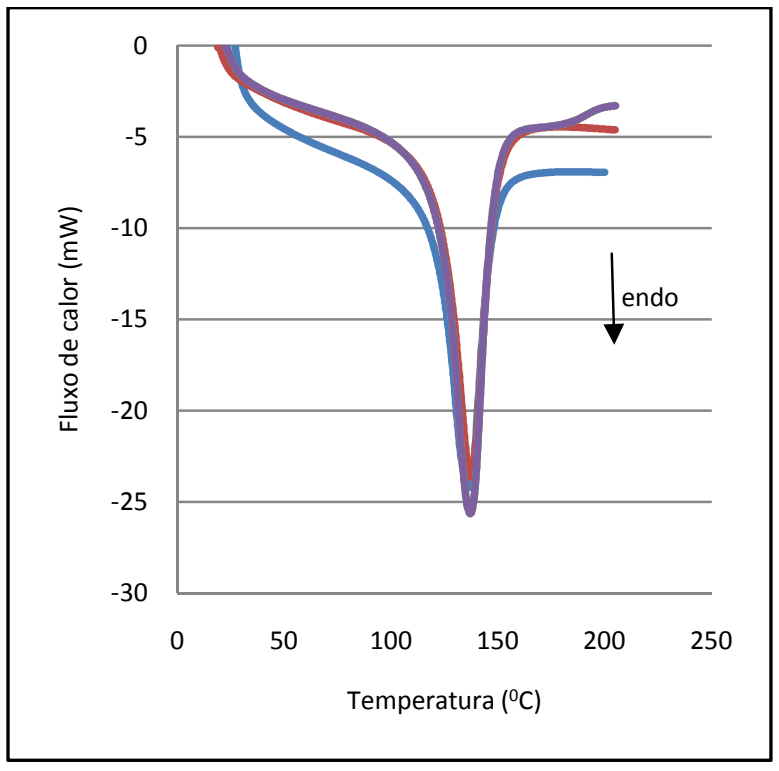

(b)

Figura 74: Curvas DSC para os compósitos:

(a) 85\%BPEAD/5\%PBHL/10\%Fibra, 85\%BPEAD/5\%PBHL/10\%Fibra tratada, 85\%BPEAD tratado/5\%PBHL/10\%Fibra, 85\%BPEAD tratado/5\%PBHL/10\%Fibra tratada;

(b) $80 \%$ BPEAD/5\%PBHL/15\%Fibra, 80\%BPEAD/5\%PBHL/15\%Fibra tratada, 80\%BPEAD tratado/5\%PBHL/15\%Fibra, 80\%BPEAD tratado/5\%PBHL/15\%Fibra tratada, atmosfera de

\section{$\mathrm{N}_{2}$, fluxo de $20 \mathrm{mLmin}^{-1}$ e razão de aquecimento de $10^{\circ} \mathrm{Cmin}^{-1}$.}

A partir das curvas de DSC obtidas para os compósitos tratados com ar ionizado, podem ser obtidos $\Delta \mathrm{H}_{\mathrm{f}}$. Na Tabela 12 são apresentadas as entalpias de fusão e $\Delta \mathrm{H}_{\mathrm{f} / \varphi_{\mathrm{m}}} \mathrm{m}$ para os compósitos. 
Tabela 12: Entalpias de Fusão

\begin{tabular}{|c|c|c|}
\hline Compósito & $\Delta \mathbf{H}_{\mathbf{f}}\left(\mathbf{J g}^{-\mathbf{1}}\right)$ & $\Delta \mathbf{H}_{\mathbf{f}} / \mathbf{\phi m}$ \\
\hline 85\%BPEAD/5\%PBHL/10\%Fibra & 142,0 & 167,1 \\
\hline 85\%BPEAD/5\% PBHL/10\% Fibra tratada & 154,89 & 182,2 \\
\hline 85\%BPEAD tratado/ 5\% PBHL/ 10\% Fibra & 152,89 & 179,9 \\
\hline 85\% BPEAD tratado/5\% PBHL/ 10\%Fibra tratada & 147,16 & 173,1 \\
\hline 80\%BPEAD/ 5\% PBHL/15\% Fibra & 144,8 & 181 \\
\hline 80\%BPEAD/5\%PBHL/15\%Fibra tratada & 151,42 & 189,2 \\
\hline 80\%BPEAD tratado/5\% PBHL/15\%Fibra & 152,2 & 190,2 \\
\hline 80\%BPEAD tratado/5\%PBHL/15\%Fibra tratada & 149,54 & 186,9 \\
\hline
\end{tabular}

Os resultados da razão de $\Delta \mathrm{H}_{\mathrm{f} /} / \phi m$ (Tabela 12 ) permitem a observação de que o tratamento prévio da fibra e ou do BPEAD com ar ionizado promovem um aumento da cristalinidade do BPEAD, tendo em vista que a cristalinidade é proporcional à esta razão. Este resultado sugere organização das cadeias BPEAD são facilitadas quando o polímero e /ou as fibras são tratadas.

\subsubsection{Análise térmica dinâmico-mecânica (DMTA)}

As Figuras 75, 76 e 77 apresentam as curvas de E',E"e tan $\delta$ versus temperatura dos compositos reforçados com fibras de curauá tratadas com ar ionizado por um periodo de $5 \mathrm{~h}$.

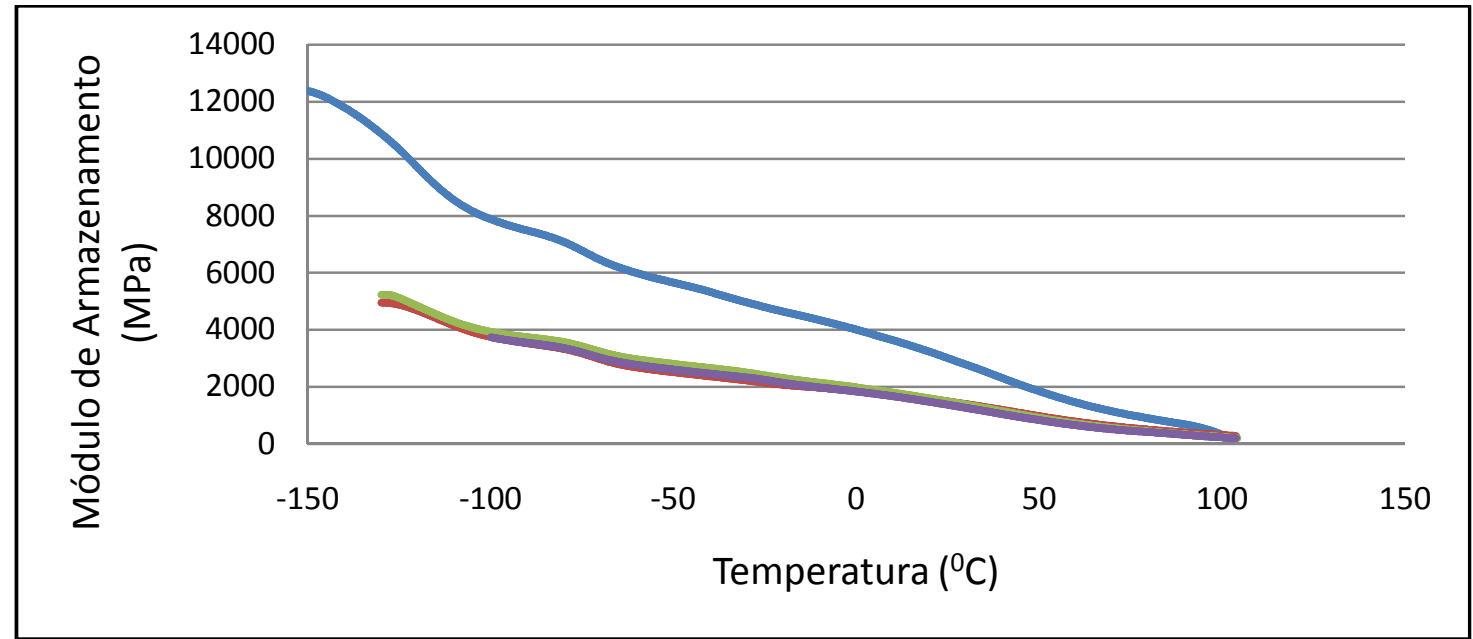

Figura 75: Módulo de armazenamento (E') em função da temperatura para os compósitos 85\%BPEAD/5\%PBHL/10\%Fibra, 85\%BPEAD/5\%PBHL/10\%Fibra tratada, 85\%BPEAD tratado/5\% PBHL/10\%Fibra, 85\%BPEAD tratado/5\%PBHL/10\%Fibra tratada. 
Os compósitos reforçados com fibras e BPEAD tratadas com ar ionizado apresentaram valores de $E^{\prime}$ inferiores ao obtido com curauá e BPEAD sem tratamento. A exposição das fibras ao ar ionizado por um período de 5 h, provavelmente leva à degradação parcial de componentes da fibra lignocelulósica, o que mostrou importante para a rigidez do material.

Todos os picos são deslocados para temperatura um pouco maior quando ocorre o tratamento com ar ionizado, o que pode sugerir que as interações intermoleculares sejam um pouco mais intensas.

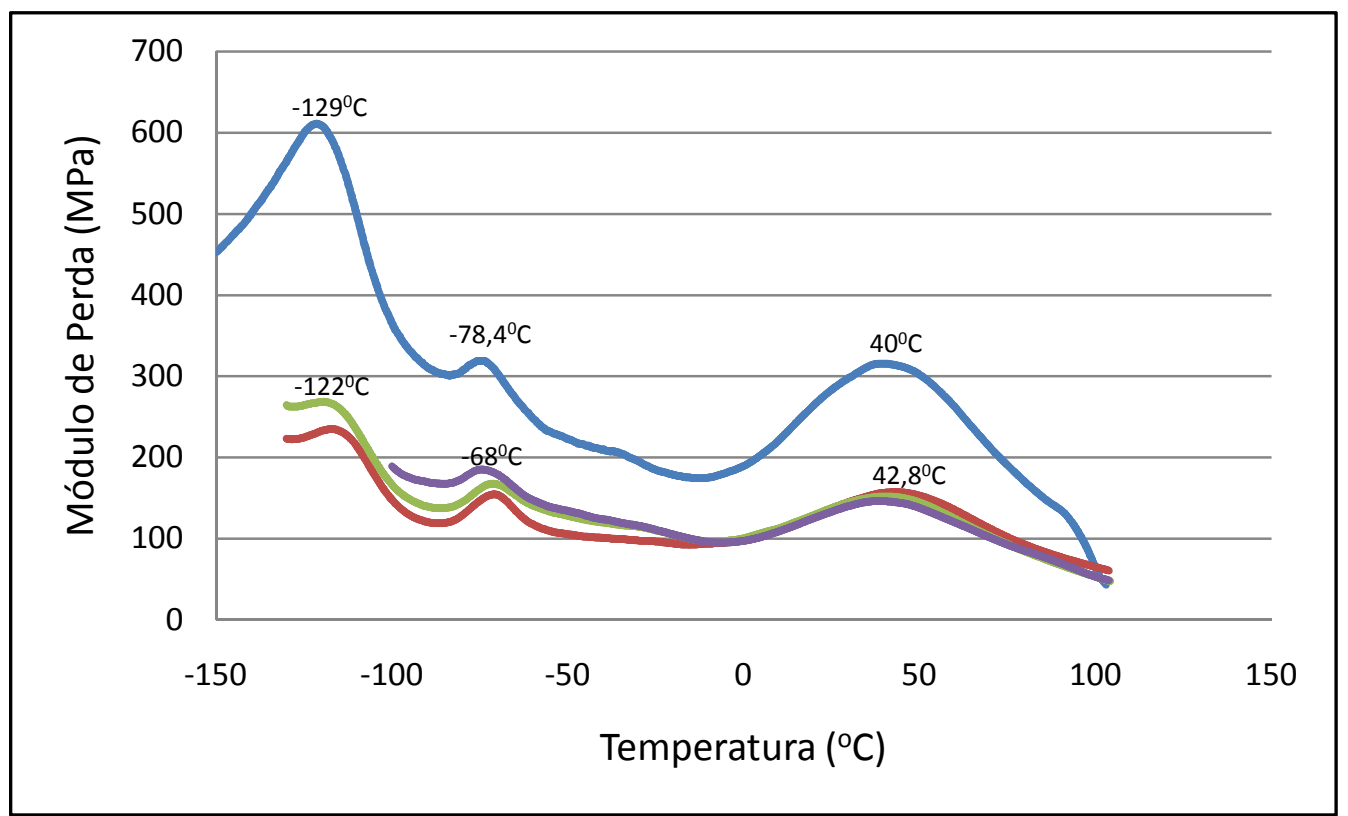

Figura 76: Módulo de perda (E") em função da temperatura para os compósitos 85\%BPEAD/5\%PBHL/10\%Fibra, 85\%BPEAD/5\%PBHL/10\%Fibra tratada, 85\%BPEAD tratado/5\% PBHL/10\%Fibra, 85\%BPEAD tratado/5\%PBHL/10\%Fibra tratada. 


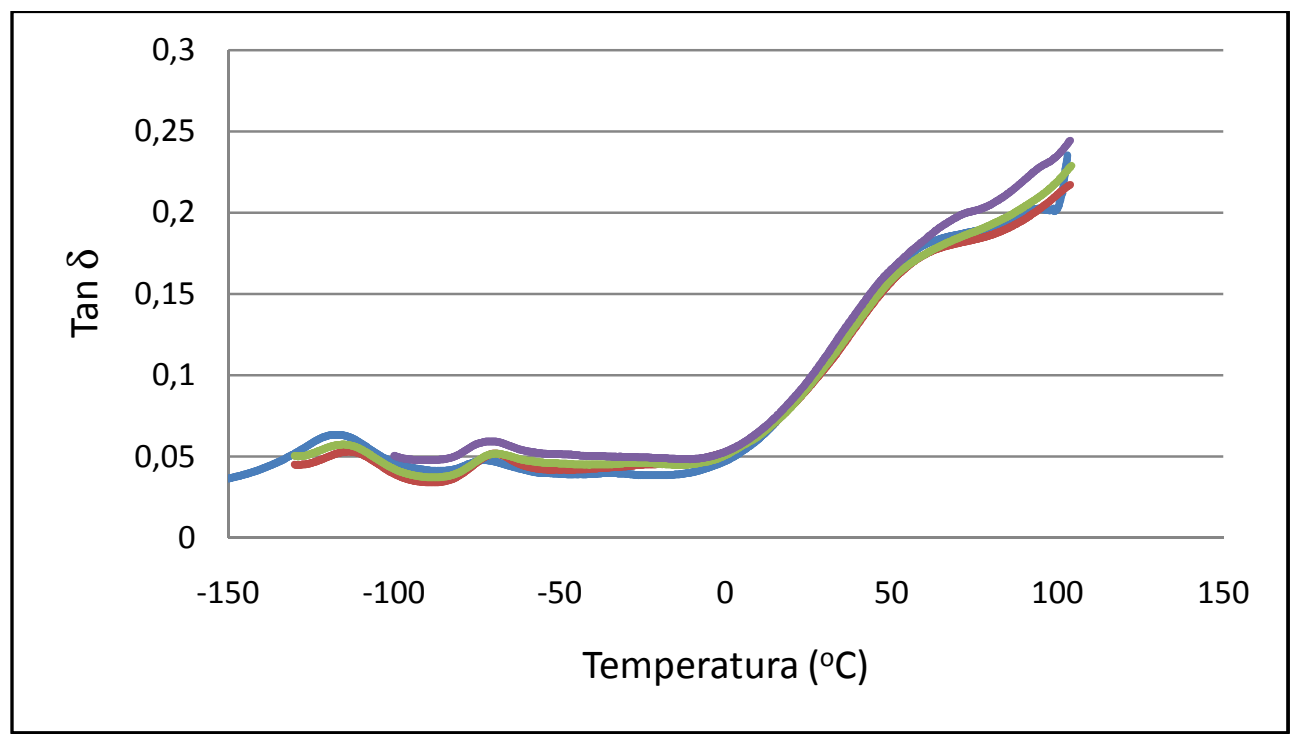

Figura 77: Tan $\delta$ em função da temperatura para os compósitos

85\%BPEAD/5\%PBHL/10\%Fibra, 85\%BPEAD/5\%PBHL/10\%Fibra tratada, 85\%BPEAD

tratado/5\%PBHL/10\%Fibra, 85\%BPEAD tratado/5\%PBHL/10\%Fibra tratada.

A curva de $\tan \delta$ apresenta picos nas mesmas regiões observadas nas curvas de E".

\subsubsection{Resistência ao impacto}

As Figuras 78 e 79 mostram que os compósitos com fibras tratadas por um período de 5 h, tem resistência ao impacto próxima do material em que houve uso deste tratamento.

Na Figura 79 observa-se uma tendência de aumento de resistência ao impacto no material em que o BPEAD e a fibra de curauá foram tratados. 


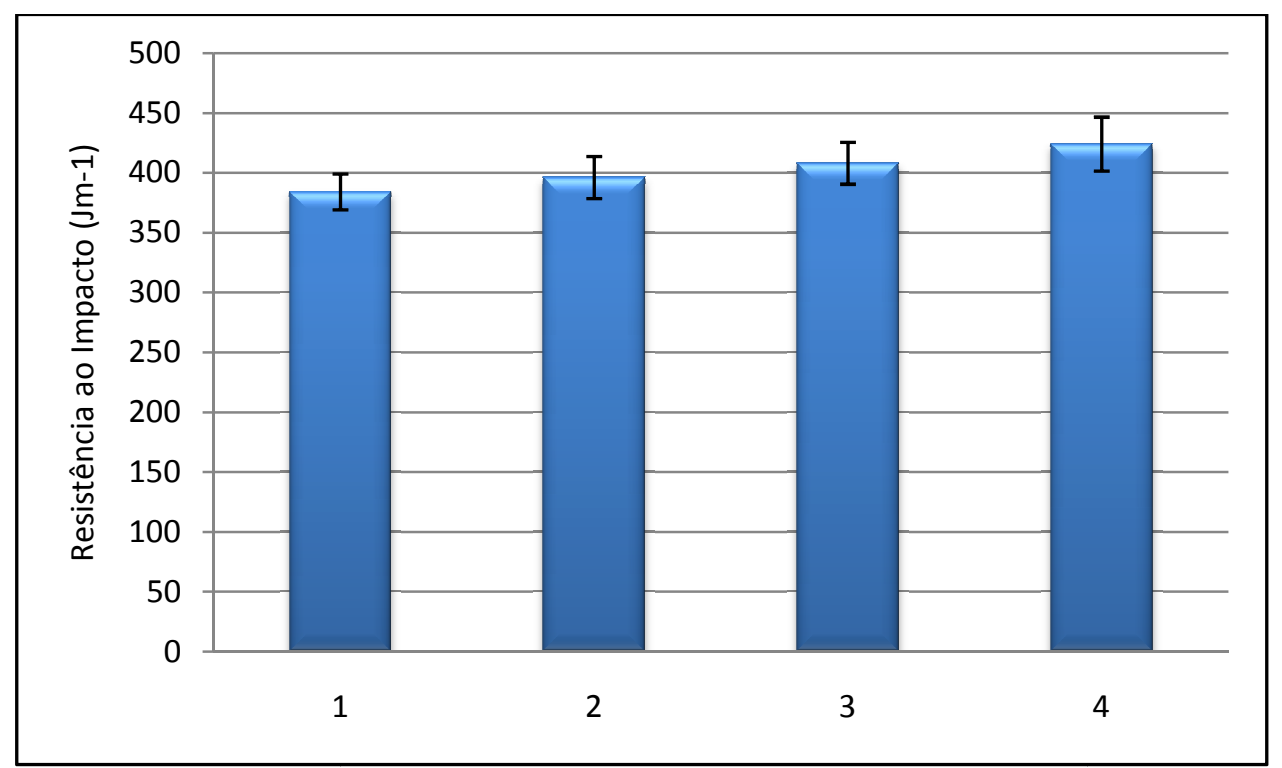

Figura 78: Resistência ao impacto para compósitos (1) 85\%BPEAD/5\%PBHL/10\%Fibra, (2) 85\%BPEAD/5\%PBHL/10\%Fibra tratada, (3) 85\%BPEAD tratado/5\%PBHL/10\%Fibra, (4) 85\%BPEAD tratado/5\%PBHL/10\%Fibra tratada.

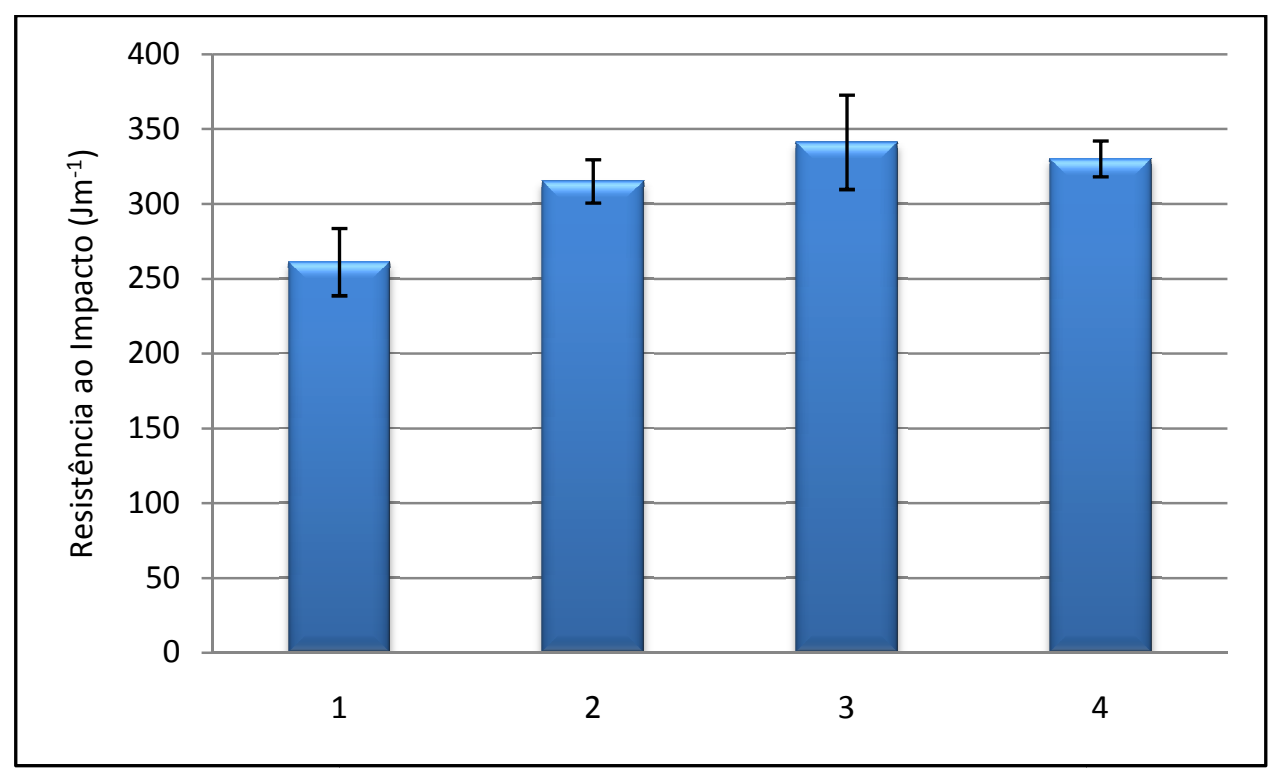

Figura 79: Resistência ao impacto para compósitos (1) 80\%BPEAD/5\%PBHL/15\%Fibra, (2) 80\%BPEAD/5\%PBHL/15\%Fibra tratada, (3) 80\%BPEAD tratado/5\%PBHL/15\%Fibra, (4) 80\%BPEAD tratado/5\%PBHL/15\%Fibra tratada.

Este tratamento possui a vantagem de ser um tratamento realizado em via seca, evitando os problemas provocados pela presença de água ou outro solvente nas fibras. Deve-se ressaltar também o baixo custo do processo, que não requer a compra e utilização 
de reagentes químicos, somente o investimento inicial para a montagem do sistema de ar ionizado.

\subsubsection{Microscopia eletrônica de varredura}

As fibras tratadas com ar ionizado apresentam feixes de fibras mais afastados do que as fibras não tratadas, a Figura 80 (a) e (b) parecem mostrar que os compósitos reforçados com as fibras tratadas com ar ionizado apresentam maior adesão entre a fibra e matriz. Com isto, a interação matriz/fibra aparentemente foi otimizada, o que se refletiu na maior resistência ao impacto.

Observa-se também que houve uma boa dispersão das fibras no polímero Figura 80 (c) e (d)) e as um parcial desfibramento das fibras.

Na Figura 80 (e) e (f) observa-se que ocorre a quebra da fibra distante da matriz (setas vermelhas), sugerindo boa adesão.

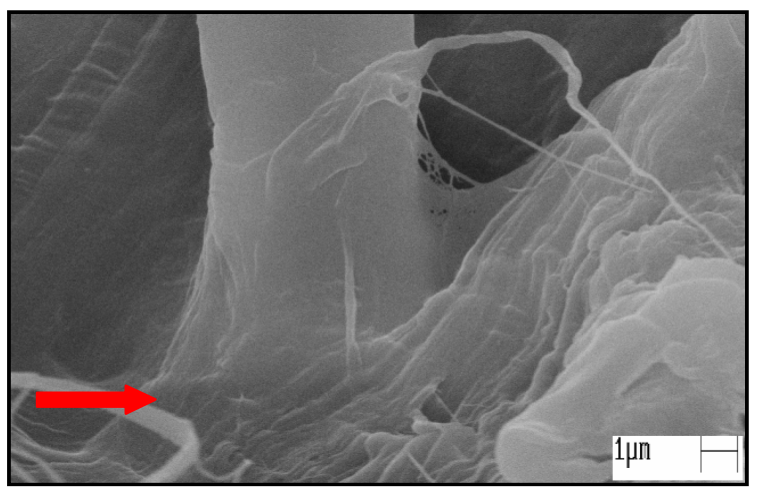

(a)

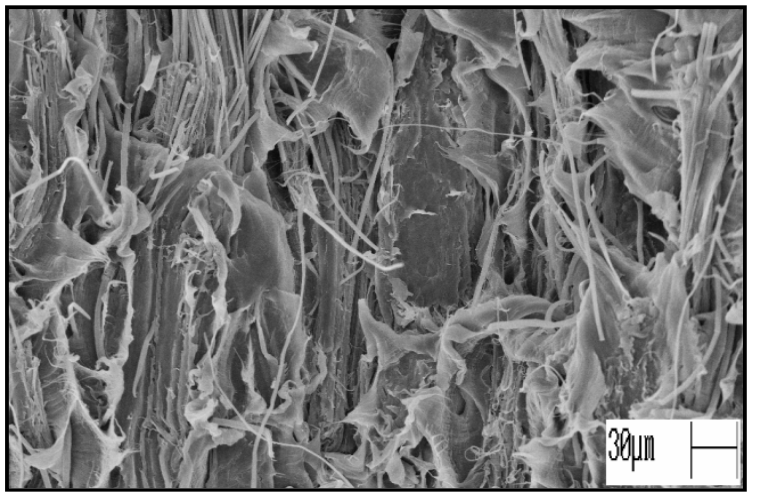

(c)

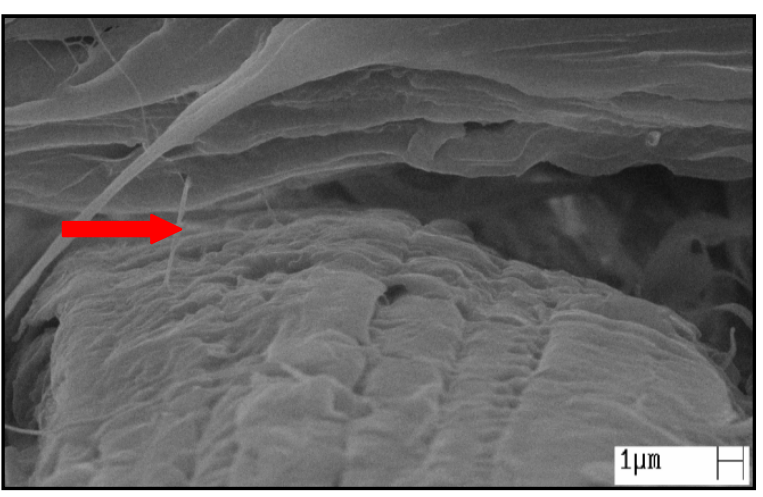

(b)

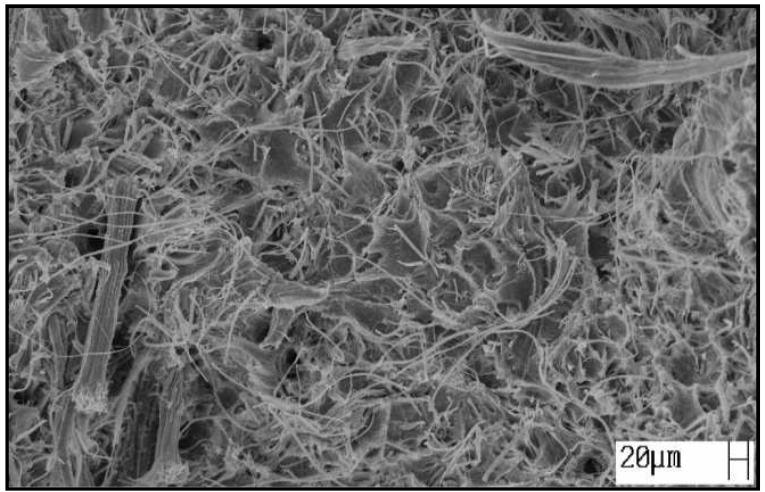

(d) 


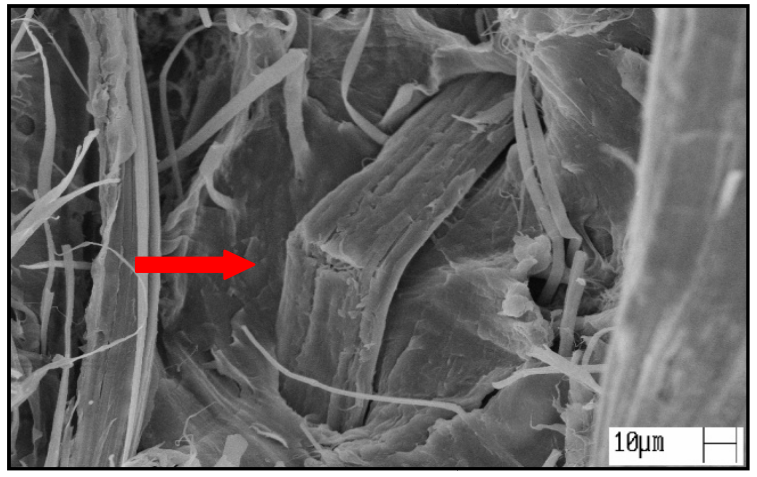

(e)

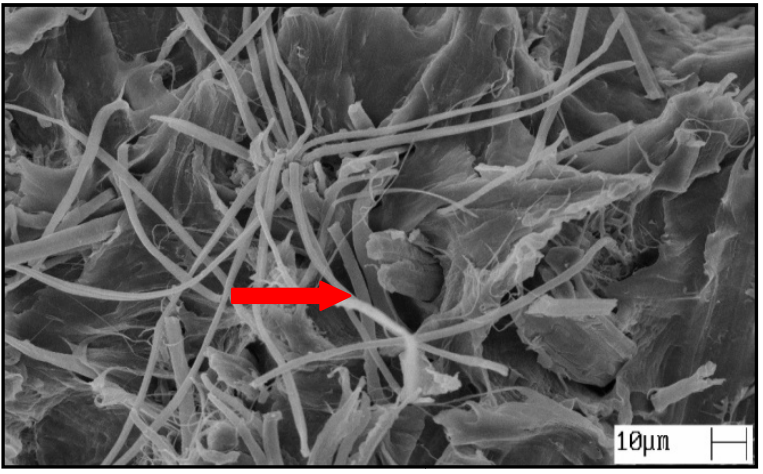

(f)

Figura 80: Micrografias obtidas por MEV a partir da superfície de fratura dos compósitos: (a) 85\%BPEAD/5\%PBHL/10\%Fibra tratada, (b) 80\%BPEAD/5\%PBHL/15\%Fibra tratada; (c) 85\%BPEAD tratado/5\%PBHL/10\%Fibra tratada, (d) 80\%BPEAD tratado/5\%PBHL/15\%Fibra tratada; (e) 85\%BPEAD tratado/5\%PBHL/10\%Fibra tratada, (f) 80\%BPEAD tratado/5\%PBHL/15\%Fibra tratada.

\subsubsection{Resistência à flexão}

As Figuras 81 e 82 apresentam o módulo e resistência à flexão para os compósitos com componentes tratados com ar ionizado.

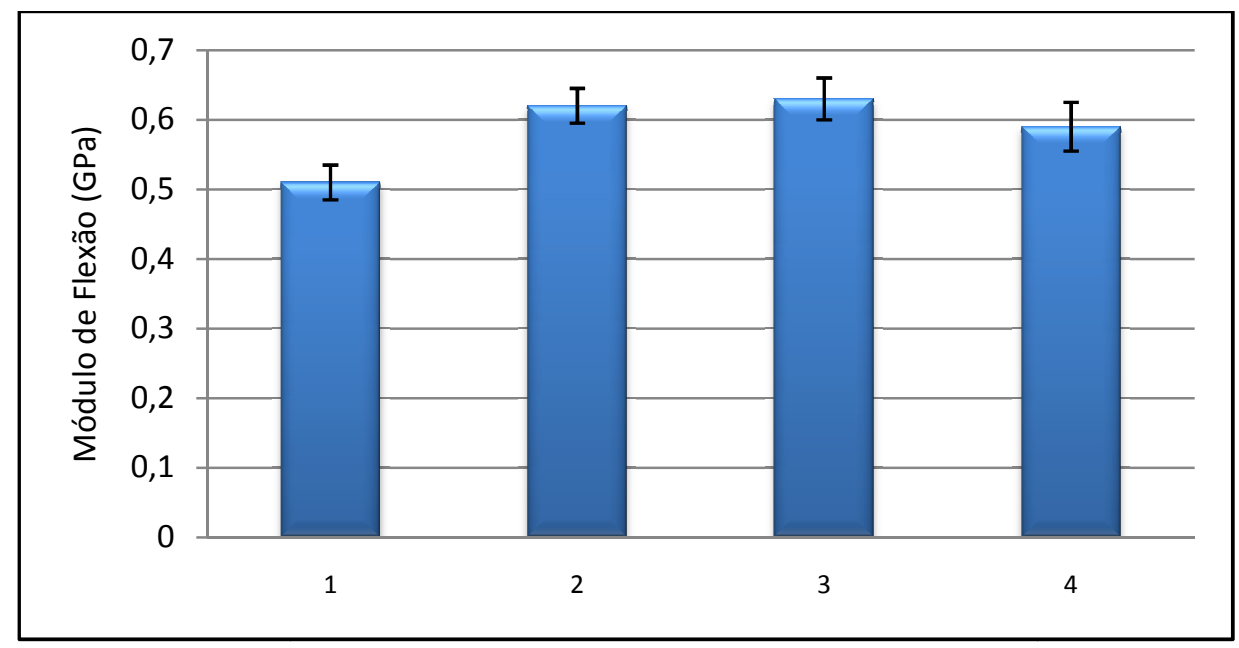

Figura 81: Módulo de flexão para compósitos (1) 85\%BPEAD/5\%PBHL/10\%Fibra, (2) 85\%BPEAD/5\%PBHL/10\%Fibra tratada, (3) 85\%BPEAD tratado/5\%PBHL/10\%Fibra, (4) 85\%BPEAD tratado/5\%PBHL/10\%Fibra tratada. 


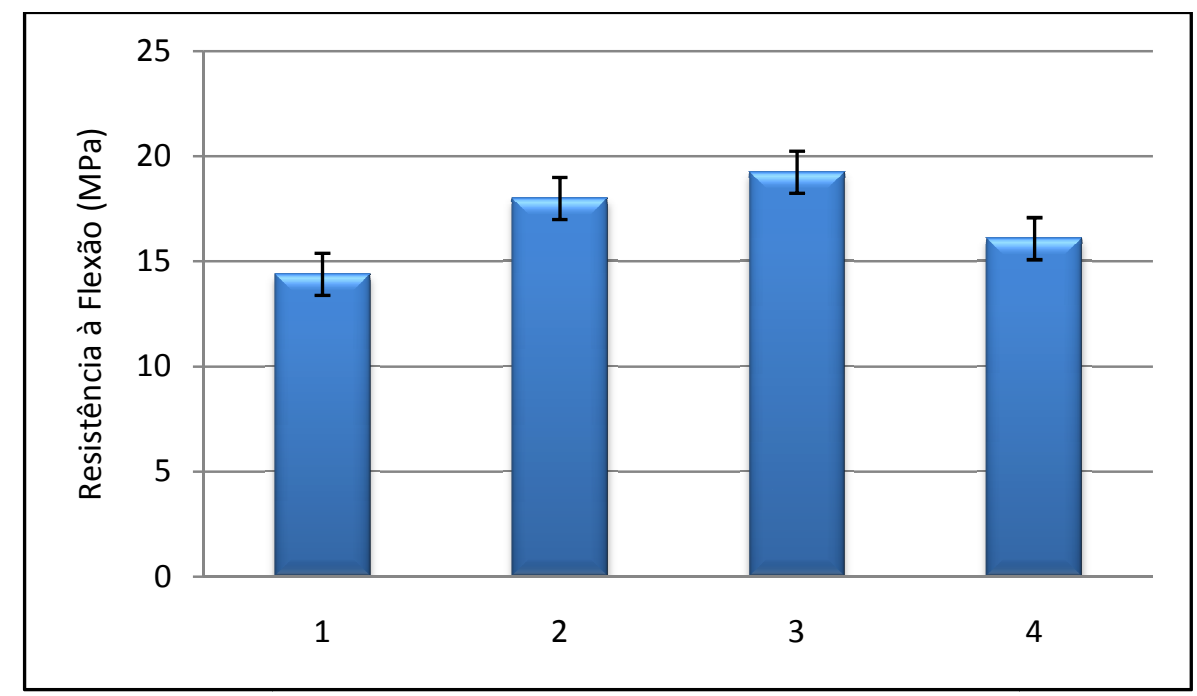

Figura 82: Resistência à flexão para compósitos (1) 85\%BPEAD/5\%PBHL/10\%Fibra, (2) 85\%BPEAD/5\%PBHL/10\%Fibra tratada, (3) 85\%BPEAD tratado/5\%PBHL/10\%Fibra, (4) 85\%BPEAD tratado/5\%PBHL/10\%Fibra tratada.

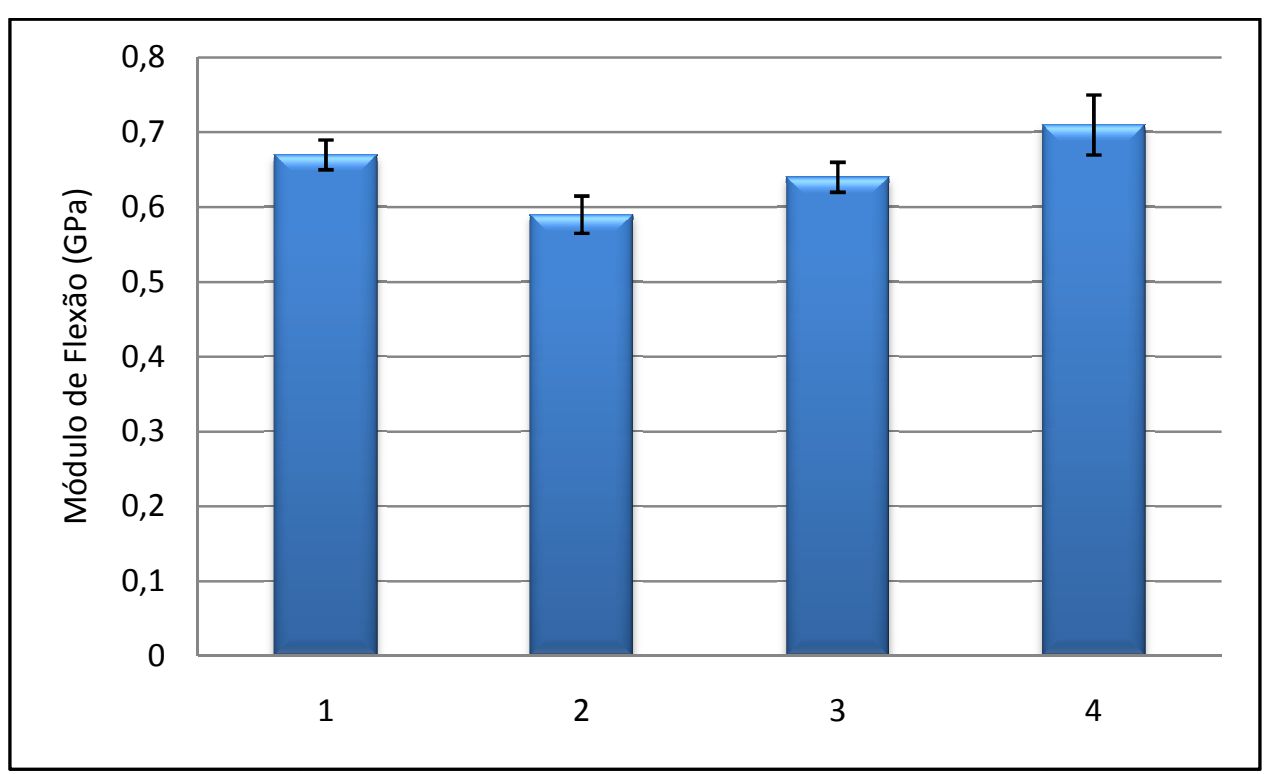

Figura 83: Módulo de flexão para compósitos (1) 80\%BPEAD/5\%PBHL/15\%Fibra, (2) 80\%BPEAD/5\%PBHL/15\%Fibra tratada, (3) 80\%BPEAD tratado/5\%PBHL/15\%Fibra, (4) 80\%BPEAD tratado/5\% PBHL/15\%Fibra tratada. 


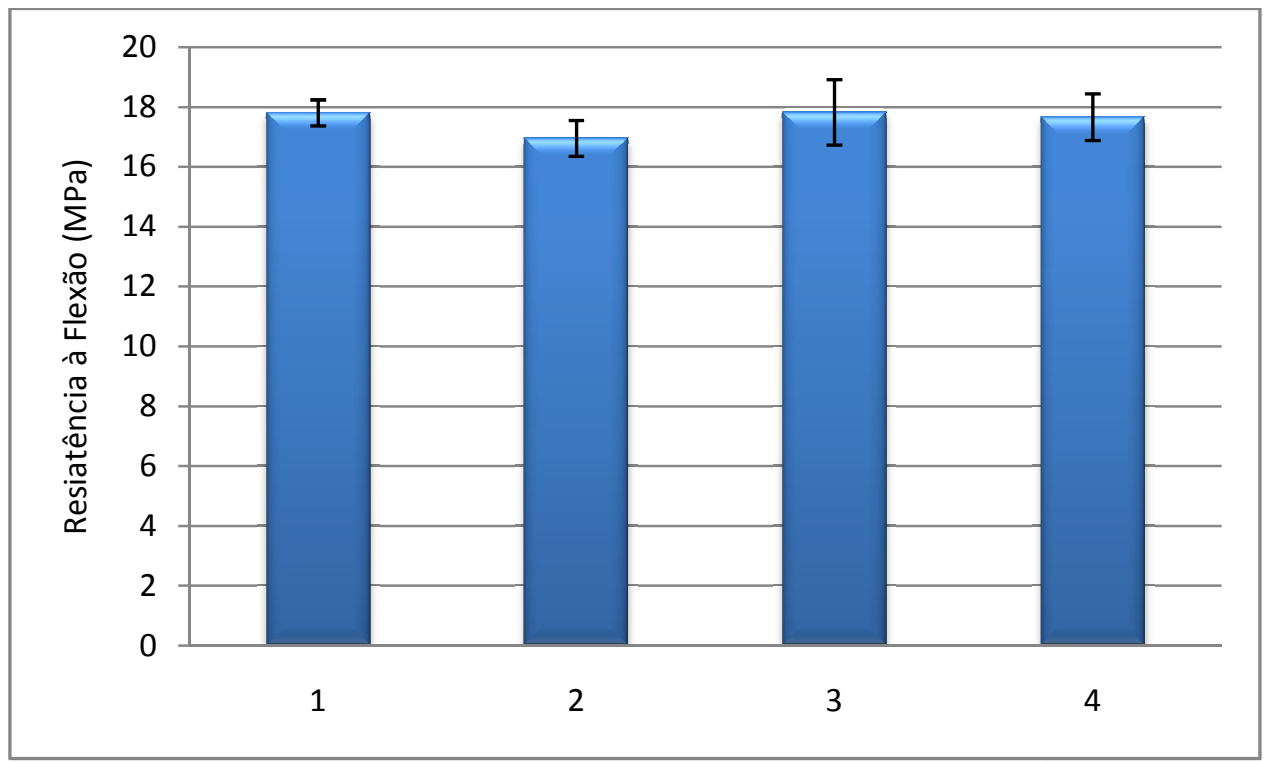

Figura 84: Resistência à flexão para compósitos (1) 80\%BPEAD/5\%PBHL/15\%Fibra, (2) 80\%BPEAD/5\%PBHL/15\%Fibra tratada, (3) 80\%BPEAD tratado/5\%PBHL/15\%Fibra, (4) 80\%BPEAD tratado/5\%PBHL/15\%Fibra tratada

As Figuras 81 e 82 mostram que o módulo e a resistência de flexão dos compósitos reforçado com $10 \%$ de fibra (5\%de PBHL) apresentam maiores valores de flexão quando a fibra é tratada. No entanto, quando BPEAD é tratado, ou ambos, não se observam diferenças. Para $15 \%$ de fibras, uma tendência de aumento é observada quando ambos fibra e matriz, são tratados. 


\section{CONCLUSÕES}

De acordo com o conjunto de resultados obtidos, pode-se concluir que a presença das fibras de curauá diminuiu a resistência ao impacto do BPEAD. Já a análise de DMTA mostrou que a presença de fibras leva a um material mais rígido e a análise morfológica dos compósitos mostrou uma boa distribuição das fibras na matriz para determinadas composições. Este resultado obtido via DMTA indica que estes compósitos podem ser usados em aplicações em que mais alto módulo de armazenamento seja necessário.

A adição de PBHL, levou uma melhor adesão e distribuição das fibras de curauá na matriz termoplástica, levando a uma melhora nas propriedades mecânicas destes compósitos, particularmente na resistência ao impacto.

Com a finalidade de se buscar atuações ainda mais eficientes destas fibras como agente de reforço, as mesmas foram expostas ao ar ionizado, assim como o BPEAD. Os feixes de fibras foram afastados, o que facilita a penetração do polímero fundido, mas, no entanto, as propriedades mecânicas dos materiais, no geral, não sofreram grande influência de as fibras terem sido tratadas com ar ionizado. Este tratamento pode ser futuramente mais profundamente investigado, pois foram observados indicadores de que o mesmo levou a alterações no polímero.

Os resultados apontam no sentido que parâmetros de processo podem ser explorados, visando minimizar a degradação do polímero, além de trazerem outros indicadores importantes, como que provavelmente uma borracha de maior massa molar média que a usada no presente trabalho possa apresentar uma ação mais significativa como modificadora de impacto; que fibras mais longas que aquelas consideradas, na mesma proporção em massa, podem ser testadas, já que fibras curtas implicam em grande número de pontas, as quais podem agir como concentradoras de tensão e prejudicar as propriedades mecânicas do compósito.

Neste estudo, materiais baseados principalmente em matéria prima proveniente de fontes renováveis foram preparados, ou seja, materiais do tipo biocompósitos, com algumas boas propriedades, atendendo aos objetivos iniciais. É importante ressaltar que, até onde se tenha conhecimento, pela primeira vez biopolietileno foi utilizado na preparação de biocompósitos reforçados com fibras lignocelulósicas. 


\section{6 REFERÊNCIAS}

ABDELMOULEH, M.; BOUFI, S.; BELGACEM, M.N.; DUFRESNE, A. Short natural-fibre reinforced polyethylene and natural rubber composites: Effect of silane coupling agents and fibres loading. Composites Science and Technology, v. 67, p. 1627-163, 2007.

AHMAD, I.; WONG, P.Y. Effects of fiber composition and graft-copoly(ethylene/maleic anhydride) on thermoplastic natural rubber composites reinforced by aramid fiber. Polymer Composites, v. 27, n. 4, p. 395-401, 2006.

ANUAR, H.;AHMAD, S.H. Essential work of fracture and acoustic emission study on TPNR composites reinforced by kenaf fiber. Journal of Composite Materials, v. 41, p. 3035-3049, 2007.

ARAÚJO, E.M.; HAJE JÚNIOR, E.; CARVALHO, A. J. F. Compatibilização de blendas de poliamida 6/ABS usando os copolímeros acrílicos reativos MMA-GMA e MMA-MA. Parte 1: comportamento reológico e propriedades mecânicas das blendas. Polímeros: Ciência e Tecnologia, v. 13, p. 205-211, 2003.

ASH in Wood and Pulp. T211 om-85. In: TAPPI Standard Method. Atlanta: TAPPI Press, 1991. v. 1.

ASHORI, A. Wood-plastic composites as promising green-composites for automotive industries. Bioresource Technology, v. 99, p. 4661-4667, 2008.

AVÉROUS, L.; HALLEY, P. J. Biocomposites based on plasticized starch. Biofuels, Bioproducts \& Biorefining, v. 3, p. 329-343, 2009.

BRÍGIDA, A.I.S.; CALADO, V.M.A.; GONÇALVES, L.R.B.; COELHO, M.A.Z. Effect of chemical treatments on properties of green coconut fiber. Carbohydrate Polymers, v. 79, p. 832-838, 2010.

BRYDSON, J. A. Plastics materials. 4. ed. London: Butterwork Scientific, 1982. p.28.

BUSCHLE-DILLER, G.; ZERONIAN, S. H. Enhancing the reactivity and strength of cotton fibers. Journal Applied Polymer Science, v. 45, p. 967-979, 1992. 
CALLISTER, W. D. Ciência e engenharia de materiais: uma introdução. 5. ed. Rio de Janeiro: LTC, 2002. p. 132-167.

CANEVAROLO JUNIOR, S.V. Técnicas de caracterização de polímeros. São Paulo: Artliber, 2004. p. 263-277.

CAÑIGUERAL, N., VILASECA, F.; MÉNDEZ, J. A.; LÓPEZ, J. P.; BARBERA, J. P., PUIG, J., PÈLACH, M.A. ; MUTJÉ, P. Behavior of biocomposite materials from flax strands and starch-based biopolymer. Chemical Engineering Science, v. 64, p. 2651-2658, 2009.

CASSU,S.N. ; FELISBERTI, M.I. Comportamento dinâmico- mecânico e relaxações em polímeros e blendas poliméricas. Química Nova, v. 28, p. 255-263, 2005.

CHEN, J.; DAVIDSON, J.H. Model of the negative DC corona plasma: comparison to the positive DC corona plasma. Plasma Chemistry Plasma Processing, v. 23, n. 1, p. 83-102, 2003.

CLEMONS, C. Wood-plastic composites in the United States: the interfacing of two industries". Journal Forest Products, v. 52, p. 10-18, 2002.

COMYN, J. Polymer permeability. London: Chapman \& Hall, 1985. p. 341-373

COUTINHO, F. M. B.; MELLO, I. L.; SANTA MARIA, L. C. Polietileno: principais tipos, propriedades e aplicações. Polímeros: Ciência e Tecnologia, v. 13, p. 1-13, 2003.

CORRADINI, E.; ITO, E.N.; MARCONCINI, J. M.; RIOS, C.T.; AGNELLI, J.A.M.; MATTOSO, L.H.C. Interfacial behavior of composites of recycled poly(ethyelene terephthalate) and sugarcane bagasse fiber. Polymer Testing , v. 28, p. 183-187, 2009.

COSTA, M. L.; REZENDE, M.C.; BOTELHO, E.C. Estabelecimento de ciclo de cura de préimpregnados aeronáuticos. Polímeros: Ciência e Tecnologia, v. 15, p. 224-231, 2005.

DE PAOLI, Marco Aurélio. Degradação e estabilização de polímeros. São Paulo: Artliber Editora, 2008. p. 11-41. 
DEPARTAMENTO DE ENGENHARIA DE MATERIAIS (DEMA). São Carlos: Universidade Federal de São Carlos, 2005. Página da UFSCar. Disponível em: < http://www.dema.ufscar.br>. Acesso em: 10 dez. 2009.

DONG, S.; SAPIEHA, S.; SCHREIBER, H. P., Rheological properties of corona modified cellulose/polyethylene composites. Polymer Engineering Science, v. 32, p. 1734-1739, 1992.

ECO Products. 2007. Disponível em : <http://www.ecoproducts.com/ - Acesso: em 25 set. 2009.

FARIAS, M.A.; FARINA, M.Z.; PEZZIN , A.P.T.;. SILVA, D.A.K. Unsaturated polyester composites reinforced with fiber and powder of peach palm: mechanical characterization and water absorption profile. Materials Science and Engineering C, v. 29, p. 510-513, 2009.

FENGEL, D.; WEGENER, G. Wood e chemistry, ultrastructure, reactions. Berlin: Walter de Gruyter, 1984. p. 613.

FENGEL D.; WEGENER G. Wood e chemistry, ultrastructure, reactions. Berlin: Walter de Gruyter, 1989. p. 1-130.

FRANCUCCI, G.; RODRÍGUEZ, E.S.; VÁZQUEZ, A. Study of saturated and unsaturated permeability in natural fiber fabrics. Composites: Part A , v. 41, p. 16-21, 2010.

GASSAN, J.; GUTOWSKI, V. S.; BLEDZKI, A. K. About the surface characteristics of natural fibres. Macromolecular Materials Engineering, v. 283, p. 132-139, 2000.

GATTI, M. C. A.; SILVA, R. V.; TARPANI, J. R. Análise térmica do laminado PEEK/carbono submetido a diferentes rotas de processamento. Revista Matéria, v. 11, p. 332 - 339, 2006.

GEORGOPOULOS, S. T.; TARANTILI, P. A.; AVGERINOS, E.; ANDREOPOULOS, A. G.; KOUKIOS, E. G. Thermoplastic polymers reinforced with fibrous agricultural residues. Polymer Degradation and Stability, v. 90, p. 303-312, 2005.

GOMES, A.; MATSUO, T.; GODA, K .; OHGI, J. Development and effect of alkali treatment on tensile properties of curaua fiber green composites. Composites Part A: Applied Science and Manufacturing, v. 38, p. 1811-1820, 2007. 
GUIMARÃES, M. J. O.C.; ROCHA, M.C.G.; COUTINHO, F.M.B. Polietileno de alta densidade tenacificado com elastômero metalocênico: 1 propriedades mecânicas e características morfológicas. Polímeros: Ciência e Tecnologia, v. 12, p. 76-84, 2002.

HASSAN, M. L.; ROWELL, R. M.; FADL, N. A.; YACOUB, S. F. Thermoplasticization of bagasse I: Preparation and characterization of esterified bagasse fibers. Journal of Applied Polymer Science, v. 76, p. 561-574, 2000.

HERAKOVICH, C. T. Mechanics of fibrous composites. New York, Wiley, 1998, p.1-7.

IANNACE, S.; ALI, R.; NICOLAIS, L. Effect of processing conditions on dimensions of sisal fibers in thermoplastic biodegradable composites. Journal of Applied Polymer Science, v. 79, 1084-1091, 2001.

INDÚSTRIA Petroquímica Brasileira. São Paulo: Braskem, 2007. Disponível em : <http://www.braskem.com.br/>. Acesso em: 18 set. 2008.

JAIDANN, M.; HAKIMA, A.R.; LAMBERT, X.L.; LUSSIER, L.S.; GAGNON, N.; BRISSON, J.Modeling and measurement of glass transition temperatures of energetic and inert systems, Polymer Engineering and Science, v. 48, p. 1141-1150, 2008.

JARUKUMJORN, K.; SUPPAKARN, N. Effect of glass fiber hybridization on properties of sisal fiber-polypropylene composites. Composites: Part B, v. 40, p. 623-627, 2009.

JOHN, M. J.; THOMAS, S. Biofibres and biocomposites. Carbohydrate Polymers, v. 71, p. 343364, 2008.

KALIA, S. ; KAITH, B.S. ; KAUR, I. Pretreatments of natural fibers and their application as reinforcing material in polymer composites-a review. Polymer Engineering and Science, $v$. 49, p. 1253-1272, 2009.

KAYNAK, C.; ARIKAN, A.; TINCER, T. Flexibility improvement of short glass fiber reinforced epoxy by using a liquid elastomer. Polymer, v. 44, p. 2433-24, 2003.

KAYNAC, C.; ORGUN, O.; TINCER, T. Matrix and interface modification of short carbon fiberreinforced epoxy. Polymer Testing, v. 24, p. 455-462, 2005. 
KHALID, M. ; RATNAM, C.T.; CHUAH, T.G.; SALMIATON, A.; CHOONG, T.S.Y. Comparative study of polypropylene composites reinforced with oil palm empty fruit bunch fiber and oil palm derived cellulose. Materials \& Design, v. 29, p. 173-178, 2008.

KONDO, Y.; MIYAZAKI, K.; TAKAYANAGI, K.; SAKURAY, K. Mechanical properties of fiberreinforced natural rubbers using surface-modified PET fibers under EB irradiation. Journal of Applied Polymer Science, v. 114, p. 2584-2590, 2009.

LEÃO, A. L.; CARASCHI, J. C, Curaua Fiber - A tropical natural fibers from amazon potential and applications in composites. In: FROLLINI, E.; LEÃO, A. L.; MATTOSO, L. H. C. (Ed.). Natural polymer and agrofibers based composites. São Carlos: USP/Embrapa/UNESP, 2000. p. 257271.

LEÃO, A. L.; CARVALHO, F.X.; FROLLINI, E. Lignocellulosic-plastics composites. São Paulo: USP/UNESP, 1997. p. 197-223.

LIANG, J.Z.; LI, R.K.Y.; TJONG, S.C. Effects of pressure and temperature on the melt and the melt flow rate of LDPE and glass bead-filled LDPE composite. Journal of Material Processing Technology, v. 91, p.167-171, 1999.

LEE, Y. H.; ALLEN, D. J.; ISHIDA, H. Effect of rubber reactivity on the morphology of polybenzoxazine blends investigated by atomic force microscopy and dynamic mechanical analysis. Journal of Applied Polymer Science, v. 100, p. 2443-2454, 2006.

LUCAS, E. F.; SOARES, B. G.; MONTEIRO, E. E. C., Caracterização de polímeros: determinação de peso molecular e análise térmica. Rio de Janeiro: E-papers, 2001. p. 613.

MAHENDRAN, A. R. ; AUST, N. ; VIJAYAKUMAR, C. T.; LEDERER, K. Preparation and characterization of partially degraded high-density polyethylene in an internal mixer. Polymer-Plastics Technology and Engineering, v. 47, p. 1142-1146, 2008.

MANO, E. B. Polímeros como materiais de engenharia. Sao Paulo: Edgar Blucher, 1991. p. 168.

MANO, B.;ARAÚJO, J.R.; SPINACÉ, M.A.S.; DE PAOLI, M.A. Polyolefin composites with curaua fibres: Effect of the processing conditions on mechanical properties, morphology and fibres dimensions. Composites Science and Technology, v. 70, p. 29-35, 2010. 
MARCOVICH, N. E.; REBORED, M. M.; ARAGURE, N. M. I. Dependence of the mechanical properties of woodfluor- polymer composites on the moisture content. Journal Applied Polymer Science, v. 68, p. 2069-2076. 1998.

MATTEWS, F. L.; RAWLINGS, R. D. Composite materials: engineering and science, New York: CRC, 1994. p. 3-12.

MAZUR, R. L.; BOTELHO, E. C.; COSTA, M. L.; REZENDE, M. C. Avaliações térmica e reológica da matriz termoplástica PEKK utilizada em compósitos aeronáuticos. Polímeros: Ciência e Tecnologia, v. 18, p. 237-243, 2008.

MSALLEM, Y.A.; JACQUEMIN, F.; BOYARD, N.; POITOU, A.; DELAUNAY, D.; CHATEL, S. Material characterization and residual stresses simulation during the manufacturing process of epoxy matrix composites. Composites: Part A, v. 41, p. 108-115, 2010.

MEGIATTO, Jackson Dirceu. Fibras de sisal: estudo de propriedades e modificações químicas visando à aplicação em compósitos de matriz fenólica. 2006. 267f. Tese (Doutorado)- Instituto de Química de São Carlos, Universidade de São Paulo, São Carlos, 2006.

MEGIATTO JUNIOR, J. D.; HOAREAU, W.; GARDRAT, C.; FROLLINI, E.;CASTELLAN, A. Sisal fibers: surface chemical modification using reagent obtained from a renewable source; characterization of hemicellulose and lignin as model study. Journal of Agricultural an Food Chemistry, v. 55, p. 8576-8584, 2007.

MEGIATTO JUNIOR, J. D.; RAMIRES, E. C.; FROLLINI, E. Phenolic matrices and sisal fibers modified with hydroxyl terminated polybutadiene rubber: Impact strength, water absorption, and morphological aspects of thermoset and composites. Industrial Crops and Products, v. 31, p. 178-184, 2010.

MOHANTY, A. K.; WIBOWO, A.; MISRA, M.; DRZAL, L. T. Effect of process engineering on the performance of natural fiber reinforced cellulose acetate biocomposites. Composites: Part A, v. 35, p. 363-370, 2004.

MOHANTY, S.; NAYAK, S. K. Dynamic and steady state viscoelastic behavior and morphology of MAPP treated PP/sisal composites. Materials Science \& Engineering, v. 443, p. 202-208, 2007. 
MONTEIRO, S. N., AQUINO, R. Performance of curaua fibers in pullout tests. Journal of Materials Science, v. 43, p. 489-493. 2008.

MOTHÉ, C. G.; ARAÚJO, C. R. Caracterização Térmica e Mecânica de Compósitos de Poliuretano com Fibras de Curauá. Polímeros: Ciência e Tecnologia, v. 14, p. 274-278, 2004.

MOTHÉ, C.G.; ARAÚJO, C.R.; WANG, S.H.Thermal and mechanical characteristics of polyurethane/curaua fiber composites. Journal of Thermal Analysis and Calorimetry, v. 95 , p. 181-185, 2009.

MOLY, K. A.; RADUSCH, H. J.; ANDROSH, R.; BAGAWAN, S. S.; THOMAS, S. Nonisothermal crystallizacion, melting behavior and wide angle $x$-ray scaterring investigations on linear low density polyethylene, vinyl acetate blends: effectas of compatibilisation and dynamic crosslinking. European Polymer Journal, v.4 1, p. 1410-1419, 2005.

MUKHOPADHYAY, S.; FANGUEIRO, R. Physical modification of natural fibers and thermoplastic films for composites - a review. Journal of Thermoplastic Composite Materials, v. 22, p. 135-162, 2009.

MULINARI, D.R.; VOORWALD, H. J.C.; CIOFFI, M. O. H.; SILVA, M.L.C.P.; CRUZ, T. G.; SARON, C. Sugarcane bagasse cellulose/HDPE composites obtained by extrusion. Composites Science and Technology , v. 69 , p. 214-219, 2009.

NUNES, R. C..; VISCONTE, L.L.Y. Natural Fibers/ Elastomeric Composites. In: FROLLINI, E.; LEÃO, A.L.; MATTOSO, L.H.C. Natural polymer and agrofibers composites. São Carlos: USP/UNESP, 2000. p. 135-157.

OLIVEIRA, G. H.; GUIMARÃES, V. A.; BOTELHO, E.C. Influência da temperatura no desempenho mecânico de compósitos Pei/fibras de vidro. Polímeros: Ciência e Tecnologia, v. 19, p. 305-312, 2009.

PAIVA, J. M. F; SILVA, S. P.; TANAKA, I. A.; TRINDADE, W. G; ANGELUCCI, C. A.; FROLLINI, E. Impact strenght of phenolic matrices reinforced with lignocellulosic material. In: MATTOSO, L. H. C.; LEÃO, A. L.; FROLLINI, E. Natural polymers and composites. São Carlos: USP/UNESP, 2000. p. 25-52.

PAIVA, J. M. F.; FROLLINI, E. Sugarcane bagasse reinforced phenolic and lignophenolic composites. Journal of Applied Polymer Science, v. 83, p. 880-888, 2002. 
PAIVA, J. M. F.; FROLLINI, E. Unmodified and modified surface sisal fibers as reinforcement of phenolic and lignophenolic matrices composites: thermal analyses of fibers and composites. Macromolecular Materials Engineering, v. 291, p. 405-417, 2006.

PANTHAPULAKKAL, S.; SAIN, M. Agro-residue reinforced high-density polyethylene composites: Fiber characterization and analysis of composite properties. Composites: Part A, v. 38, p. 1445-1454, 2007.

PEACOCK, A.J. Handbook of polyethylene: structures, properties and applications. New York: Basel, 2000. p. 43-67.

PEARSON, J.R.A.; Mechanics of polymer processing. New York: Elsevier, 1985. p. 513-533.

PEGORETTI, A .; ASKAR, M .; MIGLIARESI, C .; MAROM, G. Relaxation process in polyethylene fibre-reinforcednpolyethylene composites. Composites Science and Technology, v. 60, p. 1181-1189, 2007.

PEREÑA, J. M. The use of dynamic mechanical thermal analysis (DMTA) for studying and testing polymeric composite materials. In: INTERNATIONAL CONFERENCE ON MECHANICS AMD TECHNOLOGY OF MATERIALS, 39., 2006, Sofia. Proceeding... Sofia: Bulgarian Academic of Sciences, 2006. p. 50-55.

ROWELL, R. M; HAN, S. J. Characterization and Factors Effeting Fiber Properties. In: FROLLINI, E.; LEAO, A.L. ; MATTOSO, L.H.C. (Ed.). Natural polymers and agrofibers based composites. Sao Paulo: USP/UNESP/EMBRAPA. p. 25-48.

RULLAND, W. International tables of $\mathbf{x}$ ray crystallography. Birmingham: Kinoch Press, 1974. $85 p$.

SANTOS, Paulo Aparecido dos. Uso de fibras de curauá como agente de reforço para poliamida 6. 2006. 65f. Dissertação (Mestrado em Química na área de Química Inorgânica) -Instituto de Química, Universidade Estadual de São Paulo, Campinas, 2006.

SANTOS, P. A .; SPINACÉ, M. A. S.; FERMOSELLI, K. K. G.; DE PAOLI, M. A. Efeito da forma de processamento e do tratamento da fibra de curauá nas propriedades de compósitos com poliamida-6. Polímeros: Ciência e Tecnologia, v. 19, p. 31-39, 2009. 
SATYANARAYANA, K. G.; GUIMARÃES, J. L.; WYPYCH, F. Studies on lignocellulosic fibers of Brazil. Part I: Source, production, morphology, properties and applications.

Composites Part A: Applied Science and Manufacturing, v. 38, p. 1694-1709, 2007.

SARKHEL, G.; CHOUDHURY, A. Dynamic vulcanization of polyethylene-based thermoplastic elastomer blends. Journal of Applied Polymer Science, v. 115, p. 376-384 , 2010.

SCHOBIG, M.; GRELLMANN, W.; MECKLENBUR, T. Characterization of the fracture behavior of glass fiber reinforced thermoplastics based on PP, PE-HD, and PB-1. Journal of Applied Polymer Science, v. 115, p. 2093-2102, 2010.

SEGATELLI, M. G.; YOSHIDA, I. V. P.; GONÇALVES, M. C. Natural silica fiber as reinforcing filler of nylon 6. Composites: Part B, p. 98-105, 2010.

SILVA, A. L. N.; ROCHA, M. C. G.; GUIMARÃES, M. J. O. C.; LOVISI, H.; COUTINHO, F. M. B.; SANTA MARIA, L. C. Desenvolvimento de materiais à base de poliolefinas e elastômeros metalocênicos. Polímeros: Ciência e Tecnologia, v. 11, p. 135-141, 2003.

SILVA, R. V.; AQUINO, E. M. F. Curaua fiber: A new alternative to polymeric composites. Journal of Reinforced Plastics and Composites. v. 27, p. 103-112, 2008.

SILVA, R.; HARAGUCHI, S. K.; MUNIZ, E. C.; RUBIRA, A. F. Aplicações de fibras lignocelulosicas na química de polímeros e em compósitos. Química Nova, v. 32, p. 661-671, 2009.

SOUZA JÚNIOR, F. G.; OLIVEIRA, G.E.; RODRIGUES, C.H.M.; SOARES, B.G.; NELE, M.; PINTO, J.C. Natural brazilian amazonic (curauá) fibers modified with polyaniline nanoparticles. Macromolecular Material and Engineering, v. 294, p. 484-491, 2009.

SOYKEABKAEW, N.; ARIMOTO, N.; NISHINO, T.; PEIJS, T. All-cellulose composites by surface selective dissolution of alignedligno-cellulosic fibres. Composites Science and Technology, v. 68. p. 2201-2207, 2008.

SPINANCÉ, M.A.S.; FERMOSELLI, K.H.G.; DE PAOLI, M.A. Recycled polypropylene reinforced with curauá fibers by extrusion. Journal of Applied Polymer Science,v. 112, p. 3686-3694, 2009.

SPINANCÉ, M.A.S.; LAMBERT, C. S.; FERMOSELLI, K, K, G.; DE PAOLI, M. A. Characterization of lignocellulosic curauá fibres. Carbohydrate Polymers, v. 77, p. 47-53, 2009. 
SUN, C.; DONG, Z.; WARDSWORTH, L.C. Corona treatment of polyolefin films - a review. Advanced Polymer Technology, p. 171-180, 1999.

SWAMY, R. P.; MOHAN KUMAR, G. C.; VRUSHABHENDRAPPA, Y. Study of Areca-reinforced Phenol Formaldehyde Composites. Journal Reinforded Plastics and Composites, v. 23, p. 1373-1382, 2004.

THREEPOPNATKUL, P.; N. KAERKITCHA, N.; ATHIPONGARPORN, N. Effect of surface treatment on performance of pineapple leaf fiber-polycarbonate composites. Composites: Part B, v. 40, p. 628-632, 2009.

TITA, S. P. S. Efeito dos tratamentos de superfície das fibras de bagaço de cana-de-açucar e sisal nas propriedades de compósitos de matriz fenólica e lignofenólica. 2002. $201 \mathrm{f}$. Dissertação (Mestrado) - Instituto de Química de São Carlos, Universidade de São Paulo.

TOMCZAK, F., SATYANARAYANA, K.G. Studies on lignocellulosic fibers of Brazil: Part III Morphology and properties of Brazilian curaua fibers. Composites Part A-Applied Science and Manufacturing, v. 38, n. 10, p. 2227-2236, 2007.

TRINDADE, Wanderson Gonçalves. Influência de modificações químicas e físicas na superfície de fibras de curauá sobre propriedades de compósitos de matriz termorrígida fenólica. 2005. 121f. Dissertação (Mestrado)- Instituto de Química de São Carlos, Universidade de São Paulo, São Carlos, 2005.

TRINDADE, W. G.; HOREAU, W.; J. D MEGIATTO, J.D.; RAZERA, A..T.; CASTELLAN, A.; FROLLINI, E. Thermoset phenolic matrices reinforced with unmodified and surface-grafted furfuryl alcohol sugar cane bagasse and curaua fibers: properties of fibers and composites. Biomacromolecules, v. 6, p. 2485-2496, 2005.

TRINDADE, W. G.; PAIVA, J. M. F.; LEAO, A. L.; FROLLINI, E. Ionized-air-treated curaua fibers as reinforcement for phenolic matrices. Macromolecular Materials and Engineering, v. 293, p. 521-528, 2008.

YOSOMIYA, R.; MORIMOTO, K.; NAKAJIMA, A.; IKADA, Y.; SUZUKI, TOSHIO. Adhesion and Bonding in Composites. New York: Marcel Dekker, 1989. 357 p. 
ZAH, R.; HISCHIER, R.;LEÃO, A.L.; BRAUN, I. Curauá fibers in the automobile industry e a sustainability assessment. Journal of Cleaner Production, v. 15, p. 1032-1040, 2007.

ZHANG, D.; SUN, Q.; WADSWORTH, L. C. Mechanism of corona treatment on polyolefin films. Polymer Engineering Science, v. 38, p. 965-70, 1998. 